\title{
Entrepreneurial Orientation, Ambidexterity, the Resource Based View and Performance: \\ Evidence from micro entrepreneurs in Trinidad
}

\author{
By: \\ Christian Stone \\ EMBA, University of the West Indies, 2010 \\ M. Ed, Framingham State College, 2010 \\ B.A., Ivey School of Business, 2003
}

\begin{abstract}
A thesis submitted to the Faculty of Graduate and Postdoctoral Affairs in partial fulfillment of the requirements for the degree of:

Doctor of Philosophy :

in

Management

Carleton University

Ottawa, Ontario
\end{abstract}




\title{
Christian Stone
}

\begin{abstract}
The Entrepreneurial Orientation (EO) construct has been widely adopted within the Entrepreneurship literature, however, the operationalization of the construct has remained a contentious issue. We consider both a unidimensional and multidimensional operationalization of the EO construct and their relative relationship to performance. The effects of the EO dimensions of innovativeness, proactiveness and risk-taking were considered individually and in combination, in relation to performance, in an attempt to uncover hypothesized relationships that are contrary to the generally considered positive linear relationships proposed in the EO literature. Our results show that the dimensions of EO do not co-vary in all instances, and suggests that the risk-taking dimension plays a unique indirect mediation role between the other dimensions and performance. To further extend the body of EO research and drawing from the Resource Based View $(\mathrm{RBV})$ strategic management literature, we proposed EO and its dimensions as an important measure of an organization. EO may serve to enhance the resources and capabilities of the firm by directing the attention of top management to the utilization of the firm's resources and capabilities towards the joint discovery and exploitation of opportunities, known as ambidexterity. We considered the hypothesized main and moderating effects of ambidexterity in the relationship between EO, its individual dimensions and performance for firms that have high and low levels of ambidexterity. While ambidexterity was discovered to play a significant role as a building block of performance in its own right, we were unable to find any significant moderation effects of ambidexterity in the $\mathrm{EO} /$ performance relationship. EO and ambidexterity are considered in a micro firm context due to the greater likelihood of the EO and ambidextrous tendencies of top managers (entrepreneurs) in micro firms (as opposed to managers in larger firms) to be more representative of the overall posture of the firm. Further, we drew the research sample from a population of micro enterprises located in Trinidad, which serves as a novel sample in the study of EO.
\end{abstract}




\section{Acknowledgements}

What a journey! To Dr. G. Grant, thank you for your support and guidance through this process. Your kind, wise words and encouragement were always welcomed and appreciated. Your mentorship was invaluable, and your intelligence helped to expand my boundaries and challenge my thinking. I will be forever grateful.

Many thanks to my amazing committee members: Dr. Nardon, Dr. Rod, and Dr. Cray. In your own way you each provided me with so much experience and knowledge. It is no small compliment to say that if I had to do it all over again, I would 100 out of 100 times, hope to have you all be part of the team.

There are so many people who have helped through the course of this degree that I can not possibly name everyone, but, a big thanks to the awesome administrative staff at the Sprott School, Dr. S. Ji, the numerous professors, teachers, students, research participants and my colleagues and friends at Sprott.

Finally, I would dedicate this work to my family, the solid foundation that I was able to build upon. To my girls, Amelia and Zara, and my dad, mom and brother, Peter, Donna and David, thank you for your limitless love. To my beautiful wife Sophia, we both know that this would not have been possible without you and it is as much yours as it is mine.

Thank you, thank you, thank you! 


\section{Table of Contents}

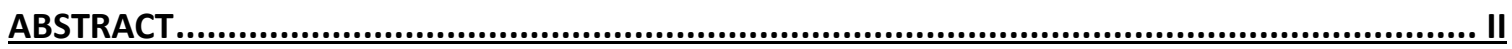

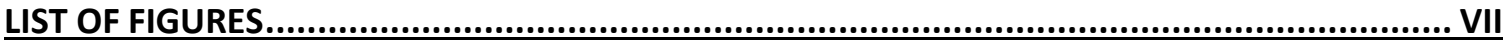

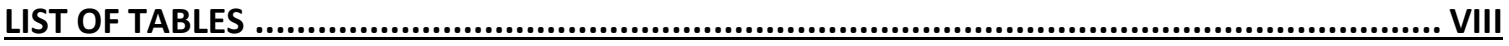

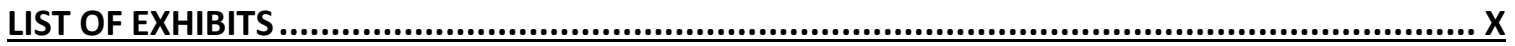

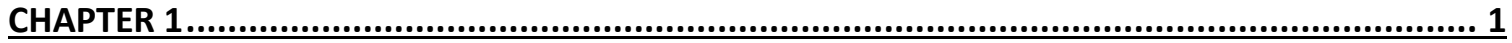

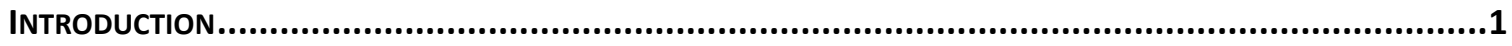

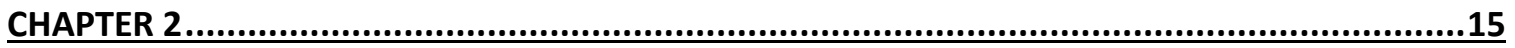

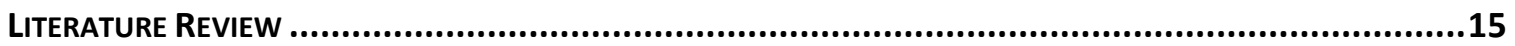

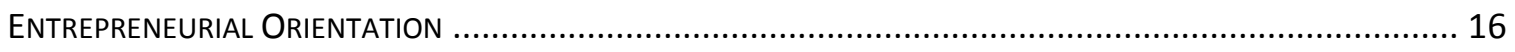

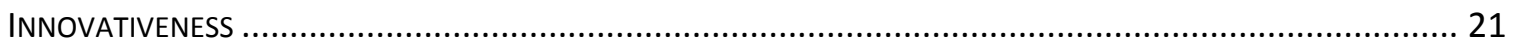

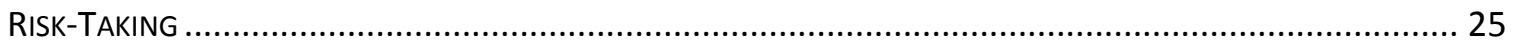

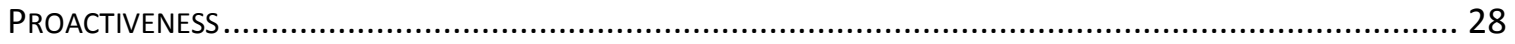

CURRENT DeBATES IN THE EO LITERATURE

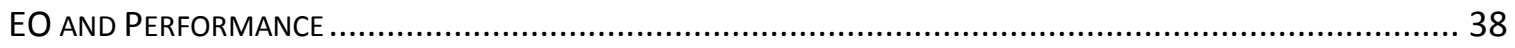

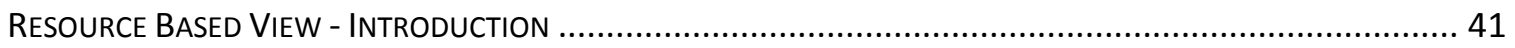

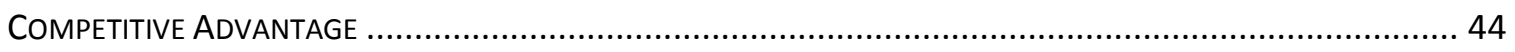

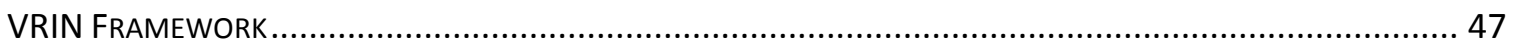

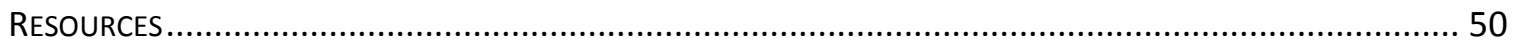

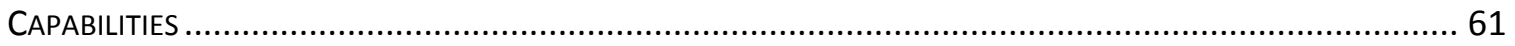

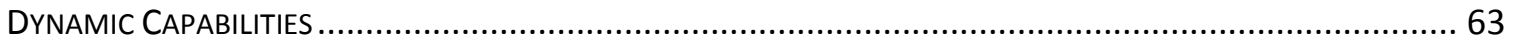

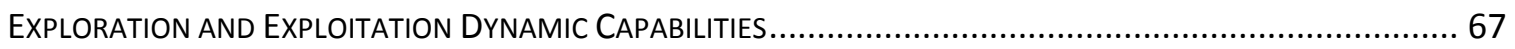

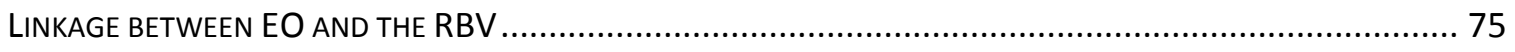

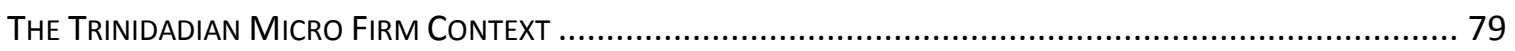

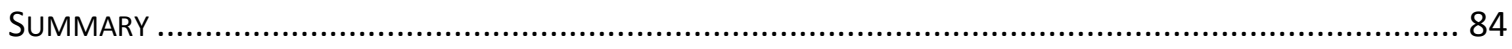

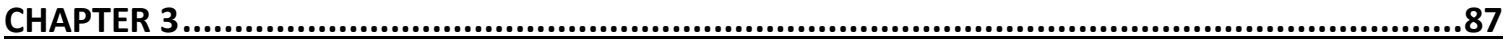

RESEARCH MOdEL AND HYPOTHESES ........................................................................87

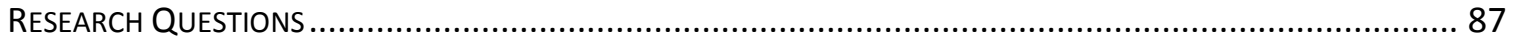

EO AS A FORMATIVE, MULTIDIMENSIONAL CONSTRUCT VERSUS EO AS A REFLECTIVE, UNIDIMENSIONAL

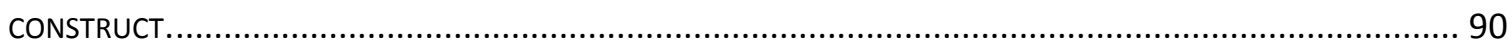

The Relationships between InNovativeness, RisK-taking, ProactivenesS ANd PerformanCE.............. 98

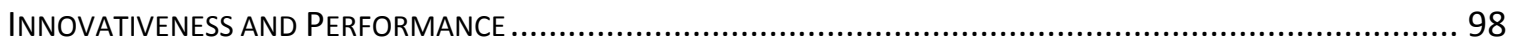

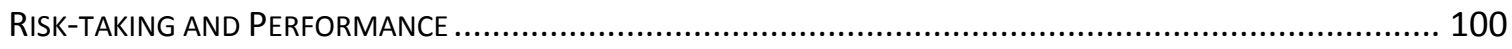

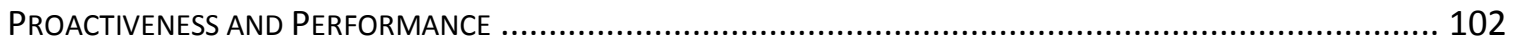

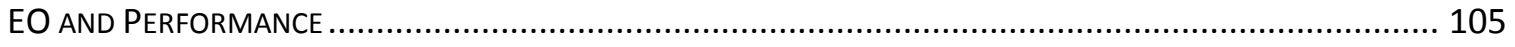

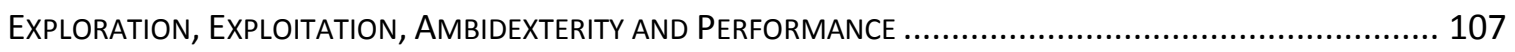

AMBIDEXTERITY AS A MODERATOR OF INNOVATION, RISK-TAKING, PROACTIVENESS AND EO ........................ 111 


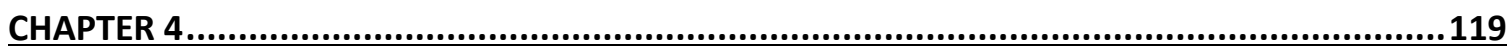

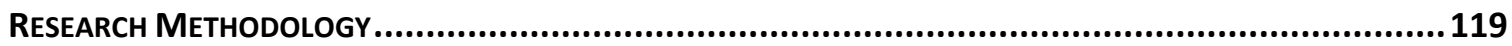

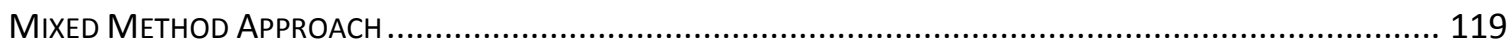

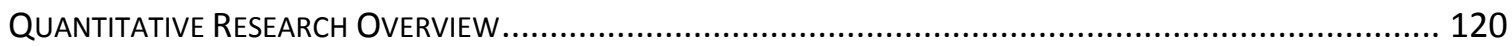

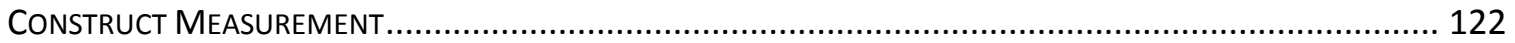

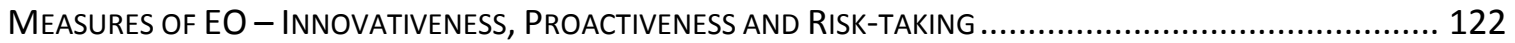

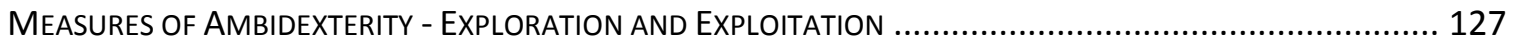

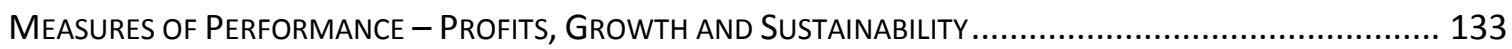

CONTROL VARIABLES - SIZE, AGE, LOCATION, INDUSTRY, ACCESS TO FINANCIAL RESOURCES ...................... 137

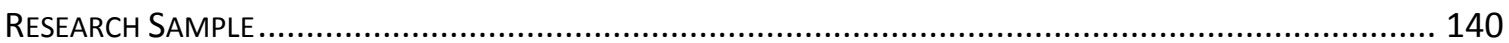

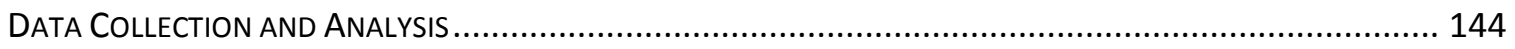

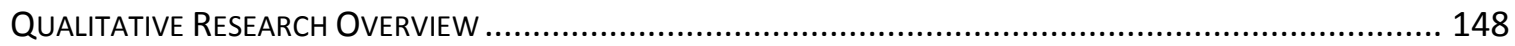

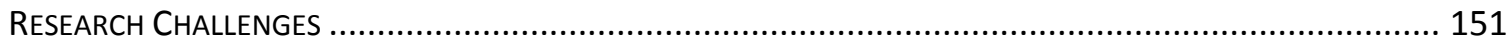

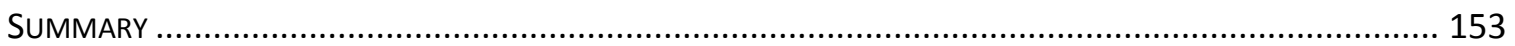

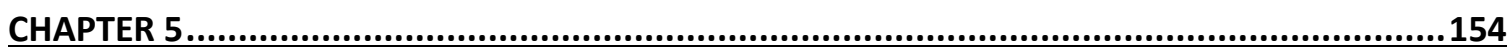

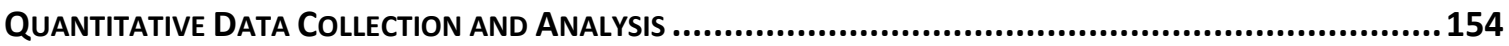

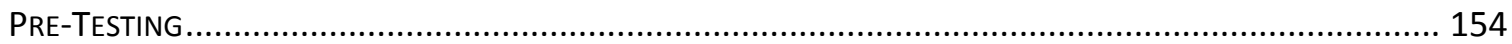

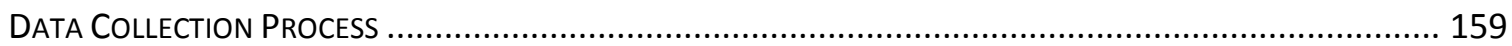

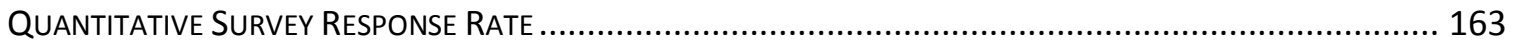

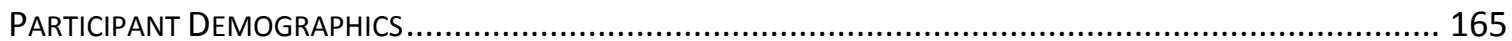

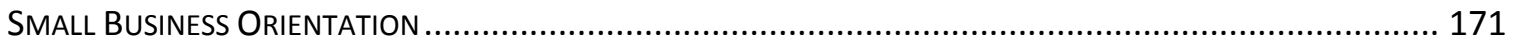

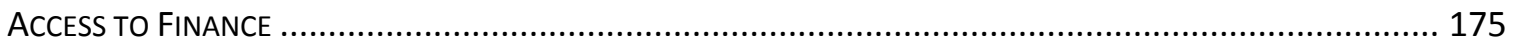

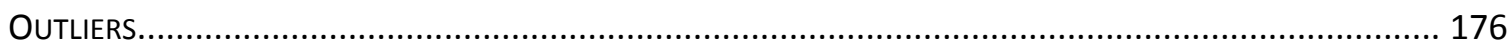

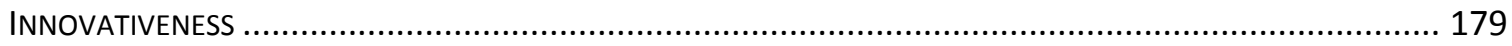

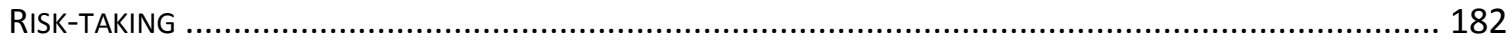

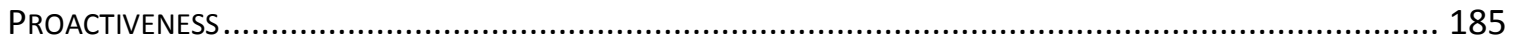

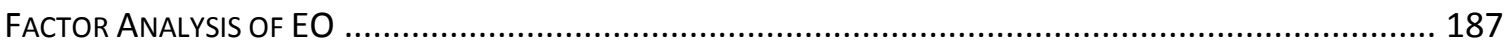

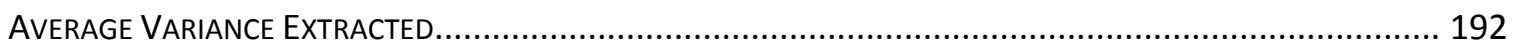

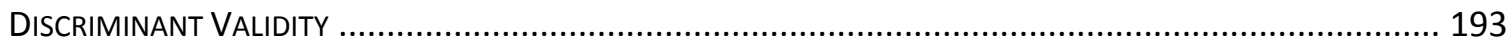

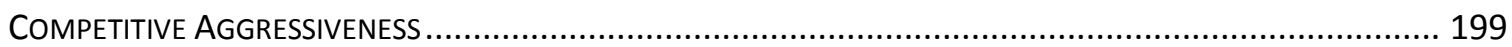

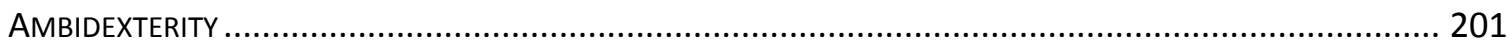

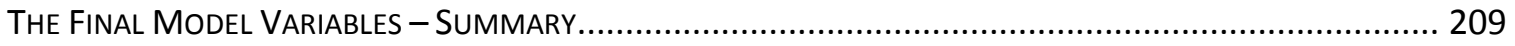

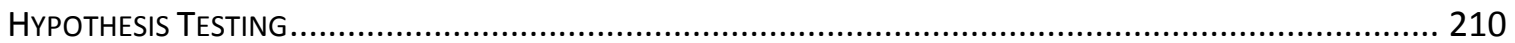

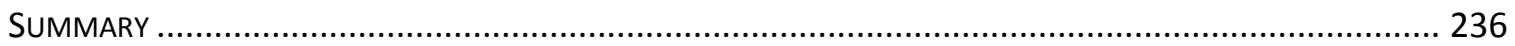

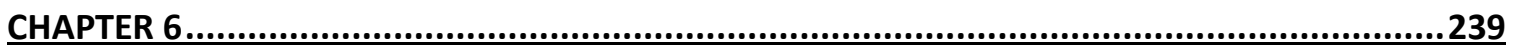

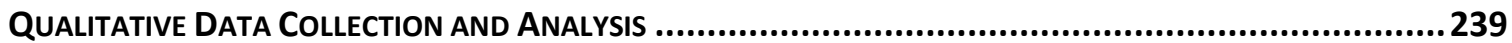

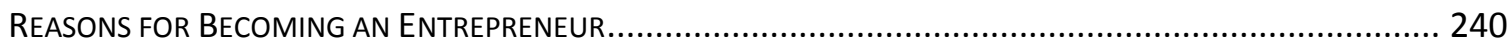

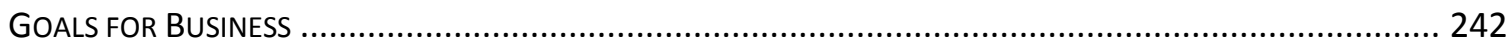

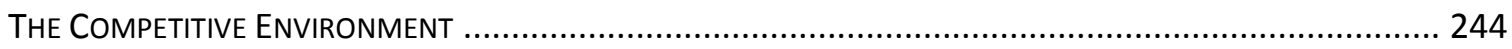

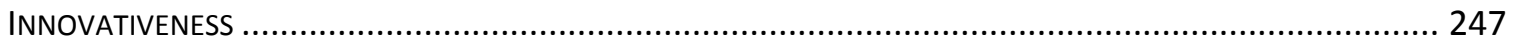

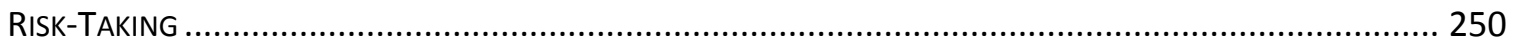

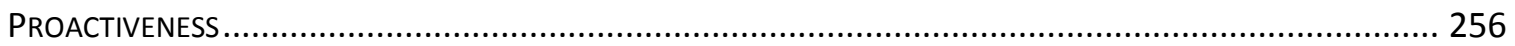

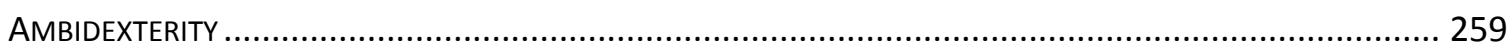




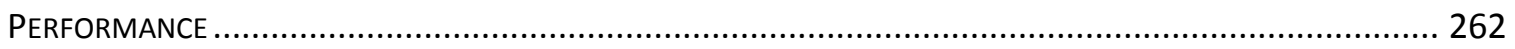

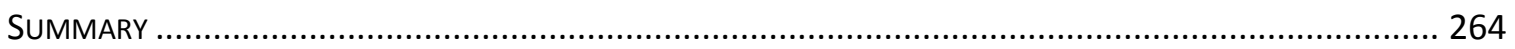

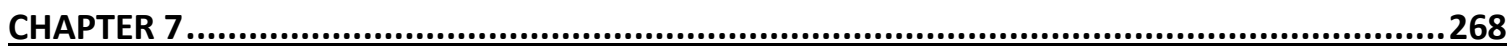

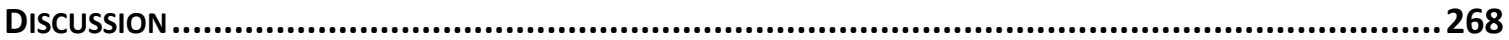

UNIDIMENSIONAL VERSUS MULTIDIMENSIONAL EO CONCEPTUALIZATIONS ...................................... 268

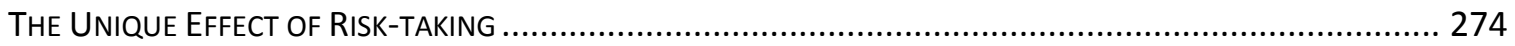

NON-LINEAR RELATIONSHIPS BETWEen EO, ITS DimEnSIONS AND PERFORMANCE.................................2 278

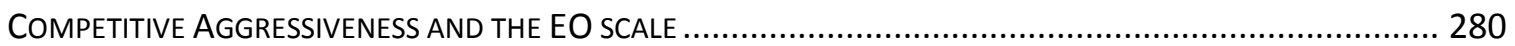

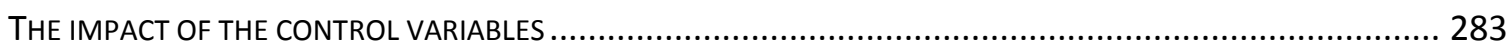

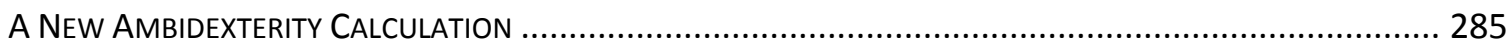

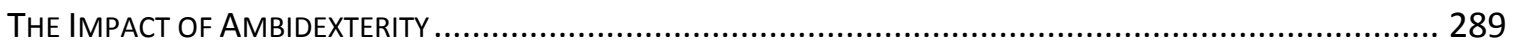

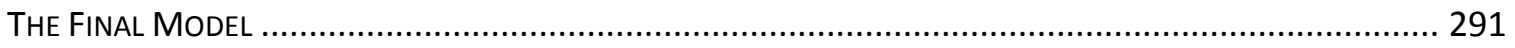

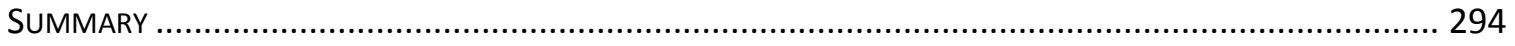

CHAPTER 8..............................................................................................295

CONCLUSION..............................................................................................295

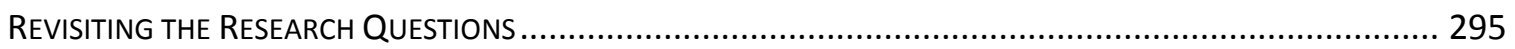

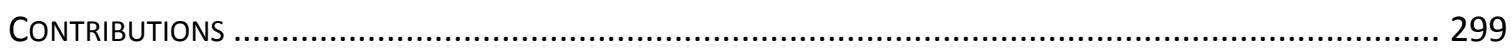

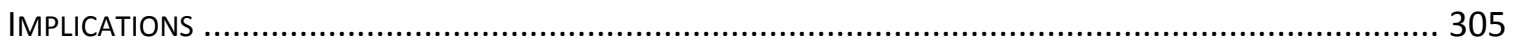

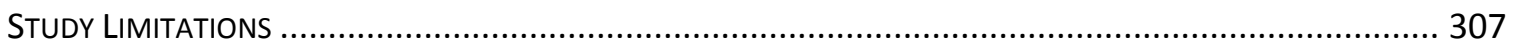

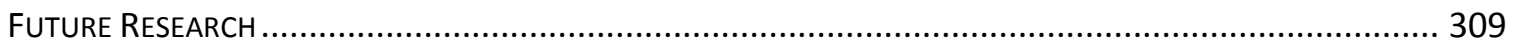

EXHIBIT 1 - QUESTIONNAIRE ...............................................................................312

EXHIBIT 2 - SEMI-STRUCTURED INTERVIEW QUESTIONS.................................................317

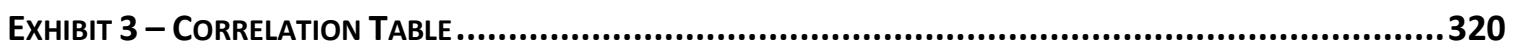

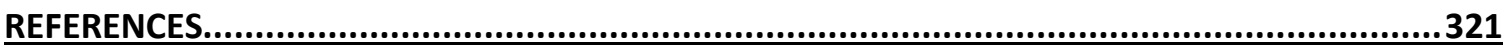




\section{List of Figures}

2.1 - Conceptual Framework of Entrepreneurial Orientation _............................... 40

2.2 - Resources as the Basis for Profitability _............................................. 51

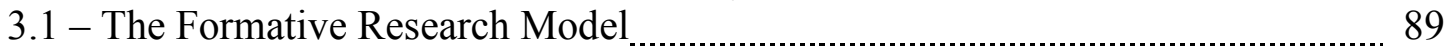

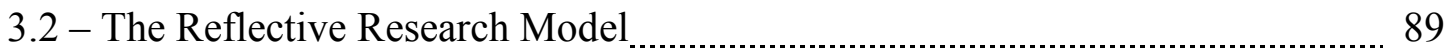

3.3 - Multidimensional versus Unidimensional Conceptualization in EO Research. 91

3.4 - Entrepreneurial Specific versus Alternative EO Research Outlets .................... 92

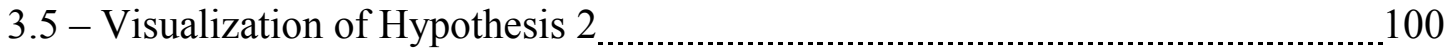

3.6 - Visualization of Hypothesis $3 \ldots \ldots$

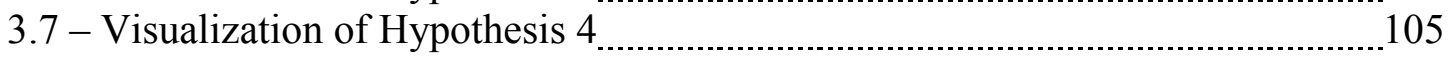

3.8 - Visualization of Hypothesis 5 — _ _ 107

3.9 - Visualization of Hypothesis $6 \ldots 111$

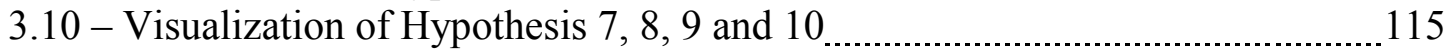

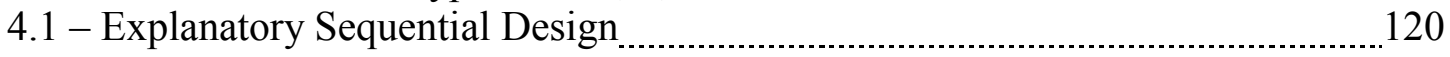

4.2 - The Process of Deduction $\ldots$

4.3 - The Process of Quantitative Research $\ldots 122$

4.4 - Illustration of Different Conceptualizations of Organizational Ambidexterity $\ldots 133$

4.5 - Map of Trinidad Showing Four Research Locations _.................................... 139

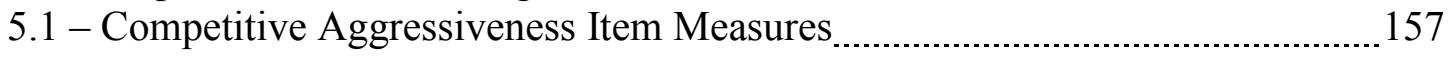

5.2 - Small Business Orientation Item Measures ……................................................. 158

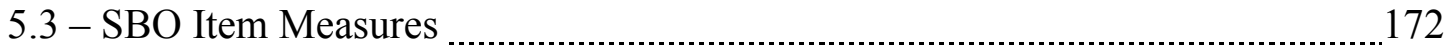

5.4 - Box-plot of Standardized Residuals

5.5 - Scree Plot - Items of EO $\quad 190$

5.6 - Visual Representation of Old versus New Ambidexterity _............................ 207

5.7 - Visualization of Non-Linear relationship between Innovativeness and Profit 217

5.8 - Visualization of Non-Linear relationship between Risk-taking and

Sustainability

5.9 - Moderation Effect of Ambidexterity on Proactiveness, with Sustainability as

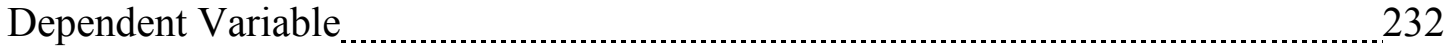
5.10 - Moderation Effect of Ambidexterity on EO, with Sustainability as Dependent Variable

7.1 - Risk-taking as a Mediator of Innovativeness and Proactiveness _....................22

7.2 - The Final Model $\ldots \ldots \ldots \ldots \ldots$ 


\section{List of Tables}

2.1 - Exploration and Exploitation Vocabulary _............................................... 69

3.1 - Summary of Hypotheses

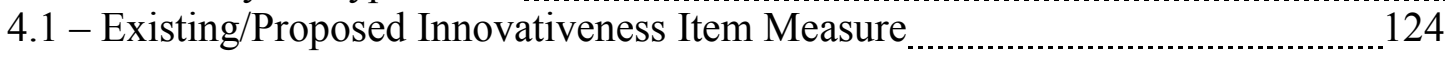

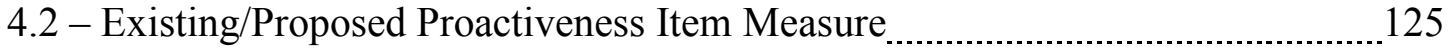

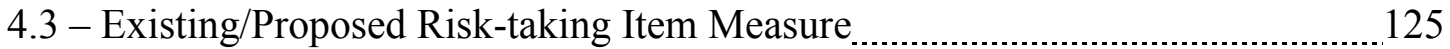

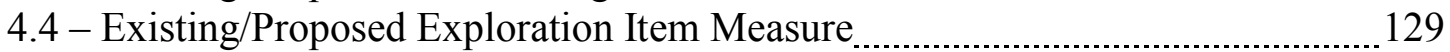

4.5 - Existing/Proposed Exploitation Item Measure $\ldots$

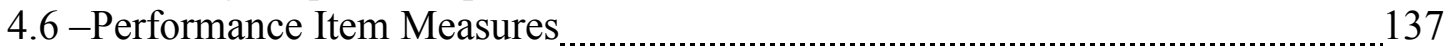

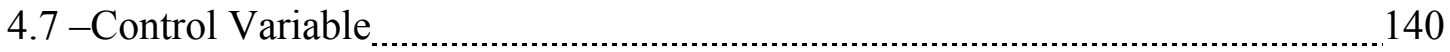

4.8 - Number of Respondents Needed for Statistical Significance _........................ 142

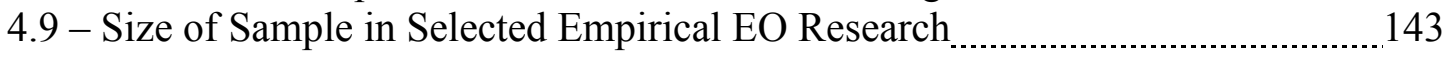

5.1 - Pre-Test - Which best describes the primary activity of your business ...............154

5.2 - Pre-testing - Time Taken to Complete Survey (in seconds) $\ldots \ldots \ldots \ldots . . . . . . . . . . . . . . . . . . . .156$

5.3 - 'Self read' Survey Participants Versus 'Read to' Participants _......................... 162

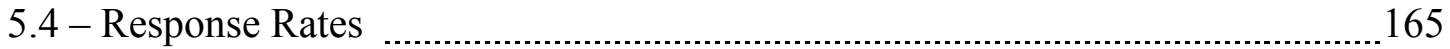

5.5 - Number of Employees - Descriptive Statistics

5.6 - Type of Business Activity $\ldots \ldots \ldots$

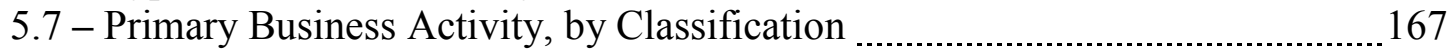

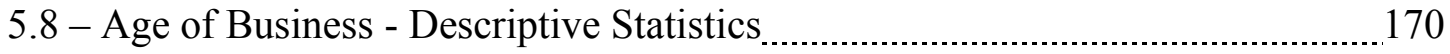

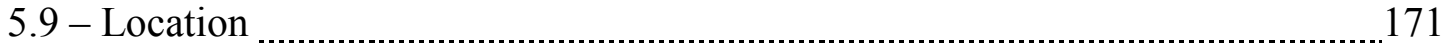

5.10 - Primary Business Location, by Classification

5.11- Small Business Orientation - Descriptive Statistics _................................... 172

5.12 - SBO Factor Analysis - Component Matrix $\ldots 173$

5.13 - SBO - Cronbach Alpha - Reliability Statistics $\ldots 174$

5.14 - Cronbach Alpha if Scale Item is Deleted - SBO (Item-Total Statistics) _....... 174

5.15 - Access to Finance - Descriptive Statistics _............................................... 175

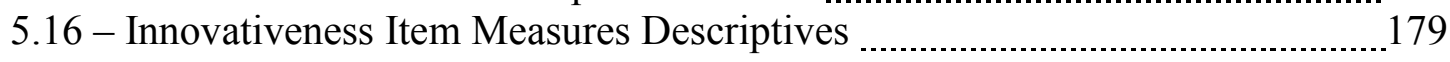

5.17 - Innovativeness - Reliability Statistics _............................................... 180

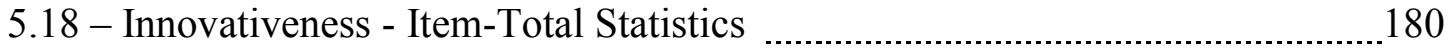

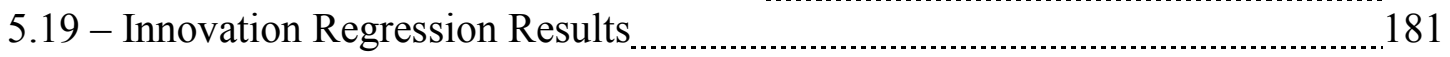

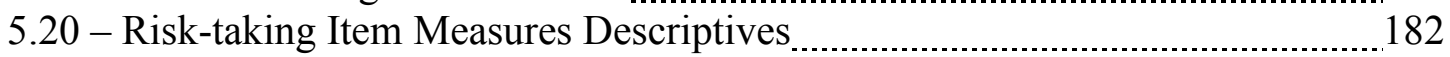

5.21 - Risk-taking - Reliability Statistics $\ldots 183$

5.22 - Risk-taking - Item-Total Statistics $\ldots$

5.23 - Risk-taking Regression Results $\ldots 184$

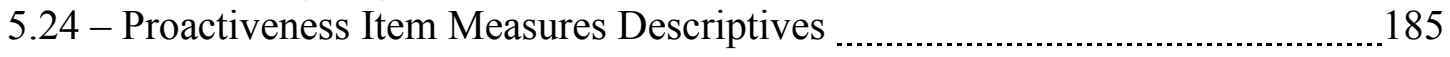

5.25 - Proactiveness - Reliability Statistics $\quad 186$

5.26 - Proactiveness - Item-Total Statistics $\ldots 186$

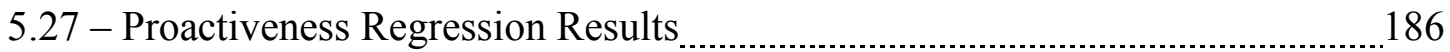

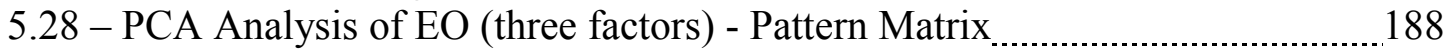

5.29 - EO (one factor) - Component Matrix $\ldots$

5.30 - Average Variance Extracted (EO) $\ldots 192$

5.31 - EO Correlations $\ldots$

5.32 - EO - Component Correlation Matrix $\ldots 195$

viii 
5.33 - Squared terms EO - Component Correlation Matrix

5.34 - Pattern Matrix - EO, Ambidexterity and Small Business Orientation _................196

5.35 - Average Variance Extracted (EO, SBO, Ambidexterity) _........................... 198

5.36 - Component Correlation Matrix (EO, SBO, Ambidexterity) _........................ 198

5.37 - - Squared Terms EO, SBO and Ambidexterity - Component Correlation

Matrix

5.38 - Addition of Competitive Aggressiveness to EO Regression Model _...…_....... 200

5.39 - Addition of Intention to Grow Control to Competitive Aggressiveness / EO

Regression Model $\quad 200$

5.40 - Exploration and Exploitation - Descriptive Statistics _.................................2 201

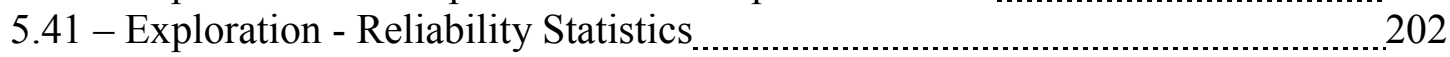

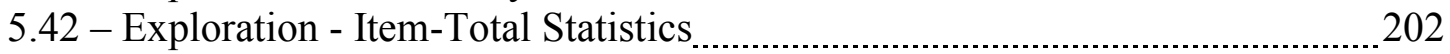

5.43 - Exploitation - Reliability Statistics _................................................ 202

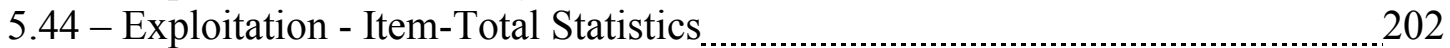

5.45 - Exploration and Exploitation Pattern Matrix _......................................... 203

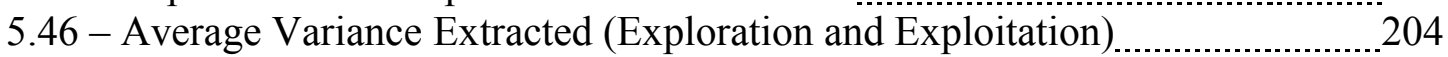

5.47 - Exploration and Exploitation Component Correlation Matrix _........................ 204

5.48 - Old versus New Ambidexterity Calculation Scores _................................ 205

5.49 - Test of Old versus New Ambidexterity - Dependent Variable $=$ Profits $\ldots \ldots . . .208$

5.50 - Test of Old versus New Ambidexterity - Dependent Variable $=$ Growth $\ldots . . . .208$

5.51 - Test of Old versus New Ambidexterity - Dependent Variable $=$ Sustainability

208

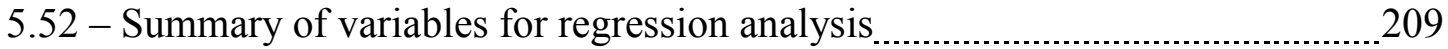

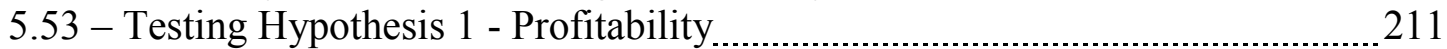

5.54 - Testing Hypothesis 1 - Growth $\ldots$

5.55 - Testing Hypothesis 1 - Sustainability _................................................ 212

5.56 - R squared for Control / Multidimensional / Unidimensional _...................... 214

5.57 - F-Statistic for Control / Multidimensional / Unidimensional _....................... 214

5.58 - Testing Hypothesis 2 - Innovativeness Non-Linear Relationship _................... 216

5.59 - Testing Hypothesis 3 - Risk-taking Non-Linear Relationship ……....................... 218

5.60 - Testing Hypothesis 4 - Proactiveness Non-Linear Relationship _.................. 220

5.61 - Testing Hypothesis 5 - EO Non-Linear Relationship …….......................... 221

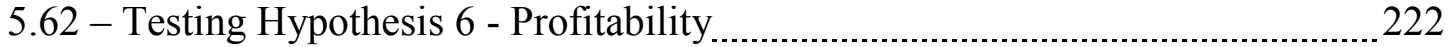

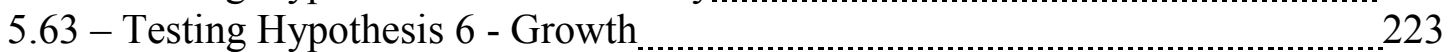

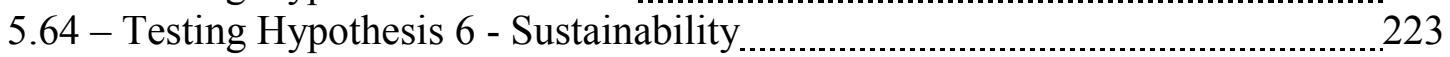

5.65 - Testing Hypothesis 7 - Ambidexterity as a Moderator of Innovativeness _.....225

5.66 - Testing Hypothesis 7 - Ambidexterity as a Moderator of Innovativeness _.....225

5.67 - Testing Hypothesis 7 - Ambidexterity as a Moderator of Innovativeness _.... 226

5.68 - Testing Hypothesis 8 - Ambidexterity as a Moderator of Risk-taking _........ 227

5.69 - Testing Hypothesis 8 - Ambidexterity as a Moderator of Risk-taking__....... 228

5.70 - Testing Hypothesis 8 - Ambidexterity as a Moderator of Risk-taking _............228

5.71 - Testing Hypothesis 9 - Ambidexterity as a Moderator of Proactiveness _...... 229

5.72 - Testing Hypothesis 9 - Ambidexterity as a Moderator of Proactiveness _...... 230

5.73 - Testing Hypothesis 9 - Ambidexterity as a Moderator of Proactiveness _........230

5.74 - Testing Hypothesis 9 - Ambidexterity as a Moderator of EO _....................... 233 
5.75 - Testing Hypothesis 9 - Ambidexterity as a Moderator of EO _..................... 234

5.76 - Testing Hypothesis 9 - Ambidexterity as a Moderator of EO _................................. 234

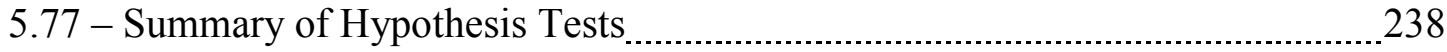

6.1 - Interview Participant Descriptive Statistics _ 239

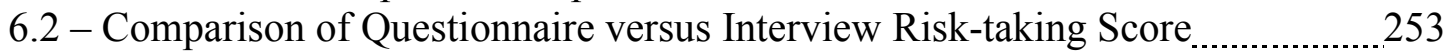

6.3 - Correlation between risk-taking responses in Questionnaire and Interview _.....254

6.4 - Questionnaire Performance and Interview Risk-taking $\quad 255$

6.5 - Summary Performance and Risk-taking by risk-taking level …....................... 255

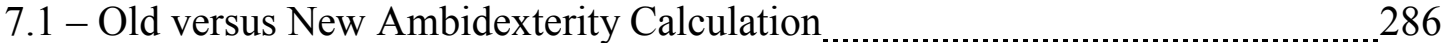

\section{List of Exhibits}

Exhibit 1: Quantitative research Questionnaire _............................................... 303

Exhibit 2: Structured Interview Protocol and Questions _................................... 308

Exhibit 3: Correlation Matrix 


\section{Chapter 1}

\section{Introduction}

The theory of Entrepreneurial Orientation (EO) has been developed in the Entrepreneurship literature in an attempt to explain differences in firm performance. EO reflects the priority that firms place on the process of identifying and exploiting market opportunities (Shane and Venkataraman, 2000). Lumpkin and Dess (1996) relate

to this concept of opportunity exploitation by highlighting the defining characteristics of entrepreneurship and an EO. They define EO as "the methods, practices and decisionmaking styles managers use to act entrepreneurial. These include such processes as experimenting with promising new technologies, willingness to seize new product-market opportunities, and having a predisposition to undertake risky ventures" (p. 136). Hitt et al. (2000) expand on this theme by noting that firms with strong EOs have the ability to make environmental uncertainty work to their benefit, while, Covin and Miles (1999) view entrepreneurship as exploiting the opportunity to renew and rejuvenate the firm.

EO has been shown to have direct significant impacts upon business performance and has become one the few established areas in entrepreneurship research (Rauch, Wiklund, Lumpkin and Frese, 2009). Based on the decisions and actions of a strategymaking process, the EO construct attempts to explain the how of entrepreneurial activity (Lumpkin and Dess, 1996). The EO construct, as it is primarily operationalized, is made up of three dimensions: innovativeness (e.g. my business is known as an innovator when compared to my competitors), proactiveness (e.g. my business takes action in anticipation of future market needs) and risk-taking (e.g. compared to my competitors, my business 
takes more risks) (Covin and Slevin, 1991, Miller, 1983). According to Lumpkin and Dess (1996), EO has as many as five dimensions, but it is usually more commonly associated with only three of the five dimensions: innovativeness, proactiveness, and risktaking (Zahra 1991; Covin and Slevin 1986; Miller 1983).

EO reflects the extent to which firms establish the identification and exploitation of untapped opportunities (Lumpkin and Dess 1996). Innovativeness refers to a willingness to support creativity and experimentation in new product development, technology adoption, and internal processes and procedures (Lumpkin and Dess 1996). It reflects a basic willingness to diverge from the status quo and embrace new ideas. Proactiveness refers to the ability of firms to seize the initiative in pursuit of marketplace opportunities. It is related to the concepts of first mover advantage, prospecting, market research, and to the overall ability of firms to act in anticipation of future changes to the market. Risk-taking reflects the willingness of owners or managers to commit a large percentage of a firm's resources to new projects and to incur heavy debt in the pursuit of opportunity (Lumpkin and Dess 1996; Miller 1983). Through the individual and combined study of the dimensions of the EO, we attempt to addresses both the unique contribution of each and also, their combined effect on the performance of a firm.

Many of the scales used to measure EO are based on the original work by Covin and Slevin (1991) and Miller (1983). The validity of the scale has not been shown to suffer if researchers carefully modify the original scale by making it more context specific (Hughes and Morgan, 2007). In fact, in some instances, contextual scale modification may improve the reliability (Rauch, Wiklund, Lumpkin, Frese, 2009). 
Further, the original work by Covin and Slevin (1991) regarded EO as a unidimensional construct, based on the summation of the innovativeness, proactiveness and risk-taking indexes. Firms that show relatively high levels in the summation of index of the three dimensions are thought to have the highest EO and theoretically show better performance than firms with a low EO. However, more recent work by Covin, Greene and Slevin (2006) and Lumpkin and Dess (2001) has suggested that the various dimensions of EO need not co-vary in all instances and may relate differently to firm performance in certain industries and context (Stetz, 2000).

Similar to the prominence of EO in the Entrepreneurship literature, in the strategy literature, the Resource Based View (RBV) is frequently used to explain different levels of performance through the operationalization of resource heterogeneity (Newbert, 2007). RBV relies on the firm's use and application of the tangible or intangible resources to create a competitive advantage. RBV theorists have argued that resources are heterogeneously distributed between firms and imperfectly mobile, allowing for the creation and sustainment of a competitive advantage (Barney, 1991). Barney (1991) argues that in order for resources to potentially generate competitive advantage, they must also possess the characteristics of being useful to exploit opportunities or neutralize threats in the operating environment, being rare to the exclusion of use to some or all competitors and also, being without strategically equivalent substitutes that could serve to offset the advantages of rarity.

Wernerfelt (1984) suggested that resources can be tangible, such as plant and machinery, or intangible, such as customer loyalty or staff experience. However, the 
categorization of resources can be far more extensive. In his meta-analysis of empirical work in the RBV field, Newbert (2007) reported 27 different resources being used in 32 articles and 232 tests. This diversity of resource operationalization speaks to the uniqueness of the importance of specific resources to individual industries. As such, the actual effect size of a resource is context dependent (Armstrong \& Shimizu, 2007).

The focus of the RBV is the competitive advantage that can be generated by the firm, from its unique set of resources (Wernerfelt, 1984; Barney, 1986, 1991). Understanding sources of sustained competitive advantage for firms has become a major area of research in the field of strategic management (Wernerfelt, 1984; Barney, 1991; Grant, 1991). According to Barney (1991), using the RBV to study a firm's internal strengths and weaknesses rests on two fundamental assumptions. First, building on Penrose (1959), we assume that firms can be thought of as bundles of productive resources and that different firms possess different bundles of these resources, in line with the assumption of firm resource heterogeneity. Second, we assume that some of these resources are either very costly to copy or inelastic in supply and relate to the assumption of resource immobility.

The most salient characteristic of the RBV is the focus on the internal forces of the firm with a great deal of interest in role of the firm's resources as the foundation for the firm's strategy (Grant, 1991). This interest reflects some dissatisfaction with the static, equilibrium framework of industrial organization economics, where the focus was in the relationship between the strategy and the external environment (Grant, 1991). 
Barney (1991) suggests that resources are, by themelves, insufficient for obtaining a sustained competitive advantage and high performance. Instead, this is possible only if the firms are able to transform resources into capabilities, and consequently into a positive performance (Barney, 1991). Firms therefore reach a superior performance, not only because they may have more or better resources, but also because of their distinctive capabilities. It follows then that the resources and capabilities of the firm are the main competences for formulating strategy (Grant, 1991).

There is a key distinction between resources and capabilities. Resources are inputs into the production process - they are the basic units of analysis (Grant, 1991). The individual resources of the firm include items of capital equipment, intellectual assets, patents and brand names among others. A capability is the capacity for these resources to perform some task or activity (Hitt et al., 2000). While resources are the source of the firm's capabilities, capabilities are often the main source of its competitive advantage.

Capabilities are often developed either in functional areas or in combinations of physical, humans or technological resources, controlled by the firm (Amit and Schoemaker, 1993). Capabilities together with resources are the core competences of a firm's strategy formulation and therefore constitute the firm's identity. Managers must select an appropriate strategy in order to effectively utilize the resources and the capabilities of the firms (Grant, 1991)

While sharing robustness for explaining differences in firm performance, the EO and RBV theories are fundamentally different in the application of the theoretical views, the variables they operationalize to do so and the stage of firm development they tend to 
focus on. In this study, we examine the circumstances and effect of the interaction between the dimensions of EO and a firm's exploration and exploitation capabilities on performance. While we believe that levels of innovativeness, proactiveness and risktaking are significantly related to performance, we also believe that the relationship is moderated by the capabilities of the firm. We argue that the impact of the EO of the firm as it relates to performance is significantly shaped by the interaction of the exploration and exploitation capabilities of the firm, termed ambidexterity. We propose that the significance of the direct relationship between EO and performance is moderated by the inclusion of a firm's ambidexterity capabilities.

In this study, performance is used as the dependent variable. Within the EO literature, the performance variable has primarily been the dependent variable of choice, demonstrating robustness with financial and non-financial indicators of performance, whether perceived or actual (Rauch, Wiklund, Lumpkin and Frese, 2009). Work within the RBV has also utilized current performance as its foremost dependent variable (Newbert, 2007). However, in keeping with strict definitions in the literature and calls from the field (Armstrong and Shimizu, 2007), consideration of a sustained performance may also be appropriate. Thus, the performance variable measures self-evaluated performance versus one's competitors for a time frame inclusive of previous years based on the dimensions of profitability, growth and sustainability of operations.

We propose that this research provides a useful framework for identifying a small firms' propensity to engage in EO, with the objective of examining the impact of EO on the performance of small firms. The current research agenda has its origins in three 
specific research questions (RQ) we seek to answer. The three broad research questions consider the dimensionality of EO, its relationships to performance and the effects of ambidexterity. They are explored through 10 hypotheses, with a focus on the EO and $\mathrm{RBV}$, their interaction, and performance in a micro firm context. As such, the aim of the study is to investigate the following questions:

1. Does a formative, multidimensional EO construct explain a significantly greater amount of variance in firm performance than a reflective, unidimensional construct?

2. How do the individual dimensions of EO and a summative EO index relate to performance? Do these dimensions and the overall EO share a linear or curvilinear relationship with performance? Are there differences in the relationships between the individual dimensions of EO and performance?

3. How does the dynamic capability of ambidexterity (the interaction of exploration and exploitation) relate to performance? Does the ambidexterity of an organization moderate the relationship between the dimensions of EO and performance?

The first research question will allow investigation into the debate found within the EO literature as to the effectiveness of a summated (index, reflective, unidimensional) versus algebraic combination (formative, multidimensional) scale as it relates to the explanation of performance. The second research question will consider the relationships that exist between the EO dimensions of innovativeness, risk-taking and proactiveness, as 
well as the relationship between the summed EO and performance. The third research question builds upon the second by linking the EO dimensions to the RBV, specifically a firm's ambidexterity, to evaluate the relationship between ambidexterity and performance and the moderating effects that ambidexterity can have on the relationship between EO, its dimensions and performance.

This study comprises both quantitative research and qualitative research components. Quantitative research is conducted through the use of questionnaires based upon the established scales that have been used in the literature, administered to the firm's entrepreneur. The responses were subjected to analysis dependent on the specific RQ, with the bulk of the analysis being conducted via hierarchical regression analysis in SPSS. With regards to the qualitative component, structured interviews were conducted with high and low performing micro firms that have been identified within the research sample in an attempt to develop an understanding of the importance of the dimensions of EO, exploration and exploitation unto performance. The collection of micro enterprise firms (less than 5 full time employees) that forms the research sample allows for a more in-depth understanding of the findings. These firms are typically small in scope and size, suggesting that the EO of the entrepreneur is integral to the overall orientation of the firm and that the identification of how and why the capabilities under review are applicable to performance. However, it should be noted that the generalizability of the analysis may be limited due to the use of this sample. For instance, an attempt to reproduce the results of this study in larger organizations may yield conflicting reports. 
Adding to our understanding of the interactions of EO, resources and performance would make a significant contribution to scholars, practitioners, and in the lives of those affected by this initiative by adding to the breadth of knowledge in the field. In this regard, we attempt to bridge the gap between two popular concepts in the entrepreneurship and strategy literature to further their application, development and understanding. In one instance, we address criticism of the RBV (Kraaijenbrink, Spender and Groen, 2010 ) that suggests that the RBV mainly accounts for ex-post sources of sustained competitive advantage. By offering a potential ex-ante source of sustained competitive advantage, we propose that EO can lead to superior resource allocation, development and acquisition decisions, which in turn leads to superior performance. Additionally, the uniqueness of the sample may offer insights that have been overlooked or were not present in past research.

The simple organizational structure of small firms enables top management's oversight of firms' practices and processes. This in turn enhances the flexibility and responsiveness of small firms to environmental events and may at least partially explain why the effects of market orientation on firm performance tend to be stronger in small firms (Pelham 2000). In addition, the recognition that the exploitation of new opportunities is the primary driver of small business entry and growth, a sample of micro entrepreneurs was chosen for the research.

This study focuses on micro enterprises in Trinidad, being defined as those enterprises with 5 or less employees. Although definitions of firm size categorizations can differ globally, using an employee count is in line with Hendrickson (2009), who 
notes that in Trinidad, firm size is often classified based on the number of employees. Specifically, firms with 6-25 employees are considered small, while 26 - 50 employees are considered medium sized organizations, and large firms have over 50 employees. The advantages of using micro firms as the research population is primarily due to the increased effect of EO in smaller as compared to larger firms (Rauch, Wiklund, Lumpkin and Frese, 2009) which may be as a result of the measurement a firm's EO based on responses from top management. In smaller firms, the EO of the entrepreneur (top management) is more likely to be representative of the overall EO posture of the entire firm than in a larger firm.

Further, the Trinidadian context offers new ground in the study of EO. In Wales, Gupta and Mousa's (2011) review of empirical EO research, they note that of the 158 articles reviewed only one was in a Latin American context (Mexico) and that no empirical EO research had been based on the Caribbean region. They note that exploration of these areas would allow for the continued generalization of EO research at an international level and encourage research in geographic areas that have been previously overlooked, with Trinidad meeting this criterion.

This research also centers on identifying best practice in micro entrepreneurship to foster the advancement, enlargement, and success of entrepreneurs at a local level, which is of particular importance, given the study's developing economy contextual foundation. Through an understanding of the theorized linkages between EO, the RBV and performance, entrepreneurs can hope to improve their performance. Specifically, knowledge of one's own EO can give insight into the types of resources that should be 
acquired and exploited based on the EO unique to that individual entrepreneur. This study is especially unique as it incorporates the constructs of $\mathrm{EO}$ and $\mathrm{RBV}$ as drivers of performance in one study.

We employ a mixed method approach, consisting of distinct quantitative and qualitative data collection periods. Creswell and Clark (2011) suggest that a mixed methods approach "occurs when a direct interaction exists between the quantitative and qualitative strands of the study" (p. 65), noting that the interaction can occur at different stages in the research process, in several ways. Specifically, for this study, an explanatory sequential research design was used. This study can serve as a guide to the Government of Trinidad and Tobago to improve the effectiveness of their service offerings as it relates to micro enterprise development. Although entrepreneurship has been recognized by the Government as integral to its Medium-Term Policy Framework, the role of the Government in advising potential entrepreneurs has been disappointing.

According to the Global Entrepreneurship Monitor (GEM), less than 5\% of potential entrepreneurs reported seeking any advice from the Government of Trinidad. According to Bailey et al. (2011), this is possibly due to the basic levels of training offered (Karides, 2005). Through an understanding of the EO, key resources, capabilities, their interaction and performance, we believe that we can close the gap that exists between entrepreneurs and the government. Specifically, by understanding the unique entrepreneurial orientation of local micro firms and its implications, the government can design and administer superior training to micro entrepreneurs. 
In terms of the structure of this paper, this introduction is followed by a review of the applicable EO and RBV literature (Chapter 2), the research model and hypotheses (Chapter 3) and research methodology (Chapter 4). Next are the quantitative and qualitative results (Chapter 5 and Chapter 6), which is followed by a discussion (Chapter 7) and conclusion (Chapter 8)

The literature review is primarily centered on the EO and RBV literature within the entrepreneurship and strategy disciplines. It considers the origins of the EO and its development and acceptance by the academic community. While the EO construct has been widely adapted within the Entrepreneurship literature, the operationalization of the construct has remained a contentious issue. Through the consideration of deconstructed dimensions of the EO construct (innovativeness, risk-taking and proactiveness), as well as the full EO construct, we consider the implications of the differing approaches to measurement due to a multi and unidimensional approach as a predictor of performance.

Drawing upon the strategy literature, the second section focuses on the RBV's origins and development, competitive advantage and how it outlines the VRIN framework (valuable, rare, in-imitable, nonsubstitutable). This is followed by a discussion of firm resources, capabilities and dynamic capabilities, with a deeper focus on the specific dynamic capabilities of exploration and exploitation. We propose EO and its dimensions as an important measure of an organization, which can serve to enhance the resources and capabilities of the firm by directing the attention of top management to the utilization of the firm's resources/capabilities towards the discovery and exploitation of opportunities. We propose that through the joint consideration of a firm's resources, 
dynamic capabilities, EO and its dimensions, on can attain a more complete explanation of firm performance than if they were considered independently. The final section discusses the linkages that exist between the EO and RBV literature and provides a contextual background for the literature review, by looking at the relevant implications of the micro firm context and the study's host country.

Building on the literature review, the third section of this paper develops the proposed research questions, the research model and derives the hypotheses that will be used to investigate the research question. The methodology that was used to test the hypotheses will then be introduced and discussed. First, an overview of the mixed method approach will be presented detailing the various steps that were taken during the explanatory sequential research design. Following is the discussion of the quantitative component of the research, which forms the largest part of this chapter. Within the quantitative section, measures of EO (innovativeness, risk-taking and proactiveness), ambidexterity (exploration and exploitation) and performance found in the literature are outlined as well as the presentation of the questionnaire. Next, the control variables that were used are discussed as well as the research population and the selection of a sample. Then, the methodological process with regards to the data analysis is detailed for each hypothesis found in the previous chapter. Finally, the qualitative research component is outlined along with the presentation of the structured interview format and method of participant selection.

Following the methodology, the quantitative and qualitative results are presented. In the quantitative results section a review is presented of the pre-testing that was carried 
out and the resulting actions that were taken. The data collection process is mapped, including an analysis of the response rate, participant demographics and data screening. The dimensions of the EO construct are explored individually and collectively, and subjected to factor analyses, tests of convergent and discriminant validity. The calculation of a new ambidexterity variable is considered and finally tests are performed (primarily hierarchical multiple regression analysis) to determine the statistical support for the hypotheses that are presented in the third chapter. The following qualitative chapter presents the results from the interviews that were conducted. This chapter lends context and understanding to the statistical based results that are presented in the quantitative results section.

The discussion is next and is an attempt to disseminate the meaning of the results that are presented in the preceding two chapters. Major themes in the discussion include the unidimensional versus multidimensional conceptualizations of the EO construct, the unique effect of risk-taking as compared to the other dimensions of EO, non-linear relationships that exist between the dimensions of EO and performance, the inclusion of competitive aggressiveness in the EO scale and the impact of ambidexterity. The conclusion revisits the original research questions as presented in the introduction and assess whether they have been adequately answered, followed by the limitations of the study and directions for future research. 


\section{Literature Review}

\section{Chapter 2}

The following literature review is primarily centered on the Entrepreneurial Orientation (EO) and Resource Based View (RBV) literature within the entrepreneurship and strategy disciplines. The first section of the literature review considers the origins of the EO, its development and acceptance by the academic community. While the EO construct has been widely adopted within the Entrepreneurship literature, the operationalization of the construct has remained a contentious issue. We consider the individual dimensions of the EO construct (innovativeness, risk-taking and proactiveness), as well as the summated index of the EO construct. Further we explore the implications of the differing approaches to measurement due to a multi or unidimensional approach with performance as the predictor.

Drawing upon the strategy literature, the second section focuses on the RBV's origins and development, competitive advantage and how it outlines the VRIN framework. This is followed by a discussion of firm resources, capabilities and dynamic capabilities, with a deeper focus on the specific dynamic capabilities of exploration and exploitation. Exploration and exploitation are considered important measures of an organization, which can help unlock the potential benefits of an EO, and which in turn may be enabled or disrupted by the EO of the organization. Through the joint consideration of a firm's resources, dynamic capabilities, EO and its dimensions, a more complete explanation of firm performance is attained than if they were considered independently. The final section discusses the linkages that exist between the EO and RBV literature and provides a contextual background for the literature review, by 
examining the relevant implications of the micro firm context and the study's host country. Analysis of EO in micro firms provides benefits relative to its study in larger organizations, due to the greater likelihood of the EO tendency of entrepreneurs in smaller firms to influence the overall posture of the firm as opposed to managers in larger firms.

\section{Entrepreneurial Orientation}

Entrepreneurship, as a field of scholarship, has been undergoing a period of growth. No longer restricted to the new venture creation process, entrepreneurship research has expanded to areas such as corporate and social entrepreneurship, (Covin and Slevin, 1991) and how, by whom, and the extent to which opportunities are discovered, evaluated and exploited (Venkataraman, 1997). As such, beyond a label for an individual who has started a business, our understanding of entrepreneurs has evolved to include individuals who act entrepreneurially in a variety of contexts.

Arguably, the most common conceptualization of what it means to act entrepreneurially has been the Entrepreneurial Orientation construct, which has been the subject of much empirical and theoretical work (Covin, Greene and Slevin, 2006). Through an understanding of the behaviour of a firm, EO attempts to capture the extent to which a firm's posture is entrepreneurial by assuming that the higher the EO of the top manager(s) of the firm, the more likely the firm's overall posture is also entrepreneurial. The study of EO has become an area of entrepreneurship research that is developing a cumulative body of work (Rauch, Wiklund, Lumpkin and Frese, 2009) having been employed in over 200 peer reviewed studies (George and Marino, 2011). 
EO's origins have been attributed to the work of authors such as Mintzberg (1973) and Khandwalla (1977) who, in their analysis of the strategy making process, attempted to describe the variables involved in decision making and found that entrepreneurial firms tended to be proactive in the search for new opportunities and to take more risks. Miller (1983), drawing on the variables that were believed to best reflect the core components of entrepreneurial strategy, identified three of the variables he believed to best represent the process of entrepreneurship itself. He states (p. 771):

"An entrepreneurial firm is one that engages in product-market innovation, undertakes somewhat risky ventures, and is first to come up with 'proactive' innovations, beating competitors to the punch. A non-entrepreneurial firm is one that innovates very little, is highly risk averse, and imitates the moves of competitors instead of leading the way. We can tentatively view entrepreneurship as a composite weighting of these three variables."

As such, Miller (1983) isolates three individual characteristics of an entrepreneurial firm, which in its decision making, is guided by innovation, risk-taking and proactiveness. He contrasts this behaviour with the non-entrepreneurial firm, which is presumed to engage in limited innovation, shy away from risk and not be very proactive in decision-making. Further, Miller argues that it is not the individual strength of each characteristic that makes a firm entrepreneurial, but rather the combination of all three. He continues (p. 780):

"In general, theorists would not call a firm entrepreneurial if it changed its technology or product-line ('innovated' according to our terminology) simply by directly imitating competitors while refusing to take any risks. Some proactiveness would be essential as well. By the same token, risk-taking firms that are highly levered financially are not necessarily considered entrepreneurial. They must also engage in product-market or technological innovation. Thus our focus upon the composite dimension is intuitively reasonable." 
Thus, according to Miller, the dimensions of EO are such that their ability to forge an advantage over their competitors cannot be exploited in isolation from each other. Rather, Miller conceptualized that EO is highest when all the individual components are high and interact with each other to form the basis of an advantage.

Based on the theory put forward by Miller (1983), Covin and Slevin (1989) were the first to operationalize the proposed construct. Using five items from existing instruments (Miller and Friesen, 1986 and Khandwalla, 1976) and four additional original items, they developed a nine-item scale that was comprised of three measures for each of the components. The three dimensions of EO put forward by Miller (1983) and Covin and Slevin (1989) have been consistently utilized in the literature since its introduction. As described by Rauch, Wiklund, Lumpkin and Frese (2009, p. 753):

"Innovativeness is the predisposition to engage in creativity and experimentation through the introduction of new products/services as well as technological leadership via $\mathrm{R} \& \mathrm{D}$ in new processes. Risk-taking involves taking bold actions by venturing into the unknown, borrowing heavily, and/or committing significant resources to ventures in uncertain environments. Proactiveness is an opportunityseeking, forward-looking perspective characterized by the introduction of new products and services ahead of the competition and acting in anticipation of future demand."

Covin and Slevin (1989) measured the level of innovation through responses to three questions, anchored on scales of 1 to 7 . The first, measured the emphasis on existing products and services as opposed to the emphasis on research and development or technical leadership. Firms that place less emphasis on the existing product and service lines are assumed to be more likely to employ new and innovative ways of serving their customers. Next, the amount of new products and services introduced in a past period (e.g. five years) is measured, ranging from no new products, to many new products. In 
this instance, there is a direct correlation between the amount of new products and services that have been introduced in the period and the level of innovation. Finally, beyond the frequency of innovation, the scale and scope of innovation is measured through responses to the scale of changes to products and services as minor or dramatic (more or less innovation respectively).

Proactiveness was also measured using three items, anchored on a scale of 1 to 7. In the first item, individuals were asked to reply to the statement $(1989$, p. 86), "In dealing with my competitors, my firm usually responds to competitive actions", or "initiates actions that competitors would then respond to", representing less or more proactiveness respectively. Next the authors asked firms about the frequency of being first to market with new products, services, operating methods and administrative techniques, ranging from seldom to often. Finally, the avoidance of competitive clashes (low proactiveness) or willing engagement in them (high-proactiveness) is measured.

To measure risk-taking, Covin and Slevin framed two of the three questions from the view of top management, while the third asks the respondents to consider the view of the firm. The first question asked respondents to consider management's proclivity for low risk projects with normal rates of return (low risk-taking) versus a high proclivity for riskier projects that offer the possibility of higher return (high risk-taking). Next, they measured risk-taking by asking if due to the environment, respondents found that top managers in the firm found it better to be timid and gradually explore the market (low risk-taking) or if a wide range of bold actions was better (high-risk-taking). Finally, they measured risk-taking through responses to the firm's position as either being a cautious 
'wait-and-see' approach to decision making or a more aggressive posture in the exploitation of potential opportunities.

One apparent shortcoming of the EO measure as described above, is its tendency to switch its levels of analysis. For both innovation and risk-taking, two questions are at the firm level, while the third is at the management level, and further, proactiveness is operationalized entirely at the firm level. An individual(s) tasked with responding to the EO scale on behalf of the entire firm, or even only its top managers, may be limited in his or her knowledge of the firm or its top management team. Further, in the event of variation in EO between employees or managers (e.g. some risk takers and some who are risk averse), it is difficult to accurately provide responses to the measurement, as the effects of individuals on the overall posture may be difficult to quantify. As noted previously, we utilized micro firms in the study, or those with less than 5 full time employees, in an attempt to minimize the implications of this level switching.

Although the items of the scale were intended to measure different aspects of EO, Covin and Slevin (1989) conducted factor analysis to determine factorial validity (Allen and Yen, 1979), with the belief that if all the items were loaded onto a single factor, the items would suggest some unidimensionality, or correlation with EO. In a reflection on his 1983 work, Miller (2011) acknowledges that based on his belief that entrepreneurship would manifest itself differently, dependent on the context, he developed the scale as a collective catchall that would capture "risk-taking in the small firm, innovation in the high-tech company, and proactiveness in an 'intrapreneurial' giant" (p. 874). He reflects in his later paper (2011) that he was initially worried that the items would not relate 
significantly, but that in the end, he need not have been. Covin and Slevin's (1989) work showed that all of the items did in fact load onto a single factor, with each of the items loading above 0.5 , at an average loading of 0.66 . Additionally they reported an inter-term reliability of 0.89 , scale mean of 4.33 and a response range of 1.22 to 6.78 . These results are used as the basis for the continued utilization of a composite measure of EO and its treatment as a unidimensional reflective construct, which we will discuss in greater detail later.

\section{Innovativeness}

Innovativeness has been shown to exhibit a positive linear relationship with performance (Kreiser, Marino and Weaver, 2002) and "reflects a firm's tendency to engage in and support new ideas, novelty, experimentation, and creative processes that may result in new products, services, or technological processes” (Lumpkin and Dess, 1996, p. 142). Entrepreneurial innovation on the other hand, is defined as the "willingness to support creativity and experimentation in introducing new products/services, and novelty, technological leadership and R\&D in developing new processes" (Lumpkin and Dess, 2001, p. 431). Corporate entrepreneurship as defined by Jennings and Young (1990, p. 55) is based on whether a firm "develops a higher than average number of new products or new markets within that industry”, while Zahra (1993 p. 47) suggests that a "distinguishing characteristic of an entrepreneurial company is its strong commitment to creating and introducing new products to the market, especially well before the competition." Although conceptualized by Jennings and Young (1990) as only an 
outcome, all the definitions propose the idea that innovativeness is tied to the support and commitment of the firm towards the development and creation of new products, services and processes.

Schumpeter (1942) was one of the first to recognize the importance of innovation as being a part of the entrepreneurial process. In his work, he coined the term 'Creative Destruction', which he suggests, “incessantly revolutionizes the economic structure from within, incessantly destroying the old one, incessantly creating a new one" (p. 83). He continues, "The fundamental impulse that sets and keeps the capitalist engine in motion comes from the new consumers' goods, the new methods of production or transportation, the new markets, the new forms of industrial organization that capitalist enterprise creates" (p. 83). Having derived a form of newness as described from innovation, the entrepreneur can utilize this temporary monopoly position to earn additional economic rents. Zaltman (1973) suggests that a critical part of the innovativeness initiation process is the openness to innovation of members of the organization. This is of importance in small organizations, as an innovative tendency of a small number of employees or likely one key person can influence the entire organization's willingness to adopt or reject innovative products and processes.

Innovations can be broadly broken down into product-market innovations and technological innovations. Product-market innovations refer to those innovations that focus on design, function, form, market research, end user service, advertising and promotion, while technological innovations span areas including product and process development, engineering, research, technical knowledge and industry expertise. Even 
with this broad categorization, there is a considerable degree of overlap. For instance, an innovation in the design of a product (product-market) may be partly driven by process development or technical knowledge, though in both cases, innovativeness forms "an important component of an EO, because it reflects an important means by which firms pursue new opportunities" (Lumpkin and Dess, 1996, p. 142).

The empirical literature centered on EO and the specific role of innovativeness, has demonstrated the importance of the EO dimension as it relates to performance. Results show an average corrected correlation (corrected for measurement and sampling errors) of .195 in the relationship between innovation and performance in EO studies that analyzed the relationship (number of studies $=10)$, (Rauch, Wiklund, Lumpkin and Frese, 2009). Some authors have argued that innovation is the most important factor in the determination of corporate entrepreneurship and though acknowledging the existence of multiple dimensions, Covin and Miles (1999) suggest that these dimensions are antecedents, consequences or correlates of innovation. They further propose, "without innovation there is no corporate entrepreneurship regardless of the presence of these other dimensions" (p. 49). Although it may be an exaggeration to conclude that, in the absence of innovation, entrepreneurship may not be possible, it does lead one to question the importance of innovation relative to the other dimensions of EO. In their study of German entrepreneurs, Bruderl, Preisendorfer and Ziegler (1992) investigate the predictors of firm growth and survival. They find that innovation is the most important factor in the growth of firms and is the most important by a significant margin.

Environmental context has also been suggested to be significant in the 
relationship between innovativeness and business performance (Zahra, 1993). A turbulent environment may foster a context in which innovation can share an important relationship with performance. In this type of environment buyer preferences change frequently as they enter and exit the market, generating wide ranging wants and needs in the marketplace with a constant emphasis on new product offerings (Hult, Hurley and Knight, 2004). Zahra and Covin (1995) report that firms that operate in hostile as opposed to benign environments were more likely to see the benefits of entrepreneurial behavior, including innovativeness, risk-taking and aggressive competitiveness.

Where the demands of buyers are constantly in flux, a firm that continuously and successfully innovates will theoretically be more prosperous than a firm that is unable to do so. In their study of large firms (sales above USD \$100 million per annum), Hult, Hurley and Knight (2004) however, found significance in the relationship of innovativeness and performance in both turbulent and non-turbulent contexts. One possible explanation for the significant finding in both contexts could be the size of the firms studied. In small firms, the level of innovativeness at the firm level is closely linked to key individuals who may be reporting the levels of innovativeness. In contrast, in larger firms, the individual who is tasked with reporting levels of innovativeness, even if he/she is a key employee, may be likely to report levels of innovativeness that do not correlate as closely with those that actually exist at the firm level due to the competing influence of many other individuals. 


\section{Risk-Taking}

Cantillon (1734) has been credited for being the first to formally use the term entrepreneur and suggested that the primary difference between entrepreneurs and paid employees was the inherent uncertainty and riskiness assumed by the entrepreneur. McClelland (1967) notes, "practically all theorists agree that entrepreneurship involves, by definition, taking risks of some kind" (p. 210). Other early definitions also proposed that entrepreneurship was based on the willingness to engage in calculated business risks or in other words the "perceived probability of receiving the rewards" (Brockhaus, 1980, p. 513). This early proposed relationship has endured in the Entrepreneurship literature and has meant that risk-taking is a trait frequently used to describe entrepreneurship (Lumpkin and Dess, 1996). This has been supported empirically as it has been shown that entrepreneurs are more likely to engage in risky activities than the corporate manager (Stewart, Watson, Carland and Carland, 1998). Risk-taking increases the likelihood of the exploitation of an opportunity by a firm in a relatively short time frame. This increased likelihood of exploitation means that opportunities that have been overlooked or delayed in search of additional information, may be more likely to be immediately exploited by those with a greater propensity for risk-taking.

Three types of strategic risks have been identified by Baird and Thomas (1985) including: "venturing into the unknown", "committing a relatively large portion of assets" and "borrowing heavily" (p. 231-232). In the first instance, venturing into the unknown suggests that there is a level of uncertainty and may include risks discussed in the literature such as personal risk, social risk or psychological risk (Gasse, 1982). In 
terms of personal risk, the entrepreneur is faced with financial risk, as often the entrepreneur's personal funds are used as capital or collateral for the new business venture, meaning that failure often results in a major personal financial loss. Social risk refers to the need for entrepreneurs to sacrifice large portions of their social and family life in order to manage and devote adequate time to the new venture. Further, entrepreneurs risk loss of face and may endure a social stigma in the event of the venture's failure. Psychologically, due to the uncertainty of new ventures, the long hours of attention they require and numerous other demands, the entrepreneur may be subject to higher levels of stress than an employee.

In the second instance, committing a relatively large portion of assets, implies that more risk is associated with increasingly committed amounts of capital as a portion of the entire asset base. Finally, borrowing heavily, suggests that there are more risks associated with this type of financing. Lumpkin and Dess (1996) also suggest these types of strategic risk proposing "firms with an entrepreneurial orientation are often typified by risk-taking behaviour, such as incurring heavy debt or making large resource commitments, in the interest of obtaining high returns by seizing opportunities in the marketplace" (p. 114). However, is it reasonable to suggest that an entrepreneur who secures an unsecured loan to finance a new venture faces less risk than an entrepreneur who utilizes his personal savings to do so? If not, a measure of the risk-taking propensity of the entrepreneur rather than an accounting measurement may be more appropriate (Sitkin and Pablo, 1992).

Further, Lumpkin and Dess (1996) discuss a measurement issue, suggesting that although most studies theorize based on the risk-taking levels of the firm, the 
measurement is often operationalized through responses by an individual. This could lead to an error, based on the assumption that "an individual aversion to a specific newventure opportunity may be overcome by either careful study and investigation or confidence in a good idea. The result may be that, at the level of the firm, risks are taken that would not be taken by a firm member" (p. 145). This again lends credence to a study that generates the data from individual entrepreneurs in micro organizations, as their responses are more likely to match the levels of the entire firm.

Although risk-taking is assumed to be linked to entrepreneurship, the relationship it shares with performance is less categorical. In a review of past empirical research that has isolated the effects to risk-taking as part of the EO construct, Rauch, Wiklind, Lumpkin and Frese (2009) report that risk-taking has an average correlation of .139 in its relationship with performance (number of studies $=12$ ). Although significant, the level of variance that is explained by risk-taking is the lowest when compared to the innovativeness and proactiveness dimensions of EO. Others have also reported inconsistencies in the relationship between risk-taking and persons who engage in new business entry (Brockhaus, 1982), while equivocal relationships between risk-taking and performance have also been suggested (Begley and Boyd, 1987). As summarized by Low and MacMillian (p. 147, 1988), "the overall evidence is that entrepreneurs are moderate risk takers and do not significantly differ from managers or even the general population."

One possible explanation for the inconsistent results in linking risk-taking and performance, is that entrepreneurs may possess a different level of risk tolerance than non-entrepreneurs. Palich and Bagby note that, "entrepreneurs may not think of 
themselves as being any more likely to take risks than non-entrepreneurs, but they are nonetheless predisposed to cognitively categorize business situations more positively" (1995, p. 426). Similarly, Busenitz (1999) reported “entrepreneurs do indeed use representativeness more in their decision making and are more overconfident than managers in large organizations" (p. 325). This overconfidence can lead to entrepreneurs viewing situations more favourably than non-entrepreneurs thereby possibly inducing error into the comparison of risk-taking of entrepreneurs and nonentrepreneurs on a single scale.

In the analysis of the relationship between risk-taking and performance, evidence of the curvilinear nature of the relationship is also notable. Unlike innovation and proactiveness whose relationship is thought to be positive and linear, risk-taking seems to be only beneficial to a point. For instance, Baron (2007) suggests that too high a propensity for risk-taking can lead to overly risky decisions and eventually unsuccessful ventures. Begley and Boyd (1987) confirm the curvilinear relationship, demonstrating that firm founders are more likely than non-founders to have a higher risk-taking propensity and demonstrate higher performance at moderate levels of risk-taking rather than low or high levels. These findings are supportive of the notion that the EO scale is a formative, multidimensional construct formed by the algebraic combination of the dimensions, as opposed to a reflective unidimensional construct formed by simple summation of the dimensions.

\section{Proactiveness}

The Collins English Dictionary (2003) defines proactive as "tending to initiate 
change rather than reacting to events", or "a mental process that affects subsequent processes." Lumpkin and Dess (2001) define proactiveness as "an opportunity-seeking, forward-looking perspective involving introducing new products or services ahead of the competition and acting in anticipation of future demand to create change and shape the environment" (p. 431). Proactiveness then entails a forward-looking process, whereby a firm's approach may involve active market research and the development of new products and services before its competitors (Lumpkin and Dess, 1996). Christensen (1997) suggests that proactive entrepreneurs can discover and exploit first mover advantages through the establishment of new market segments or the capturing of an existing market from established firms. This view is also shared by Venkatraman who outlines proactiveness as "seeking new opportunities which may or may not be related to the present line of operations, introduction of new products and brands ahead of competition, strategically eliminating operations which are in the mature or declining stages of life cycle" (1989, p. 949).

Crant (2000) suggests that proactive behaviour is driven from individual differences whereby individuals may not be "passive recipients of environmental constraints on their behaviour, rather, they can intentionally and directly change their current circumstances" (p. 439). The resulting behaviour can be then broken down into general action and context-specific behaviours. In terms of general actions, examples include the identification of opportunities, challenging the status quo and creating favourable conditions. With regards to the context specific proactive behaviours they include feedback seeking, stress coping and socialization. Both general and context 
specific behaviour can affect outcomes including job performance, feelings of control and job attitudes.

Proactiveness has been shown to have a positive correlation with the likelihood of entrepreneurial activity. In a study of undergraduates and MBA students, Crant (1996) demonstrated that there was a significant positive relationship between a proactive personality and the intention to start a new business $(\mathrm{r}=.48)$. Becherer and Maurer's (1999) study of 215 presidents of small companies showed that a proactive personality was positively associated with a growth in sales. Proactiveness has been also shown to have a positive linear relationship with performance (Miller, 1983). Rauch, Wiklund, Lumpkin and Frese (2009) reveal a corrected correlation of .178 in the relationship between performance and proactiveness, of the EO studies that tested the relationship (number of studies $=13$ ). Proactiveness however, does not suggest that a firm must be the first to market in all instances in order to increase the probability of success. Miller and Camp (1985) show that the second firm to enter new markets was also a pioneer and was just a likely to be successful due to proactiveness. Lumpkin and Dess (1996) draw attention to the tendency within the Entrepreneurship literature not to distinguish between proactiveness and competitive aggressiveness in the EO construct. They propose that ( $\mathrm{p}$. 147):

"Proactiveness refers to how a firm relates to market opportunities in the process of new entry. It does so by seizing initiative and acting opportunistically in order to "shape the environment," that is, to influence trends and, perhaps, even create demand. Competitive aggressiveness, in contrast, refers to how firms relate to competitors, that is, how firms respond to trends and demand that already exist in the marketplace."

Proactiveness, relates more to the creation and meeting of demand, whereas 
competitive aggressiveness is tied to responsiveness and competing for demand. Lumpkin and Dess (2001) cite the example of Intel, which proactively seeks new markets through the development of new chips, and once it has penetrated an established market, it will move to aggressively protect its market share. However, while researchers should be cautious about a measurement label of proactiveness being operationalized as a combination of proactiveness and competitive aggressiveness, the act of market defense, or competitive aggressiveness as defined by the authors lacks an identifiable link to entrepreneurially minded individuals and thus, the EO construct. That is, the defense of established market share is a business process that is practiced by the majority of businesses and does not lend to the idea of it being specifically entrepreneurial. In fact, one possible reason for a firm not acting to defend its market share could be the proactive desire to enter new markets based on a belief that the existing market is entering a stage of decline.

Crant (2000) discusses the findings based on the existence of proactive behaviour in the literature, noting that it is exhibited by individuals, occurs in many domains, is linked to many personal and organizational processes and outcomes and that it may be constrained or promoted through managing context. Given these consistencies Crant (2000) proposes that future research of proactive behaviour be conducted in new, previously underexplored contexts. While much research has been centered on the identification of situation antecedents that lead to proactive behaviour, less attention has been paid to the contextual circumstances that may exist, although it is reasonable to suggest that it is the combination of the two that gives rise to proactive behaviour. Given 
the relatively unexplored context of the study, an opportunity to analyze both the dispositional and situational effects of proactive behaviour can be evaluated and compared to results that exist in different contexts.

\section{Current Debates in the EO Literature}

Not all EO scholars agree that the dimensions of EO should be limited to three aspects. As two of the foremost proponents of a modified scale, Lumpkin and Dess (1996) suggest that competitive aggressiveness and autonomy be added to the construct. They define competitive aggressiveness as the intensity of a firm's effort to outperform competitors by maintaining a strong offensive posture and aggressive responses to competitor's actions, citing Miller's idea of 'beating competitors to the punch' as their inspiration. In one instance, a firm can be aggressive through head-to-head competition, for example, entering an established competitive market. In another instance, it may be reactive, for instance, lowering prices in response to a competitive threat.

Autonomy, Lumpkin and Dess (1996) argue, refers to the tendency of independent action by entrepreneurial leaders that is directed at bringing a new venture to life, noting that autonomy, "means the ability and will to be self-directed in the pursuit of opportunities. In an organizational context, it refers to action taken free of stifling

organizational constraints" (p. 140). Again, the authors look to Miller (1983), who reports that the most entrepreneurial firms tended to be the ones with the most autonomous leaders; also suggesting that entrepreneurial behaviour at the firm level is accompanied by a centralized vision and strong leadership.

Other scholars, such as Merz and Sauber (1995) propose that the EO construct 
should be limited in its inclusiveness, defining EO as, 'the firm's degree of proactiveness (aggressiveness) in its chosen product-market unit and its willingness to innovate and create new offerings" (p. 554). Notably absent from their definition is the risk-taking dimension of the original scale. Also, a limitation of the scope of EO from the overall posture of the firm to one that is determined by isolated actions seems to be suggested. Further, as pointed out by George and Marino (2011), the innovativeness dimension is limited to innovation that leads to new product development, excluding innovations that may lead to a competitive advantage but not necessarily a new product.

Zahra and Neubaum (1998) defined EO as, “the sum total of a firm's radical innovations, proactive strategic action, and risk-taking activities that are manifested in its support of projects with uncertain outcomes" (p. 125). Here, although the core EO components of innovation, proactiveness and risk-taking carry over from Miller (1983), there is an additional restriction placed on the type of innovation. Specifically, Zahra and Neubaum suggest that only radical innovation be considered for the innovation dimension. Also, the definition limits the scope of EO to individual projects, a move away from the more encompassing earlier definitions.

Despite the calls for scale modifications to include additional dimensions, or to make changes to the current measures, (an argument most convincingly made by Lumpkin and Dess, 1996), the academic community at large has persisted in its use of the original dimensions suggested by Miller (1983), and the further developed a nine item scale by Covin and Slevin (1989). In their review of work conducted in the EO field, Rauch, Wiklund, Lumpkin and Frese (2009) reveal that over half of the studies analyzed 
in their review utilized the original dimensions and 9 items scale put forward by Miller and Covin and Slevin. The most frequent modifications are reported as the number of items in the scale varying from 6 to 11 items, the inclusion of additional dimensions such as competitive aggressiveness and the stance on the EO scale as being operationalized as a singular, composite and one dimensional scale versus a multi-dimensional scale, formed by an algebraic combination of the sub-dimensions. George and Marino (2011) discuss the consequences and challenges of multiple definitions and conceptualizations of EO:

"First, if the domain is not clearly defined, we are unable to judge the validity of our measures of the construct. Second, if researchers define EO in different ways, then we cannot build our knowledge around the relationships between the construct and other constructs in the nomological network of concepts in the field of entrepreneurship. Thus, rather than creating a body of knowledge around the concept and improving our understanding of its position and relationships in the nomological net, we end up with a number of unique studies that cannot be compared and whose results do not reinforce or refute common theoretical linkages."

The authors therefore seem to suggest that researchers should be careful to be true to the original conceptualization of EO as put forward by Miller (1983) and Covin and Slevin (1989). This is not meant to be taken as limitation to the study of the antecedents, relationships and consequences of EO, but rather that in the course of the study that EO is operationalized in similar fashion to previous studies. This consistency should then aid in the development of our understanding of EO as we can effectively compare the relationships found between $\mathrm{EO}$ and other variables used in many studies due to the common definitions of the dimensions that make up the construct used to measure EO.

Beyond the debate as to the inclusion or exclusion of dimensions in the measurement of EO, there has been increasing debate in the literature concerning the unidimensionality (composite summation of dimensions) versus multi-dimensionality of 
the scale (algebraic combinations of the individual impact of each dimension). In reference to the dimensions of EO, Covin, Green and Slevin (2006, p. 80) suggest "intellectual advancement pertaining to EO will likely occur as a function of how clearly and completely scholars can delineate the pros and cons of alternative conceptualizations of the EO construct and the conditions under which the alternative conceptualizations may be appropriate," although some might suggest that the literature has been slow to embrace the advancement suggested by the authors. In their assessment of past research, Rauch, Wiklund, Lumpkin and Frese (2009) report that only about a quarter of the studies of EO that they reviewed argued for the multidimensionality of the EO scale and measured the effects of the individual dimensions on performance. However, despite a unidimensional construct being used almost three times as much as the multi-dimensional construct in the literature, several authors have begun to caution against this approach. In their 2001 study, Lumpkin and Dess focused on only two dimensions of the construct, finding that the two "dimensions of EO tend to vary independently of each other, and that their effect on performance is contingent on moderating variables" (p. 447). Future research may benefit, therefore, from "considering the independence of other dimensions of $\mathrm{EO}$ and from viewing $\mathrm{EO}$ as a multidimensional construct in order to explore these complex issues" (p. 447). Of importance to the current discussion, is their study's confirmation of independence of variance between the dimensions and their call for more research into the individual dimensions of the EO construct. They suggest that based on their finding of independence between two dimensions, a similar argument could be made for the relationship between all dimensions of EO. 
As an example of the logic of the independence of the dimensions of EO and suggested treatment as a multidimensional, rather than unidimensional construct, Lumpkin and Dess (2001) discuss a manufacturing firm that based on excess capacity, innovates and develops new products to utilize the unused capacity. They argue that despite the innovation and entrepreneurial behaviour demonstrated, the risk incurred by the firm is minimal, demonstrating the independence of variance between the dimensions. This supports an earlier claim by Lumpkin and Dess (1996, p. 50) who suggest that any “attempt to limit entrepreneurial behaviour to only those cases in which high levels of all EO dimensions are evident falls short of explaining many types of entrepreneurship."

Stetz, Howell, Stewart, Blair and Fottler (2000) also provide empirical evidence that points towards the independence of the dimensions, by establishing the discriminant validity of all the latent constructs of proactiveness, risk-taking and futurity, though admittedly the dimensions differ slightly from the conventional conceptualization (futurity instead of innovation). Despite the independence reported for the dimensions, the authors also find that the dimensions are highly correlated. They suggest these correlations need not mean that a causal mechanism is driving all the dimensions, proposing a true halo effect, whereby high levels in one dimension influences reporting of high levels in the others (Nisbett and Wilson, 1977) or an inclusion of systematic error in the score (Pedhazur and Schmelkin, 1991). On the other hand, the correlation of the dimensions opens the possibility of a causal mechanism that drives a higher order concept, and the authors do admit that making a definitive and accurate assessment as to the absolute source of variance is unlikely. 
George (2006) indirectly asks the question, what are the consequences of EO model misspecification? Based on the assumption that a unidimensional scale represents a reflective second order construct, while the multi-dimensional scale represents a formative second order construct, George uses a random data set $(n=500)$ to be analyzed using both reflective and formative models. The analysis showed that the unstandardized structural relationships between EO and other constructs can be inflated by more than $100 \%$ if EO is modeled as a second-order reflective construct, as is common in empirical studies, when a formative model is theoretically correct. Further, George reports that the standard error of parameter estimates are inflated under a reflective model, increasing the likelihood of Type I errors, that is, assuming a relationship exists, when in fact it does not. It is also worth noting that despite the potential inaccuracies with a reflective model, both models demonstrated an acceptable fit when judged by conventionally accepted statistical standards leading one to question if both methods are productive research techniques.

Stetz et al. (2000) found similar results to George (2006), though they used the futurity dimension rather than innovation. Again, both models (reflective and formative) fit the data relatively well, but the reflective model was only able to explain an additional .031 in $^{2}$ while the formative model was able to explain an additional .381 in variance of performance. Thus, they conclude that although both conceptualizations were supported by model fit, the formative construct seems to have more explanatory power, relative to that of the reflective construct.

Not all statistical evidence however points to a multidimensional formative EO 
scale. In their assessment of past research Rauch, Wiklund, Lumpkin and Frese (2009) utilized available information from existing studies to test the correlations between the dimensions of EO. They report that the innovativeness dimension $(n=10)$ had the highest corrected correlation with performance in previous studies of .195, while risk-taking $(n=12)$ was the lowest at .139. The authors tested the magnitude of the differences with the z-statistic indicating that the differences were too small to be statistically significant. If then, the differences between the individual dimensions of EO are minimal, and thus of similar magnitude, the author's suggestion that concluding a multidimensional rather than a unidimensional scale is more appropriate for the study of EO is premature.

\section{EO and Performance}

EO researchers have proposed that firms can gain an advantage from highlighting newness, responsiveness and a degree of boldness (Rauch, Wiklund, Lumpkin and Frese, 2009) and these then form the fundamental theoretical relationship between EO and performance (Miller, 1983). For instance, Miller and Friesen (1986) suggest that in an environment of quick paced change and short product life cycles, firms which adopt a strong EO may be more likely to innovate frequently and take risks in the formation and execution of their product market strategies. In another example, Ireland, Hitt and Sirmon (2003) note that concerted efforts to forecast demand and aggressively position new product offerings lead to stronger performance.

In fact, the relationship between EO and performance is one of the most frequently studied relationships in the EO literature. In their meta analysis of the literature, Rauch, Wiklund, Lumpkin and Frese (2009) identified 53 articles that test 
empirical relationships between EO as an independent variable, and a measure or measures of performance as the dependent variable(s). In the 53 studies, the relationship between EO and perceived financial performance was considered in $26(49 \%)$ of the studies, between EO and profitability in 26 (49\%), between EO and perceived nonfinancial performance in 17 (32\%), between EO and archival financial performance in 11(19\%) and between EO and growth in $7(13 \%)$.

Rauch, Wiklund, Lumpkin and Frese (2009) also report on the magnitude of the relationship between EO and performance. They reveal that the global (entire sample) correlation between EO and performance was .242, and offer Cohen's (1977) assessment of this correlation level as moderately large. The authors also report the percentage of variance that is attributed to sampling variance as 22.38 , falling below the $75 \%$ threshold in order to assume heterogeneity (Hunter and Schmidt, 1990). Thus, there are likely moderators influencing the size of the EO-performance relationship.

This suggestion is in line with that of the conceptual framework of EO and performance as suggested by Lumpkin and Dess (1996). While there is an assumed relationship between EO and performance, contingency theory suggests that the congruence of key variables is essential in attempting to achieve optimal performance (Miller, 1988). The dimensions of EO can be affected by both environmental factors such as: dynamism, munificence, complexity and industry characteristics and organizational factors such as: size, structure, strategy, strategy making process, firm resources, culture, and top management team characteristics (Lumpkin and Dess, 1996). This is shown diagrammatically in Figure 2.1. 
Figure 2.1: Conceptual Framework of Entrepreneurial Orientation Source: Lumpkin and Dess (1996, p. 152)

\section{Conceptual Framework of Entrepreneurial Orientation}

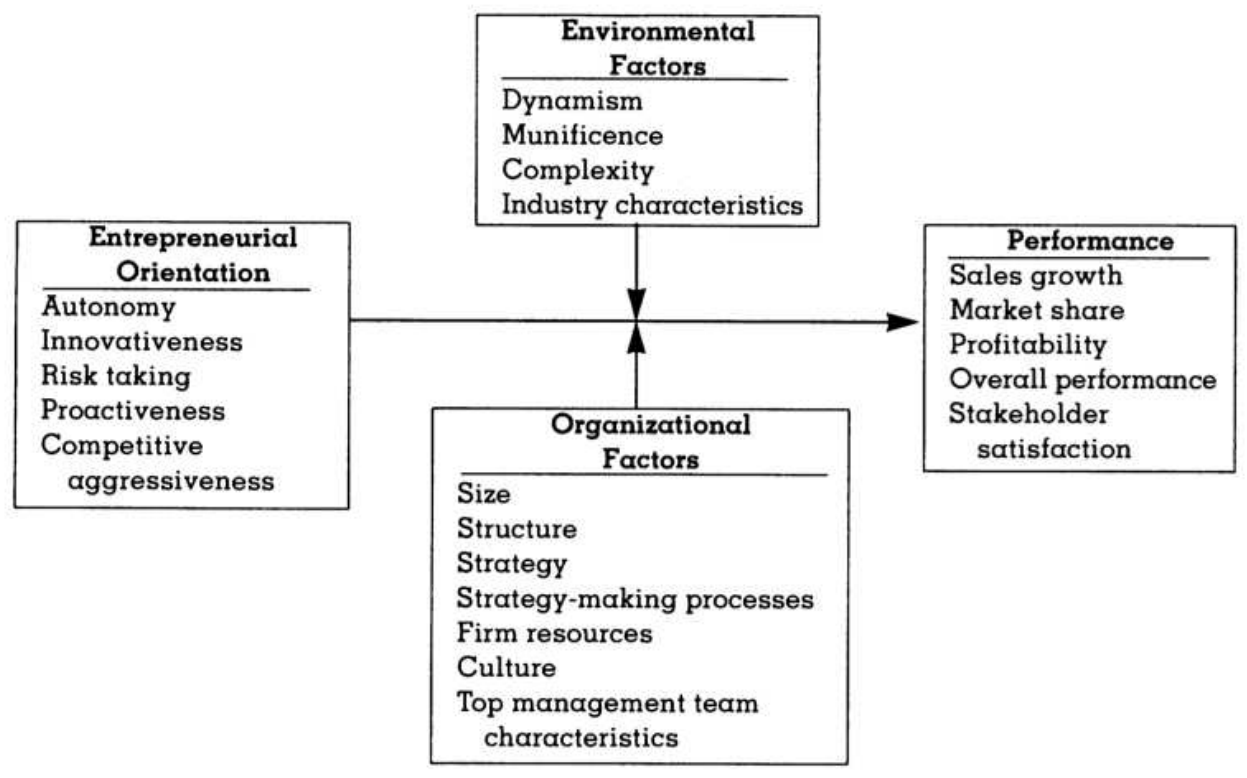

Also of note are the dimensions of performance that exist including: growth in

sales, market share, profitability, overall performance and the satisfaction of stakeholders, suggesting that performance is a multidimensional construct. As put forward by Lumpkin and Dess (p. 153, 1996):

"entrepreneurial activity or processes may, at times, lead to favourable outcomes on one performance dimension and unfavourable outcomes on a different performance dimension. For example, heavy investment in R\&D and product innovation may enable a firm to successfully enter new product-market domains and consequently enhance sales growth in the long run. However, the requisite resource commitment may detract from short-run profitability. Thus, research that only considers a single dimension or a narrow range of the performance construct (e.g., multiple indicators of profitability) may result in misleading descriptive and normative theory building."

It is therefore imperative in the investigation of the relationship between EO and performance to consider multiple measures of performance. Further, and of particular 
importance to our study, is that one should be mindful of the size and type of firm and its ownership (Lumpkin and Dess, 1996). In one instance, a micro firm may have its roots based on the desire of its key personnel to be self-employed, meaning that effective performance may be judged based on the simple existence of the firm, rather than growth or profitability. In another, the micro firm may have been brought into existence by its key personnel with the hope of steady and sustained long term growth, or in a third instance, in order to capitalize on profit opportunities that may exist within the industry, meaning that multiple measures of performance may be necessary.

\section{Resource Based View - Introduction}

Prior to the adoption of the Resource Based View (RBV) by the mainstream strategic literature, management scholars spent a great deal of time examining a firm in relation to its outputs and relative competitive position (Porter, 1980). The RBV however, promotes the examination of a firm from the resource or input side (Wernerfelt, 1984). That is, rather than trying to understand a firm's success by understanding the output of production of the firm, the resource based view tries to understand firm performance by analyzing the resources that allow for the production of those outputs. By attempting to understand the RBV, a firm may discover new strategic options, that otherwise may not be identified if the firm only considers the output of these resources. The strategic importance of a resource or bundle of resources is tied to the ability of that resource to be the driver of a competitive advantage.

Before work by Wernerfelt (1984), the RBV had yet to take on a cohesive or welldefined perspective. While management theorists to this point had made reference to 
resources of a firm as instrumental in its strategic direction, there was no clear framing of the discussion in its entirety. For example, as early as 1959, the work of Edith Penrose included the following statement in its introduction:

"There are important administrative restraints on the speed of the firm's growth. Human resources required for the management of change are tied to the individual firm and so are internally scarce. Expansion requires the recruitment of more such resources. New recruits cannot become fully effective overnight. The growth process is, therefore, dynamically constrained"

The above citation demonstrates many of the concepts that would later form the basis for the development of the RBV. Penrose (1959) identified the human capital of a firm as a resource with the potential to positively affect the performance of the firm while also holding the ability to act as a constraint. Also identified, is that the resource can be scarce and it is implied that a resource holds both value and lacks perfect mobility. These concepts were later examined in more detail by author Jay Barney.

Barney (1986) questioned if organizational culture, for example, could be a source of sustainable competitive advantage. A firm's ideology, including culture acting as a resource, introduced the field to concepts such as the value of a resource, its scarcity and the inability of competitors to perfectly imitate the resource. The article serves to qualify a framework for the RBV whereby firms which have resources that are valuable, rare and imperfectly imitable will have an advantage over rival firms who do not have such resources. The implication is not only that those who have certain resources will perform better than their rivals, but it is also implies that the creation of resources is not formulaic such that one cannot simply purchase resources and acquire the advantages of these resources. 
Later, the requirement that rivals are unable to employ strategically equivalent substitutes was included as an element of sustainable competitive advantage (Dierickx and Cool, 1989). This means that, while a resource may be rare, valuable and imperfectly imitable, it must also be free of alternate resources that can provide the same benefits, or eradicate the need for the benefits themselves. Consider the example firms Xerox and Canon. Although Xerox had an extensive service network, which for a time acted as a source of advantage, this advantage was substitutable by simply designing products that were less prone to breakdown and thus, requiring less service. By designing products that did not require as much service as Xerox, Canon was able to substitute for the resource, and the advantages of providing an extensive service network were made relatively obsolete.

If an asset holds certain characteristics, we can further think of them as resources to the firm, in the generation of a sustainable competitive advantage. The characteristics include the rarity of an asset in the marketplace, its value defined as the potential contribution to a strategic objective and heterogeneity amongst assets. Further, it includes immobility such that the asset cannot be easily transferred between firms, creating only the ability for firms to imperfectly imitate the asset and finally, non-substitutability in terms of others' assets diminishing its advantages (Barney, 1991). The assets that have been identified as resources then interact with the firm's capability, given that a firm can use these resources to exploit new opportunities for improved performance, or can serve to neutralize threats that resources of other firms may impose. As such, capabilities are a 
firm's ability to deploy its resources (Amit and Schoemaker, 1993), usually in combination and making use of organization processes to effect a desired end.

\section{Competitive Advantage}

One of the central aims of the literature in the strategic management field has been to develop an understanding of competitive advantage and to ascertain how it can be systematically created (Rumelt, 1984). Barney (1991, p. 102) proposed that a firm has a competitive advantage "when it is implementing a value creating strategy not simultaneously being implemented by any current or potential competitors," and suggested that through unique conditions created through a firm's resources, a competitive advantage becomes possible. Barney continues, "a firm is said to have a sustained competitive advantage when it is implementing a value creating strategy not simultaneously being implemented by any current or potential customers and when these other firms are unable to duplicate the benefits of the strategy" (p. 102).

Rather than being tied to a calendar time frame, sustained competitive advantage depends on the likelihood of competitive duplication, with the implication that a competitive advantage only becomes sustained once competitor efforts to unseat the advantage have failed and ceased. The suggestion that sustained competitive advantage only exists once efforts to negate its impact have ceased should not be taken to imply that a sustained competitive advantage will continue to last forever. Barney (1991) for example, proposes that changes in the economic structure of an industry may alter the value proposition within the industry, possibly eroding what may at one point in time have been a sustained competitive advantage. These 'Schumpeterian Shocks' 
(Schumpeter, 1934, 1950) redefine the importance and value of resources to the industry and firm. Wiggins and Ruefli, (2005) argue that the high degree of difficulty in achieving a sustained competitive advantage in the form it was originally defined means that in reality, sustained competitive advantage is more akin to creating a succession of competitive advantages over time. Armstrong and Shimizu (2007) caution that special attention needs to be paid to the measurement of competitive advantage so that it is actually tied to advantages over the firm's competitors. They suggest that researchers use care with regards to the confidence managers place in the ability of their own resources to impact a competitive advantage and look toward industry experts for a more accurate analysis.

Accurate measurement of sustained competitive advantage is also problematic when one conducts cross sectional research, which represents the majority of work conducted in the field (Armstrong and Shimizu 2007, Newbert, 2007). The problem encountered with cross sectional research is that a firm's performance and the resources and capabilities that generate this performance are only measured at one time, upon which assessments are made. In the first instance, sustainability is a concept that implies over a period of time, which cross-sectional research incurs difficulty trying to measure. Another issue may be the infrequency of firms who have enjoyed a sustained competitive advantage. In their 2002 study, Wiggins and Ruefi looked at 6,772 firms in 40 industries over a 25 year time frame, finding that only $4(0.0006 \%)$ firms actually enjoyed sustained superior financial performance when compared to their peers. 
Short of investing the considerable time and resources that longitudinal research requires, to counteract the difficulties with measurement of sustained competitive advantage, Armstrong and Shimizu (2007) suggest two possible alternatives. The first is that researchers look to metrics of performance that measure returns over a period of a few years, for instance, examining return on assets over the preceeding 3 years of operation. This method offers the advantage of more consideration of sustainability, but can still present problems such as exceptional performance in one year resulting in superior performance classification over the entire period. The authors also suggest that "effects of a resource in a baseline year $\mathrm{t}$ may be examined by comparing performance in year $t$ to years $t+1, t+2$, etc." (p. 969), so that the sustainability of an advantage, that may be generated from resources, can be better assessed.

Newbert (2007), considers actual studies that have utilized competitive advantage as the dependent variable and demonstrates in his review of the empirical RBV literature that 51 articles used performance as the dependent variable, 9 used competitive advantage and only 1 each used sustained performance and sustained competitive advantage. This is not surprising when one considers that in addition to the difficulty in developing suitable measures for sustained competitive advantage, there have been calls from the field to move beyond the 1990s incarnation of the RBV to more relevant recent theoretical models that recognize the importance of survival of some firms that is beyond that of a conventional competitive advantage (Ludwig and Pemberton, 2011). 


\section{VRIN Framework}

Before discussing the types of potential resources and capabilities that have been identified in the literature, an important consideration of the RBV is an understanding of the likelihood that resources and capabilities are able to contribute toward an advantageous competitive position for the firm. As such Barney (1991) introduced the valuable, rare, in-imitable and non-substitutable (VRIN) framework, which proposed the importance of value, rarity, imperfect imitability and non-substitutability. Barney suggested that the potential for a resource to develop a competitive advantage lay with the measure of each indicator. The first indicator, value, refers to the ability of a resource to exploit opportunities or neutralize threats, with the logic being that a more valuable resource will be able to exploit or neutralize more/greater opportunities or threats than a less valuable resource. An important consideration of value is tied to the transaction cost consideration (Williamson, 1979). That is, the cost of the resource should in theory be less than return from the discounted future rents that the resource generates (Conner and Prahalad, 1996).

Secondly, rarity is considered important for a resource, when compared with the firm's current and potential competitors. The rarity of a resource refers to the unique ability of a firm to own or control a resource(s) that can be used in the creation of an advantageous strategy. Barney (1986) discussed the rarity of a firm's culture, suggesting that culture could have attributes and characteristics that are not common to those of other firms. That is, a resource or capability is considered rare if competing firms do not have control over identical resources and capabilities. In order to generate a sustained 
competitive advantage a firm must have the ability to offer goods and services in a manner that other firms are incapable of offering. By possessing resources and capabilities that are unique to the firm, they can be leveraged to create a unique offering beneficial to the firm.

Thirdly, beyond rarity, resources and capabilities must be in-imitable, meaning that they should be impossible to duplicate. That is, some resources and capabilities present conditions that make it impossible for another firm to derive the ability to exploit them in the manner of another, successful firm. Lippman and Rumelt (1982) introduce what they call uncertain imitability as an explanation of why it would be impossible at times to acquire the resources that lend to the advantage of another firm. The element of ambiguity lies in the inability of competitors to imitate the resources of a rival firm. The authors describe causal ambiguity as the inability to identify exactly what resources lead to the ability to sustain favourable performance, suggesting that the inability is both a short and long term problem due to the lack of perfect information. Another consideration that may result in a firm's resources and capabilities being imperfectly imitable is the unique historical conditions of the firm (Barney 1991). Here it is believed that past conditions or events can create a unique position for the firm, which can, of course, be exploited to maintain a competitive advantage.

Finally, non-substitutability suggests that even if a resource or capability is valuable, rare and in-imitable it may fail to deliver a competitive advantage if the firm's competitors are able to counteract the resource or capabilities with a substitute. Dierickx and Cool (1989) suggest that the primary danger is substitution by different asset stocks 
that are used to render the value created by the original asset stocks obsolete. As noted earlier with the example of Xerox and Canon, the service resources and capabilities that Xerox possessed was blocked as a source of competitive advantage by Canon who introduced machines that needed far less maintenance than the machines of Xerox. While the service resource possessed by Xerox was not obtained or imitated, the effect of the new Canon machines was to serve as a substitute of Xerox's resource.

The VRIN framework is not however without its critics. Barney (1991, p. 101) suggests:

"Resources include all assets, capabilities, organizational processes, firm attributes, information, knowledge, etc. controlled by a firm that enable the firm to conceive of and implement strategies that improve its efficiency and effectiveness"

while also adding (p. 105) :

"Resources are valuable when they enable a firm to conceive of or implement strategies that improve its efficiency or effectiveness"

In the first example, the alignment of resources to effectiveness seems to overreach its scope, while failing to address the distinction between discrete resources and second level capabilities that allow for the manipulation of the resources to the firm's advantage. Kraaijenbrink, Spender and Groen (2010) point towards the tautological nature of the second definition of value as put forward by Barney. They suggest that because competitive advantage is thought of as improving efficiency (reducing cost) and effectiveness (increasing value), the value of a resource and the competitive advantage it may generate are defined identically and as such, "the explanans and the explanandum of the RBV remain the same" (p. 357). This adds to difficulty in the interpretation of value 
as well as an inability to test the relationship. Further, Hoopes, Madsen and Walker (2003) suggest that the concept of rarity may be obsolete, due to the fact that the prevalence of the other components of the framework (valuable, in-imitable and nonsubstitutability) with regards to a resource will by default render it rare.

Empirically, the VRIN framework is difficult to operationalize. Newbert's (2007) review of empirical findings in the RBV literature indicated that despite some empirical support, less than $10 \%$ of the sample employed the VRIN conceptual-level approach and not one attempted to measure non-substitutability of the components in conjunction. In fact, in-imitability was the only component of the framework studied in more than one article and took vastly different forms in each. As such, the usefulness of VRIN framework seems to me more applicable at the abstract level than as a specific tool in the operationalization of empirical study. That is, while isolation and measurement of the components as it relates to competitive advantage may be difficult, application of the theoretical underpinnings of the VRIN framework should serve to help identify the specific resources and capabilities that are most important in generating superior performance.

\section{Resources}

Resources are those available factors that are owned or controlled by the firm, from which some benefit to the firm can be gained (Amit and Schoemaker, 1993). Grant (1991) explains that while traditional firms could make strategic decisions based on who their customers were and what needs they were trying to satisfy, in the far more dynamic and volatile current environment, this process has become more complex, causing an 
externally focused firm to encounter difficulties in the development of long term strategy. Rather than the external focus, firms that look to their internal strengths may be better able to develop sustainable strategies that foster the benefits of resources that may be available for utilization.

Resources are considered to be the inputs into the productive process and as such, form a basic unit of analysis (Grant, 1991). On their own, resources generally lack the productive capacity that is feasible through the combination of resources. Consider the basic example of a farmer who also has some crop seeds. By himself the farmer is unable to grow any crops. Similarly, the seeds without the farmer are unlikely to be sowed, watered, fertilized or harvested. Together however, the individual resources become more likely to generate a beneficial position. In Figure 2.2, we can see an example of how various resources can be combined to form a basis for firm profitability.

\section{Figure 2.2 - Resources as the Basis for Profitability} Source: Grant (1991, p. 118)

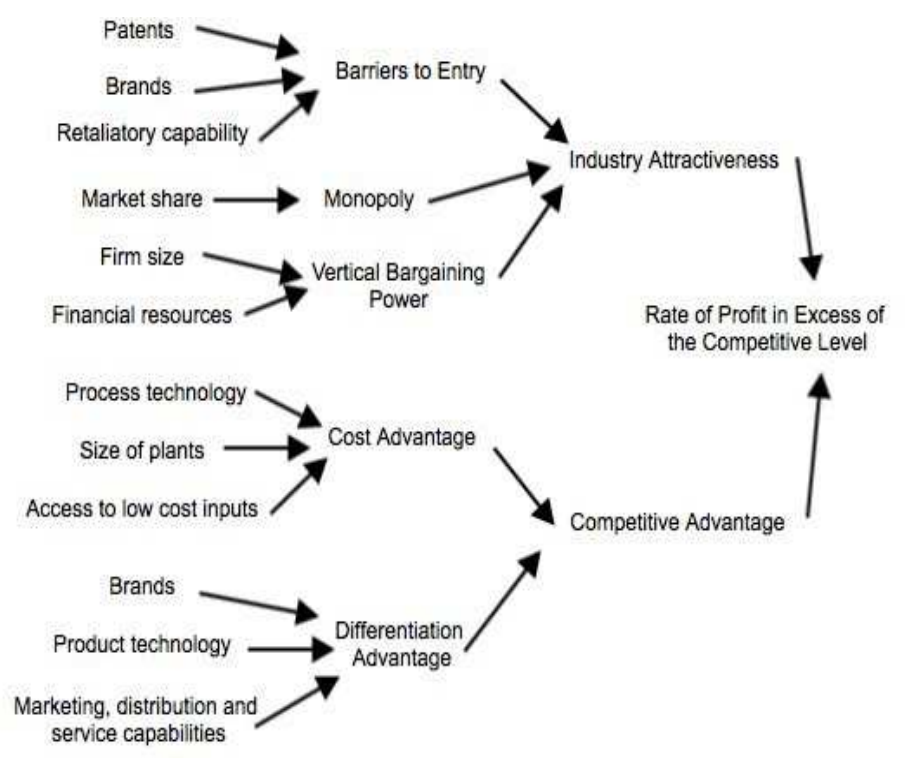


Figure 2.2 provides possible scenarios through which the combination of resources can potentially result in a beneficial position for the firm. For instance, in order to achieve a cost advantage over its competitors, a firm may control a large manufacturing plant that allows for the purchase of raw materials in bulk, resulting in lower unit costs. New technology or technology that allows for more efficient production processes can also lend to the cost advantage, as can resources, such as productive employees or cheaper access to finance.

Resources can be broadly categorized as being tangible or intangible. Amit and Schoemaker (1993) suggest that tangible resources are those that consist of know how that can be traded, for instance, licenses and patents. Intangible resources on the other hand, are termed capabilities and refer to the firm's ability to deploy the resources at their disposal and rather than being tradable, are firm specific. Based on an analysis of the literature, six different categories of resources have been identified as being the most important in the development and sustainment of a firm's competitive advantage (Barney, 1991; Grant, 1991; Amit and Schoemaker, 1993).

The first is the physical resources that are owned and controlled by a firm and can include assets such as plant and machinery. As an example, though only present online, Amazon has developed a physical resource through their warehousing capacity. By having many and large warehouses, Amazon has been able to develop an advantage in terms of the variety and speed of service it offers to its customers. Physical resources then, are tangible, and generally measurable. This implies that the key physical resources especially in smaller organizations, can be accounted for and compared relative to each 
other. Ioana (2007), considers some of the physical resources needed to start a small business which includes: transport, fixtures and fittings, plant and machinery, furniture and office equipment, raw materials, components, stock, consumables and public utilities. While not fully exhaustive or applicable to all business types, the list provides an appropriate foundation for the identification, the types and the amounts of physical resources a firm controls.

Reputational resources refer to the benefits that can be accrued as a result of a company's ability to leverage its reputation for products, services and practices. Reputation can then be regarded as an "outcome of a competitive process in which firms signal their attributes to constituents" (Peng, 2014, p. 65). The reputation of a firm often summarizes information about the firm and can shape the responses of customers, suppliers and competitors (Teece, Pisano and Shuen, 1997). For instance, the 2013 launch of the Sony Playstation 4 was met with pre-orders in excess of one million units (Sherr, 2013), a sign that Sony has developed a reputational resource in the video game console market due to their actions with past incarnations of the gaming system.

Based on their validation methodology, Walsh and Beatty (2007) propose that reputation can be most effectively measured through a five dimensional scale including: customer orientation, being a good employer, financially strong, product and service quality and environmental responsibility. With regards to the context of this study, reputational resources are assumed to be of importance to micro business due to the importance of the repurchase intent. Given that micro businesses lack the resources to generate substantial awareness and thus lack the ability to rapidly generate new 
customers, the limited awareness that is created is paramount to the survival of the firm. That is, it is important for the initial base of customers to rapidly develop and sustain a degree of trust and loyalty with the firm as awareness beyond this initial base is slowly built.

Organizational resources have also been identified as a potential resource for a firm. The structure that a firm employs, its planning, command, policies, organizational routines and control systems can be advantageous if it is able to allow for the discovery and exploitation of opportunities or the neutralization of competitive threats (Greene and Brown, 1997). For instance, mature planning systems that allow the firm to adequately forecast demand allows the firm to meet the demand without shortages or the production of excess. In a study of inter-firm variance in profitability, Hansen and Wernerfelt (1989) report that organizational factors (structure, systems, size, history) explain a significant amount of variance in profit between firms, and also they explain, approximately twice as much variance in profit than do economic factors (industry profitability, relative market share and firm size by assets).

Daily and Dalton (1992) report on the governance structure in small firms, noting that the best performing firms had entrepreneurs that were able to sacrifice some level of control, for instance, when the company had a functioning board of directors. In their examination of the influence of organization structure on the relationship between top management's EO and firm performance, Covin and Slevin (1989) report that an entrepreneurial management style (high EO) has a positive effect on performance if the firm is organically structured, whereas it has the opposite effect on mechanistically 
structured firms. However, while research linking organizational resources, entrepreneurship and performance is apparent, the same research with regards to micro firms is not so apparent. It is possible that the small number of employees, often only one individual, leads to a situation where the personal traits of the entrepreneur rather than the organization's structure are studied in relation to performance.

Financial resources have also been linked to superior firm performance. Wiklund and Shepherd (2005) suggest that entrepreneurial strategies require abundant financial resources to be successful. Firms with greater financial resources often have access to cheaper and greater amounts of capital, which can help it grow faster than the competition or allow it to survive an industry downturn. Because of their generic nature, financial resources are thought to be the easiest resource to convert into another type of resource (Dollinger, 1999). Thus, in the event of resource constraints in one area, financial resources can serve to ease the constraint. Small firms however, often face difficulty in seeking and obtaining debt and equity financing, which can limit their ability to develop as a firm (Winborg and Landstrom, 2001).

Wiklund and Shepherd (2005) suggest that financial resources should interact with EO in the explanation of performance. Available financial capital can allow firms to experiment with new strategies or innovative projects. Slack capital can therefore protect against uncertain outcomes, helping to facilitate a culture of experimentation and product innovation (Zahra, 1991). Proactiveness can also benefit from financial resources. Venkatraman (1989), notes that proactiveness involves the search for opportunities and experimentation with resources that is manifested in seeking new opportunities that may 
or may not be related to the firm's present products, the introduction of new products ahead of the competition and the elimination of mature/declining operations, all of which are believed to be positively related to financial resources. Greater financial resources can also offset the devastating negative effects of risk-taking, allowing firms to take more than one risk in search of above average returns. Finally, Stevenson and Jarillo (1990) note that it is less important to consider the ownership of financial resources, as opposed to access to the resources. For instance, a firm with savings of $\$ 100$ but no additional access to finance, should be considered to have less financial resources than a firm with $\$ 50$, but access to an additional $\$ 500$. One must be mindful however, that the measurement of access to finance can be at times less objective than the measure of currently available funds. For example it may be difficult to accurately measure all potential loans that one can theoretically secure.

Technological resources have been suggested as a firm resource that can potentially contribute toward a competitive advantage. Firms with greater technological resources may be in a position to more efficiently serve their customers, keep better track of their physical resources or innovate more effectively than their competitors. The importance of top management buy-in has been related to technological adoption, and should mean that in micro organizations, the entrepreneur is likely to be a significant factor in its implementation. On the other hand, even within small businesses, the size of the organization has been shown to be a significant factor in the explanation of technology adoption, as smaller firms may have greater resource constraints and are thus 
unable to spare resources towards technological progress (Premkumar and Roberts, 1999).

The final resource that is identified in the literature is the human capital resource. Through their relations, knowledge, experience, education and personality, human resources, both formally and informally recognized by the firm, can be a source of competitive advantage. Hills, Lumpkin and Singh (1997) found that well networked entrepreneurs pursued more opportunities and generated more ideas outside of their current industry with more success than less networked entrepreneurs. Within the broader strategic literature, the importance of weak ties has been established (Granovetter, 1973), while in regards to entrepreneurship Singh, Hills, Hybels and Lumpkin (1999) find that a large network of weak ties provided entrepreneurs with positive instances of ideas and recognition of ideas, although it should be considered as noted by Ma, Huang and Shenkar (2011) that cultural or contextual factors may play a role in the salience of strong versus weak ties in the entrepreneurial process.

The knowledge and experience of a firm's human resources have also been established as significant in the relationship between a firm's resources and its performance. Shane (2000) suggests that knowledge, for instance, knowledge of a market, can help shape the types of opportunities that an entrepreneurial firm may discover. Ucbasaran, Westhead, and Wright (2008) find that an entrepreneur with experience can leverage it to engage in the facets of entrepreneurial opportunity identification with a reduced cost of exploration, while Farmer, Yao and Kung-Mcintyre 
(2010) find support for the notion that prior experience positively influences the likelihood of opportunity exploitation.

Education also can be considered part of human capital resources. At a macro level, the higher the average education level in a country, the higher the rate of entrepreneurship (Dickson, Solomon and Weaver, 2008), while others have found that increasing levels of education result in greater entrepreneurial activity until the $\mathrm{PhD}$ level (Wetter and Wennberg, 2007). More specific to individuals, Bates (1995) notes that while higher levels of education tend to increase the likelihood of entrepreneurship, it only does so in specific industries. For instance, while high levels of education in professional occupations such as medicine, law and accounting can provide a launch pad for the establishment of self-employment, in others such as construction; higher levels of education were not found to be a significant predictor of self-employment.

In micro organizations, the personality or psychological traits of the entrepreneur can also weigh on the decisions of the firm. McCelland (1967) suggests that entrepreneurs are motivated by a high need for achievement, with Stewart, Watson, Carland and Carland (1998) finding that entrepreneurs demonstrate a greater need for achievement than managers. Having an internal locus of control has also been found to be a significant factor in entrepreneurial self-efficacy between business founders and nonfounders (Chen, Greene and Crick, 1998), which can result in greater tolerance for uncertain environments (McGrath, MacMillian and Scheinberg, 1992) and thereby increases alertness to opportunities (Harper, 1998). 
The effect of a resource on competitive advantage is context specific, with one implication being, that controls should be put in place for industry type in the study of resources (Armstrong and Shimizu, 2007). Amit and Schoemaker (1993) make the distinction between 'Strategic Industry Factors' and 'Strategic Assets'. The former refers to the resources that have become the foremost determinant of economic rents for the industry's participants, while the later is regarded as a firm level construct that forms the basis of the creation and protection of a firm's competitive advantage. The authors suggest that the unique characteristics of the firm's strategic assets and the degree to which they overlap with the strategic industry factors determine the level of rent creation allowed.

In his review of the empirical research within the RBV literature, Newbert (2007) categorized 27 different resources, used in 232 tests that served as the independent variable in the operationalization of the resource heterogeneity approach. For example, Berman, Down and Hill (2002) highlight the role of tacit knowledge as a generator of competitive advantage in the National Basketball Association. Based on the theory that over time tacit knowledge develops between teammates, the authors used shared team experience as a proxy for the measurement of tacit knowledge (a resource) and regressed the data onto wins (performance) finding support for their hypothesis. Support is also found for diminishing returns from shared experience after an optimum threshold has been reached. In another example, Makadok (1999) studied the inter-firm differences in economies of scale and their subsequent evolution into market share. Here economies of scale such as lower commission fee percentages and larger reserves to devote toward 
market forecasting, are treated as resources and show a statistically significant link towards the market share performance of the firm.

Though strides have been made in the literature with regards to differentiating the types of resources that exist, an attribute that is then paramount in pursuit of a competitive advantage is the heterogeneous nature of these resources. Consider for a moment an industry that is populated with firms who all own and control the same resources. In this situation, RBV theorists suggest that the development of a competitive advantage is not feasible as the implementation of any strategy by one firm can be duplicated and its benefits eroded by another. As a hypothetical situation, this logic may indeed be sound, but when one considers that at a very basic level, different individuals make up the workforce of each firm, the likelihood of completely identical resources amongst firms is quite implausible.

If no two firms can possess identical resources and it is the differences in resources that can lead to a variance in performance, then we should expect that the performance of no two firms are similar. So how is it that some firms can have equitable performance? One possibility is that the effect size of the different resources, though individually different, are in conjunction similar. Consider, for example the individual dimensions of the unidimensional EO scale of two firms. Firm A has low innovativeness, but high proactiveness, while Firm B has relatively high innovativeness, but lower risk taking. Despite the heterogeneity of the individual resources the performance of the two firms may be equitable if the combined effect of each resource is equal. Another explanation is that firms have in place unique mechanisms or capabilities and systems 
that allow for exploration and the exploitation of its resources. As such, scenarios of firms with similar resources but significant variance in performance and firms with significantly different resources, but similar performance can be better explained.

\section{Capabilities}

Despite the initial lumping together of resources and capabilities within the RBV literature, the importance of the distinction was too imposing to allow for the continued grouping (Newbert, 2007). The rediscovered attention to process, led to the emergence of the VRIN/O framework, with the addition of the organization of a firm $(\mathrm{O})$ (Barney, 1997). Barney noted that in addition to being valuable, rare, in-imitable and nonsubstitutable, resources must be organized in such a manner that allowed their effective utilization, citing examples of organizational components such as structure, control systems and compensation policies. The organization of a firm is considered a firm-level orientation, strategy or context that effectively utilizes the resources at its disposal. As will be developed further, we propose that EO is a firm level orientation that, in its interaction with the firm's resources and capabilities, can have an impact on performance, particularly in smaller organizations.

Resources on their own are insufficient to generate a competitive advantage and thus, must work in conjunction with the firm's organizing capabilities in order to direct the resources available to the firm. Amit and Schoemaker (1993, p. 35) suggest that capabilities:

"Refer to a firm's capacity to deploy Resources, usually in combination, using organizational processes, to effect a desired end. They are informationbased, tangible or intangible processes that are firm-specific and are developed 
over time through complex interactions among the firm's Resources. They can abstractly be thought of as 'intermediate goods' generated by the firm to provide enhanced productivity of its Resources, as well as strategic flexibility and protection for its final product or service."

Makadok (2001) notes that the above definition carries with it two important features. The first is the identification of capabilities as "firm specific, which is embedded in the organization and its processes, while an ordinary resource is not" (p. 388). This embeddedness means that ownership and control of the capability cannot be easily transferred such that it "cannot be bought and sold short of buying the firm itself, or one or more of its subunits" (Teece et al., 1997, p. 518). The second is that "the primary purpose of a capability is to enhance the productivity of the other resources that the firm possess" Makadok (2001, p. 389). In this regard, the distinction between resources and capabilities is similar to Miller and Shamsie's (1996) distinction between discrete and systemic resources. While discrete resources are thought to have stand alone value, independent of their organizational context, systemic resources have value because their components are part of a wider system. This system coordinates and allocates the individual resources creating value in the process.

Conner and Prahalad (1996) use the example of a firm who employs two persons, $\mathrm{Y}$ and Z. At its base level, the productivity of the firm would be equal to $\mathrm{Y}+\mathrm{Z}$, or the level of productivity that is to be expected from each $\mathrm{Y}$ and $\mathrm{Z}$ if they were self-directed. However, based on the organizational procedures of the firm there is the possibility of variance in the level of productivity of $\mathrm{Y}$ and $\mathrm{Z}$ as they are managed and have their activities coordinated by the firm. Thus, $\mathrm{Y}$ and $\mathrm{Z}$ can be considered the resources of the firm, while in this instance the organizational procedures used to manage the resources is 
a capability of the firm. We believe that under different organizational procedures, the variance in productivity for the $\mathrm{Y}$ and $\mathrm{Z}$ resources is likely to change.

Similarly if another two employees, A and B, were subjected to identical organizational procedures as $\mathrm{Y}$ and $\mathrm{Z}$ it is still likely that differences in performance would exist due to the uniqueness of $\mathrm{A}, \mathrm{B}, \mathrm{Y}$ and $\mathrm{Z}$. Thus, rather than resources or capabilities having only implications for competitive advantage at the main effect level, we propose that it is the interaction of resources and capabilities that is able to most significantly explain the existence of a competitive advantage. Realizing the potential value of resources is conjoined with the implementation and utilization of these resources (Hitt et al. 2000).

\section{Dynamic Capabilities}

Thus far the existence and suitability of resources have been discussed within a relatively static framework, but under these conditions, emerging organizations would have little chance of penetrating established markets. Dynamic capabilities support the notion that responsiveness and flexibility of a firm are crucial to the development of a sustainable competitive advantage. In short, dynamic capabilities are concerned with the development of new capabilities. According to Teece, Pisano and Shuen (1997, p. 515):

"The term 'dynamic' refers to the capacity to renew competences so as to achieve congruence with the changing business environment; certain innovative responses are required when time-to-market and timing are critical, the rate of technological change is rapid, and the nature of future competition and markets difficult to determine. The term 'capabilities' emphasizes the key role of strategic management in appropriately adapting, integrating, and reconfiguring internal and external organizational skills, resources, and functional competences to match the requirements of a changing environment." 
The importance of a firm's ability to develop new capabilities cannot be overstated, as these capabilities are likely what will enable the firm to enjoy a sustained competitive advantage. Given the rapid rate of technological change, globalization and the intensification of global market rivalry, no firm can hope to sustain an advantage with entirely static resources and capabilities. According to Edwards (2001) dynamic capabilities is a multi-faceted construct in that it emphasizes the firm's ability to sense opportunities and threats, to make timely decisions, to make market oriented decisions, and to change the firm's resource base.

The use of dynamic capability centric research has been gaining popularity over the past decade; there were approximately 32 dynamic capability publications per year between $2000-2005$, that has grown to an average of 201 from $2011-2013$. This growth, much from heterogeneous roots, allows for a broader and deeper understanding of dynamic capabilities, while also injecting new ideas into the field (Stefana, Peteraf and Verona, 2014). Teece (2014, p. 344) suggests, “A full understanding of how organizations and leaders exhibit strong or weak dynamic capabilities requires insight from many disciplines and sub-disciplines in the social sciences." In keeping with the understanding of Teece, we offer that this study brings insight from the entrepreneurship and EO literature in an attempt at a greater understanding of the individual and combined effects of EO and dynamic capabilities in relation to performance.

Recent research by Di Stefana, Peteraf and Verona (2014) suggest that dynamic capability researchers have been "divided over whether the focus of dynamic capabilities is on the role of the manager or on that of the organization" (p. 313), citing that different 
audiences may be interested in one or the other. The authors however suggest that the two can and should be reconciled, suggesting that dynamic capabilities involve both the individual as well as the organizational levels of analysis because "individuals set the context in the form of simple rules, which then enable and constrain a set of complex routines at the organizational level" (p. 320). In one instance, this lends credibility to the consideration of dynamic capabilities at the micro organizational level, while also offering comparative insight into the very basis of this research. That is, we can consider EO as the setting of context through basic rules; these rules can then serve to enable or constrain the firm's dynamic capabilities.

An emergent organization's knowledge that dynamic capabilities exist and are important is not enough to ensure their development and subsequent exploitation. Drawing from the literature, there are some key considerations that a firm can explore to aid in the creation of its dynamic capabilities. In the first instance, path dependency suggests that where a firm can go is a function of its current position and the paths before and ahead. As such, a firm's current position is often shaped by the path it has travelled (Teece, Pisano and Shuen, 1997). With regard to this path, the implication being drawn is that a firm's historical conditions matter to its current state and where it can go from there. While in certain regards this may be a limitation to the overall flexibility of the firm, the path it has chosen can also serve to open new paths ahead. For instance, a manufacturing firm that has invested heavily in capacity may be unable to change its short-term focus to that of a service provider, but may be able to manufacture a different set of goods than those it currently manufactures. Similarly, an organization with low 
levels of innovativeness may be unable to successfully develop and market new products in the short term.

Eisenhardt and Martin (2000) point towards an organization's learning mechanisms as playing a crucial role in the development of dynamic capabilities. The authors discuss the importance of practice in the learning mechanism, suggesting that practice helps people understand process more fully and so develop more effective routines. For instance, allowance of mistakes are said to play a role in the development of dynamic capabilities. As noted by Sitkin (1992), small losses contribute to effective learning more than either success or major failures. Managers should be aware of the importance of facilitating practice, given the fact, that reputation of the firm is not at stake and that it encourages learning. The capacity for organizational learning warrants the consideration of the evolution of dynamic capabilities.

Helfat and Peteraf (2003) suggest that an organization's capabilities change over time and introduce into the discussion the capability life cycle including: Renewal, Redeployment and Recombination. A firm may create opportunities through the renewal of its capabilities. For instance, a restaurant can enter a new geographic market, or redesign its menu, keeping the core components and feel of the menu, but improve the offering. Redeployment involves the sharing of a capability between old and new markets, with the authors suggesting that many forms of related diversification fall into this category.

Firms can also benefit from the recombination of resources and capabilities. Drawing upon work by Kogut and Zander (1992), firms can combine existing capabilities 
in new and innovative ways. For instance, a food vendor can use his/her ability to cater food and drink and its service capabilities to service demand for event management. Though the initial business concept may not have considered the possibility, the capabilities of the firm can be recombined to cater to new markets, develop new products or transform its ability to source raw materials at low cost for instance, as an opportunity to add wholesaling to their portfolio. This logic is in line with the conclusions of Di Stefana, Peteraf and Verona (2014) who suggest that moving the field of dynamic capabilities forward will involve greater discussion between scholars, noting that some have already begun to investigate the organizational mechanisms that link ambidexterity to the dynamic capability literature.

\section{Exploration and Exploitation Dynamic Capabilities}

Based on the considerations put forward by the literature reviewed, two distinct dynamic capabilities emerged as intriguing areas of interest and will form the basis of the analysis: exploratory and exploitative capabilities. These capabilities are seen as core to a firm's success through their ability to generate value en route to a competitive advantage. March (1991) defines the exploration of a firm as "experimentation with new alternatives having returns that are uncertain, distant and often negative", while defining exploitation as "the refinement and extension of existing competencies, technologies and paradigms exhibiting returns that are positive, proximate, and predictable" (p. 85). The dynamic implications of these definitions are the continuous need for experimentation (exploratory) in the first instance and constant refinement (exploitative) in the second. The difference between the two is also clear; exploratory capabilities may emerge from 
the desire to discover something new, or as put by Levinthal and March (1993), "the pursuit of knowledge, of things that might come to be known", while exploitative capabilities are related to things that already exist or "the use and development of things already known" (p. 105).

Although different, exploitation and exploration capabilities are also closely related (Rothaermel and Deeds, 2004). Lee and Ryu (2002) note that exploitation can eventually lead to the exhaustion of an advantage, which then causes firms to engage in exploration as they attempt to reveal new advantages which will be later exploited. As put forward by March (1991) "since long-run intelligence depends on sustaining a reasonable level of exploration, these tendencies to increase exploitation and reduce exploration make adaptive processes potentially self-destructive" (p. 73). This suggests that exploitation in the absence of exploration may be short lived as eventually the exploitation can become ineffective. Conversely, firms excessively engaging "in exploration to the exclusion of exploitation are likely to find that they suffer the costs of experimentation, without gaining many benefits" (March, 1991, p. 71).

A relationship also exists between exploitation and exploration to the extent that exploitation can create the available financial resources to engage in exploration, while it has been argued that engaging in exploration facilitates the development of technological assets and capabilities, which can then serve the exploitation process (Garcia, Calantone, and Levine, 2003). Yalcinkaya, Calantone and Griffith (2007, p. 71-72) argue that "exploitation forms the foundation on which exploration can exist" and find empirical support for their claim of the significance of the relationship. Without the low-risk stream 
of income from the existing customer, costly exploration may not be possible. Katila and Ahuja (2002) conclude that exploitation, while a broad concept, is more beneficial to the firm than may be believed, while exploration through search breadth and depth can lead to new product innovation, but only to a point until the returns begin to diminish.

Several authors have attempted to measure the exploratory and exploitative capabilities of a firm. Based on their qualitative case study approach Bonesso, Gerli and Scapolan (2014) propose terms used in the vocabulary of managers who face a trade-off between exploration and exploitation activity, shown in Table 2.1.

Table 2.1 - Exploration and Exploitation Vocabulary, from: Bonesso, Gerli and Scapolan (2014)

\begin{tabular}{|c|c|}
\hline Exploration & Exploitation \\
\hline $\begin{array}{l}\text { Adventure, anticipate, astound, autonomy, } \\
\text { being the first, breaking away from change, } \\
\text { create, creativity, decentralization, } \\
\text { development, discontinuity, discovery, } \\
\text { distant search, diversify, diversity, } \\
\text { dynamic, evolution, expand, } \\
\text { experimentation, explore, fantasy, far } \\
\text { beyond, flexibility, forefront, freedom, } \\
\text { idea, innovation, invent, inventive, long } \\
\text { term, low codification, low formalization, } \\
\text { low standardization, new, new clients, new } \\
\text { markets, new products, novelty, open } \\
\text { mentality, patent, planning, proactive, R } \\
\text { and D alliance, release, revolution, risk, } \\
\text { search, slow learning, something extra, } \\
\text { spirit of initiative, start up, tactic } \\
\text { knowledge, transform uncertainty, vary, } \\
\text { wide background }\end{array}$ & $\begin{array}{l}\text { Accelerate, adaption, adjustment, applied } \\
\text { research, automate, aversion to risk, } \\
\text { bureaucracy, caution, centralization, } \\
\text { certainty, certification, clarity, codification, } \\
\text { commercial alliance, continuity, control, } \\
\text { correct correction, customer loyalty, deep } \\
\text { background, defend, differentiate, } \\
\text { efficiency, execution, existing clients, } \\
\text { existing markets, existing partners, existing } \\
\text { products, fast, formalization, } \\
\text { implementation, improvement, incremental } \\
\text { innovation, local search, modular } \\
\text { protection, operational strategies, } \\
\text { perfecting, planning, practicality, precision, } \\
\text { predictability, procedure, program, } \\
\text { prudence, rationalization, reactive, } \\
\text { reduction of costs, refinement, reliability, } \\
\text { restyling, result based objective, routine, } \\
\text { rules, serial production, short term, shorten, } \\
\text { stability, standardization, up-date, variant, } \\
\text { verification }\end{array}$ \\
\hline
\end{tabular}

Yalcinkaya, Calantone and Griffith (2007) investigate exploration and 
exploitation capabilities, in an attempt to understand their conversion from resources, using a sample of U.S. based importers. They suggest that technological resources may influence the development of exploration capabilities, while marketing resources may help to develop a firm's exploitation capabilities. In addition, the authors also found that exploration capabilities may be the catalyst for the development of exploitation capabilities, further noting "that whereas exploitation capabilities are negatively related to the degree of product innovation, exploration capabilities positively influence both the degree of product innovation and market performance" (p. 63). One explanation for the negative relationship found between exploitation and the level of product innovation could be that firms that are successfully exploiting an opportunity see little need to explore other options or divert resources to new products or services at that time.

To operationalize exploration and exploitation capabilities, the authors used a seven-point Likert scale, consisting of two questions each. Specific to exploration, respondents were asked if the firms chose new processes, products or services compared to those of the past and if the firm has included some new aspects to its process, products or services as compared to its prior strategies. For exploitation, respondents were asked if employees of the firm continuously tried to improve the processes, products or services, and secondly, if the employees of the firm believed it was their responsibility to improve upon the processes, products or services of the firm. Both measures displayed high standard loadings and internal reliability.

Unlike the EO construct however, the criteria used to measure exploration and exploitation does not share uniformity. In a study that examines the organizational and 
environmental factors of influence in capability building for multinationals in foreign markets, Luo (2002) suggests that a firm's exploitation capability is inversely related to the complexity of the environment and industrial uncertainty. To measure exploitation capability Luo asks respondents three base questions relating to the extent to which their parent company had committed and exploited its strategic resources that are: rare and specific, difficult to imitate and that can generate abnormal returns. These base questions were applied to product and process technology, industrial or intellectual property rights or managerial and organizational skills. Here, the links to the VRIN/O framework are evident, as is the difference from the scale employed by Yalcinkaya, Calantone and Griffith (2007).

In a paper that studied the effects of exploratory and exploitative innovation, its organizational antecedents, environmental moderators and performance, Jansen, Bosch and Volberda (2006) suggest that a centralized organizational structure negatively affects exploratory innovation, while having the opposite effect on exploitative innovation. With so few employees, micro organizational structures tend to be centralized to the extent that often, sole decision-making is left to the entrepreneur of the organization. Transposing these findings to micro organizations however seems less intuitive if we assume that they possess an ability to swiftly discover and respond to market trends and shifts (exploratory), many micro organizations still fail to successfully deliver methods to exploit this advantage.

Further, the connectedness between a firm's units could have implications for both exploration and exploitation. For the centralized micro organization that may lack 
the units that may exist in larger organizations the implications are unclear, suggesting the need for further research. The authors also suggest that exploratory innovation may be of more use to a firm in dynamic environments, while in more competitive environments, exploitative innovation may be more beneficial. To measure exploratory and exploitative innovation, and based on the lack of appropriate scales, the author developed two seven item measures. Though different from those described already, the items used seem to carry similar themes. With respect to exploratory innovation for example, the focus is on newness (products, services, markets), while for exploitative the focus is on refinement, adaptation, strengthening and improvement.

Chen, Li and Evans (2012) find that an interaction orientation (customer, concept, interaction response capacity, customer empowerment, customer value management) and EO improve the exploratory and exploitative capabilities of the firm (mediator variables), which in turn can improve organizational performance. To measure the organizational capabilities, the authors employ a 9 item measurement ( 5 exploration questions, 4 exploitation questions) ranging from 1 to 5 (no extent to a great extent). As with the previous studies, and despite citing the work of Jansen, Bosch and Volberda (2006) the authors developed a scale unique to the context and purpose of their study. At 9 items between exploration and exploitation the scale is shorter than Jansen et al.'s 14, but has more than twice as many items as Yalcinkaya, Calantone and Griffith's (2007) 4 item measure. What does carry over from the existing studies however, is the vocabulary used by the authors. Four of the exploratory capability items reference 'new' while the fifth references 'no prior experience'. With regards to exploitation, the authors make use of the 
words: refined, adaptations, upgraded, strengthened and enhanced.

Thus, while research into the exploratory and exploitative capabilities of the firm is growing in popularity (Jansen, Bosch and Volberda, 2006) and has been shown to be significant in the explanation of differences in firm performance, there does not seem to be an agreed upon scale. While several measures have been used to determine the exploratory or exploitative capabilities of a firm, a frequently used terminology that is aimed at measuring the two capabilities runs through all the conceptualizations that have been modified for their specific purpose. Specifically, the exploratory capability of the firm refers to the firm's ability to introduce new products, services or processes, while the exploitative capability of a firm refers to the extent to which the firm can improve upon its existing processes, products and services and profit from doing so.

\section{Ambidexterity}

Although Duncan (1976) is credited with being the first to use the term organizational ambidexterity, March's (1991) article is considered to be the stimulus for much of the current interest in the field (Raisch and Birkinshaw, 2008). In his article, March (1991) proposes that exploration and exploitation represent two differing activities that firms devote their resources and attention towards. March (1991) links exploration to "search, variation, experimentation, and discovery" (p. 102), while suggesting that exploitation involves "refinement, efficiency, selection, and implementation" (p. 102), with the implication that each activity may require a unique strategy. Some research into firm ambidexterity investigates the trade off that may exist in aligning the firm to explore 
new competences or exploit existing ones (Ancona, Goodman, Lawrence and Tushman, 2001; Levinthal and March, 1993), with some authors suggesting that organizational practices that simultaneously attempt to achieve productive levels of exploration and exploitation were impossible (McGill, Slocum and Lei, 1992; Miller and Friesen, 1986).

However, while March (1991) proposed that exploration and exploitation represent differing activities, he also proposes that successful firms need to be aligned to productively do both. Here, the implication is that if a firm has a one-sided focus on exploration it may come at the expense of the productive exploitation of their efforts. Conversely, by only focusing on exploitation, a firm may be unable to respond to changes in demand or fail to recognize product and process improvements that undercut its ability to effectively carry out exploitation activities. Therefore, given the performance tradeoffs that may exist with an over reliance on either exploration or exploitation by a firm, it may be advantageous to a firm to attempt to be adept at both exploration and exploitation, or in other words, ambidextrous.

In order to be an ambidextrous organization firms must be "capable of operating simultaneously to both explore and exploit" (He and Wong, 2004, p. 483), suggesting that through the pursuit of both exploration and exploitation, the shortcomings of a focus on only one aspect can be avoided. However, beyond the general agreement that ambidexterity represents an ability to engage in both exploration and exploitation, there is some confusion as to whether firm ambidexterity increases as a result of the combined magnitude of both exploration and exploration (a multiplication of the two measures) or if greater ambidexterity is achieved through the balance of exploration and exploitation, 
where closer exploration and exploitation levels would indicate a more ambidextrous firm. Although the implications of the use of a combined or balanced firm ambidexterity measurement instrument are discussed in greater detail in Chapter 4 (Methodology) we take the position that both the combined and balanced measurement of ambidexterity are important in the determination of a firm's ambidexterity levels and thus the interaction between the combined and balanced measurement is considered.

\section{Linkage between EO and the RBV}

Having considered the literature of importance in the EO and RBV streams, for the purpose of this study, it is imperative that a linkage be established between the two. The importance of entrepreneurship has been widely acknowledged in early strategic management literature (Andrews, 1971, Chandler, 1962) and more recently, its interaction with dynamic capabilities (Zahra, Sapienza and Davidsson, 2006), however, there has been sparse empirical consideration of the impact strategic resources have on the relationship between $\mathrm{EO}$ and performance. This is especially perplexing given Miller's assertion (2003, p. 883) where he proposes that, "There is a natural and necessary complementarity between the resources a firm has and the decision-making processes needed to harness those resources for profitable purposes".

Within the strategic management literature, there has been a large body of work that investigates the direct link that exists between individual resources, or resource configurations, with less attention being devoted to understanding how management can utilize the resources at their disposal more effectively (Helfat, 2000). Although acknowledging an exception in the study of complementary resources (Christmann, 
2000), Wiklund and Shepherd (2003) assert that if we consider "the VRIO terminology, there has been little consideration of the inter-relationship between a firm's organization ('O') and its resources ('VRI') in explaining performance' (p. 1308). They suggest that the relationship may be worth investigating, as there is some evidence that management can respond to environmental changes and new opportunities by taking action that influences the resources of the firm and how those resources are utilized. EO is proposed as an important measure of an organization which can enhance the resources of the firm by directing top manager's attention to the utilization of the firm's resources towards the discovery and exploitation of opportunities. Empirically, Wiklund and Shepherd (2003) demonstrate that a firm's resources and its organization, if considered together, provide a more complete explanation of differences in firm performance than if considered independently.

Similarly, in the EO literature, much attention has been devoted to the independent effects of EO on performance, and despite calls from the field (Lumpkin and Dess, 1996) limited work has investigated how the internal resources of a firm moderate and mediate the relationship between EO and performance. As put by Wiklund and Shepherd (2003, p. 1308), "It appears, therefore, that EO scholars have focused on how the firm is organized ('O') to undertake entrepreneurial endeavours, ignoring resources internal to the firm (i.e., 'VRI')". This appears as a gap in the literature in line with the assertion of Lumpkin and Dess (1996) who propose that the relationship between EO and performance is more complex than only the main effect of the dimensions. As such scholars could benefit from consideration of moderating effects of the characteristics 
internal to the firm, for instance, availability of resources. One such possible

conceptualization as noted by Lee, Lee and Pennings is the treatment of EO as a resource in itself. The authors point out (2001,p. 617):

"EO can be regarded as organizational resources that provide sustainable competitive advantages, since EO is embedded in organizational routines, is intangible, and is dispersed among organization members. Firms cannot buy a high level of EO from the market and should invest a great deal of time to cultivate such culture and thus EO can be a source of sustainable competitive advantage".

In the citation above, the authors argue that EO is a firm resource and continue by suggesting that there is an inability by firms to purchase EO, reinforcing the valuable, rare and in-imitable elements of the EO resource, while also developing the notion of EO as an organizational capability, noting that it is embedded in organizational routines. The importance of VRIN resources was identified by Lin and Wu, (2014) in their study of the mediating effect of dynamic capabilities on resources and improved performance. Their results demonstrated that VRIN resources significantly aid in improving performance, while non-VRIN resources have only an insignificant effect. Further, the authors showed that VRIN resources could help to positively affect dynamic capabilities (e.g. learning), while non-VRIN resources do not significantly affect the development of dynamic capabilities. They conclude that dynamic capabilities serve to mediate the relationship between VRIN resources and performance and through their accumulation and interaction with the firm's dynamic capabilities, a firm can improve its competitive position and enhance its performance.

Treating EO as a resource itself and part of a larger set of resources, Price, Stoica and Weaven (2013) conducted statistical analysis on the relationship between five 
resource categories: human, organizational, social, knowledge-based resources and entrepreneurial orientation (EO) and firm performance, with findings indicating that the resource dimensions of EO and knowledge-based resources are most important to SMEs. In a study conducted by Julienti, Baker and Ahmad (2010), findings reveal that dimensions of EO may also be affected by levels of resources. They conclude that intangible resources, in particular, product reputation, serve to drive product innovation. In essence, if a firm were to have a good product reputation, innovativeness by the firm is likely to be well received by the market.

The view that a relationship exists between the individual dimensions of EO and resources has also been suggested by Miller (2011, p. 884), who asks, "might knowledgebased resources promote innovation while ample financial capital induces proactiveness?" He proposes that social capital as a resource may increase innovation and risk-taking, if for instance, the firm can build relationships with suppliers and or facilitate elevated levels of trust respectively. On the other hand, he notes that social capital can also hinder innovation if it were to be adversely affected by cronyism and cartels. Most interesting, and within the scope of this research are his questions (p. 884):

"Perhaps a more interesting question is which resources do EO give rise to: does innovation attract talented people who lead to more innovation? Does risk-taking or proactiveness expose a firm to more potential partnering opportunities and thereby create valuable relationships and social capital?"

We argue the notion that EO precedes, and thus influences the availability and ability to exploit a firm's resources and the exploration of new opportunities. Consider the EO dimension of innovativeness, and a resource, such as financial resources. Now assume a firm is asked to evaluate its access to financial resources. As an example of our 
logic, we propose that a firm with a tendency towards innovativeness will be able to identify more avenues to financial resources than an individual with a lower tendency towards innovativeness. While the firm with a low tendency towards innovativeness may only be able to identify traditional methods of capital access such as loans and shares, the more innovative firm may be able to identify additional forms of capital (e.g. kickstarter.com, angel investors) that are not considered by less innovative firms. This example demonstrates the possible implications of varying EO dimensions as they relate to resource efficacy.

It is also assumed that this relationship will be most identifiable when resources are measured through perceptions rather than absolute measures. In the previous example, although the innovative firm may report greater access to financial resources, it does not necessarily entail that this firm actually has access to more resources, but rather only a perceived access. Given that the majority of EO studies have utilized self-reporting as the primary indicator of both independent and dependent variables, the idea that EO precedes resource availability, exploratory capabilities and the capability to exploit these resources is conceivable. A similar argument will also be made for types of relationships between the other dimensions of EO and resources and capabilities.

\section{The Trinidadian Micro Firm Context}

This study is focused on micro enterprises or organizations established in Trinidad with fewer than 5 full time employees. Being heavily reliant on the income from the sale of its oil and gas reserves, the 1980s was a time of hardship for Trinidad and Tobago, born out of depressed commodity prices. Since this time, the government has 
incorporated micro-business development as a strategy to alleviate poverty and boost employment (Karides, 2005). The Global Entrepreneurship Monitor (GEM, 2010)

National Report for Trinidad and Tobago, outlines that the government's entrepreneurial development framework consists of the provision of credit and other sources of finance, coordination of development agencies, training and human resource development, marketing opportunities and other support services for potential entrepreneurs (Murdock, Mc Donald, Joseph, Dardaine-Edwards, and Carrillo, 2010). Recent steps have also been taken by the government to introduce entrepreneurship as an independent subject that is available as a credit at the high school level (Ramkissoon-Babwah, 2012).

The significance of Small and Medium Enterprises (SME) and specifically microenterprises to the country and its people was outlined by the local daily Newsday (2014):

"Closer to home, in Caricom (2012), SMEs contribute 40 percent of the Region's GDP and are key sources of employment. Caricom estimates that micro, small, and medium enterprises contribute more than 70 percent of jobs. In 2010 it was estimated that in Trinidad and Tobago, SMEs numbered approximately 18,000, contributing nearly 28 percent to GDP and employing 200,000 persons approximately 30 percent of the labour force. The Ministry of Labour and Small and Micro Enterprise Development has indicated that 91 percent of business establishments locally are SMEs with 75 percent being micro-enterprises."

Considering that in 2012, the energy (primarily oil and gas) revenue accounted for $\$ 18.1$ of the $\$ 47$ Billion dollar GDP of the country (38.5\%), SMEs with their 28\% contribution to GDP represent the second largest contributor to GDP in the country. Of these SMEs, the largest contributor is the consumer-oriented sector consisting mainly of retail business at over 50\% (Bailey, Pacheco, Carrillo, and David, 2012). Thus while the integral importance of SMEs has been established, the GEM Trinidad and Tobago report (2012) also suggests that $70 \%$ of surveyed national experts agreed that the policies of the 
Trinidad and Tobago government generally do not favour new and growing firms. The vast majority of respondents also agreed that new and growing firms are faced with high levels of bureaucracy and regulatory requirements (88\%) and heavy tax burdens $(50 \%)$.

Further, the experts generally agreed that while programs offered by the government to promote growth existed, these programs were either ineffective, inaccessible, managed by incompetent people or constrained by bureaucracy. A gap then exists between the needs and offerings, with the suggestion, that more should be done to shift to need/competencies based training and education programmes (RamkissoonBabwah, 2012). We offer that this research represents a step in this direction by offering an analysis of the entrepreneurial dimensions of micro entrepreneurs in Trinidad and Tobago. Given the importance of entrepreneurship to the local economy, its significance in governmental policy and strategy, and the lack of research that exists, this context is believed to hold the potential for new and meaningful findings.

Culturally, Trinidad and Tobago also offers an interesting scenario as it relates to the EO construct. The 2012 GEM report for Trinidad and Tobago reports on the perceptions of national experts on three cultural and social norms that closely mirror the dimensions of the EO construct. On a scale including completely false, somewhat false, neither true nor false, somewhat true and completely true, participants were asked to rate their perception of the following statements: "The national culture encourages creativity and innovativeness", "The national culture encourages entrepreneurial risk-taking" and "The national culture emphasizes self-sufficiency, autonomy and personal initiative" (Bailey, Pacheco, Carrillo, and David, 2012, p. 42). Only 22\% of respondents believed 
that the national culture encouraged creativity and innovation, $11 \%$ that the national culture encouraged risk-taking and 19\% that the culture encouraged self-sufficiency, autonomy and personal initiative. The same GEM report states that over $80 \%$ of early stage entrepreneurs in Trinidad and Tobago use no new technologies, while only $15 \%$ of entrepreneurship is driven by necessity.

These reports, combined with the large volume of employment and economic activity driven by SMEs are perplexing. In their study of 229 SMEs in the United States of America, Price, Stoica and Weaven (2013) report a statistically significant relationship between the EO of SMEs and performance, concluding that high-performing SMEs possess a predisposition for EO. If this is true, and the national experts surveyed in the GEM report are to be believed about the low levels of national culture relating to the EO dimensions, is it that Trinidad and Tobago has few high performing SMEs? Or is it that the national experts are mistaken, and higher levels of innovation, risk-taking and proactiveness exist in SME businesses than believed? Possibly, the national experts are only partially correct, and lower levels of innovation are overcome by higher than normal levels of risk-taking or another productive formula.

We believe this research to be the first of its kind, measuring and analyzing information relating to the dimensions of EO and performance in Trinidad. Policy makers and analysts can use the data in forming a greater understanding of the types of businesses that make up the micro enterprise sector and the role that EO has in the variance in performance between firms. In one instance, the levels of innovation, risktaking and proactiveness can be measured using accepted scales and then compared 
against the opinions of the national experts who, as noted above, are pessimistic as to the levels of all three of the EO dimensions. Further, this research will allow for the investigation of performance differences between firms by type of operation, location and their ability to engage in successful exploration, exploitation or both. Practical contributions from these findings could be the discovery of systematic success or failure or micro organizations that either engage in a specific type of business, do so in a specific area. Further, the relative impact of exploration and exploitation on performance, or the existence of these capabilities within micro organizations can be uncovered, informing local policy makers as to the status of these capabilities within the sample, and a better understanding of the wider population. As an example, should we uncover unusually high levels of exploitation, combined with low levels of exploration being carried out by micro enterprises, it can be used as the catalyst for changes in the services and infrastructure that the government provides to the sector (for instance, reducing import duties on machinery used in production, while increasing import duties on the finished goods that can now be manufactured by the machinery).

Moreover, micro firms offer a unique and interesting context for the study of resources. As noted by Kelliher and Reinl (2009, p. 521):

"Literary findings suggest that, considering micro-firms' internal resource constraints, minimal environmental power, and owner-centred culture, it is vital for these organisations to embed their valuable resource in their core business strategy, to ensure survival in the longer term."

If organizations that control embedded resources are favoured to survive, then the entrepreneur's own characteristics can become a source of advantage. That is, the innovativeness, risk-taking and proactiveness attributes of the entrepreneur can be the 
driver of a competitive advantage for the firm and thus higher levels of performance, given that these characteristics are VRIN/O.

The exploration of entrepreneurial behaviour in micro firms also offers the advantage of a greater likelihood of founder and firm EO alignment than in larger firms. Some have argued that top management's values are major determinants of competitive choices (Andrews, 1980) while Lee, Lee and Pennings (2001) state that, "several previous studies in the entrepreneurship fields have assumed that the start-up firm is an extension of the founder" (p. 616). While in large firms, the assumption that the EO of the CEO adequately represents the EO of the firm as a whole is debatable, as the size of the firm decreases, this relationship is assumed to become more significant. If a firm is classified as micro, and thus has less than five employees, it is likely that the EO of the entrepreneur will permeate the entire organization. This is in line with the assumption of the "predominant role of the founder-manager's strategic philosophy in the emergence and persistence of a strong entrepreneurial culture likely to shape the firm's collective behaviour" (Campos, Nuno de la Parra, Parellada, 2012, p. 62). In a test demonstrating the relative effect of firm size in past EO research, Rauch, Wiklund, Lumpkin and Frese (2009), report that micro firms (1 to 49 employees) showed a corrected correlation of 345 in the relationship between EO and performance, which was significantly higher than the relationship for both small ( $\mathrm{r}=.198,50$ to 499 employees) and large $(\mathrm{r}=.240$, more than 500 employees).

\section{Summary}

The literature review begun by considering EO's roots, its application and 
acceptance, with specific attention being paid to its use as a reflective (unidimensional scale) or a formative (multidimensional scale), of which only the latter considers the possible contextual benefits of varied levels of each of EO's dimensions. The RBV is also traced from inception through to its impact on the dynamic capability literature. Specific attention is paid to a firm's exploratory and exploitative dynamic capabilities, and their combined dimension of ambidexterity, which is believed to allow for the enactment or constriction of the benefits of a firm's EO in relation to performance.

Also the micro firm context in Trinidad is considered, while offering the importance of the sector to the overall economy of the country and outlining the need and benefit of this type of research. The Trinidadian entrepreneurial context has been described by local national experts as lacking when it comes to the encouragement of innovation, risk-taking or proactiveness. If this were indeed true at the micro firm level, traditional EO theory would suggest that there is also a lack of successful micro organizations. This however is not supported by statistics that outline the size in terms of employment or revenues of actual micro firms in the country. As such we hope to uncover the levels of the EO dimensions as reported by the firms themselves and compare it to the views of the national experts, which are assumed to be unfairly deflated. This scenario is interesting in that it is possible either the levels of EO are much higher than is believed by the national experts, or the experts are indeed correct, and despite low levels of innovativeness, proactiveness and risk-taking the local firms still manage to be successful, contradicting the views of EO theorists.

Using the literature in this review as a foundation for the theoretical implications 
of the research, the following chapter will examine the specific research questions that attempt to both connect and investigate the current gaps that have been identified in the literature, as well as connect the EO and dynamic capability concepts in a novel manner and context. 


\section{Chapter 3}

\section{Research Model and Hypotheses}

Building on the literature review, chapter 3 will develop the proposed research questions, the research model and derive the hypotheses that will be used to investigate the research questions. Three broad research questions that consider the dimensionality of EO, its relationships to performance and the effects of organizational ambidexterity (exploration and exploitation capabilities) are explored through 10 hypotheses.

\section{Research Questions}

This study is focused on the EO, RBV, dynamic capabilities and their interaction and performance in a micro firm context. As such, the aim of the study is to investigate the following questions:

1. Does a formative, multidimensional EO construct explain a significantly greater amount of variance in firm performance than a reflective, unidimensional construct?

2. How do the individual dimensions of EO and EO overall relate to performance? Do these dimensions and the overall EO share a linear or curvilinear relationship with performance? Are there differences in the direction and significance of the relationships between the individual dimensions of EO and performance?

3. How does the dynamic capability of ambidexterity (the interaction of exploration and exploitation) relate to performance? Does the 
ambidexterity of an organization moderate the relationship between the dimensions of EO and performance?

The first research question will allow investigation into the debate found within the EO literature as to the effectiveness of a summated (unidimensional) versus algebraic combination (multidimensional) scale as it relates to the explanation of performance. The second research question will consider the relationships that exist between the EO dimensions of innovation, risk-taking and proactiveness, as well as the relationship between the summed EO and performance. The third research question builds upon the second by linking the EO dimensions to the RBV, specifically a firm's ambidexterity, to evaluate the relationship between ambidexterity and performance and the moderating effects that ambidexterity can have on the relationship between EO, its dimensions and performance. Figure 3.1 and Figure 3.2 below depict the components of the research models and introduces the hypothesized relationships $(\mathrm{H} 2-\mathrm{H} 10)$ that will be discussed in the chapter. We consider a dual analysis of the reflective and formative conceptualization of EO requiring the use two separate models. Figure 3.1 shows the formative research model, which deconstructs the dimensions of the EO construct, considering each dimension individually. Figure 3.2 shows the reflective model that will be used for investigation. Contrary to the formative model, the reflective model considers a summative dimension of EO. 
Figure 3.1: The Formative Research Model

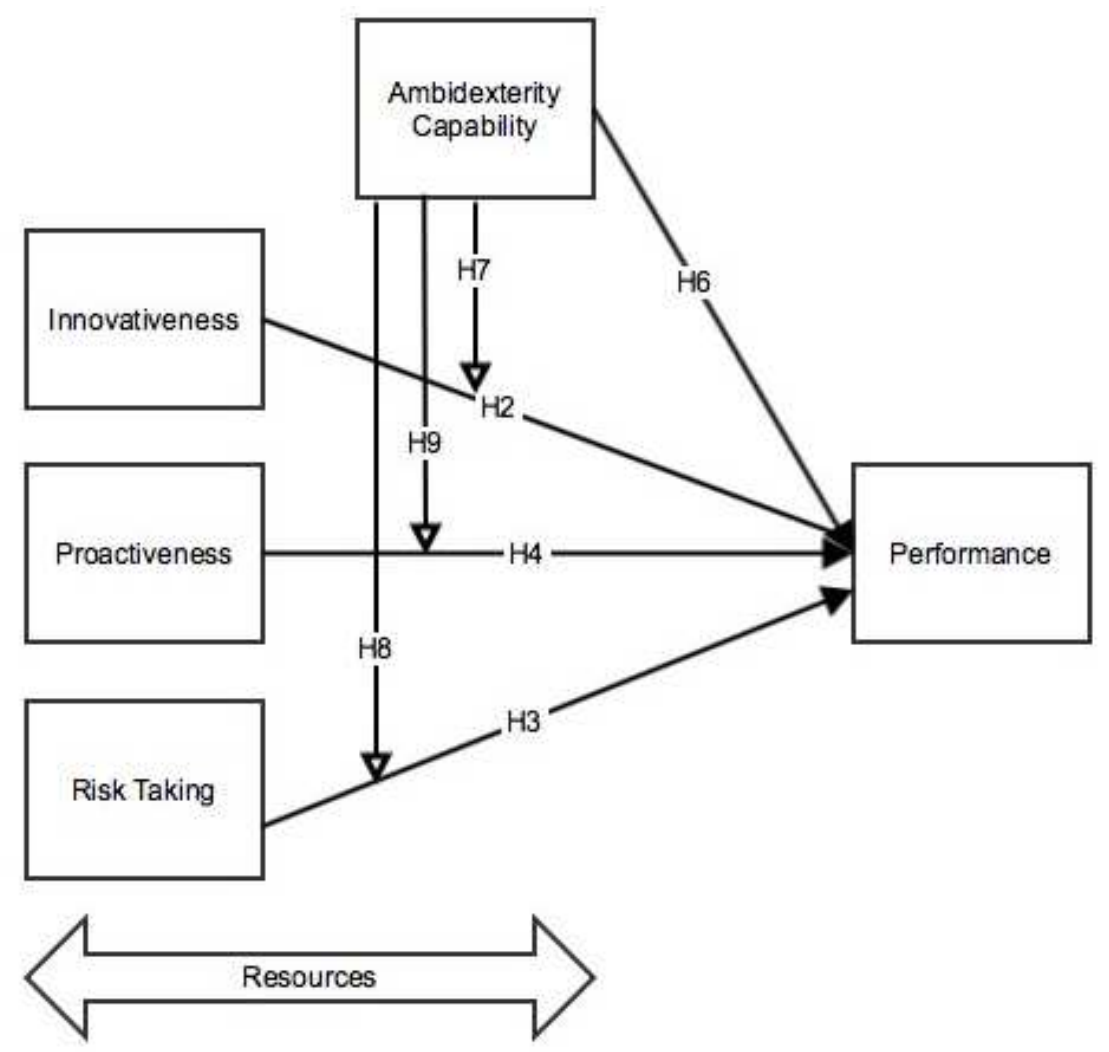

Figure 3.2: The Reflective Research Model

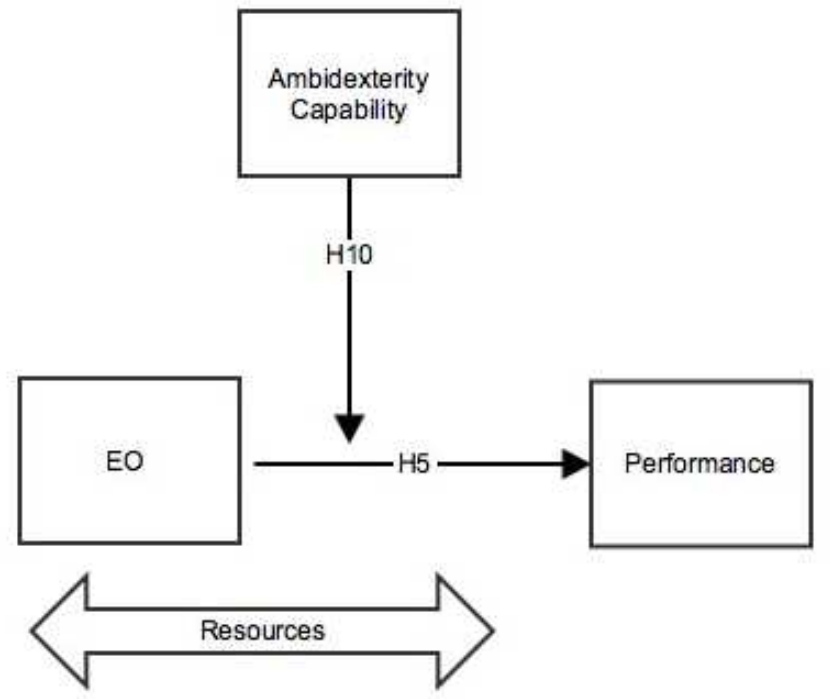




\section{EO as a formative, multidimensional construct versus $\mathrm{EO}$ as a reflective, unidimensional construct.}

Covin, Green and Slevin (2006) suggest that the selection of EO dimensionality is of utmost importance for researchers of EO. As discussed in the previous section, the debate within the literature as to the most effective measurement technique of EO is currently a point of contention. Based on a review of $158 \mathrm{EO}$ focused articles, Wales, Gupta and Mousa (2011) show that 123 (78\%) of the articles examine EO as a unidimensional construct, with $80 \%$ of those articles utilizing the innovativeness, risktaking and proactiveness dimensions, while only 10 of the 123 unidimensional articles employed dimensions other than the three dimensions listed above. The authors also reveal that $41(26 \%)$ articles examined EO as a multidimensional construct, while six (4\%) examined the construct from both a unidimensional and multidimensional point of view. Further, the likelihood of authors using a multidimensional scale has increased relative to the likelihood of a unidimensional measure (Wales, Gupta and Mousa, 2011).

Figure 3.3 below shows the numbers of EO research articles that have utilized a unidimensional or multidimensional scale for the years 1983 - 2010. Figure 3.2 reveals two useful pieces of information. The first is the growing dichotomy between the usages of the two measurement techniques. While early EO research was dominated by a unidimensional conceptualization, in more recent times the multidimensional conceptualization of EO has been growing in popularity. The second is the growth in total EO research over the time period. Since 2000, based on the articles selected for review, (Wales, Gupta and Mousa, 2011) the amount of EO research has multiplied several times, 
from less than 5 per year to over 25 articles in the most recent year examined in the study (2010).

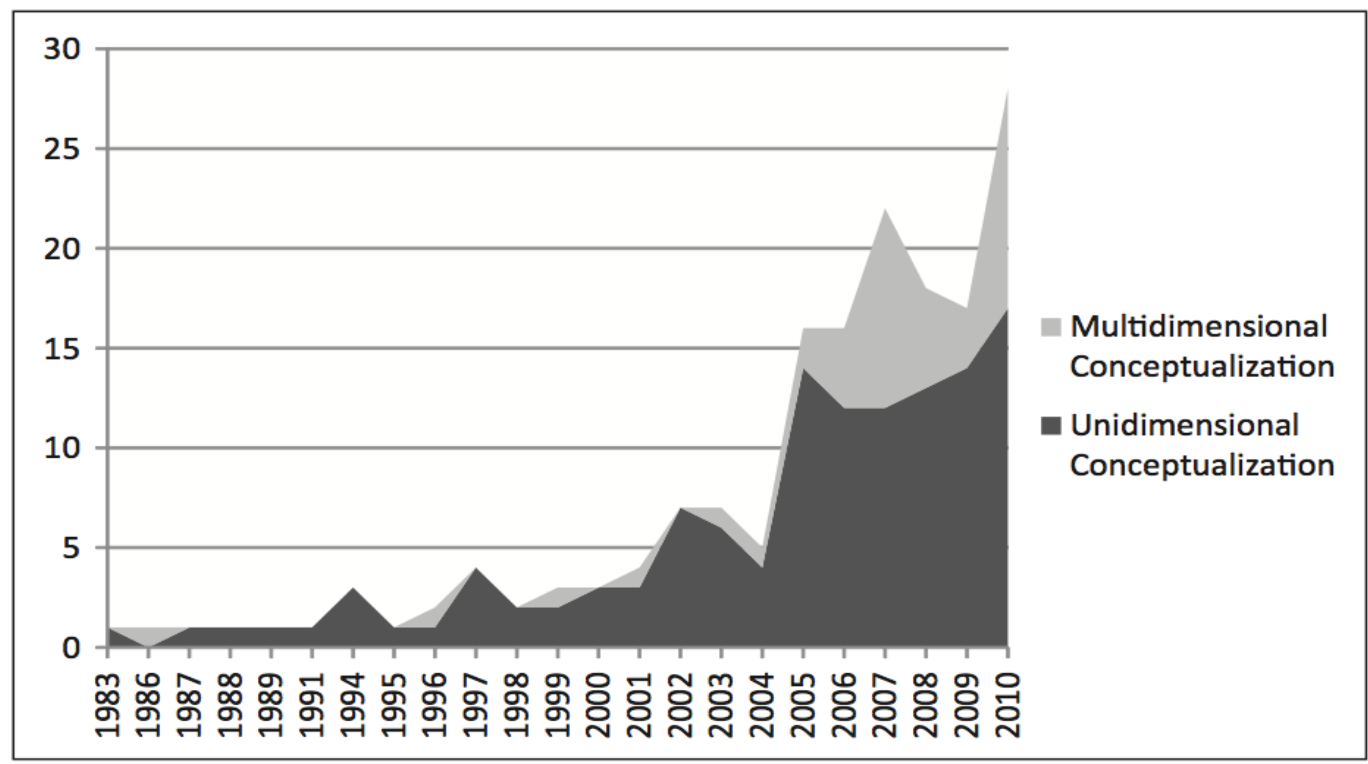

Figure 3.3 - Multidimensional versus Unidimensional conceptualization in EO research. From Wales, Gupta and Mousa (2011).

This growth in studies around this concept is a positive sign for researchers in the field and signifies the importance of EO. However, a deeper look reveals that new growth is being generated from scholarly publications outside the entrepreneurship domain. This is shown below in Figure 3.4 in which we can see how the academic community outside of Entrepreneurship have begun to embrace the EO construct. While EO research published in entrepreneurship specific journals has taken an upward trend since 1983, the quantity of EO research in non-entrepreneurship specific journals has risen by a relatively greater amount in the more recent years. Further, of these non-entrepreneurship specific journals that act as outlets for EO research, the largest, or $43 \%$ of all the reviewed articles were published in management related journals. This information is encouraging given 
that a major facet of this research is to link the EO (entrepreneurship) and RBV (strategy/management) fields.

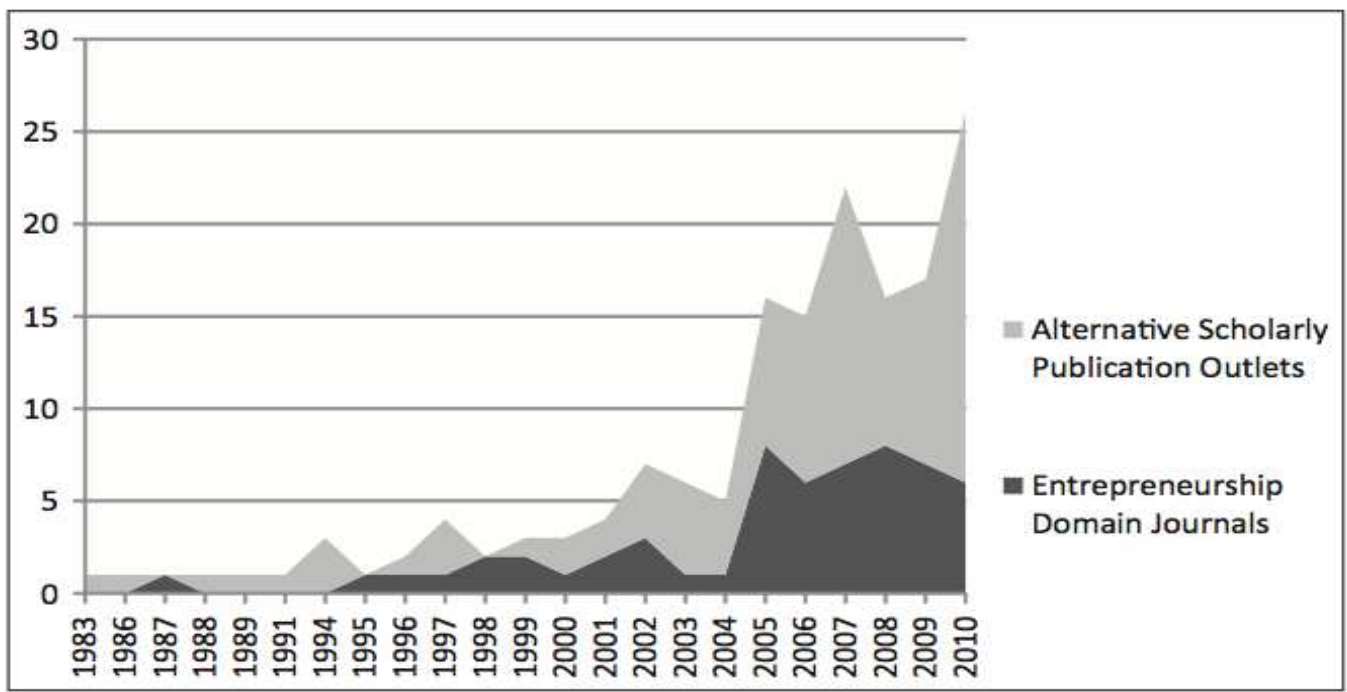

Figure 3.4 - Entrepreneurial specific versus alternative EO research outlets. From Wales, Gupta and Mousa (2011).

As mentioned in the literature review, the debate as to the most appropriate conceptualization of EO is far from over and requires additional consideration. Taking a step into general theoretical and empirical considerations, Coltman, Devinney, Midgley and Venaik (2008) propose a framework for the assessment of reflective and formative constructs. In terms of the theoretical concerns, they propose three issues that should be considered. First, one should consider the nature of the construct as either existing (reflective) or as being formed (formative). Here, EO researchers should ask if they believe that the EO construct exists independently of the dimensions that are used to measure EO or if the dimensions instead combine to form EO? Although this matter still lacks any consensus, the inclination of EO studies to be conducted through a summative 
measure of the dimensions indicates that many researchers consider the EO construct as existing independently of innovativeness, risk-taking and proactiveness.

Secondly, the direction of causality should be considered. For reflective constructs, the direction of causality is from the construct to the dimensions. Variation in the construct therefore will lead to variation in the items that were used to measure the construct, while variation in the measures of the construct does not necessarily cause variation in the construct. If we consider this for EO, we would be suggesting that isolated variation in innovativeness for instance, does not lead to a change in the EO, as suggested by George and Marino (2011) who wrote (p. 1002):

"it would seem that EO represents a larger concept than simply the sum of its dimensions and that these dimensions are merely reflections of this larger, unobservable construct that represents the firm's strategic posture. We would also suggest that conceptually we would expect an increase in EO, as an organizational phenomenon, to result in an increase in all of its dimensions. For example, if we were to take a firm and increase their innovativeness without increasing risktaking and proactiveness, would they be more entrepreneurial? We would argue that changing one dimension in isolation does not represent a change in strategic posture but rather only one aspect of it. As such, we believe that a reflective model of EO is more consistent with the theoretical and conceptual definition of the construct."

The authors therefore suggest that changes in the measures of EO do not necessarily cause variation in the construct as a whole. This proposition seems rather inconsistent given that the assigned EO on a conventional summation scale would in fact change a firm's EO if one dimension were to increase, leading to a discrepancy between the theory and measure. Further, not all scholars agree that a change in one dimension of EO has no effect on the construct, as noted in a previous example with the firm who were indeed acting entrepreneurially when they innovatively used their extra capacity, though 
it was low risk. Lumpkin and Dess (1996) argue that depending on the context of the change, a change in one dimension can lead to a change in the overall construct, suggesting that limiting entrepreneurial behavior to instances with high levels of all the dimensions is flawed. They cite the example of Sony and Matsushita as two competitors with different dimensions of EO. Sony, the authors suggest, is well known for its firstmover advantage that is derived from new product innovation, while Matsushita typically copies the innovations of others, and uses its strength in manufacturing and marketing to compete. They conclude (p. 150):

"Although few observers would argue that Sony has a strong EO, we suggest that Matsushita also has a strong EO. That is, it incurs risks through capital investment in plant and equipment, is proactive by entering markets early in the product life cycle, and displays intense competitive aggressiveness through its strategies that are intended to build strong market share."

Lumpkin and Dess (1996) also cite the work of Cooper and Dunkelberg (1986) who acknowledge that starting a business involves innovativeness, creativity and personal risk. However, a counter to this argument may be that entrepreneurial owners who achieve their position through promotion or inheritance are generally not required to be as innovative or assume a substantial degree of risk. In another example, Lumpkin and Dess (1996) discuss the implications of an organic setting to innovation, suggesting that the innovativeness dimension would be positively related to performance when organic. This is due to the decentralization and low formalization often found in organic organizations, which promote the autonomy and creativity required for innovation. If one were to consider the proactiveness dimension in an organic setting, an argument could be made 
that the setting would detract from the ability to coordinate the firm's activities and thus restrict being effectively proactive.

A third theoretical consideration suggested by Coltman, Devinney, Midgley and Venaik (2008) in the assessment of reflective versus formative constructs is the characteristics of the items used to measure the construct. Here, for a reflective model, one should consider if the items are manifested from the construct, or in the case of a formative model, whether the items define the construct. They suggest that for reflective models, the items should share a common theme, can be interchangeable and the adding or dropping of items does not change the conceptual domain of the construct. It would be wise then to consider if innovation, proactiveness and risk-taking are interchangeable items. We take the position that the items are not interchangeable as they each pertain to unique and distinct characteristics of the firm, affirming the notion that the formative construct's theoretical bases is superior in the regard.

Further, although the unidimensional reflective model's dimensions are primarily operationalized as a summation, they do not appear to be interchangeable as the literature has been generally consistent in its use of the big three items (Rauch, Wiklund, Lumpkin, Frese, 2009). This suggests that the dimensions of innovativeness, proactiveness and risktaking define the construct, an indication of the presence of a formative construct rather than reflective construct. While, the dimensions of EO, as noted above do not appear interchangeable, in defining the EO construct as a formative model, authors have at times tended to be inconsistent in the use of dimensions. In addition to, or in place of innovativeness, proactiveness and risk-taking, authors have used dimensions such as 
autonomy, competitive aggressiveness (Lumpkin and Dess, 1996), futurity (Venkatraman, 1989), venturing, strategic renewal (Zahra, 1996), analysis, and defensiveness (Tan and Tan, 2005) thereby hampering the ability to compare and generalize research in the field.

An empirical consideration that must be pondered is found in the correlations between items. For a reflective model, one assumes that items have strong positive correlations with each other. As noted above, this belief has appeared in the literature with authors suggesting that a high EO is a result of high levels of each of the measured dimensions (Rauch, Wiklund, Lumpkin, Frese, 2009). The internal consistency and reliability is measured through Cronbach's alpha, the average variance extracted and the loadings of the factors. In the case of the formative model, the items need not possess any specific pattern of correlation, and can range from low to high. Considering the acknowledgement put forward by Miller (2011) that successful entrepreneurship would manifest itself differently in varying contexts, it may be reasonable to judge the formative scale as superior in this regard. That is, if we assume that differing levels of innovativeness, risk-taking and proactiveness will be beneficial to performance in varying amounts, dependent on the specific industry or context, a formative construct would more adequately serve the purpose.

George (2006) insists that "rather than asking whether the dimensions of EO covary, we should be asking if the dimensions of EO should covary based on its theoretical definition." (p. 1307). This carries a practical implication as well. If EO had a positive relationship with firm performance, managers would then be interested in 
increasing the level of EO. If EO is a formative construct, firms would be interested in the sub-dimensions that make up EO, based on the belief that higher levels of any of the dimensions can increase $\mathrm{EO}$ and thus performance. If, however, $\mathrm{EO}$ is a reflective construct the individual sub-dimensions are interchangeable and of little consequence to the overall entrepreneurial posture of the firm, as a change in one does not affect EO. By increasing EO as an overall posture however, the firm's benefit would be manifested in high risk-taking, proactiveness and innovativeness (George 2006).

As noted, there is support in the literature for both reflective and formative models, which utilize either a unidimensional or multidimensional scale respectively. Miller (2011) suggests that "perhaps in some research contexts, 'the best of both worlds' may entail analyses that present results for the EO construct and for each of its components" (p. 880). While we do not suggest that a unidimensional EO scale does not have a significant relationship with performance, we do suggest that the multidimensional EO scale can do a better job at an explanation due to the fact that it considers the unique effects of the dimensions. Consider an example of two possible measures from each scale (range 1 - 7) where one firm reports EO dimensions (innovativeness, risk-taking, proactiveness) of 7, 1 and 1 . Another firm reports dimensions of 3, 3 and 3 . When using a unidimensional scale, these two individuals would be considered to have equal amounts of EO. However, a multidimensional scale is able to get more nuanced information as it would consider the result for each dimension individually, meaning that the differences between dimensions $(7 / 3,1 / 3,1 / 3)$ could also be analyzed. Therefore, based on the 
theoretical and empirical support that has been discussed above, H1a and H1b are shown below:

Hla: Both a reflective, unidimensional EO scale and a formative, multidimensional EO scale are positively and significantly related to performance

$H 1 b$ : A formative, multidimensional EO scale explains significantly more variance in performance than a reflective, unidimensional EO scale

\section{The Relationships between Innovativeness, Risk-taking, Proactiveness and Performance}

Based on the advantage of a multidimensional scale's ability to consider the unique effects of the EO dimensions, this section proposes testable relationships between the individual dimensions and performance. This approach will allow an understanding of which dimensions are most important to performance in the context of the study. Whereas the conventional EO theory suggests that higher EO is reflected in higher levels of innovativeness, risk-taking and proactiveness, we propose that low, moderate or high levels of each of the dimensions can have differing effects on performance that may not be in line with the conventional 'more EO is better' thinking the pervades the literature.

\section{Innovativeness and Performance}

Innovativeness or the "tendency to engage in and support new ideas, novelty, experimentation, and creative processes that may result in new products, services, or technological processes" (Lumpkin and Dess, 1996, p. 142), has been shown to have a positive linear relationship with performance (Kreiser, Marino and Weaver, 2002). Innovation is often considered important in firm growth, new product and service development, process improvements and enhancing overall market value (Cho and Pucik, 
2005). For instance, firms can leverage their innovativeness to stimulate experimentation and creativity to refine their products and improve their offerings (Ireland and Hitt, 1999).

While this positive linear relationship may exist in some contexts, there are reasons to believe that it may not be universal. Kreiser, Marino, Kuratko and Weaver (2013) suggest that despite the positive relationship identified by past research efforts, the costs of innovation, particularly in the SME context, should be considered. Given the resource shortage faced by SMEs, a successful innovation strategy that requires the development of heterogeneous capabilities early in the innovation process is a challenge (Rosenbusch, Brinkmann, Bausch, 2011). Further, there is the likely large financial a priori expenditure, which can alter the ability of smaller firms to meet their short-term operational obligations. The costs of innovative activity therefore can encompass the upfront investments and R\&D expenditure in the early stages, suggesting that a return on innovation investment is only possible once the benefits from innovativeness begin to exceed these up-front costs (Kreiser, Marino, Kuratko and Weaver, 2013).

At higher levels of innovativeness, a firm may have greater capacity to spread these upfront costs across markets (Zahra and Garvis, 2000), while at lower levels of innovativeness the benefits of standardization can be exploited (Choi, Levesque and Shepherd, 2008). In other words, there may be advantages from either high or low levels of innovativeness. Dai, Maksimov, Gilbert and Fernhabler (2014) propose that there are consequences of being stuck in the middle where as at high levels of innovativeness, firms may be able to experience the benefits of successful innovation in excess of its 
costs. At lower levels, the costs of innovation are mostly avoided and firms can focus their attention on standardization and efficiency of product and process also leading to better performance. However, firms that display only moderate innovativeness are less likely to enjoy successful innovation than firms with high innovativeness, but more likely to bear the financial burden of innovation than firms with lower innovativeness. In line with Kreiser, Marino, Kuratko and Weaver (2013), it is expected therefore, that "the costs may outweigh the benefits when SMEs transition from low-to-moderate levels of innovativeness, but that the benefits are likely to outweigh the costs when SMEs move from moderate-to-high levels of innovativeness" (p. 277). It is therefore hypothesized that:

H2: Firms that report high or low levels of innovativeness will perform better than firms that report moderate levels of innovativeness, reflecting a U-shaped relationship

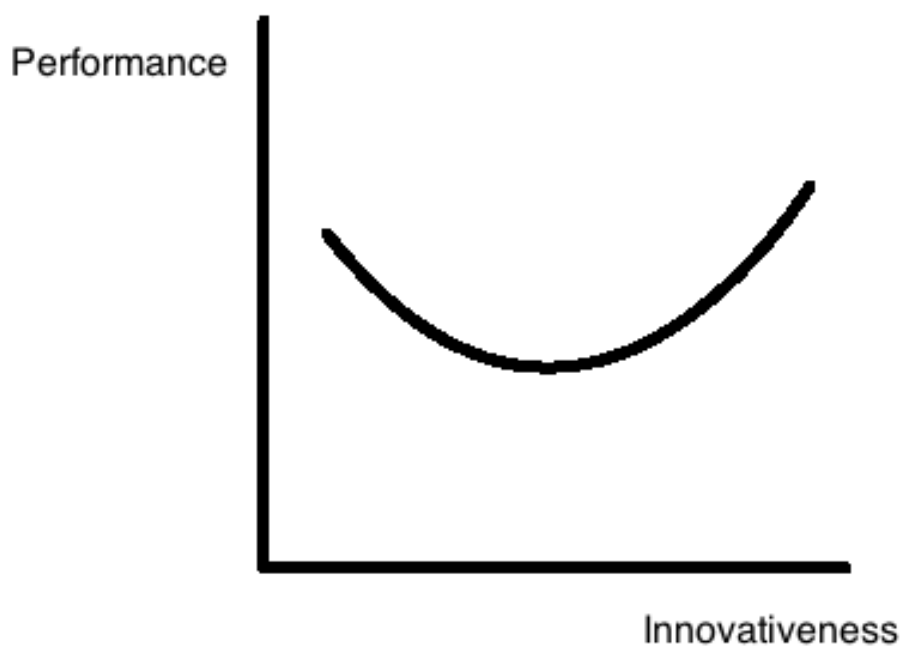

Figure 3.5 - Visualization of Hypothesis 2

\section{Risk-taking and Performance}


As noted in the literature review, although a risk-taking propensity has been demonstrated to be more likely exhibited by entrepreneurs relative to other types of workers (Stewart, Watson, Carland and Carland, 1998), its relationship with performance is still equivocal. Conventional EO theorists propose that firms are likely to benefit from an EO posture, whereby innovativeness, risk-taking and proactiveness are all relatively high (Covin and Slevin, 1989) and lead to greater performance. Thus, a firm that engages in more risk-taking is likely to see an improvement in its performance. Without the benefit of individual analysis, risk-taking is assumed by the unidimensional EO researcher to have a positive linear relationship with performance.

The actual effect of a firm's risk-taking propensity has been shown to be more complex than a simple positive linear relationship and may be dependent on the firm's situational context. In their 'deconstruction' of the dimensions of EO and their relationship with performance at the embryonic stage of business, Hughes and Morgan (2007) proposed a positive relationship between risk-taking and performance, but instead found a significant negative relationship between the two, noting that the, "findings indicate that uniform effort in all EO dimensions does not generate consistent gains in business performance"(p. 657). Kreiser and Davis (2010) suggest that the external environment can have an impact upon the relationship between risk-taking and performance. They stated that dynamic environments should result in a stronger link between firm risk-taking and performance, with firms that fail to take risks, losing market share. Further, munificent environments rather than hostile environments may reward risk-taking due to the availability of resources in those environments. 
There are also costs associated with high levels of risk-taking. Dai, Maksimov, Gilbert and Fernhabler (2014) suggest that firms with a high tolerance for risk-taking are more willing to commit resources, for instance, towards diversification. In addition, firms that have risk takers, exhibit a greater tendency to be over optimistic about opportunities, increasing the likelihood of failure. Conversely, firms that are risk adverse may 'miss out' on opportunities and experience a high opportunity cost for their risk aversion (Hughes and Morgan, 2007). As suggested by Kreiser, Marino, Kuratko and Weaver (2013), "SMEs often take initial risks in order to elevate their level of performance. However, excessive risk-taking significantly increases the chances of downside loss" (p. 278). Thus, while too much risk-taking may be harmful, too little risk-taking can also be harmful to performance. Thus, it is hypothesized:

H3: Firms that report a moderate level of risk-taking will perform better than firms that report a high or low level of risk-taking, reflecting an inverted $U$ shaped relationship

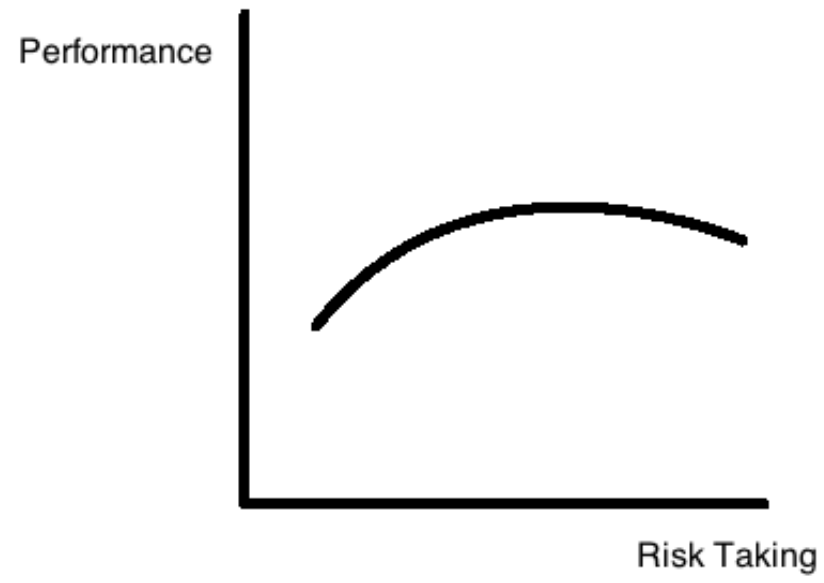

Figure 3.6 - Visualization of Hypothesis 3

\section{Proactiveness and Performance}

Proactiveness is a forward looking perspective where firms actively seek to 
anticipate opportunities, develop and introduce new and improved products and detect future trends in the market. A proactive firm's disposition increases the firm's awareness of, and receptiveness to market signals and customer needs. Through the active anticipation and preparation for change, firms that are proactive can mobilize resources well in advance of their rivals, putting them in a better relative position. Proactiveness also leverages a firm's responsiveness capability and creates a propensity to act to meet new circumstances (Hughes and Morgan, 2007). Firms with greater levels of proactiveness can influence the industry dynamics to a greater extent than their rivals, who merely react to changes. This suggests that in order to maximize potential benefits, the levels of proactiveness should be correspondingly high.

As early as Miller (1983) proactiveness has been positively linked to performance. In their study of firms located within business incubators, Hughes and Morgan (2007) report that in addition to innovation, proactiveness significantly explains variation in performance across the firms studied. Covin and Miles (1999) propose that firms that are successfully proactive benefit from higher demand, customer loyalty and profitability. In their study of the interactions between EO dimensions, Tang, Kreiser, Marino, Dickson and Weaver (2009) suggest that proactiveness may be the most beneficial of all the EO dimensions to firm performance. Their results demonstrate that entrepreneurial firms displaying proactiveness report increased environmental opportunity perception, and only then, use innovative and risk-taking behaviors to capitalize on the opportunity. Further, increased levels of opportunity perception as a result of proactiveness were shown to influence innovation and risk-taking. 
Beyond the positive linear effect of proactiveness as both an independent variable and as part of the unidimensional EO construct research (Rauch, Wiklund, Lumpkin and Frese, 2009), there has been some investigation into the existence of a non-linear relationship. In their study of the EO dimensions and SME internationalization, Dai, Maksimov, Gilbert and Fernhabler (2014) acknowledge the benefit of high proactiveness, but qualify it by discussing the related costs. Specifically, proactiveness involves time and resource costs, for instance obtaining market knowledge may be more beneficial at lower levels than at moderate levels. For instance, firms with low or moderate proactiveness may both lack the ability to identify opportunities, but a firm with moderate proactiveness may still wish to utilize resources to investigate the market. Kreiser, Marino, Kuratko and Weaver (2013) also propose a non-linear relationship between proactiveness and performance. They suggest that proactiveness' positive benefits, such as opportunity identification, are maximized at higher levels. However, there are upfront costs to the development of a firm's proactiveness, for instance, market research can outweigh the potential benefits, particularity at lower levels of proactiveness. Thus, a firm with high proactiveness is likely to enjoy an advantageous performance over its competitors. However, a firm that is moving from low to moderate proactiveness can expect the costs to outweigh the benefits. Thus, it is hypothesized:

H4: Firms that report high or low levels of proactiveness will perform better than firms that report moderate levels of innovativeness, reflecting a U-shaped relationship 


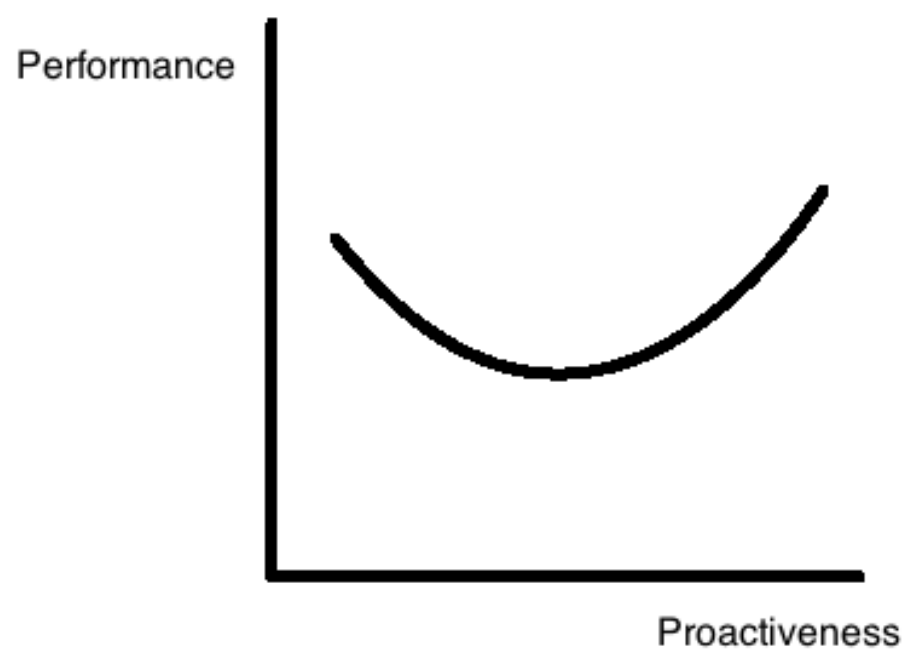

Figure 3.7 - Visualization of Hypothesis 4

\section{EO and Performance}

The previous chapter outlined the existence of the relationship between the EO construct and performance (Rauch, Wiklund, Lumpkin and Frese, 2009). As has been noted, the relationship has been primarily theorized as being a positive linear relationship, whereby, increasing levels of EO are proposed to positively impact performance levels. However, in more recent publications, there has been a trend towards a non-linear understanding of the relationship between EO and performance. Chen and Hsu (2013), find evidence pointing towards a significant inverted $\mathrm{U}$ relationship between each individual dimension and performance, with both the innovativeness/performance and risk-taking/performance relationships showing the significance (proactiveness was insignificant). However, the authors did not combine their findings into an EO representation and they are based the study on non-profit firms.

Wales, Patel, Parida and Kreiser (2013) do examine a possible non-linear 
relationship between the full EO construct and performance. Based on an analysis of 258 small firms from Sweden, the authors conclude that there exists an inverted U-shaped relationship between EO and performance, with too much EO possibly becoming harmful, particularly in a resource poor environment. Tang, Tang, Marino, Zhang and Li (2008) suggest that within the Chinese context, the positive effects of EO diminishes at high levels. There has also been support for a non-inverted U shaped relationship. Liu, Manolova and Edelman (2009) suggest that the environment can have an impact on the type of relationship that exists between EO and performance. In resource poor environments, the authors found that an inverted U-shaped relationship between EO and performance exists. However, when resource endowment is munificent, the relationship is also curvilinear, but in the opposite direction (U-shaped). The finding of a U-shaped relationship between the individual dimensions of EO and performance are discussed above and based on the limited studies that exist on the curvilinear relationship, the findings are seemingly equivocal. In combination with the individual curvilinear relationships that exist between the individual dimensions of EO (as discussed above), the direction of the summated EO curve is an average of each of these relationships. Therefore, the direction of the EO/performance curve (U or inverted $\mathrm{U}$ ) would be in the same direction as those of the strongest individual predictor relationships.

Assuming equal weightings and relationships between innovativeness, risk-taking and proactiveness and relationships as proposed in earlier hypotheses described above, this would mean a U-shaped relationship between EO and performance that is not as pronounced as the U-shaped relationships between the individual dimensions and 
performance. This is due to innovativeness and proactiveness being in the opposite directions as risk-taking. Even without the assumption of equal weightings, innovativeness and proactiveness have been shown to exhibit the greatest significance in the explanation of performance amongst the EO variables (Tang, Kreiser, Marino, Dickson, Weaver, 2009; Rauch, Wiklund, Lumpkin and Frese, 2009). The significance of innovativeness and proactiveness beyond risk-taking would cause the combined scale to bend in the direction of innovativeness and proactiveness and thus, it is hypothesized:

H5: Firms that report high or low levels of EO will perform better than firms that report moderate levels of EO, reflecting a U-shaped relationship

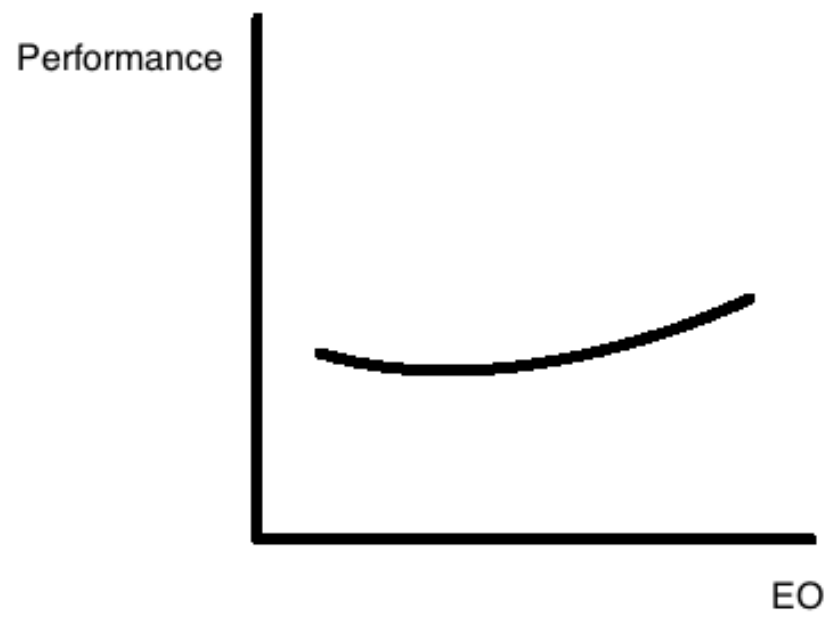

Figure 3.8 - Visualization of Hypothesis 5

\section{Exploration, Exploitation, Ambidexterity and Performance}

Helfat (1997) explains that dynamic capabilities are the competencies or capabilities that allow the firm to create new products, services or processes to meet changing market circumstances. Zahra, Sapienza and Davidsson (2006) add that firms that continuously create, define, discover and exploit entrepreneurial opportunities are 
able to leverage their dynamic capabilities, "in the manner envisioned and deemed appropriate by its principal decision-maker(s)" (p. 918). Next, we will investigate the dynamic capabilities of exploration and exploitation, while proposing that organizational ambidexterity, or the ability to "reconcile internal tensions and conflicting demands in their task environments" (Raisch and Birkinshaw, 2008, p. 375) is significant in the explanation of performance beyond the main effects of exploration and exploitation.

March (1991) proposes that exploitation and exploration represent two different activities, which can be viewed as two ends of a continuum. Exploitation, consists of activities including "refinement, efficiency, selection and implementation" (p. 102), while exploration includes "search, variation, experimentation and discovery" (p. 102). Exploitation and exploration both compete for organizational resources and as such, there may be trade-offs involved in a firm's ability to explore or exploit. In summarizing March's logic, Gupta, Smith and Shalley (2006) note that "notwithstanding the adaptation benefits of both exploration and exploitation, the interplay between the two occurs in the form of a zero-sum game where exploration and exploitation compete for scarce resources, attention, and organizational routines" (p. 695).

Given March's logic that the two are incompatible, it would be reasonable to assume that there may be benefit in the maximization of either exploration or exploitation. However, sacrificing one for the other is not enough to explain a sustained competitive advantage. While a firm that attempts to maximize exploitation may experience some performance gains in the short run, doing so at the expense of exploration may result in an inability respond to changes in the environment (Ahuja and 
Lampert, 2001). On the other hand, a firm that does much exploration, but little exploitation may find themselves in a cycle of search and change that goes unrewarded (Volberda and Lewin, 2003). Critics of this approach argue that exploration and exploitation need to be re-combined to create value (Eisenhardt and Martin 2000), while the mere co-existence of the two capabilities in differing departments though important, is not enough to consider a firm ambidextrous (Gilbert, 2006).

Recent research has begun to acknowledge the importance of balancing the two seemingly contrasting activities, terming organizations that can do both as ambidextrous organizations. Ambidextrous organizations are "able to implement both incremental (i.e., exploitative) and revolutionary (i.e., exploratory) changes” (Tushman and O'Reilly, 1996, p.8), are "capable of operating simultaneously to explore and exploit" (Smith and Tushman,2005, p. 524) and are "capable of exploiting existing competencies as well as exploring new opportunities with equal dexterity" (Lubatkin, Simsek, Ling and Veiga,2006, p.2). Gupta, Smith and Shalley (2006) note that exploration and exploitation may occur in a complementary, rather than competing manner with regards to the resources required, with Cao, Gedajlovic and Zhang (2009) arguing that the two processes can be supportive of each other and assist in leveraging the effects of each other.

Cao, Gedajlovic and Zhang (2009) give reasons for some of the positive effects of exploitation and exploration, suggesting that exploitative efforts can lead to improvements in firm exploration performance, particularly in the development of resources and knowledge that support new products and markets. They argue that a firm's 
position and functionality can be better understood by management through the repeated use of existing knowledge and resources. The result is that firms "become more capable of initiating various reconfigurations of existing knowledge and resources already under its control, capabilities associated with novel discoveries in products and markets" (p. 784). For instance, Intel's existing knowledge and competencies in the memory chip industry, enabled managers to recognize and capitalize on emerging markets and trends (Burgelman, 1994). Additionally, Cao, Gedajlovic and Zhang (2009) suggest that high levels of exploitative capabilities can better enable a firm to "recognize and assimilate new external knowledge and resources" (p. 784). Zahra and George (2002) suggest that prominent exploitation capabilities are positively related to the development of new products and technologies.

Exploration can also have positive effects on exploitation. Cao, Gedajlovic and Zhang (2009) cite the example of Apple Computer's iPod line as revitalizing the entire brand, showing how successful exploration can complement exploitation. The authors also suggest that "successful exploration can also improve the economics of existing exploitative endeavors" (p. 784) and give the example of United Parcel Service (UPS). They note that UPS engaged in exploratory action in the development of new business units that afforded customers novel logistics and supply chain services, but also had the effect of increasing the economies of scale, positively affecting its traditional exploitative activities. He and Wong (2004) find support that a firm's ambidexterity is positively related to sales growth, finding that an imbalance between exploration and exploitation was negatively related to sales growth. In a test of the significance of the combined 
dimension of exploration and exploitation (ambidexterity), Cao, Gedajlovic and Zhang (2009) find significance of the dimension unto performance beyond that of their main effects only. Thus, it is hypothesized:

H6: Firm ambidexterity (the interaction of exploration and exploitation capabilities) is positively and significantly related to firm performance

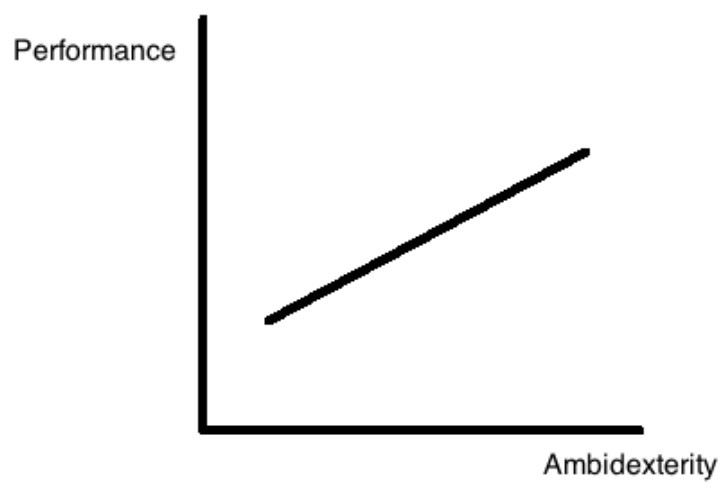

Figure 3.9 - Visualization of Hypothesis 6

\section{Ambidexterity as a moderator of Innovation, Risk-taking, Proactiveness and EO}

Having considered the individual relationships that are hypothesized to exist between EO and its dimensions to performance, as well as the relationship between ambidexterity and performance, the relationship between the EO, its dimensions, ambidexterity and performance will now be discussed. Specifically, we propose that a firm's ambidexterity moderates the relationship between EO and its dimensions and performance. Wales, Gupta and Mousa (2011) note that although some consideration has been given to external variables that moderate the EO/Performance relationship, few studies have examined the moderating role of the factors that reside within the organization. This is despite observations from Covin, Green and Slevin (2006), who 
suggest that in order to benefit from EO, organizations must adequately manage their entrepreneurial decisions.

EO may be a necessary but insufficient condition for performance advantages (Stam and Elfring, 2008) while in the absence of a suitable context, high levels of EO can create a drain on resources (Covin and Slevin, 1991). Wales, Gupta and Mousa (2011) suggest that arguments and findings from the field that conclude that EO may not be universal in its applicability, should lead to research based on the contingent factors of EO. In this vein, we propose that a firm's ambidexterity capability positively moderates the relationship between EO and its dimensions and performance, such that at high levels of ambidexterity, the relationship between $\mathrm{EO}$ and its dimensions to performance is enhanced, while at low levels of ambidexterity the relationship is reduced. Ambidexterity then allows for enactment of the innovativeness, risk-taking proclivity and proactiveness of a firm into suitable and effective strategic actions.

Covin and Slevin (1991) note that the resources and capabilities that are possessed by a firm represent boundary conditions with regards to the impact of innovative, risktaking and proactive strategic actions. The availability of these resources and capabilities affect the firm's ability to develop, execute and enjoy the rewards of entrepreneurial behavior. Smaller firms however, are likely to be limited in the amount of tangible and unencumbered resources at their disposal (Thornhill and Amit, 2003), thereby increasing the salience of intangible resources as a basis for competitive advantage (Newbert, 2007).

Anderson and Eshima (2013), suggest "the possession or constraint of intangible resources represents an important factor in the ability of SMEs to pursue strategies that 
result in positive organizational outcomes" (p. 418). They reason that for high levels of EO to translate into performance, high demands are put on the existing resource base or necessitate the search for additional resources. At lower levels of resources "the fewer the number of entrepreneurial initiatives able to be pursued; as resource levels increase, so too does the quantity and variability of opportunities able to be exploited" (Anderson and Eshima, 2013, p. 418). The 'resources' outlined by Anderson and Eshima refer both to tangible and intangible resources or capabilities. A firm with the capacity to be ambidextrous is likely to enjoy the resource benefits of quantity and variability of opportunities (exploration), while also acting in a manner that allows for the exploitation of these opportunities.

Sanchez, Heene and Thomas (1996) suggest that successful firms have the capacity to manage a mix of competence-leveraging and competence-building activities. Whereas competence leveraging works to apply existing competences, competencebuilding allows for the development of new capabilities. This competence-leveraging and competence-building is reflective of the moderation effect of ambidexterity on EO and its dimensions. The EO dimensions; innovativeness, risk-taking and proactiveness are akin to competence building, whereby it is proposed that the EO dimensions of a firm, form the foundation of competencies, whereas ambidexterity allows for the leveraging of these competencies. Just as a recipe is more than a list of ingredients, successful management is about the organization process or making it happen.

Consider the example of two firms who report similar scores on levels of innovativeness, risk-taking and proactiveness. Conventional EO analysis would suggest 
that the two firms would benefit equally from their orientation. If however, one of the two firms reported a high level of ambidexterity, while the other low ambidexterity, it seems reasonable to suggest that despite similar scores on the EO dimensions, differences in the levels of ambidexterity between the two could be a source of performance differences. For example, assume there are high levels of innovativeness in both firms. The firm with low ambidexterity may indeed be innovative, but is likely unable to have the ability to effectively commercialize their ideas. The same level of innovativeness in a highly ambidextrous firm can instead become a source of advantage, as the firm is likely to be able to adequately turn innovation into commercial products and services, and reap the rewards of doing so.

In a similar vein, two firms that report low levels of risk-taking would not appear to have an advantage with regards to each other. If however, there was a dichotomy in their reported ambidexterity, the firm with higher ambidexterity is likely to have a performance advantage. For example, assume both firms report low levels of risk-taking, while one reports high ambidexterity and the other low ambidexterity. The firm that reports low risk-taking and low ambidexterity is both unlikely to capitalize on its existing production and unlikely to identify and explore new products and markets. A low risktaking, but ambidextrous firm may also be unlikely to identify and explore new markets, but is more likely to seek to improve the efficiency of current operations, for instance, seeking low risk measures that can increase economies of scale or streamline production. Proactiveness too can be moderated by the ambidexterity of a firm. Differences in ambidexterity between similarly proactive firms can ensure that the time spent 
proactively seeking new opportunities or in the strategic elimination of declining operations, is more likely to result in products and services that will capture an adequate share of the market, or that the resources freed up during the elimination of some operations can be put to better use elsewhere. Thus it is hypothesized:

H7: Firm ambidexterity positively moderates the relationship between innovativeness and performance at all levels of innovativeness

H8: Firm ambidexterity positively moderates the relationship between risk-taking and performance at all levels of risk-taking

H9: Firm ambidexterity positively moderates the relationship between proactiveness and performance at all levels of proactiveness

H10: Firm ambidexterity positively moderates the relationship between EO and performance at all levels of $E O$

Figure 3.10 - Visualization of Hypothesis 7, 8, 9 and 10

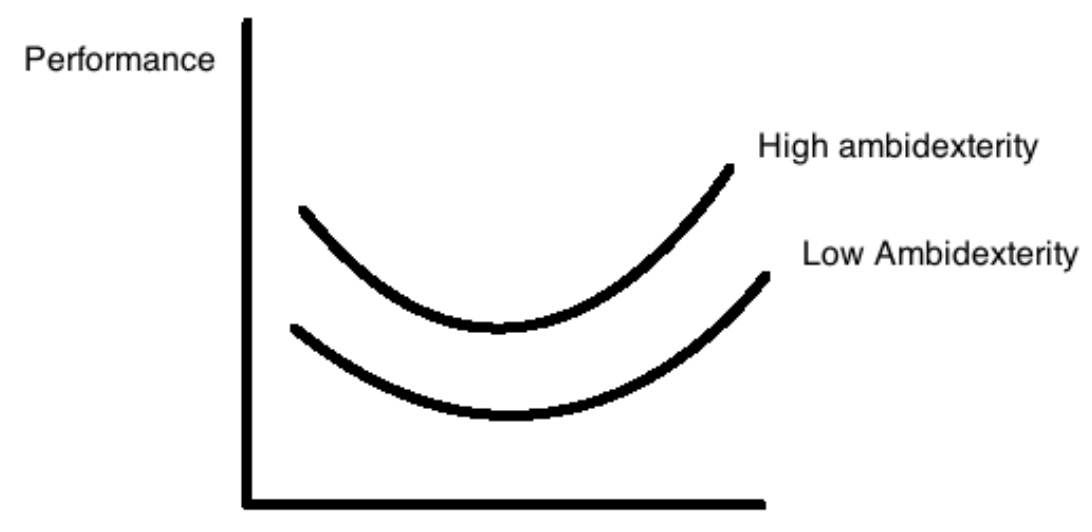

Innovativeness

H7 


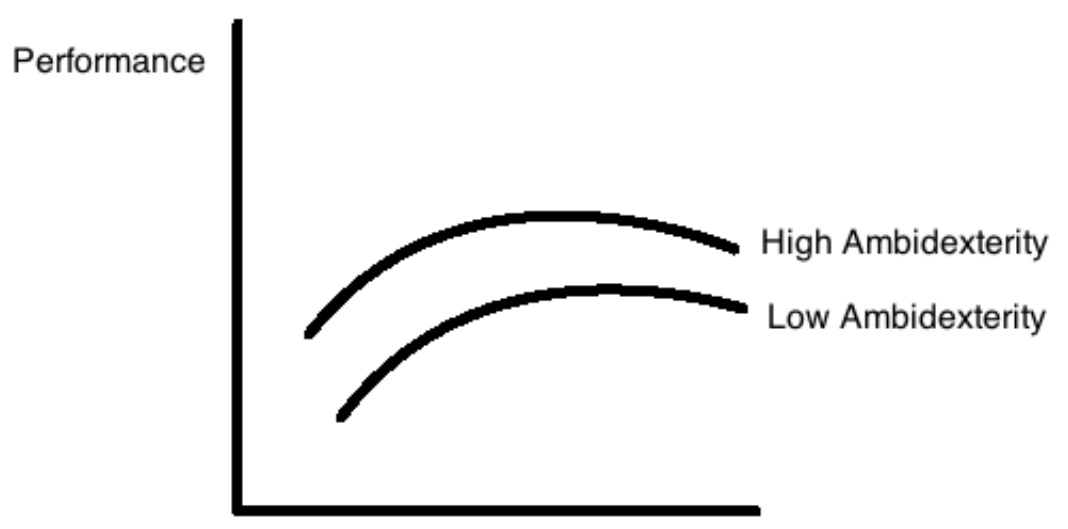

Risk Taking

H8

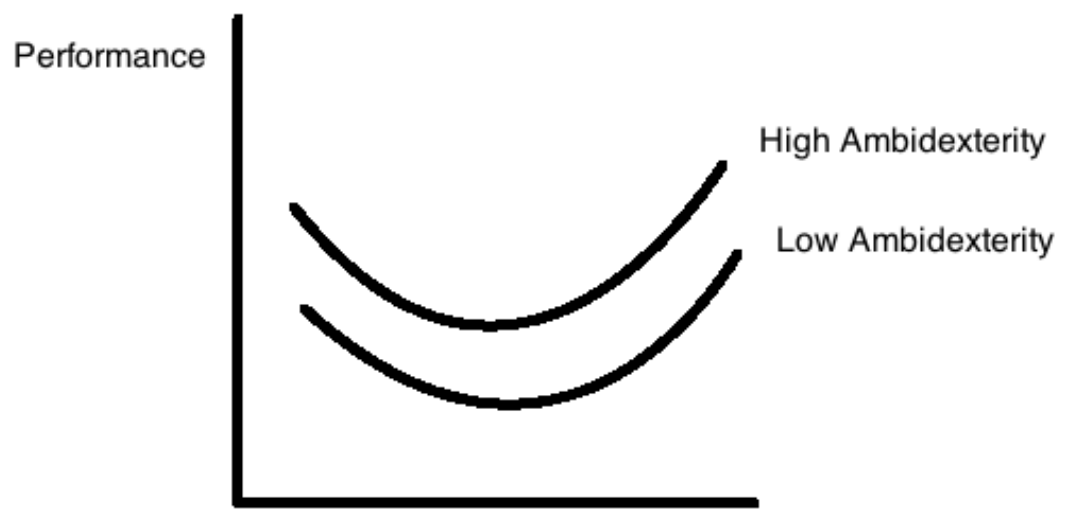

Proactiveness

H9

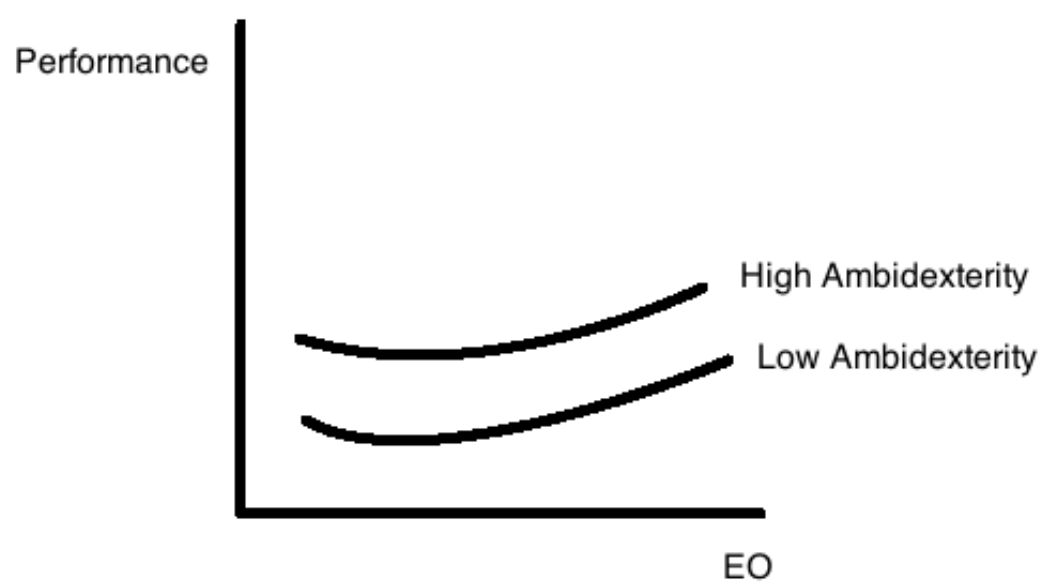

H10

This chapter has laid out the guiding research questions and hypotheses that will 
be investigated in the following chapters. In brief, this study is centered around three related, but distinct research questions. The first is an assessment of the unidimensional versus the multidimensional operationalization of the EO construct, and an analysis of their relative explanatory power of variance in performance. The second research question considers the individual relationships between the dimensions of EO (innovativeness, proactiveness and risk-taking) and performance. Here, evidence of nonlinear relationships between these dimensions and performance will be sought, while also considering the unique direction of each dimension in search of any evidence that the three dimensions may differ in their relationship to performance relative to the other dimensions. Finally, the dynamic capabilities of exploration, exploitation and ambidexterity are considered as moderators in the relationship between EO and its dimensions to performance. Ambidexterity is proposed as a firm capability that allows for the enactment of innovativeness, proactiveness and risk-taking, essentially amplifying or negating the positive effects of the EO dimensions on performance. To investigate the research questions, 10 hypotheses have been developed and discussed above. Below is a summary listing of the hypotheses:

Table 3.1 - Summary of Hypotheses

\begin{tabular}{|l|l|}
\hline \multicolumn{1}{|c|}{ Hypothesis } & \multicolumn{1}{c|}{ Research } \\
\hline $\begin{array}{l}\text { H1a: Both a reflective, unidimensional EO scale and a } \\
\text { formative, } \text { multi-dimensional EO scale are positively } \\
\text { and significantly related to performance }\end{array}$ & RQ1 \\
\hline $\begin{array}{l}\text { H1b: } \text { A formative, multidimensional EO scale explains } \\
\text { significantly more variance in performance than a }\end{array}$ & RQ1 \\
\hline
\end{tabular}




\begin{tabular}{|c|c|}
\hline reflective, unidimensional EO scale & \\
\hline $\begin{array}{l}\text { H2: Firms that report high or low levels of } \\
\text { innovativeness will perform better than firms that report } \\
\text { moderate levels of innovativeness, reflecting a } U \text { - } \\
\text { shaped relationship }\end{array}$ & RQ2 \\
\hline $\begin{array}{l}\text { H3: Firms that report a moderate level of risk-taking } \\
\text { will perform better than firms that report a high or low } \\
\text { level of risk-taking, reflecting an inverted U-shaped } \\
\text { relationship }\end{array}$ & RQ2 \\
\hline $\begin{array}{l}\text { H4: Firms that report high or low levels of } \\
\text { proactiveness will perform better than firms that report } \\
\text { moderate levels of innovativeness, reflecting a } U \text { - } \\
\text { shaped relationship }\end{array}$ & $\overline{\mathrm{RQ} 2}$ \\
\hline $\begin{array}{l}\text { H5: Firms that report high or low levels of EO will } \\
\text { perform better than firms that report moderate levels of } \\
\text { EO, reflecting a U-shaped relationship }\end{array}$ & $\overline{\mathrm{RQ} 2}$ \\
\hline $\begin{array}{l}\text { H6: Firm ambidexterity (the interaction of exploration } \\
\text { and exploitation capabilities) is positively and } \\
\text { significantly related to firm performance }\end{array}$ & $\overline{\mathrm{RQ3}}$ \\
\hline $\begin{array}{l}\text { H7: Firm ambidexterity positively moderates the } \\
\text { relationship between innovativeness and performance } \\
\text { at all levels of innovativeness }\end{array}$ & RQ3 \\
\hline $\begin{array}{l}\text { H8: Firm ambidexterity positively moderates the } \\
\text { relationship between risk-taking and performance at all } \\
\text { levels of risk-taking }\end{array}$ & RQ3 \\
\hline $\begin{array}{l}\text { H9: Firm ambidexterity positively moderates the } \\
\text { relationship between proactiveness and performance at } \\
\text { all levels of proactiveness }\end{array}$ & RQ3 \\
\hline $\begin{array}{l}\text { H10: Firm ambidexterity positively moderates the } \\
\text { relationship between } E O \text { and performance at all levels } \\
\text { of EO }\end{array}$ & $\overline{\mathrm{RQ} 3}$ \\
\hline
\end{tabular}




\section{Chapter 4}

\section{Research Methodology}

This chapter outlines the methodology used to test the hypotheses that were described in the previous chapter. First, an overview of the mixed method approach will be presented detailing the various steps that will be taken during the explanatory sequential research design. Following is the discussion of the quantitative component of the research, which forms the largest part of this chapter. Within the quantitative section, measures of EO (innovativeness, risk-taking and proactiveness), ambidexterity (exploration and exploitation) and performance found in the literature are outlined as well as the presentation of the questionnaire. Next, the control variables that were used are discussed as well as the research population and the selection of a sample. Then, the methodological process with regards to the data analysis is detailed for each hypothesis found in the previous chapter. Finally, the qualitative research component is outlined along with the presentation of the structured interview format and method of participant selection.

\section{Mixed Method Approach}

This study employs a mixed methods approach, consisting of both quantitative and qualitative strands. Creswell and Clark (2011) suggest that a mixed methods approach "occurs when a direct interaction exists between the quantitative and qualitative strands of the study" (p. 65), noting that the interaction can occur at different stages in the 
research process, in several ways. Specifically, for this study, an explanatory sequential research design was used.

Creswell and Clark (2011) suggest that the explanatory sequential design occurs in two phases. In the first phase, the collection and analysis of quantitative data is prioritized given its applicability to answering the study's questions. The second phase, the collection of qualitative data is designed in such a way that it assists in the interpretation of quantitative analysis preformed in the previous stage. As such, the collection and analysis of the qualitative data, helps to explain relationships between variables of interest discovered in the quantitative research. This process is illustrated in Figure 4.1 below.

Figure 4.1: Explanatory Sequential Design

Source: Creswell and Clark (2011, p. 69)

The explanatory sequential design

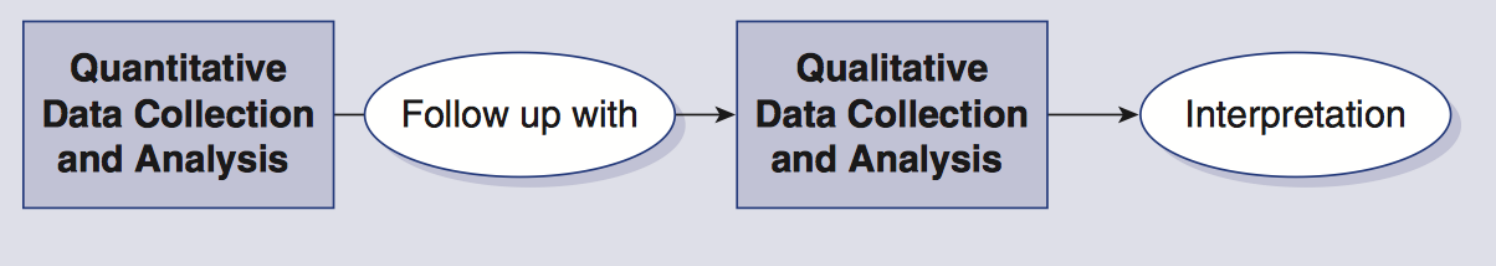

\section{Quantitative Research Overview}

For this study we have primarily utilized a deductive approach, which is based on what is known in a domain of interest, by formulating hypotheses that are then subject to empirical consideration. This process is shown in Figure 4.2 below. Though at times there is limited overlap, similar to the deduction process suggested by Bryman (2004), we have previously presented both existing theory (Chapter 2) and developed the hypotheses 
(Chapter 3). Chapter 4 considers the methodological issues and outlines the data collection and analysis techniques that were employed in the study. Finally chapter 5 onwards will consider the findings from the collection of data, review its consistency with regards to the previous hypotheses and if necessary, revise the theory to better align it with the findings (which also introduces an element of induction).

\section{Figure 4.2: The Process of Deduction}

Source: Bryman, 2004

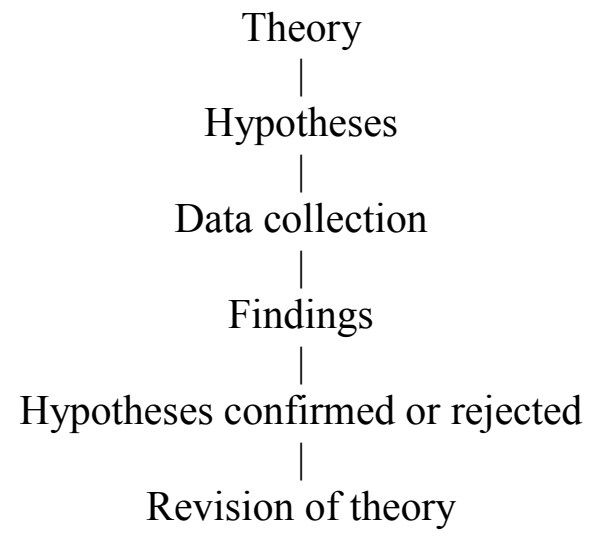

Further, this research was primarily conducted by employing a quantitative research strategy. As defined by Bryman (2004) a quantitative research strategy as "entailing the collection of numerical data and as exhibiting a view of the relationship between theory and research as a deductive, a predilection for a natural science approach (and of positivism in particular), and as having an objectivist conception of social reality" (p. 62). In order to collect the quantitative data, a survey questionnaire was administered to the entrepreneurs of micro firms located in Trinidad. Bryman (2004) outlines the process of quantitative research as shown in Figure 4.3 below: 
Figure 4.3: The Process of quantitative research

Source: Bryman, 2004

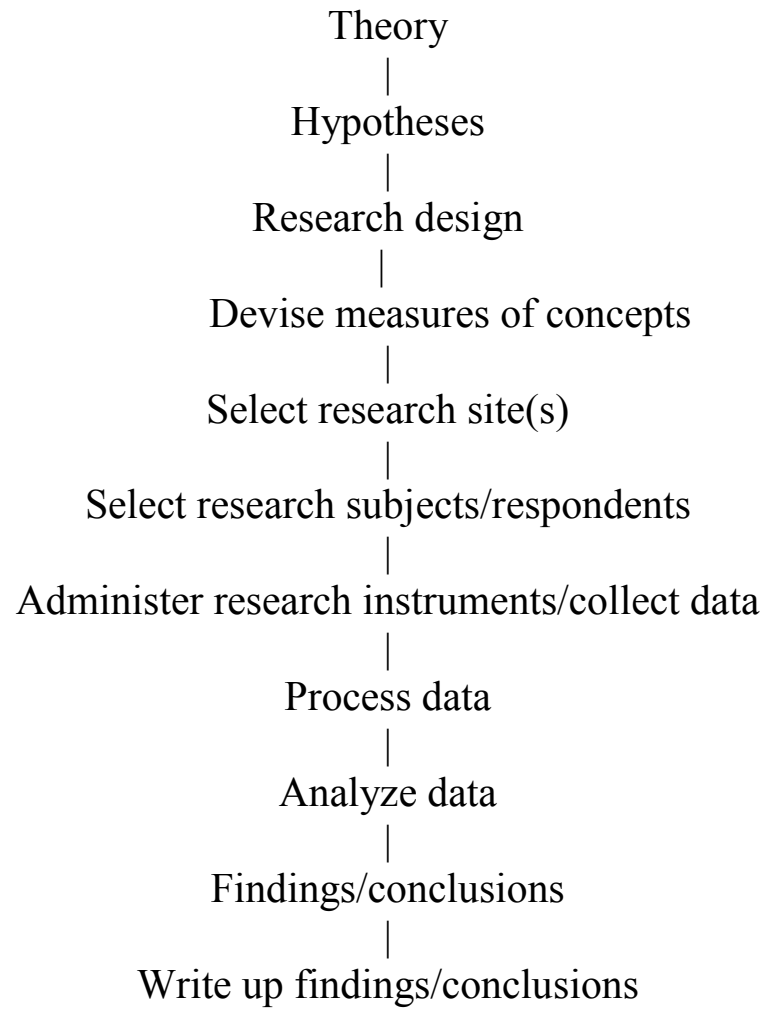

\section{Construct Measurement}

Previously, theories relating to EO, ambidexterity and performance were developed into hypotheses. In order to accept or reject the previously proposed hypotheses, it is necessary to operationalize the constructs so that they can be measured and tested. The following will consider the various dimensions and scale items that make up the EO, ambidexterity and performance constructs as well as the control variables.

\section{Measures of EO - Innovativeness, Proactiveness and Risk-taking}

The item measures that form the foundation of work on the EO of a firm were first introduced by Covin and Slevin (1989) based upon the original work by Miller (1983). 
In their review of the EO literature, Rauch, Wiklund, Lumpkin and Frese, (2009) note that three dimensions have been identified and consistently employed in the literature; innovativeness, proactiveness and risk-taking, while others suggest the use of these three dimensions comprise $80 \%$ of all the EO articles published (Walkes, Gupta and Moussa, 2013). These dimensions also tend to show inter-correlations that range from $\mathrm{r}=.39$ to $\mathrm{r}=$ .75 , which may have been a catalyst for the combining of the dimensions into one single factor as with the unidimensional construct (Rauch, Wiklund, Lumpkin and Frese, 2009).

Although previous EO scholars have found a relationship between the EO construct and performance, these findings have been primarily based on the study of North American firms (Arbaugh, Cox and Camp, 2009). To test the scales applicability to firms outside of North America, Arbaugh, Cox and Camp (2009) utilized Covin and Slevin's original 9 item EO scale, with three items each for innovativeness, proactiveness and risk-taking, and administered the survey to firms in 17 countries, 13 of which had not been previously included in EO research. They conclude that the EO construct, appears to be globally generalizable, and suggest that EO has great potential for explaining firm behavior in developing countries. Finally, they call for additional research into EO, particularly in countries where no EO research has been conducted before, a criterion that Trinidad meets.

Tang, Tang, Marino, Zhang and Li (2008) suggest that in some contexts, the modification of the EO concept and its operationalization is justified. While allowing for the generalizability of this research by staying true to the number, types and theme of items that make up the original scale, minor modifications were made to the wording of 
some questions relative to the original Covin and Slevin (1989) scale. Specifically, corrections were made for the use of British English in Trinidad, while questions that were worded "the top managers of my company" were changed to "my business" to better reflect likely contextual situation in a micro firm with fewer than five employees. This change also assists in bridging the level of analysis issues that have been noted to exist with the EO item measures. By asking respondents to only consider 'my business' rather than interchangeably consider 'top managers' or 'my firm' an element of consistency is introduced to the item measures. Further, by using 'my business', it is assumed that respondents are likely to consider both their personal impact, as well as that of the other resource elements that impact the orientation of the firm.

The original item measures for innovativeness, proactiveness and risk-taking are shown below, in addition to the modified item measures, which are believed to be more applicable to the sample. The full questionnaire is available in Exhibit 1.

Table 4.1: Existing/Proposed Innovativeness Item Measures Source: Covin and Slevin (1989)

\begin{tabular}{|c|c|}
\hline Existing Item Measure & Proposed Item Measure \\
\hline $\begin{array}{l}\text { 1. In general, the top managers of my } \\
\text { company favor: } \\
\text { (1)...a strong emphasis on the } \\
\text { marketing of tried and true } \\
\text { products or service } \\
\text { (7)... a strong emphasis on R\&D } \\
\text { technology leadership and } \\
\text { innovations }\end{array}$ & $\begin{array}{l}\text { 1: In general, my business favours: } \\
\text { (1)... a strong emphasis on the } \\
\text { marketing of tried and true products } \\
\text { and services } \\
\text { (7)... a strong emphasis on the } \\
\text { marketing of innovative products } \\
\text { and services }\end{array}$ \\
\hline $\begin{array}{l}\text { 2. How many lines of products or services } \\
\text { has your company marketed during the } \\
\text { past } 5 \text { years? } \\
\text { (1) No new lines of products or } \\
\text { services }\end{array}$ & $\begin{array}{l}\text { 2. How many new types of products or } \\
\text { services has your business marketed during } \\
\text { the past } 3 \text { years? } \\
\text { (1) No new types of products or } \\
\text { services }\end{array}$ \\
\hline
\end{tabular}




\begin{tabular}{|c|c|}
\hline $\begin{array}{l}\text { (7) Very many new lines of } \\
\text { products or services }\end{array}$ & $\begin{array}{l}\text { (7) Very many new types of } \\
\text { products or services }\end{array}$ \\
\hline $\begin{array}{l}\text { 3. Changes in product or service lines } \\
\text { have: } \\
\text { (1)...been mostly of a minor nature } \\
\text { (7)...usually been quite dramatic }\end{array}$ & $\begin{array}{l}\text { 3. Changes in the types of product or service } \\
\text { my business provides has: } \\
\text { (1)...been mostly of a minor nature } \\
\text { (7)...usually been quite dramatic }\end{array}$ \\
\hline
\end{tabular}

Table 4.2: Existing/Proposed Proactiveness Item Measures Source: Covin and Slevin (1989)

\begin{tabular}{|c|c|}
\hline Existing Item Measure & Proposed Item Measure \\
\hline $\begin{array}{l}\text { 1. In dealing with my competitors, my } \\
\text { firm: } \\
\text { (1)...typically responds to actions } \\
\text { which competitors initiate } \\
\text { (7)...typically initiates actions } \\
\text { which competitors then respond to }\end{array}$ & $\begin{array}{l}\text { 1. In dealing with my competitors, my } \\
\text { business: } \\
\text { (1)...typically responds to actions } \\
\text { which competitors initiate } \\
\text { (7)...typically initiates actions } \\
\text { which competitors then respond to }\end{array}$ \\
\hline $\begin{array}{l}\text { 2. In dealing with my competitors, my } \\
\text { firm: } \\
\text { (1) Is very seldom the first } \\
\text { business to introduce new } \\
\text { products/services, administrative } \\
\text { techniques, operating technologies, } \\
\text { etc. } \\
\text { (7) Is very often the first business } \\
\text { to introduce new products/services, } \\
\text { administrative techniques, } \\
\text { operating technologies, etc. }\end{array}$ & $\begin{array}{l}\text { 2. In dealing with my competitors, my } \\
\text { business: } \\
\text { (1) Is very seldom the first business } \\
\text { to introduce new products, services } \\
\text { and ways of doing business } \\
\text { (7) Is very often the first business to } \\
\text { introduce new products, services and } \\
\text { ways of doing business }\end{array}$ \\
\hline $\begin{array}{l}\text { 3. In dealing with my competitors, my } \\
\text { firm: } \\
\text { (1) Typically seeks to avoid } \\
\text { competitive clashes, preferring a } \\
\text { 'live-and-let-live' posture } \\
\text { (7) Typically adopts a very } \\
\text { competitive, 'undo-the } \\
\text { competitors' posture }\end{array}$ & $\begin{array}{l}\text { 3. In dealing with my competitors, my } \\
\text { business: } \\
\text { (1) Typically seeks to avoid } \\
\text { competitive clashes, preferring a } \\
\text { 'live-and-let-live' approach } \\
\text { (7) Typically adopts a very } \\
\text { competitive, 'undo-the competitors' } \\
\text { approach }\end{array}$ \\
\hline
\end{tabular}

Table 4.3 : Existing/Proposed Risk-taking Item Measures Source: Covin and Slevin (1989) 


\begin{tabular}{|c|c|}
\hline $\begin{array}{c}\text { (Covin and Slevin, 1989, George } \\
\text { and Marino, 2011) } \\
\end{array}$ & \\
\hline $\begin{array}{l}\text { 1. In general, the top managers of my firm } \\
\text { have: } \\
\begin{array}{l}\text { (1)...A strong proclivity for low- } \\
\text { risk projects (with normal and } \\
\text { certain rates of return) } \\
\text { (7)...A strong proclivity for high- } \\
\text { risk projects (with chances of very } \\
\text { high return) }\end{array}\end{array}$ & $\begin{array}{l}\text { 1. In general, my business has: } \\
\text { (1)...A strong tendency for low-risk } \\
\text { projects (with normal and certain } \\
\text { rates of return) } \\
\text { (7)...A strong tendency for high-risk } \\
\text { projects (with chances of very high } \\
\text { return) }\end{array}$ \\
\hline $\begin{array}{l}\text { 2. In general, the top managers of my firm } \\
\text { believe that: } \\
\text { (1) Owning to the nature of the } \\
\text { environment, it is best to explore it } \\
\text { gradually via, timid incremental } \\
\text { behavior } \\
\text { (7) Owning to the nature of the } \\
\text { environment, bold, wide-ranging } \\
\text { acts are necessary to achieve the } \\
\text { firm's objectives }\end{array}$ & $\begin{array}{l}\text { 2. In general, my business believes that: } \\
\text { (1) Because of the nature of the } \\
\text { business environment, it is best not } \\
\text { to take any risks } \\
\text { (7) Because of the nature of the } \\
\text { business environment, taking risks is } \\
\text { essential }\end{array}$ \\
\hline $\begin{array}{l}\text { 3. When confronted with decision-making } \\
\text { situations involving uncertainty, my firm: } \\
\text { (1) Typically adopts a cautious, } \\
\text { 'wait-and-see' posture in order to } \\
\text { minimize the probability of making } \\
\text { costly decisions } \\
\text { (7) Typically adopts a bold, } \\
\text { aggressive posture in order to } \\
\text { maximize the probability of } \\
\text { exploiting potential opportunities. }\end{array}$ & $\begin{array}{l}\text { 3. When confronted with decision-making } \\
\text { situations involving uncertainty, my } \\
\text { business: } \\
\text { (1) Typically adopts a cautious, } \\
\text { 'wait-and-see' approach in order to } \\
\text { minimize the chances of making } \\
\text { costly decisions } \\
\text { (7) Typically adopts a bold, } \\
\text { aggressive approach in order to } \\
\text { maximize the chances of exploiting } \\
\text { potential opportunities. }\end{array}$ \\
\hline
\end{tabular}

As can be seen from the existing and proposed EO construct items, all items are anchored on a seven-point scale, from 1 to 7 . In order to calculate the level of each dimension, the responses were added together, and divided by the number of questions in order to ascertain the average. For instance, in the event that a firm responded to the innovativeness questions with a 6,5 and 7 respectively for the three innovation questions, the firm's innovation EO dimension would be 6/7. Assuming the same firm reported 
proactiveness and risk-taking dimensions of 4 and 5 respectively, the EO would then be able to be calculated. As is common with the unidimensional scale, simply finding an average of the three dimensions $((6+4+5) / 3)$ means that the EO of this sample firm would be 5. This EO level would then be used in the analysis of EO and performance or other dependent variables. Thus, the above scales give us the measurement tool for innovativeness, proactiveness and risk-taking and from this data the EO is also calculated.

\section{Measures of Ambidexterity - Exploration and Exploitation}

As has been noted in Chapter 2, unlike the EO scale, which has enjoyed relative consistency in its item measures, the measurement of exploration and exploitation has been less consistent. From those articles that presented their item measures, the number

of item measures used for exploration and exploitation has been quite varied. Yalcinkaya, Calantone and Griffith (2007) used 4 items (2 each for exploration and exploitation), while Jansen, Bosch and Volberda's (2006) measure included 7 items each for exploration and exploitation. In the interest of parsimony and consistency, we chose to utilize three item measures (the same as the EO dimensions) for exploration and exploitation and operationalize the items at the firm level. Ambidexterity research has been carried out at the firm, business unit, sub-organizational unit and individual level, with Raisch and Birkinshaw (2008) suggesting that all are equally valid, though researchers need to be explicit about the level they are working with. 
Exploration and exploitation are conducted at the firm level and draw from the item measures reported by Mom, Van Den Bosch and Volberda (2007), and Abebe and Angriawan (2014). Mom, Van Den Bosch and Volberda (2007) propose five item measures for exploration and six item measures for exploration, that are shown in tables 4.4 and 4.5. For the exploration items, the authors report factor loadings between .65 and .84 and .62 to .82 for the exploitation items, with all items being measured on a sevenpoint scale from $1=$ to a small extent to $7=$ to a very large extent. It is of note that Mom, Van Den Bosch and Volberda (2007) position the questions as "to what extent did you...” (p. 919) suggesting that firm-level exploration or exploitation may largely originate from individual managers' activities. They find that some managers simultaneously engage in high levels of exploitation and exploration and serve as important sources of firm ambidexterity.

Abebe and Angriawan (2014) state that consistent with past research, they use the Mom, Van Den Bosch and Volberda (2007) scale as the basis for the development of a modified scale that has three item measures for exploration and two for exploitation (shown in table 4.4 and 4.5$)$. They report high loadings for each item measure $(.935, .952$ and .668 for exploration and .822 and .853 for exploitation) based on their factor analysis and a Cronbach's alpha of .847 and .635 for exploration and exploitation respectively, demonstrating the ability to modify the Mom, Van Den Bosch and Volberda (2007) scale, to the extent that the authors positioned the scale at a firm level and used less item measures. 
Table 4.4: Existing/Proposed Exploration Item Measures Source: Mom, Van Den Bosch and Volberda (2007), Abebe and Angriawan (2014)

\begin{tabular}{|c|c|}
\hline $\begin{array}{l}\text { Existing Item Measure } \\
\text { Mom, Van Den Bosch and } \\
\text { Volberda (2007), }\end{array}$ & Proposed Item Measure \\
\hline $\begin{array}{l}\text { To what extent did you, last year, engage } \\
\text { in work related activities that can be } \\
\text { characterized as the following: } \\
\text { (1) Searching for new possibilities with } \\
\text { respect to products/services, processes } \\
\text { or markets: } \\
\text { (1) To a very small extent } \\
\text { (7) To a very large extent } \\
\text { (2) Evaluating diverse options with respect } \\
\text { to products/services, processes or } \\
\text { markets: } \\
\text { (1) To a very small extent } \\
\text { (7) To a very large extent } \\
\text { (3) Focusing on strong renewal of } \\
\text { products/services or processes: } \\
\text { (1) To a very small extent } \\
\text { (7) To a very large extent } \\
\text { adaptability of you: } \\
\text { (1) To a very small extent } \\
\text { (7) To a very large extent } \\
\text { (5) Activities requiring you to learn } \\
\text { (1) To a very small extent } \\
\text { (7) To a very large extent }\end{array}$ & 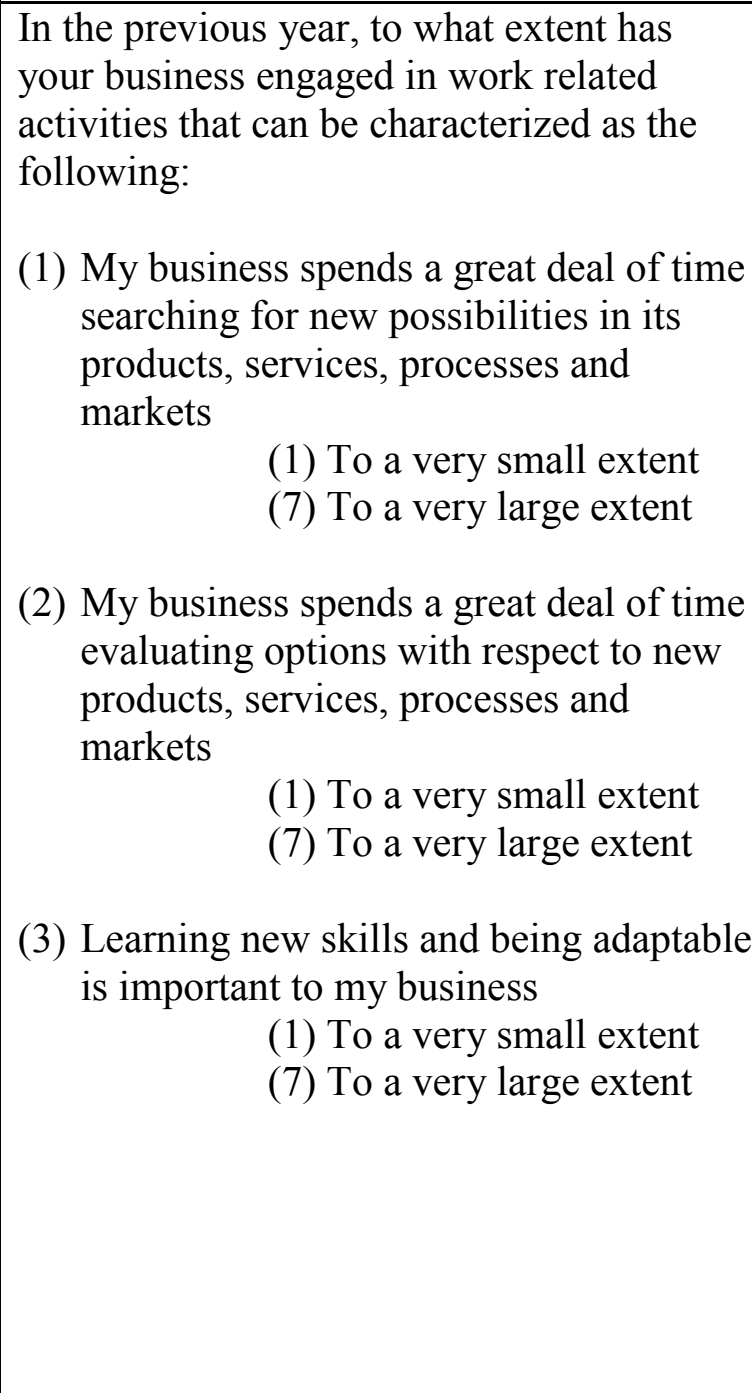 \\
\hline $\begin{array}{l}\text { Existing Item Measure } \\
\text { Abebe and Angriawan (2014) }\end{array}$ & \\
\hline $\begin{array}{l}\text { (1) "we spend a great deal of time } \\
\text { searching for new possibilities in our } \\
\text { product/services and processes" } \\
\text { (2) "we spend a great deal of time } \\
\text { evaluating diverse options for our } \\
\text { products/services, and processes" }\end{array}$ & \\
\hline
\end{tabular}


(3) "our company has a strong emphasis on learning new skills and techniques in the business"

Table 4.5: Existing/Proposed Exploitation Item Measures

Source: Mom, Van Den Bosch and Volberda (2007), Abebe and Angriawan (2014)

\begin{tabular}{|c|c|}
\hline $\begin{array}{c}\text { Existing Item Measure } \\
\text { Mom, Van Den Bosch and Volberda } \\
(2007),\end{array}$ & Proposed Item Measure \\
\hline $\begin{array}{l}\text { To what extent did you, last year, engage in } \\
\text { work related activities that can be } \\
\text { characterized as the following: } \\
\text { (1) Activities of which a lot of experience } \\
\text { has been accumulated by yourself: } \\
\text { (1) To a very small extent } \\
\text { (7) To a very large extent } \\
\text { (2) Activities which serve existing (internal) } \\
\text { customers with existing } \\
\text { services/products: } \\
\text { (1) To a very small extent } \\
\text { (7) To a very large extent } \\
\text { (3) Activities of which it is clear to you how } \\
\text { to conduct them: } \\
\text { (1) To a very small extent } \\
\text { (7) To a very large extent } \\
\text { (4) Activities primarily focused on achieving } \\
\text { short-term goals: } \\
\text { (1) To a very small extent } \\
\text { (7) To a very large extent } \\
\text { (5) Activities which you can properly } \\
\text { conduct by using your present knowledge: } \\
\text { (1) To a very small extent } \\
\text { (7) To a very large extent } \\
\text { (6) Activities which clearly fit into existing } \\
\text { company policy: } \\
\text { (1) To a very small extent }\end{array}$ & $\begin{array}{l}\text { In the previous year, to what extent has } \\
\text { your business engaged in work related } \\
\text { activities that can be characterized as the } \\
\text { following: } \\
\text { (1) My business strongly emphasizes our } \\
\text { existing products, services, processes } \\
\text { and customers: } \\
\text { (1) To a very small extent } \\
\text { (7) To a very large extent } \\
\text { (2) Operating my business involves the } \\
\text { using the knowledge I already have: } \\
\text { (1) To a very small extent } \\
\text { (7) To a very large extent } \\
\text { (3) Reducing expenses and improving } \\
\text { efficiency are important } \\
\text { preoccupations to my business: } \\
\text { (1) To a very small extent } \\
\text { (7) To a very large extent }\end{array}$ \\
\hline
\end{tabular}




\begin{tabular}{|c|c|}
\hline (7) To a very large extent & \\
\hline Existing Item Measure & \\
Abebe and Angriawan (2014) & \\
\hline (1) "we strongly emphasize our existing & \\
products/services and operational & \\
processes" & \\
(2) "reducing operational expenses and & improving efficiency are important \\
preoccupations" & \\
\hline
\end{tabular}

Once the data is collected on a firm's exploration and exploitation activity, it is important to consider the operationalization of the ambidexterity construct. Cao, Gedajlovic and Zhang (2009) suggest a lack of consensus on the underlying construct has led to numerous measures attempting to operationalize ambidexterity. Through their review of the literature the authors suggest that ambidexterity is actually comprised of two related, but distinct measures that they term "balance dimension of ambidexterity" (BD) and "combined dimension of ambidexterity" (CD). In the first instance, the balance dimension of ambidexterity is a measure of the difference between exploration and exploitation, with relatively smaller differences meaning higher levels of ambidexterity. On the other hand, the combined dimension is a measure of the combined magnitude of exploration and exploitation (multiplication). An example of the differing conceptualizations is shown below in Figure 4.4. 


\section{Figure 4.4: Illustration of Different Conceptualizations of Organizational Ambidexterity Source: Cao, Gedajlovic and Zhang (2009)}

\begin{tabular}{ccccc}
\hline & & & $\begin{array}{c}\text { Assessment } \\
\text { of balance } \\
\text { dimension of } \\
\text { ambidexterity } \\
\text { (BD) }\end{array}$ & $\begin{array}{c}\text { Assessment } \\
\text { of combined } \\
\text { dimension of } \\
\text { ambidexterity } \\
\text { (CD) }\end{array}$ \\
\hline Firm A & 10 & 5 & Low & High \\
Firm B & 5 & 5 & High & Low \\
\hline
\end{tabular}

As shown above, as a result of the differing dimensions, the interpretation may be ambiguous. If ambidexterity were thought of as the balance between exploration and exploitation, Firm B would appear more ambidextrous, while if conceptualized as the combined magnitude, Firm A is more ambidextrous. As is consistent with the reasoning of our research, Cao, Gedajlovic and Zhang (2009) propose that "high CD will exert a more positive effect on firm performance when the firm also maintains a high level of BD” (p. 784), suggesting a synergistic effect on performance. The authors demonstrate the significance of these synergies through the use of multiple regression analysis, showing that "a greater balance of exploration and exploitation will lead to more opportunities to leverage knowledge and resources across activities... the positive performance effect of a high level of CD is significantly enhanced by a high level of BD" (p. 790). Thus, for the purpose of calculating Ambidexterity in the analysis the two measures of ambidexterity (CD and BD) will be multiplied. This calculation is intended to capture the synergistic effects of high levels of both $\mathrm{CD}$ and BD. 
The exploration and exploitation scales were anchored on a 7-point scale, with each dimension being calculated as an average of the responses of its item measures. For instance, a firm that responds to the three exploration items with a 7, 5 and 6 , has an exploration score of 6 . If the same firm's exploitation item responses are 5, 2 and 2, its exploitation is $3((5+2+2) / 3)$. To calculate the CD of ambidexterity for this firm, the exploration and exploitation measures would be multiplied ( $6 * 3)$ equaling 18 . To calculate the $\mathrm{BD}$ we find the absolute difference between exploration and exploitation (|63|) equaling 3. To help with the interpretation of the $\mathrm{BD}$, and consistent with Cao, Gedajlovic and Zhang (2009), the absolute BD was subtracted from the maximum BD, in this case 7 , meaning that the higher the number the higher the $\mathrm{BD}$ ambidexterity measure. For instance, if the BD for a firm is 0 (equal exploration and exploitation), subtracting this from 7, would yield a BD score of 7/7, or the highest BD possible. Finally, to calculate (old) ambidexterity as referred to in this paper the $\mathrm{CD}$ is multiplied by the $\mathrm{BD}$, which in the above example would yield an ambidexterity of $72(4 * 18)$. However, in the following chapter and based on the initial results from our analysis, the ambidexterity calculation was slightly modified. The reasoning for the modification is explained in greater detail in the following chapter.

\section{Measures of Performance - Profits, Growth and Sustainability}

Murphy, Trailer and Hill (1996) propose that accurate and appropriate measurement of performance is essential to entrepreneurship research as without it, theory development is impeded and recommendations to entrepreneurs may lack usefulness. As noted earlier, Lumpkin and Dess (1996), suggest that at times, 
entrepreneurial activity may lead to favorable results on one performance dimension, but an unfavorable result on another. Consider a firm that has reduced it prices significantly in a bid to increase its sales. While the firm may report high levels of growth (driven by the price cutting strategy), it may also be likely that the firm's profitability will suffer as a result of the move to drop prices, as the newer lower price will mean lower or even negative net profit margins. Thus, research that only considers a single performance dimension may be misleading in the implications it draws from its findings.

Based on a review of 51 articles published within entrepreneurship, Murphy, Trailer and Hill (1996) suggest as many as 71 different measures of performance were observed. The majority of the data was collected through primary data collection techniques, which is in line with entrepreneurship researchers who note a lack of relevant secondary sources for entrepreneurship centric data. The authors also report that from their analysis they observed that 8 dimensions of performance were used in the reviewed literature, although the $71 \%$ of the articles used 4 or less measures and none used more than 5. The most frequently used performance dimensions was efficiency, which measured return on investment, return on assets and the internal rate of return. Also used frequently, were the measures of growth and profit. Growth, the authors found, is measured through changes in sales, market share of employee and change in net income. Profit is in several instances similar to efficiency, being measured through the return on sales, net profit levels or the gross/net margins of the business. Size and liquidity are two additional measures that have been suggested by Murphy, Trailer and Hill (1996) who report performance measures such as the sales level, number of employees and the cash 
flow level. Also of note was the use of the success/failure dimension that was employed to evaluate performance. Operationalized as whether the business has been discontinued and subjective assessments by the researcher and business owner, the success/failure dimension resembles a measure of the survivability, which has been suggested by some to have importance beyond the conventional competitive advantage discussed in the literature (Ludwig and Pemberton, 2011).

In keeping with the suggested practice of using multiple measures of performance (Murphy, Trailer and Hill, 1996), we considered three main dimensions: profitability, growth and survivability which represent to some degree, the potential trade-offs that may exist in an actual business setting. Daily and Dalton (1992) suggest that it is unlikely that any one dimension of performance can sufficiently capture the entire performance of a firm. Murphy, Trailer and Hill (1996) report that less than half of the performance measures they analyzed are significantly correlated, with the suggestion that those that do correlate are due to statistical chance. In fact, the authors report that more than $25 \%$ of the significant correlations of measures of performance were negative, demonstrating the perils of using a single measure of performance.

The performance dimensions of profits and growth captured the relative positive effects of exploitation and exploration respectively, such that effective exploitation should result in high levels of profits, while effective exploration should result in the growth of the firm. The third dimension, survivability, is used in acknowledgement that beyond profits and growth, many micro organizations face real issues with regards to survival. Not all firms may enjoy high levels of profits and/or growth at all stages of their 
existence. Rather, some firms may be solely striving for the ability to live another day, meaning that by doing so they are enjoying a degree of success.

A further consideration of the performance dimension is its relationship to the RBV literature. Newbert (2007) is his review of RBV centric articles, reported that of the 55 articles under consideration, 51 used performance as the dependent variable of study, signifying that performance is an accepted measure in the strategic management literature as well as the Entrepreneurship literature. Interestingly, although a pillar of the RBV is the notion of a 'sustained' performance advantage, only 2 of the 55 articles considered the sustainability of a performance or sustained competitive advantage. One possible reason for the lack of research on sustained performance advantages is the demands in terms of time taken to conduct longitudinal research, meaning that unique measurement at distant time points to compare a firm's change over time is seldom conducted. This research is also bound by time considerations and as such, considered the performance of a firm based on a response at a single point in time. In an attempt to capture performance beyond the momentary performance at the time of data collection, the profit and growth performance items each measured from the perspective of the previous three years (Cao, Gedajlovic and Zhang, 2009, Engelen, Kube, Schmidt and Flatten, 2014), while asking the relative performance based on that of competitors (Wiklund, 1999, Wiklund and Shepherd, 2003).

Finally, the measures of performance relied on self-reported data. Although selfreported data may be subject to bias due to social desirability, memory decay or common method bias, Rauch, Wiklund, Lumpkin and Frese (2009) argue that self-reporting offers 
robustness for multiple performance measures. Given that the intended sample of firms are micro enterprises it is likely that objective measures of performance may not exist at the firm level, or if they do, for instance profit and loss statements, would be closely guarded by the firms. Below, Table 4.6 shows the performance measures that were utilized in data collection:

Table 4.6: Performance Item Measures Source: Murphy, Trailer and Hill (1996)

1: Over the past three years, in comparison to my competitors my business profits are: Well below normal $\begin{array}{lllllll}1 & 2 & 3 & 4 & 5 & 6 & 7\end{array}$ Well above normal

2: Over the past three years, the business' growth in sales has been:

$\begin{array}{lllllllllll}\text { Very weak } & 1 & 2 & 3 & 4 & 5 & 6 & 7 & \text { Very strong }\end{array}$

3: At its present level of operations my business is sustainable for at least 3 more years:

Not true at all $\begin{array}{lllllll}1 & 2 & 3 & 4 & 5 & 6 & 7\end{array}$ Very true

\section{Control Variables - Size, Age, Location, Industry, Access to Financial Resources}

Beyond the independent and dependent variables discussed above, and based on precedents in the literature, various control variables were used in the study. These control variables were introduced as they help to simplify complex social situations. By controlling certain variables, we rule out variables that may not be of immediate interest, but that may explain some aspects of the phenomenon under investigation (Singleton and Straits, 2010).

In their review of EO and performance literature, Rauch, Wiklund, Lumpkin and Frese (2009) report that firm size and industry type have been frequently used as control 
variables in the literature. In their study of EO and small business, Wiklund and Shepherd (2005) propose that businesses of different sizes and industries may exhibit different organizational and environmental characteristics that may influence performance. To control for the effects of size, Wiklund and Shepherd (2005) use the number of employees as a proxy for the size of the firm. Respondents were asked the number of full time employees including: working owners and part-timers. To control for industry, Wiklund and Shepherd (2005) ask respondents if their primary line of business was in manufacturing, service or retailing.

A third control variable that we employed in this study is the age of the firm, measured by asking respondents, the commencement year of the business and subtracting from the current year. Murphy, Trailer and Hill (1996) report from their review of performance in the Entrepreneurship literature that four control variables were relevant to a majority of the studies: firm size, risk, industry and age. Of these four, three will be used as control variables, with the fourth, risk, forming part of the EO construct. A fourth control variable included in this study is that of firm location. Firms from various cities and towns throughout Trinidad will be included, due to the possibility of the location as having an influence on the success of a firm. To operationalize location, all firms will be categorized as belonging to the West, Central, East and South region. These regions correspond to the four primary centers of business activity and population density and encompass the entire country. A map representing the four regions is shown below: 
Figure 4.5

Map of Trinidad showing four research locations

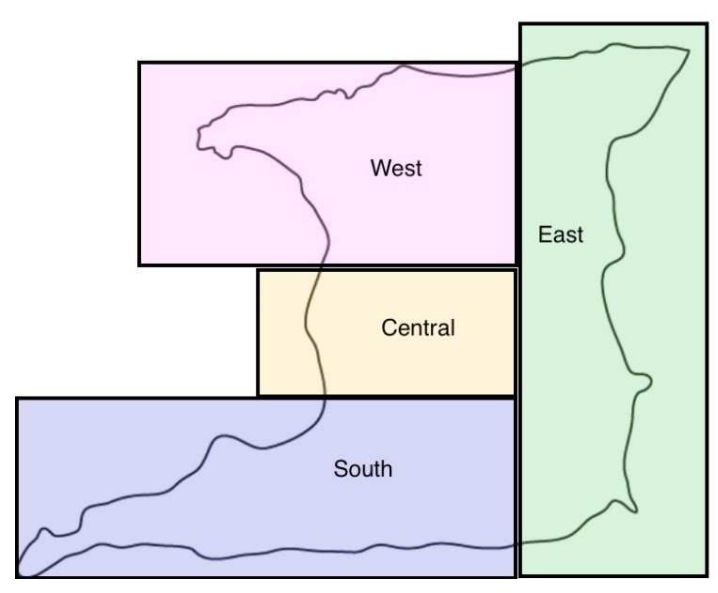

$$
\begin{aligned}
& \text { West }=1 \\
& \text { Central }=2 \\
& \text { South }=3 \\
& \text { East }=4
\end{aligned}
$$

A final control variable that was selected was access to financial resources. EO has been positioned as a resource consuming orientation (Covin and Slevin, 1991), suggesting that access to more resources can facilitate EO. Dollinger (1999) suggests that financial resources are the most generic type of resource and the most readily convertible into other types of resources, as such, easing the possible resource constraints of the business. Given this, it follows that entrepreneurial strategies require considerable financial resources to be successful. On the other hand, Wiklund and Shepherd (2005) suggest that EO, in combination with minimal financial resources and a non-dynamic environment can lead to higher relative performance. They suggest that this follows the concept of resource based logic, whereby, under resource constraints and stable market conditions, EO provides a greater differentiation mechanism than in situations of resource abundance and dynamic market conditions. Thus, given the possible linkages that may exist between a firm's access to financial resources and its performance, access to financial capital will be used as a control variable, to ensure that the relationships 
discovered between the variables on interest exclude the possible confounding effect of differing access to finance. Below, Table 4.7 shows the control variables for the study:

\section{Table 4.7: Control Variables}

1. How many years has your business been in continuous operation?

2. How many employees does your business have? (This question was later broken down into full time and part time employees)

3.With 1 representing not true at all and 7 representing very true, how true is the following statement: "If there was a need for business financing, my business would be able to secure any amount it needed":

$\begin{array}{llllllllll}\text { Not true at all } & 1 & 2 & 3 & 4 & 5 & 6 & 7 & \text { Very true }\end{array}$

4. Firm location?

5. Primary product/service/industry?

\section{Research Sample}

Having determined what to study, it is necessary to consider whom to study

(Firebaugh, 2008). As has been previously discussed in Chapter 2, this study focuses on micro enterprises in Trinidad, being defined as those enterprises with 5 or fewer employees. This is in line with Hendrickson (2009), who notes that in Trinidad, firm size is often classified based on the number of employees. Specifically, firms with $6-25$ employees are considered small, while 26 - 50 employees are considered medium sized organizations, and large firms as over 50 employees.

The advantages of using micro firms as the research population have been discussed in more detail previously, but it is primarily the increased effect of EO in smaller as compared to larger firms (Rauch, Wiklund, Lumpkin and Frese, 2009), which may be as a result of the measurement a firm's EO based on responses from top 
management. In smaller firms, the EO of the entrepreneur (top management) is more likely to be representative of the overall EO posture of the entire firm than in a larger firm.

Further, the Trinidadian context offers new ground in the study of EO. In Wales, Gupta and Mousa's (2011) review of empirical EO research, they note that of the 158 articles reviewed that only one was in a Latin American context (Mexico) and that no empirical EO research had been based on the Caribbean region. They offer that exploration of these areas can allow for the continued generalization of EO research at an international level and encourage research in geographic areas that have been previously overlooked, with Trinidad meeting this criterion.

Ascertaining an approximation of the total population size, that is, the total number of micro enterprises in Trinidad is difficult and inexact. According to published reports by the Central Statistical Office (CSO) of Trinidad and Tobago (CSO Pocket Digest, 2010), there exist 8,792 and 4,574 registered firms with 0-1 and $2-4$ employees respectively, though the same report also notes that of the total 29,582 firms, 9,116 of these firms did not report their number of employees. As such it is possible that the number of micro firms is indeed larger than $13,366(8,792+4,574)$.

It is likely that not all micro organizations legally register themselves and are recorded as part of the database as collected by the $\mathrm{CSO}$, with one possible reason being avoiding the tax burden (Vuletin, 2008). In a 1999 speech, then Governor of the Central Bank of Trinidad and Tobago noted, "In measuring economic activity, we should also note the contribution of the informal sector to the job creation process. When one takes 
into account this type of activity in the economy, the unemployment rate can be adjusted downwards by a further 2 per cent" (Lewis and Hosein, 1999). This figure may be quite conservative as actual research suggested that though relative to other Caribbean islands, Trinidad's informal sector may be smaller, it is estimated to range between $15-25 \%$ of the total GDP (Vuletin, 2008). Using $20 \%$ as a rough estimate of the ratio of informal micro enterprise to formally registered micro enterprises, and based on the above numbers, we get a total population size of $13,336+20 \%=16,039$.

The calculation of the total population size is an important consideration in determining an appropriate sample size for the study. Two additional considerations are the confidence intervals (margins of errors) and confidence level (accuracy). Confidence intervals refer to how accurately the responses of the sample, represent that of the sample, while confidence levels, refer to how accurately the sample represents the population. Based on differing levels of confidence intervals and levels, the necessary number of respondents varies as well. Below in Table 4.8, the number of respondents needed based on a total population of 16,039 and various confidence intervals and levels are shown:

Table 4.8: Number of respondents needed for statistical significance

\begin{tabular}{|c|c|c|c|}
\hline Total Pop & $\begin{array}{c}\text { Confidence } \\
\text { Interval }\end{array}$ & $\begin{array}{c}\text { Confidence } \\
\text { Level }\end{array}$ & $\begin{array}{c}\text { Sample } \\
\text { Needed }\end{array}$ \\
\hline 16039 & $90 \%$ & $90 \%$ & 68 \\
\hline 16039 & $90 \%$ & $95 \%$ & 95 \\
\hline 16039 & $90 \%$ & $99 \%$ & 164 \\
\hline 16039 & $95 \%$ & $90 \%$ & 267 \\
\hline 16039 & $95 \%$ & $95 \%$ & 373 \\
\hline 16039 & $95 \%$ & $99 \%$ & 632 \\
\hline 16039 & $99 \%$ & $90 \%$ & 4475 \\
\hline 16039 & $99 \%$ & $95 \%$ & 5536 \\
\hline 16039 & $99 \%$ & $99 \%$ & 7310 \\
\hline
\end{tabular}


The pattern above is rather straightforward in that with greater levels of confidence, there is also a need for a large sample, which grows exponentially as the confidence levels increase. Though a larger sample is better for reducing error, given financial and time considerations, gathering hundreds of responses is both costly and time consuming. In fact, an ad hoc review of some of the articles mentioned within this research revealed the following:

Table 4.9: Size of Sample in Selected Empirical EO research

\begin{tabular}{|l|l|l|}
\hline \multicolumn{1}{|c|}{ Author } & \multicolumn{1}{c|}{ Year } & Sample Size \\
\hline Miller & 1983 & 52 \\
\hline Covin and Slevin & 1989 & 80 \\
\hline Zahra & 1991 & 119 \\
\hline Wiklund & 1999 & 132 \\
\hline Lee, Lee and Pennings & 2001 & 137 \\
\hline Lumpkin and Dess & 2001 & 94 \\
\hline Stam and Elfring & 2008 & 87 \\
\hline Arbaugh, Cox and Camp & 2009 & 61 (average per country) \\
\hline Hansen et al. & 2011 & 187 (average per country) \\
\hline Chen and Hsu & 2013 & 307 \\
\hline
\end{tabular}

The average number of respondents of this ad hoc review is just under 126 respondents, which we considered a suitable minimum number of responses to collect. This belief was based on the fact that the ratio of sample size to total population size for the above research is much smaller in relation to the small island economy found in Trinidad. For instance, Wiklund (1999) considered a sample of 132 Swedish firms as representative of the entire population. According to the World Bank, Sweden's GDP is approximately 22 times that of Trinidad, with a population that is over 7 times larger. This suggests that if the same sized sample were used in the two countries, it is likely that the country with the lower total population (Trinidad) would demonstrate greater 
reliability, due to a larger percentage of the total population size having taken part in the research.

\section{Data Collection and Analysis}

Quantitative data was collected using a questionnaire that was administered directly to the participant, in person. Using this method of data collection responses were obtained immediately and the authenticity of the participant as the entrepreneur could be verified. The supplementary qualitative data was collected via interviews with the entrepreneurs of selected firms from the quantitative data set. We also conducted interviews face to face which served to add richness and depth to the explanation of the findings of the quantitative survey. Creswell and Clark (2011) offer that the explanatory sequential design is most useful when the researcher wants to assess relationships with quantitative data and also be able to explain the mechanisms at work in the process. Further, the established and fundamentally quantitative construct designs of EO and ambidexterity align with the explanatory sequential design. Thus, based upon the findings in the quantitative stage, the qualitative stage gave an opportunity to gain additional insight into the findings

One possible limitation of this type of research in the time it takes to carry it out. Since data for the quantitative and qualitative strands are collected sequentially, it requires two distinct data collection periods. Additionally, the selection of participants in the second phase could have been difficult. Specific firms of interest could have declined to participate in the second phase of data collection. However, because of the relatively 
low percentage of participants that are required in phases one and two as compared to only phase one, it was not an issue to find sufficient participants in the second phase.

The technique used in the analysis of the quantitative data is dependent upon the specific hypothesis that the question is attempting to test. Once all the survey data was collected, it was coded into the statistical software package SPSS and then multiple regressions executed to test the hypotheses. Multiple regression analysis is a statistical tool that allows the simultaneous examination of multiple independent variables and their relation to a dependent variable (Higgins, 2005). In the previous chapter, predictions were made based upon the relationship between the dimensions of EO and ambidexterity to performance, while in the presence of control variables. Multiple linear regression is thought to be a useful technique if the independent variables have an understandable relationship to the dependent variable, and have the added advantage of maintaining their efficacy with small samples (Tobias, 1995). In the first instance, given the body of research on the variables and performance that already exists, the technique is appropriate. Further, as has been noted, the sample of this research has not been used in previous EO research. Based on the absence of prior reports as to the adequacy of the sample and the possibility that access to participants, or the response rate may have been low, multiple regression would have still been able to serve its purpose adequately (in the event of limited completed questionnaires).

Prior to the analysis of the data to test the hypotheses and additional checks to ensure the reliability and validity of the data, it is good practice to pre-screen the data. One such technique that was utilized is the centering of all independent variables. This 
technique reduces the potential for multicollinearity between the variables, which can lead to misinterpretation of the data. This step was also considered important given the likelihood of some multicollinearity amongst the dimensions that are being measured (for instance, innovation and exploration or the dimensions of EO itself). Once this step was performed, the variance inflation factor was measured in the hope that no VIF values exceed two, suggesting an absence of a significant effect of multicollinearity on the results (Neter, Wasserman and Kutner, 1990). Further, because multiple regression can be unduly influenced by outliers in the data set, prescreening of the completed questionnaires was conducted to identify and possibly eliminate results that are not truly representative of the data but would otherwise serve to significantly influence the results.

Further, factor analysis was conducted on all item measures to ensure they correctly load onto the expected variables. In addition, the Cronbach Alpha calculation was used to determine the correlations that exist between the items that are believed to measure a latent construct such as innovativeness. A Cronbach Alpha score that is greater than 0.7 is taken to indicate a reliable measure, with the closer the score to 1 , the stronger the reliability.

In order to test $\mathrm{H1}$ a, (both a unidimensional and multidimensional are positively and significantly related to performance) the control variables and EO (summation) were regressed on performance to determine the significance of a unidimensional conceptualization of EO. Similarly, the control variables and the individual dimensions of EO (innovativeness, risk-taking, proactiveness) were regressed on performance in order to assess their significance. To test $\mathrm{H} 1 \mathrm{~b}$, (multidimensional construct explains 
significantly more performance than unidimensional construct) a F-test was used to compare the two models, which indicated which is the more statistically appropriate model. The F-test is appropriate for testing the significance of the different models despite a difference in the number of independent variables. While it is likely that the inclusion of more variables will improve the R squared of the model, the F-test considers the relative advantage of a parsimonious model that may be less significant than a model with more variables.

$\mathrm{H} 2, \mathrm{H} 3, \mathrm{H} 4$ and H5 hypothesize the existence of curved relationships between EO and the dimensions of EO and performance. In order to test hypotheses 2, 3 and 4, hierarchical regression analysis was used. Model 1 included only the control variables, while Model 2 added the linear terms for innovativeness, risk-taking and proactiveness. Model 3 included the quadratic terms for innovativeness, risk-taking and proactiveness, which were derived by squaring the linear terms for each dimension (Kreiser, Marino, Kuratko and Weaver, 2013). A significant and positive coefficient of the linear term would mean that there is primarily a positive relationship, while a significant and negative coefficient of the linear term would imply a negative relationship (Aiken and West, 1991). If there were a curve, this would be identified by the significance and sign of the coefficient of the squared term. If this coefficient is significant and positive, it would suggest a $U$ shaped relationship between the dimension and performance, while if it were significant and negative, this would demonstrate an inverted $U$ shaped relationship. To test hypothesis 5, the same technique as described above was used with the summated EO taking the place of the three individual dimensions. 
H6 suggests that firm ambidexterity is positively and significantly related to performance. As with above, hierarchical regression analysis was used to test the effect of ambidexterity on performance, with Model 1 containing the control variables, Model 2 including exploration and exploitation, and Model 3 including ambidexterity. A positive and significant coefficient of ambidexterity in Model 3 would confirm the hypothesis.

$\mathrm{H} 7, \mathrm{H} 8, \mathrm{H} 9$ and $\mathrm{H} 10$ propose that firm ambidexterity positively moderates the relationship between innovativeness, risk-taking, proactiveness and the summated EO and performance. Building upon the models that were used to test $\mathrm{H} 2$ - $\mathrm{H} 5$, additional variables were added to the hierarchical regression to test the moderation effect of ambidexterity in relation to the individual EO dimensions. Specifically the model also includes the interaction terms for innovativeness/ambidexterity, risk-taking/ambidexterity as well as the interaction terms proactiveness/ambidexterity. H10 requires a separate regression as EO replaces the individual dimensions in this model. Here, interaction terms EO/ambidexterity are added to the model with the control variables, EO and EO squared.

\section{Qualitative Research Overview}

Having administered, collected and analyzed the quantitative data as described above, there are likely to be findings that possibly support or reject the various hypotheses that have been put forward. As was indicated previously, by utilizing a sequential research design, more detailed explanations for the existence of these findings were then sought through structured interviews that were conducted with select members 
of the quantitative research sample. Interviews were expected to last approximately 30 minutes and were conducted in a semi-structured format that maintained some consistency between the questions asked to all participants, while also allowing for more in-depth questioning of firms that tend to act in a manner that can assist in the explanation of the findings of the quantitative analysis.

All firms that completed the quantitative research questionnaire were asked about the possibility to engaging in an interview at a later date. All the firms that answered yes formed the total population of the qualitative research. From these firms a total of 12 firms were selected based on availability for semi-structured interviews. Firms that displayed some extremes in their responses (for example high risk-taking or exploration) were asked to participate in the interview process first. We reasoned that that firms that show the extremes in their responses are able to shed light on the advantages and disadvantages of doing so. Further, attempts were made to include firms from each geographic area under consideration (West, East, Central and South) as well as ensuring that the sum of the participants represented the three industries under study (Retails, Services and Manufacturing).

The structure of the interview was similar to the format of the quantitative questionnaire in that, there were sections for innovativeness, risk-taking, proactiveness, exploration, exploitation and performance. These questions served to provide additional information such as what types of product were introduced (beyond the fact that new ones were introduced) and what posture contributed toward being a risk taker (beyond the firm taking risks). In addition the interviewer gave the opportunity to ask a few 
background questions of the entrepreneur such as the reason for engaging in entrepreneurship and an assessment of the competitive environment. The questions that were asked and the interview protocol are shown in Exhibit 2.

With the permission of the firm, the interviews were recorded and transcribed for analysis. Qualitative data was reviewed independently, known as within case, and was also be compared against each other, known as cross case. One example of the technique that was utilized for the qualitative data is word identification. For instance, Chapter 2 outlined over a hundred words that had been utilized in the past to be representative of either exploration or exploitation. All of words that pertained to either exploration or exploitation were searched for, then compared and contrasted with the other qualitative and quantitative data that has been previously analyzed. In addition, the context in which these words were used was assessed for implications based on the findings of the quantitative research component.

It is important to note that the qualitative research component acted in a supplementary manner to the quantitative research. As such, the primary objective of the qualitative component of the research was to assist in the explanation of the findings in the quantitative component, specifically the results of the hierarchical regression analysis. As such, the interviews were structured in a manner that reflected the constructs that are explored in the regression analysis. Exhibit 2 shows the interview protocol that was used to administer the qualitative research, though based on the unique situation of the individual firm that was being interviewed, additional follow up questions were asked to 
extract data that was considered useful in aiding the explanation of the findings of the quantitative component.

\section{Research Challenges}

There are several limitations to this study that are discussed below. One such limitation is the potential for introduction of common method bias, whereby measured variance may be attributable to the method of measurement, rather than attributable to the dimensions being measured. For instance, the recency bias suggested by Groves et. al (2009) in face to face interviews. This bias leads to a situation whereby the respondent may be more likely to answer questions based on the most recent choice that was given by the interviewer. This can lead to false conclusions based on the significance or not of relationships that are influenced by the bias.

Podsakoff, MacKenzie, Lee and Podsakoff (2003) suggest measures to deal with common method bias. Although for this study it was not possible to obtain the predictor and dependent variables from different sources or contexts, in the absence of this the authors suggest the separation of the predictor and dependent variables psychologically. For instance, the questionnaire was arranged so that there were minimal contextual cues between questions, such as using unrelated questions as separators. Further, the authors suggest, that participants be assured of anonymity and reminded that there are no right or wrong answers, with all being equally valid (this was done in all cases).

Another limitation with the study was the potential of non-response bias. The context for the research was relatively unknown when compared to more established 
research contexts in North America or Europe and it was the case that some potential respondents were wary of participation and avoided doing so. This could have resulted in a lower than expected sample size, hampering the ability to draw believable results from the data, or a systematic participation refusal by certain sectors of participations, causing the results to be skewed. Conversely, the novelty to being a research participant was appealing to some participants and resulted in a higher than expected response rate.

Further, we used perceptive measures of performance and other dimensions, based upon responses by the entrepreneur of micro firms. We attempted to bridge the levels of analysis gap (firm and individual) that is believed to exist in both the EO and dynamic capability literature. However, given that in the research sample many firms have more than one employee, situations where the respondent's perceived EO of the firm may differ from the actual EO of the firm based on a combination of all employees may still exist. Further, the use of perceptual measures necessitates the use of recall by participants, which may be subject to memory decay, confusion or other bias.

Finally, beyond the individual participants, the research was also limited in its access to the full listing of registered companies with fewer than five employees that exists in Trinidad. Though the local Ministry responsible for the tracking of the data received our requests and responded favorably, a listing of companies was never received. This is discussed in greater detail in the following chapter, in addition to the implications of such. 


\section{Summary}

This chapter has considered the methodological approach and implications as it related to the investigation of the research questions and hypotheses that were outlined in the previous chapter. We utilized an explanatory sequential research design that first employed a questionnaire to ascertain quantitative data that can be analyzed to determine the validity of the hypotheses that were put forward, and followed with structured interviews that attempted to achieve theoretical saturation. The measures of EO, ambidexterity and their (initial) calculations have been discussed along with the slight modifications that have been made to make it more contextually specific. Further, the control variables or size, industry, age, location and access to finance were introduced. The sample population of 16,039 was determined, and finally, the techniques that were used to statistically analyze the data from the quantitative component of the research were outlined. The following chapter considers the results from the pre-testing or the survey instruments as well as the results of the actual data collection. 


\section{Chapter 5}

\section{Quantitative Data Collection and Analysis}

\section{Pre-Testing}

During the month of February 2015 we pre-tested the quantitative survey instrument. We selected a group of 30 individuals (primarily entrepreneurs) that were sourced from the personal network of the author and invited them to participate in completing the questionnaire online. Pre-testing was conducted using the online survey tool website QuestionPro and consisted of 23 questions. Of the 30 individuals invited to participate, 25 completed the survey. Invited participants represented a mix of industries including: consulting, education, law, construction, food services and retail. A frequency analysis of the primary industry (retail, manufacturing and services) is shown below in Table 5.1:

Table 5.1- Pre-Test - Which best describes the primary activity of your business?

\begin{tabular}{|c|c|c|c|c|c|}
\hline & & Frequency & Percent & Valid Percent & $\begin{array}{c}\text { Cumulative } \\
\text { Percent }\end{array}$ \\
\hline \multirow[t]{4}{*}{ Valid } & Manufacturing & 2 & 8.0 & 8.0 & 8.0 \\
\hline & Services & 17 & 68.0 & 68.0 & 76.0 \\
\hline & Retail & 6 & 24.0 & 24.0 & 100.0 \\
\hline & Total & 25 & 100.0 & 100.0 & \\
\hline
\end{tabular}

The goal of the pre-test was to gather feedback on the comprehensibility of the item measures and the individual questions that were used in the survey. After completion of the questionnaire, all participants in the pre-testing phase were contacted again and asked to provide feedback on the questions. From this process, two typographical errors were discovered and corrected. Further, two participants 
recommended clarification on one specific item measure. As a result of the request for clarification, the item measure was re-worded for the final version of the survey. A further three participants were thankful for having been given the opportunity to pre-test the survey as they all indicated that it helped them to reflect on their business processes and procedures, including but not limited to: better understanding their own modus operandi and their individual inclination towards a unique focus on the dimensions of EO: innovativeness, risk-taking, proactiveness. They also stated that it prompted reflection on their propensity for exploration and exploitation capabilities. In sum, the item measures used did not require many corrections. This can be attributed to the fact that the item measures in the EO construct have already been widely used in past research and were utilized in this research with only minor changes to reflect the local expectations of the sample in Trinidad.

In total, there were 48 online views of the survey, of which 25 were completed. During pre-testing we discovered that there were issues with the display of the survey on mobile devices. Specifically, the use of the semantic differential scale in the survey did not scale well on mobile devices, meaning that several participants were unable to complete the survey on their preferred device. Rather, it was necessary to use a laptop or desktop computer, which caused several participants to have to revisit the survey at a later time when they had access to a laptop or desktop computer. The pre-testing also revealed the time to complete the survey. While participants were asked to budget approximately 15 minutes in order to complete the survey, it was found that some individuals required as little as 2 minutes. On the other extreme, one individual required 
just over 20 minutes, though this pre-test participant was the only participant that required more than the expected 15 minutes. The average time taken to complete the survey was slightly under 8 minutes, while the standard deviation was approximately 4 minutes and 15 seconds. The length of time to completion results are shown below in Table 5.2:

Table 5.2 - Pre-testing - Time Taken to complete survey (in seconds)

\begin{tabular}{|l|r|r|r|r|r|}
\hline & $\mathrm{N}$ & Minimum & Maximum & \multicolumn{1}{c|}{ Mean } & $\begin{array}{c}\text { Std. } \\
\text { Deviation }\end{array}$ \\
\hline Time Taken to & 25 & 126 & 1249 & 454.56 & 255.269 \\
Complete (Seconds) & 25 & & & & \\
Valid N (listwise) & 25 & & & & \\
\hline
\end{tabular}

In addition to the correction of the errors noted above, based on the feedback from the participants in the pre-testing phase as well as input from academic advisors, two additional scales were added to the final questionnaire. The first was the inclusion of a competitive aggressiveness scale. As has been discussed previously, Lumpkin and Dess (1996) have noted the tendency of EO research to lump together competitive aggressiveness and proactiveness into a single scale. The goal of this research is to understand the unique effects of the individual dimensions of the EO construct, so in an attempt to keep in line with this goal, the dimensions of proactiveness and competitive aggressiveness were separated. As such, we added two questions pertaining exclusively to competitive aggressiveness to the final questionnaire that did not appear in the pre-test. The questions pertain specifically to the competitive aggressiveness dimension that has been proposed as an element of the EO construct (Zahra and Covin, 1995, Lumpkin and 
Dess, 1996, Lumpkin and Dess, 2001). The additional questions dealing with competitive aggressiveness are shown below:

\section{Figure 5.1 - Competitive Aggressiveness Item Measures}

10: In dealing with my competitors, my business:

$\begin{array}{lllllllll}\begin{array}{l}\text {...makes no special effort to } \\ \text { take market share from the }\end{array} & 1 & 2 & 3 & 4 & 5 & 6 & 7 & \begin{array}{l}\text {...is very aggressive and } \\ \text { intensely competitive }\end{array}\end{array}$
competition

11. In dealing with my competitors, my business:

$\begin{array}{llllllllll}\text { Typically seeks to avoid } & 1 & 2 & 3 & 4 & 5 & 6 & 7 & \text { Typically adopts a very }\end{array}$ competitive clashes, competitive, 'undo-the preferring a 'live-and-letcompetitors' approach live' approach

The second scale that was added to the final questionnaire was that of Small Business Orientation. Based on the suggestions of academic advisors, it was noted that it would be helpful to have the ability to distinguish between participants who may be either a small business owner or those who may be entrepreneurs. Though often confused small business owners and entrepreneurs tend to differ in their goals and reasons for starting a business. Carland et al. (1984) proposed that small business owners operated businesses that tended to be an extension of their personality, while Jenkins and Johnson (1997) suggest that small business owners, as opposed to entrepreneurs, wished to make a living with additional personal time. Cooper (1993) notes that small business owners may be motivated by their level of comfort or other personal goals, reaching acceptable levels of performance that may fall short of maximizing the potential performance of the business. Further, small business owners may have less preference for innovation and often do not wish to grow the business. The scale items used to measure small business 
orientation are shown below in Figure 5.2 and were adapted from the work of Runyan, Droge and Swinney (2008):

\section{Figure 5.2 - Small Business Orientation Item Measures}

21: I have no plans to significantly expand the size of my business:

$\begin{array}{lllllllll}\text { Not true at all } & 1 & 2 & 3 & 4 & 5 & 6 & 7 & \text { Very true }\end{array}$

22: I established my business because it better fit my personal life than working for someone else:

$\begin{array}{lllllllll}\text { Not true at all } & 1 & 2 & 3 & 4 & 5 & 6 & 7 & \text { Very true }\end{array}$

23: I consider my business to be an extension of my personality:

$\begin{array}{lllllllll}\text { Not true at all } & 1 & 2 & 3 & 4 & 5 & 6 & 7 & \text { Very true }\end{array}$

24: I am emotionally attached to my business:

$\begin{array}{lllllllll}\text { Not true at all } & 1 & 2 & 3 & 4 & 5 & 6 & 7 & \text { Very true }\end{array}$

Finally, one additional question was included in the questionnaire that did not form a part of the pre-test questionnaire. In the pre-test questionnaire, we asked participants about the number of employees in their business, however, based on feedback from the participants, a few required clarification on whether the total employees pertained to only full time, or if it also included part time employees. As such, the final questionnaire distinguished between full time and part time employees. In keeping with the goal of the research to study micro organizations, a cap of 5 full time employees was implemented, whereas the number of part time employees could vary above or below that amount. 


\section{Data Collection Process}

In the previous chapter, the methods for the collection of the quantitative data were described. Specifically, based on company listings that were to be provided by the Central Statistical Office of Trinidad and Tobago (CSO) and the National Entrepreneurial Development Corporation of Trinidad and Tobago (NEDCO), the potential sample population was to be established. Once, the full listing of potential businesses that met the criteria for study was received, a random record generator was to be used to randomly select businesses within the population. These businesses would have then been contacted, either by email or in person, regarding the possibility of completing the research survey.

However, conducting research in novel settings does not always follow the proposed plan and such was the case in this instance. Although both local institutions agreed to send their listings, in the end, neither did. With regards to the CSO the first request for data was made by email on October 1st 2014. Although this request was acknowledged within a week, communication from the CSO after their promise to fulfill the request became non-existent. Follow up requests were made via email on the October 23, 2014, October 30, 2014 and again on February 12015 . Having failed to respond to the emails a personal visit was made to the CSO office on the 24th March 2015. Upon this visit a meeting with the individual responsible for business statistics was held and he assured us of his support. A follow up email with the request for a company listing and a confirmation reply were sent and received on the same day and it seemed as though some progress was being made. However, follow up emails to the contact individual at the 
CSO on April 1, 2015 and April 14, 2015 went unanswered and given time constraints, the CSO was abandoned as a source of information.

Similarly, efforts to source data from NEDCO proved futile. A first request for data was made on September 30th 2014 and a reply received 2nd October 2014 promising to provide the contact information for the appropriate individual at the NEDCO office. After several more emails, the contact information for the individual who could assist with the provision of listing of businesses was received on February 11, 2015. We sent an email to the individual on that day, and he replied immediately to acknowledge the request and to say that more information would be given in good time. After a month of waiting a follow up email was sent to inform the contact at NEDCO that a trip had been scheduled to Trinidad and we wished to personally meet with him. He agreed to a meeting and apologized for not following up to the emailed requests. Additional emails were sent on the March 19, 2015 and March 23, 2015 as well as a telephone call on that day to request a time for the meeting but all communication went unanswered. Undeterred, we made an unscheduled visit to the NEDCO offices on March 24, 2015 and were able to meet with the contact individual who asked that more information be emailed. This request was fulfilled on the March 30, 2015 and the following day we received a reply that the survey had been vetted and was approved for distribution to the potential listing of businesses that they would provide. Finally, on May 21, 2015 an email was sent by NEDCO starting that they were unable to get 'systems set up' on their end to facilitate the request. As with the $\mathrm{CSO}$, at that time a decision was 
made to abandon NEDCO as a source of a listing of companies with less than 5 employees.

Having no other potential formal government sources to turn to a decision was made to use a more localized approach. At the end of March 2015, we posted classified ads in a popular local daily newspaper requesting individuals to function as research assistants and to collect data from the field. Interviews with several potential candidates were conducted during the week of 25th March to 30th March. Based on the interviews, four candidates were deemed to have possessed the qualifications and skills necessary for adequate completion of the task. The individuals were selected to assist with the canvasing of micro businesses with the goal of having these businesses complete the research survey. The candidates were chosen based on their research experience, interpersonal skills, personal networks and their geographic reach. Having received clearance from the Carleton University Research Ethics Board on April 1, 2015 the candidates were trained in the proper protocol for conducting the survey and began work in the field the week following their interview.

We scheduled to complete the collection of survey data within the months of April and May 2015, however, in actuality; collection of survey data ran from the start of April to the end of July 2015. The initial data collection plan had assumed that email and online completion of surveys would be a channel of data collection, however, due to the absence of a formalized listing from the relevant authorities this channel of data collection was abandoned. As such, all survey data collected was done through the use of face-to-face meetings with entrepreneurs. Typically, a researcher would identify a cluster 
of micro organizations within a geographic radius of about one mile and one by one approach the entrepreneurs of these businesses to inquire as to whether they would be willing to participate. This method of approaching businesses one at a time was time consuming and led to the extra time needed to collect the survey data beyond the budgeted amount.

Those entrepreneurs who agreed to participate completed the survey in one of two ways. In the first instance, the majority of respondents read and answered the questions from the survey by themselves. A minority of participants requested that the survey be read to them and orally indicated their answers. Table 5.3 shows the breakdown of those who read and answered the survey independently of the researcher and those who had the survey read to them and answered orally. Although information regarding the reasons for the request to be 'read to' was not available for all persons, in some instances it believed that the request was due to the participant being illiterate. Others, often those who worked with their hands, for example cobblers and hairdressers, asked for the survey to be read to them so that they could continue with their work and still participate in the research. Also included in the 'read to' listing are those who with the help of the researcher (read together) completed the survey $(n=6)$. Other reasons for asking that the survey be read to the participants included: eating lunch, concerns over business legitimacy (e.g. pirated DVDs), caring for children and being a non-native English speaker.

Table 5.3 - 'Self read' survey participants versus 'Read to' participants

\begin{tabular}{|c|c|}
\hline Self read & Read to \\
\hline 229 of $304(75.3 \%)$ & 75 of $304(24.7 \%)$ \\
\hline
\end{tabular}




\section{Quantitative Survey Response Rate}

During the four month survey data collection period a total of 791 micro businesses were approached to request participation in the research. Of these businesses, 304 completed the survey completely, resulting a response rate of $38.4 \%$. As a benefit of the face-to-face research method, there were no unusable surveys due to missing information (researchers ensured all surveys were completed in full). In their review of response rates from CEOs in small firms, Bartholomew and Smith (2006) report that the average response rate of surveys for articles published in the journals Entrepreneurship, Theory and Practice and Journal of Small Business Management over the years 1998 2004 was 27\%. Baruch (1999) reported that in his study of the response rates in 175 organizational studies in the years 1975, 1985 and 1995 the average response rate was 55.6\%. Interestingly between 1975 and 1995 the average response rate fell 16\% to just over $48 \%$, without reason to believe the trend would be reversed. When further breaking down the data by the organizational position of individual respondents, he found that top managers' response rate stood at about $36 \%$.

Based on comparisons with the response rates reported above, this study's response rate of $38.4 \%$ appears sufficient. However, due to the lack of comparable studies in Trinidad, or even the wider Caribbean, it is difficult to ascertain with any certainty whether the response rate is relatively high or low. Baruch (1999) also cites common reasoning for a failure to respond to a questionnaire. He notes that there are two main reasons for the failure to respond, the first being that the potential participant never actually receives the questionnaire. 
As noted above, survey data for this research was collected through face-to-face meetings. However, in the overwhelming majority of the businesses that were visited and asked to participate, the researcher showed up to the place of business unannounced. As a result, of the 791 businesses that were visited, the entrepreneur of the business was not on site at the time in 355 of those businesses (44.9\%). It is also worth mentioning that it is likely (and confirmed in a couple cases) that the entrepreneur was in fact present, however he/she was reported not to be there. Based on conversations with entrepreneurs this tendency is primarily due to security fears of the entrepreneurs. Though it has slowed in recent years Trinidad's business community has been the victim to multiple kidnappings for ransom (ttcrime.com). Kidnapping peaked at 155 kidnappings in 2007 or about 15 per 100,000 citizens, which ranked Trinidad amongst the highest in the world (nationmaster.com). Given that the majority of kidnappings that have taken place in Trinidad targeted the family members of business owners it is understandable why some entrepreneurs did not wish to identify themselves in order to participate in the survey.

Some entrepreneurs $(n=132)$ who were available at the time of the researcher's visit declined to participate. This means that of the businesses with the entrepreneur present, in 304 of 436 cases, representing $69.7 \%$, a completed survey was obtained, while in $30.3 \%$ cases it was not. Many of the entrepreneurs who declined did so without giving a reason, however of those who did offer an explanation for refusal to participate reasons included: too busy at time of visit, too tired, too personal, not applicable to type of business and did not speak English well enough. Of the reasons given for unwillingness to participate, the entrepreneur being too busy was the primary reason. Although it is 
nearly impossible to completely avoid this type of response in an organizational setting during working hours, it should be considered that the unwillingness to participate by these individuals might introduce some bias into the results. That is, it may be possible that entrepreneurs who declined to participate due to being too busy were the most successful in the research population. Those that were able to participate may have only been able to do so because their sales and activity were slower and thus had more free time available. It is also worth noting the types of businesses that declined due to the perceptions that the survey was not applicable to their type of business. In particular, doctors, lawyers, dentists and accountants held the view that the survey did not relate very well to their operations. Technically micro entrepreneurs, individuals who operate within these types of professional services may therefore be under-represented in the data that has been collected, another potential source of bias. Table 5.4 shows a summary of the response rate statistics from the collection of the quantitative data.

Table 5.4 - Response Rates

\begin{tabular}{|l|l|}
\hline Total Businesses Visited & 791 \\
\hline Completed Surveys & $304(38.4 \%)$ \\
\hline Non-respondents & $487(61.6 \%)$ \\
\hline Non-respondents - Entrepreneur not present & $355(44.9 \%)$ \\
\hline $\begin{array}{l}\text { Non-respondents - Other (too busy, too tired, too } \\
\text { personal, not relevant, language barrier) }\end{array}$ & $132(16.7 \%)$ \\
\hline
\end{tabular}

\section{Participant Demographics}

As discussed in Chapter 4, various control variables were included in the questionnaire. By controlling certain variables it is possible to simplify complex situations and to ensure that the investigation of the variables of interest is not 
confounded by the impact of the control variables. One control variable that was previously discussed is firm size, measured by proxy through the number of employees of the business. As such, the questionnaire asked respondents to divulge the number of full time employees as well as the number of part time employees. We made the distinction due to the fact that many of the businesses that participated in the survey enlisted the part time help of friends and family in order to facilitate their operations, especially in busy seasonal periods. These individuals often had full time jobs in different organizations, yet they contributed to the micro organizations in which they assisted.

Below are the descriptive statistics in Table 5.5 showing the minimum, maximum, mean and standard deviation for both full and part time employees. From the table we can see that $n=304$ and that the number of full time employees ranges from 1 to 5 , including the entrepreneur (this meets with the micro organization criteria established earlier in the paper). On average, the businesses surveyed had a full time staff of 2.58 employees, with a standard deviation of 1.33. In terms of part time employment, the range was between 0 and 20 part time staff, with a mean of 1.41 and a standard deviation of 2.4 .

Table 5.5 - Number of Employees - Descriptive Statistics

\begin{tabular}{|c|c|c|c|c|c|}
\hline & $\mathrm{N}$ & Minimum & Maximum & Mean & $\begin{array}{c}\text { Std. } \\
\text { Deviation }\end{array}$ \\
\hline $\begin{array}{l}\text { Full Time } \\
\text { Employees } \\
\text { Part Time } \\
\text { Employees } \\
\text { Valid N (listwise) }\end{array}$ & $\begin{array}{c}304 \\
304 \\
304\end{array}$ & 1 & $\begin{array}{r}5 \\
20\end{array}$ & $\begin{array}{l}2.58 \\
1.41\end{array}$ & $\begin{array}{l}1.332 \\
2.402\end{array}$ \\
\hline
\end{tabular}


Another variable that can confuse the interpretation of our results (if not controlled) is the industry type. That is, beyond the main effects under consideration, the type of industry firms operate within can have an impact on their performance and as a result should be measured and controlled. Based on the precedent of Wiklund and Shepherd (2005) firms reported their primary line of operations, which was then classified as retailing, service or manufacturing. Table 5.6 below shows the primary line of business, separated by the categorization, while table 5.7 shows the various types of firms that made up each category. The first category (1) was distribution or retailing. This included all participants whose primary line of operations was to resell goods that it has purchased either through importation or from a wholesaler, without modifications. The second category (2) were service providers, while the third (3) consisted of firms that manufactured or produced their own goods for sale.

Table 5.6 - Type of Business Activity (1-Distribution/Retail, 2-Service, 3-Manufacturing/Production)

\begin{tabular}{|r|r|r|r|r|}
\hline & Frequency & Percent & Valid & Cumulative \\
Percent & Percent \\
\hline Valid 1 & 150 & 49.3 & 49.3 & 49.3 \\
& 99 & 32.6 & 32.6 & 81.9 \\
3 & 55 & 18.1 & 18.1 & 100.0 \\
Total & 304 & 100.0 & 100.0 & \\
\hline
\end{tabular}

Table 5.7 - Primary Business Activity, by Classification (brackets indicate number of firms within subset)

\begin{tabular}{|l|l|}
\hline 1. Distribution/ & Agriculture Supplies (1), Arcade (1), Automotive Retail (6), \\
Retail & Beauty/Cosmetology Sales (7), Bicycle Sales (1), Book Store (1), \\
Cleaning Supplier (1), Children Clothing Sales (4), Clothing Retail \\
(23), Clothing Wholesale, (1), Clothing/Mixed Retail (6), Dental \\
& Supplies (1), DVD Sales (3), Electrical Retail (3), Electronics \\
& Retail (4), Fitness/Health Sales (1), Fruit Vendor (2), Food Service \\
& Retail (11), Furniture Retail (2), Garden Equipment (2), Grocery \\
\hline
\end{tabular}




\begin{tabular}{|l|l|}
\hline & (11), Hair Sales (2), Hardware (2), Jewelry Retail (3), Lamps (1), \\
& Maternity (1), Mixed Retail (26), Party Supplies (3), Pet Supplies \\
& (3), Pharmacy (3), Phone Retail (2), Sporting Equipment (3), \\
Stationary (1), Watch Sales (2), Wholesaler (5), Total: 150 \\
$\mathbf{( 4 9 . 3 \% ) ~ b u s i n e s s e s ~}$
\end{tabular}

As can be seen in the above tables, of the 304 participants in the survey, almost half $(150,49.3 \%)$ were categorized as primarily conducting retail or distribution. The total number of businesses categorized as service providers was just under one third (99, $32.6 \%$ ) and there were 55 manufacturers, representing $18.1 \%$ of the sample. When compared with the breakdown of micro businesses of the entire population $(\mathrm{CSO}$, Pocket Digest, 2010) the figures match up relatively well. Of the registered 13,366 micro businesses in Trinidad, 8,014 (59.9\%) are categorized as retail and distribution. A further 4,231 (31.7\%) are categorized as service providers, while the total population of manufacturing and production is $1,121(8.4 \%)$. 
One relatively significant difference between the sample and entire populations is the percentage of the sample population for manufacturing $(18.1 \%)$ verses the categorization of the entire population of manufacturing $(8.4 \%)$ for micro sized businesses. One explanation for the variation is the data collection technique used by the Central Statistical Office, whereby the declaration of commencing or ceasing operations is not mandated and as a result a completely accurate number of micro business is relatively difficult to ascertain. Additionally, according to the CSO handbook (2010), there are only 69 micro organizations listed in the food and drink categorization, making up just about half of one percent of the total population. However based on the sample population alone, if we group together bakeries, bars, restaurants and wine producers (those that produce for sale), their total participation in the research numbers 34 , which represents $11.2 \%$ of the sample population. Such a large disparity in one instance can be explained through the low likelihood of small food producers (for instance street vendors) being registered with the CSO. Alternatively, the low transparency of the CSO's categorization may mean that many of these business owners engaging in food and beverage production are included in the total population, but have been categorized under different headings. In any event, the relatively higher number of businesses categorized as engaging in production and manufacturing for the sample (relative to the CSO figures) is considered to be a fair representation of the actual numbers and types of businesses that exist in the Trinidadian marketplace.

Another control variable we included in this research is the age of the business. This is because age may impact the relationships between the variables of 
interest. For instance, a firm that is very new may experience growth that is superior to a firm that has been established for many years. This difference may not be as a result of differences in their entrepreneurial orientation or capabilities but rather as a function of the age of the business. Table 5.8 shows the minimum, maximum, mean and standard deviation in the ages of the businesses that participated in the study. From the table we can see that the youngest firm included in the study was 1 month old, while the oldest had been in existence for 70 years. On average, firms had been established for just over 11 years, with a standard deviation of 11.6 years.

Table 5.8 - Age of Business - Descriptive Statistics

\begin{tabular}{|l|r|r|r|r|r|}
\hline & $\mathrm{N}$ & Minimum & Maximum & Mean & Std. Deviation \\
\hline Number of Years in & 304 & .1 & 70.0 & 11.120 & 11.5580 \\
Operation & 304 & & & & \\
Valid N (listwise) & & & & \\
\hline
\end{tabular}

The geographic location of a business can also impact the performance of a business. This study attempted to source businesses from several areas of Trinidad and broadly broke down the locations as West, Central, South and East. Table 5.9 reveals the frequency of participants from the four areas mentioned above, while Table 5.10 shows the breakdown of the locations by the various towns and cities that made up each location categorization. 
Table 5.9 - Location (1-West, 2-Central, 3-South, 4-East)

\begin{tabular}{|r|r|r|r|r|}
\hline & Frequency & Percent & $\begin{array}{c}\text { Valid } \\
\text { Percent }\end{array}$ & $\begin{array}{c}\text { Cumulative } \\
\text { Percent }\end{array}$ \\
\hline Valid 1 & 93 & 30.6 & 30.6 & 30.6 \\
& 79 & 26.0 & 26.0 & 56.6 \\
3 & 72 & 23.7 & 23.7 & 80.3 \\
4 & 60 & 19.7 & 19.7 & 100.0 \\
Total & 304 & 100.0 & 100.0 & \\
\hline
\end{tabular}

Table 5.10 - Primary Business Location, by Classification (brackets indicate number of firms within subset)

\begin{tabular}{|l|l|}
\hline 1. West Trinidad & $\begin{array}{l}\text { Barataria (3), Belmont (1), Cascade (1), Champs Fleurs (1), } \\
\text { Curepe (15), Deigo Martin (20), El Soccorro (9), Maraval (2), Port } \\
\text { of Spain (14), Saint James (7), San Juan (12), Santa Cruz (6), } \\
\text { Woodbrook (2) - Total: 93 (30.6\%) }\end{array}$ \\
\hline 2. Central Trinidad & $\begin{array}{l}\text { Chaguanas (34), Cunupia (6), Saint Augustine (29), Saint Joseph } \\
\text { (3), Tacarigua (1), Valsayn (3), Warrenville (3) - Total: 79 (26\%) }\end{array}$ \\
\hline 3. South Trinidad & $\begin{array}{l}\text { Couva (11), Marabella (6), Penal (1), Point Fortin (1), Princes } \\
\text { Town (25), San Fernando (23), Siparia (5) - Total: 72 (23.7\%) }\end{array}$ \\
\hline 4. East Trinidad & $\begin{array}{l}\text { Arima (14), Blanchisseuse (1), El Dorado (2), La Fillette (5), Las } \\
\text { Cuevas (3), Maracus (2), Sangre Grande (11), Trincity (6), } \\
\text { Tunapuna (9), Wallerfield (7) - Total: 60 (19.7\%) }\end{array}$ \\
\hline
\end{tabular}

\section{Small Business Orientation}

It has been suggested in the Entrepreneurship literature that not all small business

owners are entrepreneurs, such that the two groups may have differing short and longterm goals (Carland, 1984). Miles, Covin and Heeley, (2000) note that a significant number of small business owners may be likely to have more of a small business orientation (SBO) than an entrepreneurial orientation. To identify if the micro business owners represented in the research sample share a small business orientation disposition, item measures based on the research of Runyan, Droge and Swinney (2008) were 
included in the questionnaire we gave to participants. The item measures relating to SBO are shown below in Figure 5.3:

Figure 5.3 - Item Measures (Adapted from: Runyan, Droge and Swinney, 2008) Small Business Orientation

21: I have no plans to significantly expand the size of my business:

$\begin{array}{llllllllll}\text { Not true at all } & 1 & 2 & 3 & 4 & 5 & 6 & 7 & \text { Very true }\end{array}$

22: I established my business because it better fit my personal life than working for someone else:

$\begin{array}{lllllllll}\text { Not true at all } & 1 & 2 & 3 & 4 & 5 & 6 & 7 & \text { Very true }\end{array}$

23: I consider my business to be an extension of my personality:

$\begin{array}{lllllllll}\text { Not true at all } & 1 & 2 & 3 & 4 & 5 & 6 & 7 & \text { Very true }\end{array}$

24: I am emotionally attached to my business:

$\begin{array}{lllllllll}\text { Not true at all } & 1 & 2 & 3 & 4 & 5 & 6 & 7 & \text { Very true }\end{array}$

Based on the results of the research, the descriptive for the SBO item measures are shown below:

Table 5.11 - Small Business Orientation - Descriptive Statistics

\begin{tabular}{|c|c|c|c|c|c|}
\hline & $\mathrm{N}$ & Minimum & Maximum & Mean & $\begin{array}{c}\text { Std. } \\
\text { Deviation }\end{array}$ \\
\hline $\begin{array}{l}\text { Small Business } \\
\text { Orientation Q1 (q21) }\end{array}$ & 304 & 1 & 7 & 3.22 & 2.352 \\
\hline $\begin{array}{l}\text { Small Business } \\
\text { Orientation Q2 (q22) }\end{array}$ & 304 & 1 & 7 & 6.55 & .932 \\
\hline $\begin{array}{l}\text { Small Business } \\
\text { Orientation Q3 (q23) }\end{array}$ & 304 & 1 & 7 & 6.23 & 1.235 \\
\hline $\begin{array}{l}\text { Small Business } \\
\text { Orientation Q4 (q24) }\end{array}$ & 304 & 1 & 7 & 5.74 & 1.640 \\
\hline Valid N (listwise) & 304 & & & & \\
\hline
\end{tabular}


Above we can see that the range of responses was between 1 and 7 for all questions, while the means showed more variation. Participants were asked whether they had plans to expand their business (3.22, Q21) and this mean was lower than when asked if the business is a fit for personal life $(6.55, \mathrm{Q} 22)$, an extension of personality $(6.23$, Q23) or if there is an emotional attachment to the business (5.74, Q24). A factor analysis performed on the item measures for the SBO scale suggested a similar distinction within the items measured. Table 5.12 shows the un-rotated (due to the search for only one factor) component matrix derived from a factor analysis (based on eigenvalues of more than 1) of the 4 item measures for SBO.

\section{Table 5.12 - SBO Factor Analysis - Component Matrix}

\begin{tabular}{|l|r|r|}
\hline & \multicolumn{2}{|c|}{ Component } \\
\cline { 2 - 3 } & \multicolumn{1}{|c|}{1} & \multicolumn{1}{c|}{2} \\
\hline Small Business & .249 & .923 \\
Orientation Q1 & & \\
Small Business & .644 & -.376 \\
Orientation Q2 \\
Small Business \\
$\begin{array}{l}\text { Orientation Q3 } \\
\text { Small Business } \\
\text { Orientation Q4 }\end{array}$ & .797 & -.062 \\
\hline
\end{tabular}

Extraction Method: Principal

Component Analysis.

Table 5.12 demonstrates the failure of the item measures for the SBO construct to all load onto one dimension. SBO question 1 loads onto its own dimension (average loading $=.923$ ), while SBO questions 2, 3 and 4 load onto another dimension (average loading $=.725$ ). Below tables 5.13 and 5.14 show the Cronbach's Alpha for the 4 item 
scale as well as the calculations for the adjusted Cronbach's Alpha if any item measure were to be deleted:

Table 5.13 - SBO - Cronbach Alpha - Reliability Statistics

\begin{tabular}{|r|r|}
\hline $\begin{array}{c}\text { Cronbach's } \\
\text { Alpha }\end{array}$ & N of Items \\
\hline .394 & 4 \\
\hline
\end{tabular}

Table 5.14 - Cronbach Alpha if Scale Item is Deleted - SBO (Item-Total Statistics)

\begin{tabular}{|l|r|r|r|r|}
\hline & $\begin{array}{c}\text { Scale Mean if } \\
\text { Item Deleted }\end{array}$ & $\begin{array}{c}\text { Scale } \\
\text { Variance if } \\
\text { Item Deleted }\end{array}$ & $\begin{array}{c}\text { Corrected } \\
\text { Item-Total } \\
\text { Correlation }\end{array}$ & $\begin{array}{c}\text { Cronbach's } \\
\text { Alpha if Item } \\
\text { Deleted }\end{array}$ \\
\hline $\begin{array}{l}\text { Small Business } \\
\text { Orientation Q1 } \\
\text { Small Business } \\
\begin{array}{l}\text { Orientation Q2 } \\
\text { Small Business } \\
\text { Orientation Q3 } \\
\text { Small Business } \\
\text { Orientation Q4 }\end{array}\end{array} \quad 18.52$ & 8.072 & .109 & .556 \\
\hline
\end{tabular}

With reference to the first table above, the Cronbach Alpha of the entire SBO scale is .394, which would generally be considered unacceptable for a reliable scale (George and Mallery, 2003). While deleting question 1 (intention for business expansion) would improve the scale's Cronbach measure to .556 doing so would defeat the real purpose of the scale. That is, the scale was used in the survey as a way to control for the possibility that some entrepreneurs may be satisfied with the size and scope of their current operations and as such may actively choose to maintain the current business operations rather than attempt to grow. It can be assumed that the specific question relating to the entrepreneur's intention to grow is more applicable to understanding 
his/her intentions for growth than questions relating to lifestyle, personality fit or emotional attachment. Based on this assumption the decision was taken to eliminate SBO questions 2, 3 and 4 from the results and analysis. Rather, only SBO question 1 (plans to expand business, Q21) was included in the analysis as a control variable. This inclusion helps to ensure that the findings from the main relationships under investigation (EO, ambidexterity and measures of performance) are not confounded by the fact that some people may actively be limiting the performance of the organization due to personal rather than business reasons.

\section{Access to Finance}

Another variable that can unduly affect the understanding between the main effect relationships of interest is the ability of a firm to access finance and as a result, was measured and controlled in the data analysis. Table 5.15 shows the minimum, maximum, mean and standard deviation of the participant's responses to the question: "If there was a need for business financing, my business would be able to secure any amount it needed". Higher scores indicate a greater ability to access financing while lower scores indicate and inability to access business financing.

Table 5.15 - Access to Finance - Descriptive Statistics

\begin{tabular}{|l|r|r|r|r|r|}
\hline & $\mathrm{N}$ & Minimum & Maximum & Mean & $\begin{array}{c}\text { Std. } \\
\text { Deviation }\end{array}$ \\
\hline Access to Finance & 304 & 1 & 7 & 4.23 & 1.968 \\
Valid N (listwise) & 304 & & & & \\
\hline
\end{tabular}

It can also be noted that responses to question 1 of the SBO scale (intentions to 
grow) and access to finance both show acceptable levels of skewedness and kurtosis, thereby meeting the assumption of normality. Stevens (1996) suggests that ranges for skewedness should be between -2 to 2 and both item measures fall comfortably within this range $(\mathrm{SBO} \mathrm{Q} 1=.542$, access to finance $=-.152)$. Norusis $(2004)$ suggests that a kurtosis score between -7 to 7 is an acceptable range. Again both measures fall within range $(\mathrm{SBO} q 1=-1.31$, access to finance $=-1.06)$.

\section{Outliers}

In the analysis of the data, it may be the case that some responses are more impactful on the data than is warranted. This is because certain observations in the data set may lie an abnormal distance from the other observations. This can create a scenario where the results from the data analysis overly compensate to account for the extremes of these observations, commonly known as outliers. As a tool to assist in the detection of outliers, the standardized residual coefficient was calculated for each participant's responses as a function of the three dimensions of performance. Observations that had a residual value that was approximately above 2 or below -2 (plus or minus two standard deviations above or below expected value) were isolated and we investigated the responses manually. Based on this analysis, we isolated a total of 20 participants. Upon assessing the responses there were some obvious issues with some of the responses that created a cause for concern.

In 5 of the 20 potential outliers, the data showed a clear bias to the extremes of scale. That is, 5 of the participants answered all questions with a 1 or a 7 , the extremes in 
range. In another instance, the responses of the participant all tended toward the highest end of the scale and as such, answered nearly every question with a 7. Further, one other participant showed high levels of inconsistency in answering the questionnaire (this was also noted at the time of data collection). In this instance, similar questions were answered very differently and while we believe this is occasionally acceptable, it is our belief that the participant did not appropriately answer the questions to the extent that all items were fairly considered and answered truthfully. Thirteen of the twenty cases that we isolated did not show any obvious signs of having been answered improperly and as such remained in the final data set. In the end, 7 of the 20 (participant numbers: 5, 17, 67, $68,71,112$ and 218) potential outliers were deemed to have issues that warranted their removal from the data set and do not form part of the analysis and results that follow.

Figure 5.4 shows the boxplot indicating the potential outliers based on the residuals when regressed on profitability, growth and sustainability.

Figure 5.4 - Box-plot of Standardized Residuals

Profitability

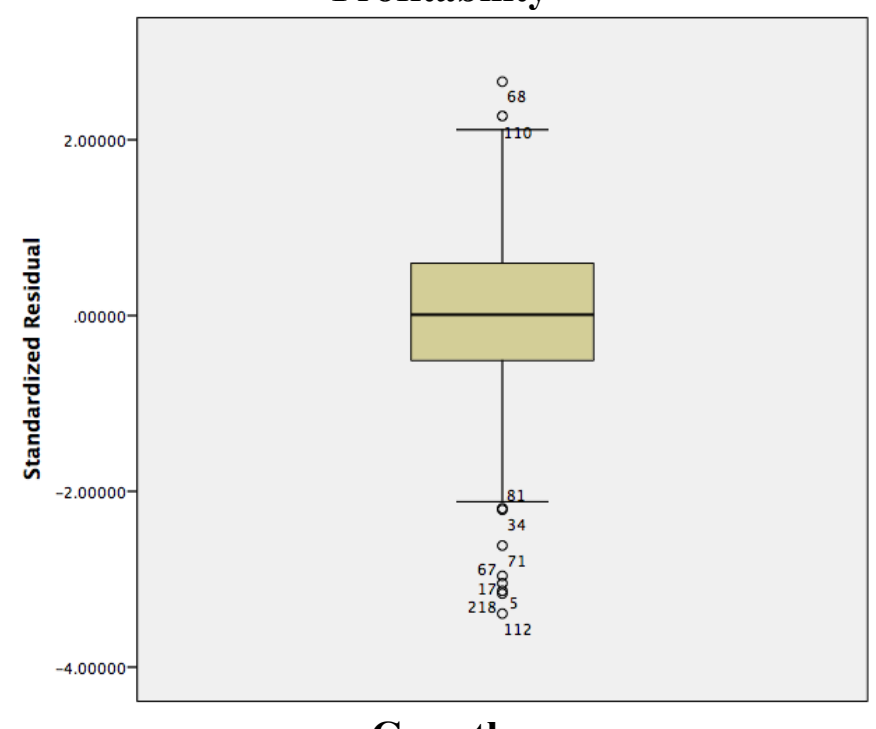

Growth 

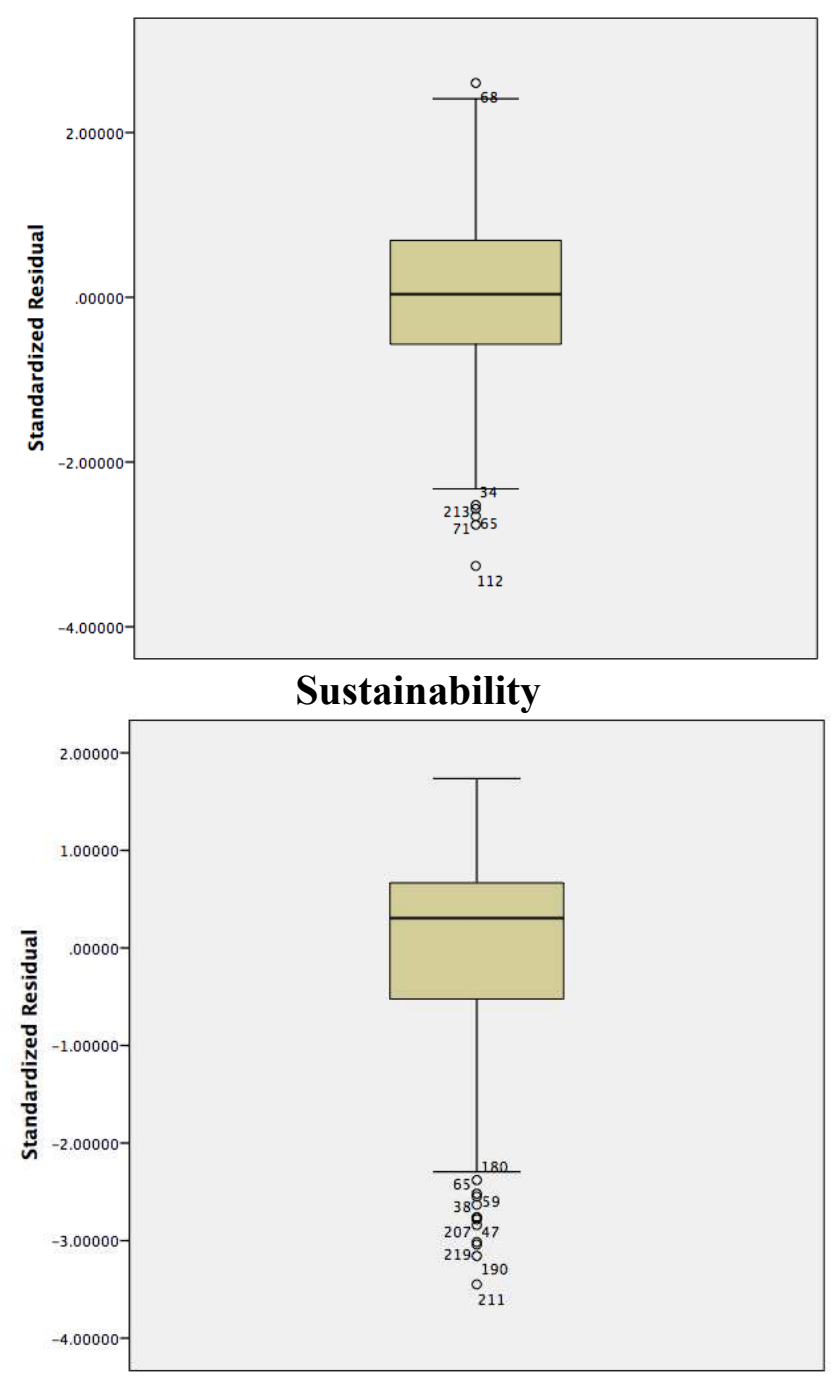

\section{Convergent Validity - Testing Dimensions of Entrepreneurial Orientation}

This study considers the impact of the individual dimensions of the entrepreneurial orientation scale. The section will report the findings for each of the dimensions with the aim of a greater understanding of their unique impacts on performance. 


\section{Innovativeness}

The innovativeness component of the quantitative research consisted of three questions including: (q1) the emphasis on tried and true products versus new and innovative products, (q2) the quantity of new products/services introduced and (q3) the scale of product change. Based on the responses from the innovation component of the questionnaire, Table 5.16 below shows the descriptive statistics $(\mathrm{n}=297)$ :

Table 5.16 - Innovativeness Item Measures Descriptives

\begin{tabular}{|l|l|l|l|l|l|l|}
\hline Question & Mean & Min. & Max. & St. Dev. & Skewedness & Kurtosis \\
\hline $\begin{array}{l}\text { Q1: Emphasis on } \\
\text { new/innovative products }\end{array}$ & 3.6 & 1 & 7 & 2.22 & .157 & -1.144 \\
\hline $\begin{array}{l}\text { Q2: Quantity of } \\
\text { new/innovative products }\end{array}$ & 4.48 & 1 & 7 & 1.97 & -.377 & -1.031 \\
\hline $\begin{array}{l}\text { Q3: Scope of } \\
\text { product/service changes }\end{array}$ & 3.6 & 1 & 7 & 1.90 & .253 & -.965 \\
\hline
\end{tabular}

As can be seen above, all questions had responses that fell on or between the 1 to 7 answer rage as well as the calculations for the item mean and standard deviation.

Further, the skewedness and kurtosis of each item measure fell within acceptable levels to maintain the assumption of normality. Through this analysis, the three items on the innovativeness scale were assumed to be related as they combine to measure the latent construct of innovativeness. To test the assumption of internal consistency the Cronbach Alpha was calculated for the scale and is shown below in Table 5.17 and Table 5.18: 
Table 5.17 - Innovativeness - Reliability Statistics

\begin{tabular}{|r|r|}
\hline $\begin{array}{c}\text { Cronbach's } \\
\text { Alpha }\end{array}$ & N of Items \\
\hline .686 & 3 \\
\hline
\end{tabular}

Table 5.18 - Innovativeness - Item-Total Statistics

\begin{tabular}{|l|r|r|r|r|}
\hline & $\begin{array}{c}\text { Scale Mean } \\
\text { if Item } \\
\text { Deleted }\end{array}$ & $\begin{array}{c}\text { Scale } \\
\text { Variance if } \\
\text { Item Deleted }\end{array}$ & $\begin{array}{c}\text { Corrected Item- } \\
\text { Total } \\
\text { Correlation }\end{array}$ & $\begin{array}{c}\text { Cronbach's } \\
\text { Alpha if Item } \\
\text { Deleted }\end{array}$ \\
\hline Innovation Q1 & 8.08 & 11.018 & .467 & .646 \\
Innovation Q2 & 7.20 & 12.144 & .502 & .592 \\
Innovation Q3 & 8.07 & 12.136 & .542 & .546 \\
\hline
\end{tabular}

In Table 5.17 above, we can see that the Cronbach Alpha calculation for the three innovativeness scale items is .686.. In this case it is noted that the calculation falls slightly below .7, and does raise some questions as to whether the item measures on the scale are indeed related. However, because the measurement is very close to .7 there is still considerable reason for the justification of the items as all being measures of innovativeness. In Table 5.17, we are presented with the Cronbach Alpha if the item is deleted. Here we note that the overall Cronbach Alpha is reduced if any one item is removed from the scale. Also of note is the disparity in the calculation depending on which item is being removed. Based on these calculations, we see that Innovativess Q1 may have the least internal consistency with the scale. This is because the Cronbach Alpha calculation falls the least if this item were to be removed. However, in keeping with the scales that have been consistently used in the field, we opine that all the innovativeness item measures warrant inclusion in the analysis that follows. 
In order to get a better understanding of the relationship that is shared between innovativeness and different measures of performance, innovativeness (a summation of the three item measures) was regressed onto profit (P1), growth (P2) and sustainability (P3). The results summary is shown below in Table 5.19:

Table 5.19 - Innovation Regression Results

\begin{tabular}{|l|l|l|l|}
\hline & Profit & Growth & Sustainability \\
\hline F-Statistic & $30.8^{* * *}$ & $29.92^{* * *}$ & $6.19^{* *}$ \\
\hline R squared & .091 & .092 & .021 \\
\hline Unstandardized Coefficient & $.261^{* * *}$ & $.277^{* * *}$ & $.149^{* *}$ \\
\hline
\end{tabular}

$* * * \mathrm{p}<.001, * * \mathrm{p}<.05, * \mathrm{p}<.1$

We can see from the table above that the relationship between innovativeness and performance seems to be significant for all three measures of performance. With regards to its relationship with profit, innovativeness can be said to explain approximately $9.1 \%$ of the variability in profit and has and F-statistic of 30.8 which is significant at the $p<.001$ level. Growth performance shares a similar relationship with innovativeness explaining $9.2 \%$ of the variability in growth and a F-statistic of 29.92 which is also significant at the $\mathrm{p}<.001$ level. Innovativeness and performance in terms of sustainability still share a significant relationship according the f-statistic $(6.19, \mathrm{p}<.05)$, however innovativeness explains a relatively low $2.1 \%$ of the variance in sustainability. The unstandardized coefficients are all positive, which suggests that they share a linear relationship with the performance measures such that an increase in innovativeness should lead to an increase in performance. The size of the coefficient reveals the expected change in performance with a unit change in innovativeness. Based on the unstandardized coefficient of profits 
for instance (.261) suggests that for every increase of one unit in innovativeness (independent variable) the profit performance (dependent variable) of the firm increases by .261 (on a 7-point scale). Thus, from the table we can see that the impact of a change in innovativeness should impact profit $(.261)$ and growth $(.277)$ to a greater extent than sustainability (.149).

\section{Risk-taking}

The risk-taking component of the quantitative research also consisted of three questions including: (q1) tendency for low or high risk projects, (q2) environmental view of risk (risk to be avoided or risk as essential) and (q3) cautious 'wait and see' versus bold and aggressive approach to opportunities. Based on the responses from the risk-taking component of the questionnaire, Table 5.20 below shows the descriptive statistics $(n=297)$ :

Table 5.20 - Risk-taking Item Measures Descriptives

\begin{tabular}{|l|l|l|l|l|l|l|}
\hline Question & Mean & Min. & Max. & St. Dev. & Skewness & Kurtosis \\
\hline $\begin{array}{l}\text { Q1: Tendency for low of } \\
\text { high risk projects }\end{array}$ & 3.47 & 1 & 7 & 1.95 & .384 & -.964 \\
\hline $\begin{array}{l}\text { Q2: Risk adverse or risk } \\
\text { seeker }\end{array}$ & 4.37 & 1 & 7 & 2.06 & -.228 & -.1 .185 \\
\hline $\begin{array}{l}\text { Q3: Wait and see versus } \\
\text { bold and aggressive }\end{array}$ & 3.85 & 1 & 7 & 2.00 & .120 & -1.227 \\
\hline
\end{tabular}

Again, it can be seen above that all risk-taking questions had responses that fell on or between the 1 to 7 answer range, and the calculation of the item mean and standard deviation is also given. The skewedness and kurtosis of each question fell within 
acceptable levels to maintain the assumption of normality. As with innovativeness and proactiveness, the three items on the risk-taking scale have been assumed to be related as they combine to measure the latent construct of risk-taking. To test the assumption of internal consistency the Cronbach Alpha was calculated for the items and is shown below in Table 5.21 and Table 5.22:

Table 5.21 - Risk-taking - Reliability Statistics

\begin{tabular}{|r|r|}
\hline $\begin{array}{c}\text { Cronbach's } \\
\text { Alpha }\end{array}$ & N of Items \\
\hline .723 & 3 \\
\hline
\end{tabular}

Table 5.22 - Risk-taking - Item-Total Statistics

\begin{tabular}{|l|r|r|r|r|}
\hline & $\begin{array}{c}\text { Scale Mean if } \\
\text { Item Deleted }\end{array}$ & $\begin{array}{c}\text { Scale } \\
\text { Variance if } \\
\text { Item Deleted }\end{array}$ & $\begin{array}{c}\text { Corrected } \\
\text { Item-Total } \\
\text { Correlation }\end{array}$ & $\begin{array}{c}\text { Cronbach's } \\
\text { Alpha if Item } \\
\text { Deleted }\end{array}$ \\
\hline Risk-taking Q1 & 8.22 & 11.955 & .553 & .623 \\
Risk-taking Q2 & 7.31 & 11.351 & .553 & .623 \\
Risk-taking Q3 & 7.84 & 11.971 & .524 & .657 \\
\hline
\end{tabular}

In Table 5.21 above, we can see that the Cronbach Alpha calculation for the three proactiveness scale items is .723 , indicating an acceptable internal consistency. In Table 5.22, we are presented with the Cronbach Alpha if any of the item measures are deleted. In all cases the Cronbach Alpha calculation will fall if an item is deleted, suggesting that all the item measures help to explain the latent construct under investigation.

As with the other EO variables, in order to get a better understanding of the relationship that is shared between risk-taking and the different measures of performance, risk-taking (a summation of the three item measures) was regressed onto profit (P1), growth (P2) and sustainability (P3). The summary of results is shown below in Table 5.23: 
Table 5.23 - Risk-taking Regression Results

\begin{tabular}{|l|l|l|l|}
\hline & Profit & Growth & Sustainability \\
\hline F-Statistic & $24.38^{* * *}$ & $39.92^{* * *}$ & $8.35^{* *}$ \\
\hline R squared & .076 & .119 & .028 \\
\hline Unstandardized Coefficient & $.233^{* * *}$ & $.313^{* * *}$ & $.171^{* *}$ \\
\hline
\end{tabular}

$* * * \mathrm{p}<.001, * * \mathrm{p}<.05, * \mathrm{p}<.1$

We can see from the table above that the relationship between risk-taking and performance seems to be significant for all three measures of performance. With regards to its relationship with profit, risk-taking can be said to explain approximately $7.6 \%$ of the variability in profit and has and F-statistic of 24.38 which is significant at the $\mathrm{p}<.001$ level. Growth performance shares a similar relationship with risk-taking explaining $11.9 \%$ of the variability in growth and a F-statistic of 39.92 which is also significant at the $\mathrm{p}<.001$ level. Risk-taking and sustainability performance also share a significant relationship according the f-statistic $(8.35, \mathrm{p}<.05)$, however explains a relatively lower $2.8 \%$ of the variance in sustainability. The unstandardized coefficients are all positive, which suggests that the measures of risk-taking share a linear relationship with the performance measures such that an increase in risk-taking should lead to an increase in performance. The size of the coefficient reveals the expected change in performance with a unit change in risk-taking. The unstandardized coefficient of sustainability for instance, (.171) suggests that for every increase of one unit in risk-taking (independent variable) the sustainability performance (dependent variable) of the firm increases by .171. 


\section{Proactiveness}

The proactiveness component of the quantitative research also consisted of three questions including: (q1) likelihood of being first to market with new products and services, (q2) leader or follower in the introduction of new product and ideas and (q3) responder to actions or initiator of market actions. Based on the responses from the proactiveness component of the questionnaire, Table 5.24 below shows the descriptive statistics $(\mathrm{n}=297)$ :

Table 5.24 - Proactiveness Item Measures Descriptives

\begin{tabular}{|l|l|l|l|l|l|l|}
\hline Question & Mean & Min. & Max. & St. Dev. & Skewness & Kurtosis \\
\hline $\begin{array}{l}\text { Q1: Likelihood of being } \\
\text { first to market }\end{array}$ & 4.34 & 1 & 7 & 1.82 & -.336 & -.842 \\
\hline $\begin{array}{l}\text { Q2: Leader or follower in } \\
\text { introduction of new } \\
\text { products/ideas }\end{array}$ & 4.67 & 1 & 7 & 1.92 & -.400 & -.989 \\
\hline $\begin{array}{l}\text { Q3: Responder or initiator } \\
\text { of market actions }\end{array}$ & 4.45 & 1 & 7 & 1.72 & -.343 & -.709 \\
\hline
\end{tabular}

Again, it can be seen above that all proactiveness questions had responses that fell on or between the 1 to 7 answer range, the calculations of the item mean and standard deviation are also given. The skewedness and kurtosis of each question fell within acceptable levels to maintain the assumption of normality. As with the innovativeness and risk-taking scales above, the three items on the proactiveness scale have been assumed to be related as they combine to measure the latent construct of proactiveness. To test the assumption of internal consistency the Cronbach Alpha was calculated for the items and is shown below in Table 5.25 and Table 5.26. 
Table 5.25 - Proactiveness - Reliability Statistics

\begin{tabular}{|r|r|}
\hline $\begin{array}{c}\text { Cronbach's } \\
\text { Alpha }\end{array}$ & N of Items \\
\hline .771 & 3 \\
\hline
\end{tabular}

Table 5.26 - Proactiveness - Item-Total Statistics

\begin{tabular}{|l|r|r|r|r|}
\hline & $\begin{array}{c}\text { Scale Mean if } \\
\text { Item Deleted }\end{array}$ & $\begin{array}{c}\text { Scale Variance } \\
\text { if Item Deleted }\end{array}$ & $\begin{array}{c}\text { Corrected Item- } \\
\text { Total } \\
\text { Correlation }\end{array}$ & $\begin{array}{c}\text { Cronbach's } \\
\text { Alpha if Item } \\
\text { Deleted }\end{array}$ \\
\hline Proactiveness Q1 & 9.12 & 10.076 & .611 & .685 \\
Proactiveness Q2 & 8.79 & 9.242 & .649 & .642 \\
Proactiveness Q3 & 9.01 & 11.111 & .560 & .740 \\
\hline
\end{tabular}

In the first table above, we can see that the Cronbach Alpha calculation for the three proactiveness scale items is .771 and as such is considered acceptable. In the second table, we are presented with the Cronbach Alpha if any of the item measures are deleted. In all cases the Cronbach Alpha calculation will fall if an item is deleted, suggesting that all the item measures help to explain the latent construct under investigation.

In order to get a better understanding of the relationship that is shared between proactiveness and the different measures of performance, proactiveness (a summation of the three item measures) was regressed onto profit (P1), growth (P2) and sustainability (P3). The results summary is shown below in Table 5.27:

Table 5.27 - Proactiveness Regression Results

\begin{tabular}{|l|l|l|l|}
\hline & Profit & Growth & Sustainability \\
\hline F-Statistic & $35.98^{* * *}$ & $44.19^{* * *}$ & $17.29^{* * *}$ \\
\hline R squared & .109 & .13 & .055 \\
\hline Unstandardized Coefficient & $.295^{* * *}$ & $.349^{* * *}$ & $.258^{* * *}$ \\
\hline
\end{tabular}


$* * * \mathrm{p}<.001, * * \mathrm{p}<.05, * \mathrm{p}<.1$

We can see from the table above that the relationship between proactiveness and performance seems to be significant for all three measures of performance (even slightly beyond the strength of the relationship with innovativeness). With regards to its

relationship with profit, proactiveness can be said to explain approximately $10.9 \%$ of the variability in profit and has and F-statistic of 35.98 which is significant at the $p<.001$ level. Growth performance shares a similar relationship with innovativeness explaining $13 \%$ of the variability in growth and a F-statistic of 44.19 which is also significant at the $\mathrm{p}<.001$ level. Proactiveness and performance in terms of sustainability also share a significant relationship according the f-statistic $(17.29, \mathrm{p}<.001)$, however explains a relatively lower $5.5 \%$ of the variance in sustainability. The unstandardized coefficients are all positive, which suggests that the measures of proactiveness share a linear relationship with the performance measures such that an increase in proactiveness should lead to an increase in performance. The size of the coefficient reveals the expected change in performance with a unit change in proactiveness. Based on the unstandardized coefficient of growth for instance (.349) suggests that for every increase of one unit in proactiveness (independent variable) the growth performance (dependent variable) of the firm increases by .349 .

\section{Factor Analysis of EO}

Having considered the descriptive statistics, the assumption of normality and the internal reliability of the individual dimensions of the EO we can proceed to a factor analysis. Factor analysis is a statistical tool that uses the variability that is 
extrapolated between observed, correlated variables (the individual item measures) in order to reduce these measures into unobserved variables known as factors. In the case of the EO construct, as has been discussed earlier we believe that there are three factors that should emerge from the factor analysis of the nine item measures of the EO construct. That is, innovativeness, risk-taking and proactiveness each had three item measures that have been designed such that they are assumed to be each measuring a different unobserved phenomenon (innovativeness, risk-taking and proactiveness.) The factor analysis above was carried out using the extraction technique of Principal Component Analysis, while employing the oblique rotation method Promax and further requiring SPSS to extract three factors. Oblique rotation methods (as opposed to orthogonal methods) assume that the factors are correlated. Theoretically, the analysis presented in this paper has suggested that the EO factors are indeed correlated, but still offer enough differences to warrant their individual analysis. The result from the factor analysis are shown below in Table 5.28:

Table 5.28 - PCA Analysis of EO (three factors) - Pattern Matrix

\begin{tabular}{|l|r|r|r|}
\hline & \multicolumn{3}{|c|}{ Component } \\
\cline { 2 - 4 } & 1 (Proactiveness) & 2 (Risk-taking) & 3 (Innovativeness) \\
\hline Innovation Q1 & .182 & .222 & $\mathbf{. 4 5 7}$ \\
Innovation Q2 & .006 & -.154 & $\mathbf{9 3 7}$ \\
Innovation Q3 & -.089 & .250 &. $\mathbf{6 8 9}$ \\
Risk-taking Q1 & -.069 & .778 & .119 \\
Risk-taking Q2 & -.077 & $\mathbf{. 8 4 7}$ & .025 \\
Risk-taking Q3 & .235 & $\mathbf{. 7 0 0}$ & -.139 \\
Proactiveness Q1 & $\mathbf{. 7 1 7}$ & -.034 & .244 \\
Proactiveness Q2 & $\mathbf{. 8 8 5}$ & -.109 & .066 \\
Proactiveness Q3 & $\mathbf{. 8 2 2}$ & .140 & -.210 \\
\hline
\end{tabular}

Extraction Method: Principal Component Analysis.

Rotation Method: Promax with Kaiser Normalization. 
The Kaiser-Meyer-Olkin measure of sampling adequacy for the above factor analysis was .885 , which indicates that the data was appropriate for factor analysis as it exceeded .7 (Gorsuch, 1983). The above pattern matrix suggests that there are indeed three distinct dimensions of EO. The items that were assumed to be related to innovativeness all load onto the third factor with loading scores of $.457, .937$ and .689 for innovativeness questions $1-3$ respectively (average loading $=.694$ ). As a general rule, a loading of .7 and above indicates that an item measure loads strongly onto a factor and supports convergent validity (Chin, 1998). However, when working within the Social Sciences, some have argued that while a loading in excess of .7 is strong, a loading cut off point of .4 is sufficient to justify the inclusion of an item as a component of the factor in question (Stevens, 2001). All the loadings for innovativeness exceed the .4 level, but questions 1 and 3 do fall below the .7 (question 3 is very close) and necessitate some additional consideration. When considering that the highest loading for both questions are on the innovativeness dimension, the items did not load above .3 on any other factor and the fact that these questions have been utilized in numerous EO research studies, we decided to include all the item measures for innovativeness for the remainder of the analysis.

The item measures for risk-taking all load onto the second factor, with each measure loading at or exceeding the .7 loading score $(\mathrm{q} 1=.778, \mathrm{q} 2=.857, \mathrm{q} 3=.700$, average loading $=.775$ ) strongly suggesting that these items are measuring the risk-taking construct. Finally, the proactiveness item measures also all loaded onto the first factor 
with all items surpassing the strong loading score of $.7(\mathrm{q} 1=.717, \mathrm{q} 2=.885, \mathrm{q} 3=.822$, average loading $=.808)$.

While the factor analysis is encouraging in that it appears to support the theoretical proposition that EO is made up of three distinct concepts (and thus tends towards being a formative rather reflective scale) it is prudent to discuss the implications of requiring SPSS to extract three factors. Some researchers have suggested that the cut off for the inclusion of a factor is that its eigenvalue score exceeds one (Stevens, 2001). Below we see a scree plot of the eigenvalue for above factor analysis:

Figure 5.5 - Scree Plot - Items of EO

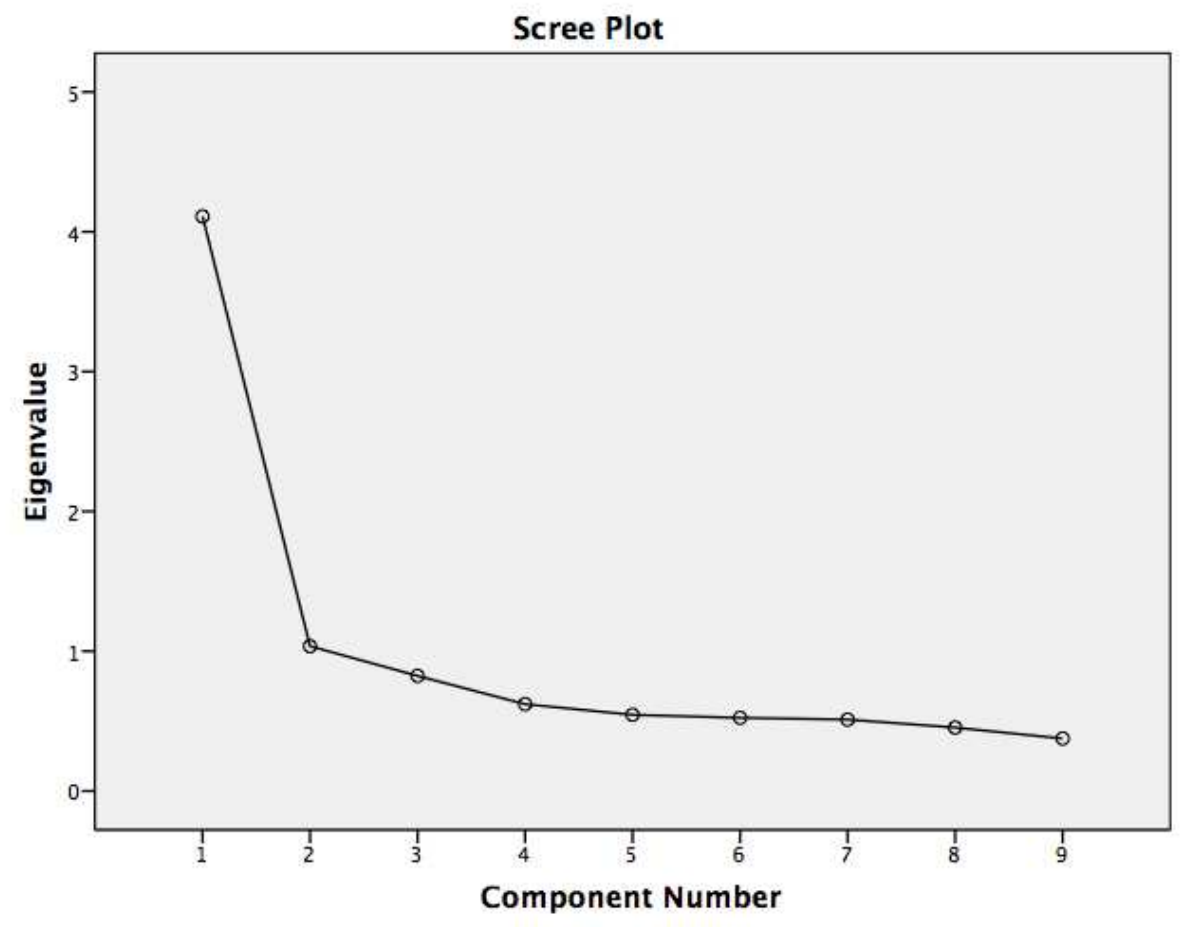

From the above scree plot it is apparent that only two factors have an eigenvalues above 1 with the first being 4.11 , the second 1.036 and the third .824 . Thus, even the second eigenvalue barely meets the cut off eigenvalue level, while the third would be 
thrown out as a factor by some researchers. Other researchers have suggested that the rate of change between eigenvalues can provide valuable information, with the implication that the factors that exist do so before the scree plot 'elbows' (Introduction to SAS). From the above scree plot then, this test would imply that there is only one factor as there is a large drop from the first to the second factor with eigenvalues leveling thereafter. This carries with it the implication that the EO scale is reflective rather than formative, meaning that variation in the dimensions comes from variation in the level of EO (as opposed to formative which would suggest that variation in EO is as a result of variation in the dimensions). As a further test, we ran the factor analysis again, this time requiring SPSS to base its calculations on the inclusion of only one factor. The result from this analysis is shown below in Table 5.29:

\section{Table 5.29 - EO (one factor) - Component Matrix}

\begin{tabular}{|l|r|}
\hline \multirow{2}{*}{} & Component \\
\cline { 2 - 2 } & 1 \\
\hline Innovation Q1 & .687 \\
Innovation Q2 & .587 \\
Innovation Q3 & .664 \\
Risk-taking Q1 & .696 \\
Risk-taking Q2 & .676 \\
Risk-taking Q3 & .684 \\
Proactiveness Q1 & .749 \\
Proactiveness Q2 & .689 \\
Proactiveness Q3 & .638 \\
\hline
\end{tabular}

Extraction Method: Principal Component Analysis.

Based on the criteria established above of factor loadings ideally exceeding .7, but being acceptable over .4 , we would be forced to accept the factor analysis with only one 
factor as also appropriate. In this instance, all factors load over the .4 cut off, but only one loads above .7 (average loading = .674). Based on these results, it seems as though both a three factor and one factor solution fits the data appropriately implying convergent validity for both models. However, due to the fact that with the three factor solution 7 of the 9 items load at over .7, while with the one item factor solution only 1 of 9 items load at over .7, the three item factor solution seems to be slightly more appropriate in meeting the requirements of convergent validity.

\section{Average Variance Extracted}

An additional test that can be conducted to satisfy the convergent validity of the model utilizes the average variance extracted (AVE) for each construct as a measure. This test measures the level of variance captured within each construct in the same model versus the variance that is created by the measurement error. Hair et al. (2010) suggest that an AVE that exceeds .5 is acceptable. Table 5.30 below shows the AVE calculations for each dimension of the EO, as well as the full EO.

Table 5.30 - Average Variance Extracted (EO)

\begin{tabular}{|l|l|l|}
\hline \multicolumn{1}{|c|}{ Dimension } & $\begin{array}{l}\text { Average } \\
\text { Factor } \\
\text { Loading }\end{array}$ & \multicolumn{1}{c|}{ AVE } \\
\hline Innovativeness & .694 & .482 \\
\hline Risk-taking & .778 & .600 \\
\hline Proactiveness & .808 & .653 \\
\hline Full EO & .674 & .453 \\
\hline
\end{tabular}


Above we can see that the risk-taking and proactiveness dimensions satisfy the AVE test supporting the convergent validity of these scales as both are above the .5 cut off (.600 and .653 respectively). As with the Cronbach Alpha tests previously, innovativeness again fell slightly short of the strict test of convergent validity, missing the .5 cut off with an AVE of .482. The AVE of the one factor solution also fell short of being supported by the AVE convergent validity test registering a .453 . However, by conducting a reliability test of the full EO scale, the Cronbach Alpha score is .849. Contrary to the AVE test that suggests that the individual dimensions show greater convergence than the entire scale, the Cronbach Alpha test shows the opposite, suggesting that the one factor EO construct is more internally reliable, based on a comparison of Cronbach Alpha scores $(\mathrm{EO}=.849$, Innovativeness=.686, Risktaking $=.723$, Proactiveness $=.771$ ). Thus, tests of validity have been conducted including a measure of Cronbach Alpha, a principal component analysis and measures of AVE.

Based on the results of these tests it is assumed that both models of EO (three dimensions and one dimension) tend towards satisfying convergent validity, though due to the variance in scores between the models based on the Cronbach Alpha, AVE and Factor Analysis, it would be premature to offer which one of the two models fit the data better.

\section{Discriminant Validity}

Having demonstrated the convergent validity of the both the dimensions of the dimensions of the EO construct as well as the construct as a whole, it is prudent to also establish discriminant validity. While convergent validity implies that items that are 
theoretically related, are in actuality related, discriminant validity implies that constructs that are not intended to be related are in fact unrelated. Two tests that can be applied to test discriminant validity are conducted through an analysis of correlations between constructs (Hiar et al, 2010) and by comparing the AVE of constructs to the squared correlation estimate between constructs obtained from the factor analysis (Fornell and Larcker, 1981).

According to Hiar et al. (2010), if the correlations of two latent variables exceed 0.9 , they have significant overlapping constructs suggesting that the constructs fail to meet the assumption of discriminant validity. Table 5.31 below shows the correlation matrix based on the dimensions of the EO construct that we included in the analysis.

Table 5.31 - EO Correlations

\begin{tabular}{|l|l|l|l|}
\hline & Innovativeness & Risk-taking & Proactiveness \\
\hline Innovativeness & 1 & & \\
\hline Risk-taking & $.584 * * *$ & 1 & \\
\hline Proactiveness & $.520 * * *$ & $.559 * * *$ & 1 \\
\hline
\end{tabular}

$* * * \mathrm{p}<.001, * * \mathrm{p}<.05, * \mathrm{p}<.1$

From the table above we can see that the dimensions of EO all share a significant positive correlation with the other dimensions. However, no correlation is large enough to the extent that it violates the .9 correlation limit as suggested by Hiar et al (2010) suggesting the discriminant validity of the dimensions of EO. The second test of discriminant validity outlined by Fornell and Larcker (1981) advocates comparing the AVE of each construct with the square of the shared correlation between those constructs. If the square of the shared correlation (as derived from the component relation matrix) is 
less than the AVE for both of the constructs, we can assumed that discriminant validity exists between the constructs. As has been shown in Table 5.30 the AVE for the constructs under consideration are: innovativeness -.482 , risk-taking -.600 and proactiveness - .653 . Below is the component correlation matrix that is generated from the factor analysis conducted on the item measures of the dimensions of the EO construct followed by a table showing the calculations of the squared terms.

\section{Table 5.32 - EO - Component Correlation Matrix}

\begin{tabular}{|l|r|r|r|}
\hline Component & \multicolumn{1}{|c|}{1} & \multicolumn{1}{|c|}{2} & \multicolumn{1}{c|}{3} \\
\hline 1 - Proactiveness & 1.000 & .536 & .438 \\
2-Risk-taking & .536 & 1.000 & .508 \\
3 - Innovativeness & .438 & .508 & 1.000 \\
\hline
\end{tabular}

Extraction Method: Principal Component Analysis.

Rotation Method: Promax with Kaiser Normalization.

Table 5.33 - Squared terms EO - Component Correlation Matrix

\begin{tabular}{|c|c|}
\hline Proactiveness / Risk-taking & .287 \\
\hline Proactiveness / Innovativeness & .192 \\
\hline Risk-taking / Innovativeness & .258 \\
\hline
\end{tabular}

To test the discriminant validity of the proactiveness and risk-taking constructs, we compared the square of their component correlation (.287) to the AVE of both proactiveness (.653) and risk-taking (.600). Since $.287<.653$ and $.287<.600$, we can infer that the assumption of discriminant validity between the proactiveness and risk-taking constructs holds. Similarly, the square of the component correlation between proactiveness and innovativeness (.192) is less that the AVE of both constructs 
(proactiveness .653 and innovativeness .482). Finally, the square of the component correlation between risk-taking and innovativeness (.258) is less than the AVE of the risk-taking (.600) and innovativeness (.482) constructs. As such the discriminant validity between the individual dimension constructs of the EO has been established.

Testing the discriminant validity of the entire EO construct would require the use of separate constructs that are assumed to be different from the EO construct. Based on the data that has been collected, we can attempt to utilize the components of the ambidexterity capability and small business orientation (excluding question 1 which did not load onto construct as demonstrated previously) constructs to assess whether the EO construct as a whole meets the criteria for discriminant validity. First, a factor analysis must be executed on the three constructs and is shown below:

Table 5.34 - Pattern Matrix - EO, Ambidexterity and Small Business Orientation

\begin{tabular}{|l|r|r|r|}
\hline \multirow{2}{*}{} & \multicolumn{3}{|c|}{ Component } \\
\cline { 2 - 4 } & 1 & 2 & 3 \\
\hline Innovation Q1 & $\mathbf{. 7 6 7}$ & -.155 & -.108 \\
Innovation Q2 & $\mathbf{. 6 2 4}$ & -.051 & .004 \\
Innovation Q3 & $\mathbf{. 6 5 8}$ & .000 & .075 \\
Risk-taking Q1 & $\mathbf{. 6 9 7}$ & .046 & -.136 \\
Risk-taking Q2 & $\mathbf{. 6 2 8}$ & .103 & .027 \\
Risk-taking Q3 & $\mathbf{. 6 2 8}$ & .134 & -.050 \\
Proactiveness Q1 & $\mathbf{. 7 7 2}$ & -.075 & .028 \\
Proactiveness Q2 & $\mathbf{. 6 7 0}$ & .004 & .034 \\
Proactiveness Q3 & $\mathbf{. 6 1 0}$ & -.013 & .131 \\
Small Business Orientation Q2 & -.013 & .148 & $\mathbf{. 6 2 6}$ \\
Small Business Orientation Q3 & .012 & .083 &. $\mathbf{7 6 1}$ \\
Small Business Orientation Q4 & -.007 & -.166 &. $\mathbf{7 6 0}$ \\
Exploration Capability Q1 & .192 & $\mathbf{. 6 6 2}$ & .017 \\
Exploration Capability Q2 & .105 & $\mathbf{7 1 8}$ & -.001 \\
Exploration Capability Q3 & .083 & $\mathbf{. 7 1 8}$ & .078
\end{tabular}




\begin{tabular}{|l|r|r|r|} 
Exploitation Capability Q1 & -.018 & $\mathbf{. 6 6 5}$ & .063 \\
Exploitation Capability Q2 & -.213 & $\mathbf{. 6 4 5}$ & .129 \\
Exploitation Capability Q3 & -.131 & $\mathbf{. 6 8 4}$ & -.286 \\
\hline
\end{tabular}

Extraction Method: Principal Component Analysis.

Rotation Method: Promax with Kaiser Normalization.

From the factor analysis we can see that the 9 item measures from the EO scale all load onto one factor, while the three SBO items load together and the 6 ambidexterity item measures load together as well. The fact that the all the EO item measures, as well as, all the ambidexterity measures load on different factors is supportive of the quantitative differences between the two scales. Although an argument can be made that the scales are conceptually similar, they differ with regards to what the item measures investigate. For example, consider the innovativeness versus exploration item measures. The innovativeness component of EO construct asks the participant to consider the number of new products and the intensity of change from the existing product offering, while the exploration component of ambidexterity considers the time spend in the exploration of new product offerings. A firm can theoretically then explore, without innovating, and innovate without much exploration. The linkages between the two are analyzed later in the chapter. Based on the factor analysis we can calculate the AVE for each factor which is shown below (Table 5.35), in addition to the component correlation matrix directly under (Table 5.36) and Table 5.37 showing the squared terms from the component correlation matrix: 
Table 5.35 - Average Variance Extracted (EO, SBO, Ambidexterity)

\begin{tabular}{|l|l|l|}
\hline \multicolumn{1}{|c|}{ Dimension } & \multicolumn{1}{|c|}{$\begin{array}{c}\text { Average } \\
\text { Factor } \\
\text { Loading }\end{array}$} & AVE \\
\hline EO & .673 & .452 \\
\hline SBO & .716 & .512 \\
\hline Ambidexterity & .682 & .465 \\
\hline
\end{tabular}

Table 5.36 - Component Correlation Matrix (EO, SBO, Ambidexterity)

\begin{tabular}{|l|r|r|r|}
\hline Component & \multicolumn{1}{|c|}{1} & \multicolumn{1}{|c|}{2} & \multicolumn{1}{c|}{3} \\
\hline $1-\mathrm{EO}$ & 1.000 & .381 & .135 \\
$2-\mathrm{SBO}$ & .381 & 1.000 & .121 \\
3 - Ambidexterity & .135 & .121 & 1.000 \\
\hline
\end{tabular}

Extraction Method: Principal Component Analysis.

Rotation Method: Promax with Kaiser Normalization.

Table 5.37 - Squared terms EO, SBO and Ambidexterity - Component Correlation Matrix

\begin{tabular}{|c|c|}
\hline EO / SBO & .145 \\
\hline EO / Ambidexterity & .018 \\
\hline SBO / Ambidexterity &. .015 \\
\hline
\end{tabular}

Based on the above, we can infer that the correlations between EO and other constructs are well below the .9 threshold as proposed by Hiar et al. (2010) as a measure of discriminant validity. Further, the AVE of EO (.452), SBO (.512) and Ambidexterity $(.465)$ are all much greater than the squared component correlation terms $(.145, .018$ and .015) providing further evidence of the discriminant validity if the full EO construct.

Thus divergent validity conditions for both the individual dimensions as well as the full EO construct have been satisfied. 


\section{Competitive Aggressiveness}

As discussed in the literature review, there has been considerable debate surrounding the dimensions that make up the EO construct. Beyond the main dimensions of innovativeness, risk-taking and proactiveness, some researchers have advocated the inclusion of additional dimensions, specifically competitive aggressiveness and autonomy. With regards to the latter, it was not measured in the course of this research. This is because EO research is often conducted in large organizations, with middle to top management as the participants. Being a part of large organizations often tends to carry bureaucratic constraints that do not exist in smaller organizations. Since the focal point of research for this analysis was micro entrepreneurs (sometimes the only firm employee), measuring the level of autonomy was assumed to be redundant. That is, by having only the owner of the business complete the questionnaire, autonomy loses its value as a predictor. In short, being a business owner should imply full autonomy, as opposed to a manager who may face limitations on his/her autonomy. However, this redundancy does not apply to competitive aggressiveness and thus warrants further exploration.

To test whether the competitive aggressiveness dimension should be included in the final model, a series of regression analyses were conducted to measure the effect of including the competitive aggressiveness dimension in the analysis of the other dimensions. Table 5.38 below show the effect of adding the competitive aggressiveness dimension to regression models that already include the three main EO dimensions. 
Table 5.38 - Addition of Competitive Aggressiveness to EO regression model

\begin{tabular}{|l|l|l|l|}
\hline & \multicolumn{1}{|c|}{ Profit } & \multicolumn{1}{c|}{ Growth } & \multicolumn{1}{c|}{ Sustainability } \\
\hline Change in R squared & .002 & .01 & .000 \\
\hline Change in F & .654 & $3.464^{*}$ & .001 \\
\hline $\begin{array}{l}\text { B unstandardized } \\
\text { coefficient }\end{array}$ & .038 & $.092^{*}$ & .001 \\
\hline
\end{tabular}

$* * * \mathrm{p}<.001, * * \mathrm{p}<.05, * \mathrm{p}<.1$

Based on an evaluation of the table above, it appears that competitive

aggressiveness fails to significantly add to the explanation of the variance in performance

as is explained by the other dimensions of EO. With regards to profitability and

sustainability, it appears that competitive aggressiveness is not significant beyond the significance of the other EO dimensions supporting its exclusion from further analysis.

The growth dimension does show some weak significance $(\mathrm{p}<.1)$, though the significance fails to meet the commonly used $\mathrm{p}<.05$ significance test. To further investigate the possible effects of competitive aggressiveness on growth, another regression was run, this time including the previously discussed control variable, intention to grow. The results from this regression are shown below:

Table 5.39 - Addition of Intention to grow control to Competitive Aggressiveness / EO regression model

\begin{tabular}{|l|l|}
\hline & \multicolumn{1}{|c|}{ Growth } \\
\hline Change in R squared & .003 \\
\hline Change in F & 1.166 \\
\hline $\begin{array}{l}\text { B unstandardized } \\
\text { coefficient }\end{array}$ & .054 \\
\hline$* * * \mathrm{p}<.001, * * \mathrm{p}<.05, * \mathrm{p}<.1$ \\
\hline
\end{tabular}


As seen from the table above, when the control variable measuring an entrepreneur's growth intentions is added to the regression, competitive aggressiveness loses the already weak significance it shared with regards to growth. Combining this finding with the lack of additional significance offered by competitive aggressiveness in terms of the explanation of profits or sustainability, we decided to exclude competitive aggressiveness from the remainder of the analysis.

\section{Ambidexterity}

Having considered the control variables, as well as the dimensions that make up the EO construct, the final element to consider before testing the hypothesis is that of ambidexterity. As has been discussed previously, ambidexterity is thought of as the interaction between exploration and exploitation on the dimensions of combined effect (exploration*exploitation) and the balance effect (7-|exploration - exploitation|). The descriptive statistics of the two constructs that combine to form ambidexterity are shown below in Table 5.40:

Table 5.40 - Exploration and Exploitation - Descriptive Statistics

\begin{tabular}{|l|c|r|r|r|r|}
\hline & $\mathrm{N}$ & \multicolumn{1}{|c|}{ Minimum } & Maximum & Mean & Std. Deviation \\
\hline ExplorationTotal & 297 & 1.00 & 7.00 & 5.2727 & 1.56277 \\
ExploitationTotal & 297 & 1.33 & 7.00 & 5.9091 & 1.00055 \\
Valid N (listwise) & 297 & & & & \\
\hline
\end{tabular}

From the table above we can identify the minimum (exploration $=1$, exploitation $=1.33)$, maximum $($ exploration $=7$, exploitation $=7)$ means $($ exploration $=5.2727$, exploitation $=5.9091)$ and standard deviation $($ exploration $=1.56$, exploitation $=1.00)$ of 
exploration and exploitation. Tests of normality were also conducted and showed that both variables met the criteria for normality with regards to skewedness (exploration = .829 , exploitation $=-1.419)$ and kurtosis (exploration -.068 , exploitation $=3.134)$. As a test of internal consistency, a Cronbach Alpha calculation was preformed and the results are shown below first for exploration and then for exploitation:

Table 5.41 - Exploration - Reliability Statistics

\begin{tabular}{|r|r|}
\hline Cronbach's Alpha & N of Items \\
\hline .796 & 3 \\
\hline
\end{tabular}

Table 5.42 - Exploration - Item-Total Statistics

\begin{tabular}{|l|r|r|r|r|}
\hline & $\begin{array}{c}\text { Scale Mean } \\
\text { if Item } \\
\text { Deleted }\end{array}$ & $\begin{array}{c}\text { Scale } \\
\text { Variance if } \\
\text { Item Deleted }\end{array}$ & $\begin{array}{c}\text { Corrected } \\
\text { Item-Total } \\
\text { Correlation }\end{array}$ & $\begin{array}{c}\text { Cronbach's } \\
\text { Alpha if Item } \\
\text { Deleted }\end{array}$ \\
\hline Exploration Capability Q1 & 11.03 & 9.529 & .679 & .682 \\
Exploration Capability Q2 & 10.40 & 10.659 & .679 & .681 \\
Exploration Capability Q3 & 10.21 & 12.105 & .571 & .791 \\
\hline
\end{tabular}

Table 5.43 - Exploitation - Reliability Statistics

\begin{tabular}{|r|r|}
\hline Cronbach's Alpha & N of Items \\
\hline .573 & \\
\hline
\end{tabular}

Table 5.44 - Exploitation - Item-Total Statistics

\begin{tabular}{|l|r|r|r|r|}
\hline & $\begin{array}{c}\text { Scale Mean } \\
\text { if Item } \\
\text { Deleted }\end{array}$ & $\begin{array}{c}\text { Scale } \\
\text { Variance if } \\
\text { Item Deleted }\end{array}$ & $\begin{array}{c}\text { Corrected } \\
\text { Item-Total } \\
\text { Correlation }\end{array}$ & $\begin{array}{c}\text { Cronbach's } \\
\text { Alpha if Item } \\
\text { Deleted }\end{array}$ \\
\hline Exploitation Capability Q1 & 11.89 & 4.873 & .381 & .472 \\
Exploitation Capability Q2 & 11.64 & 5.063 & .413 & .430 \\
Exploitation Capability Q3 & 11.93 & 4.643 & .357 & .516 \\
\hline
\end{tabular}

As seen from the above tables, the exploration construct shows strong internal consistency with a Cronbach Alpha calculation of .796. For the exploration construct, it can be seen in Table 5.42 that should any item measure be deleted, the overall Alpha 202 
score would fall suggesting that all items align appropriately. Exploitation however, does not show the same level of consistency. The Cronbach Alpha score for exploitation is .573 and as seen from Table 5.44 if any of the items were removed from the scale, the overall Alpha score would fall. According to George and Mallery (2003) as a rule of thumb Cronbach Alpha scores below .5 are unacceptable, though those above can still be used in research. Admittedly, they describe scores that fall between .5 to .6 as generally poor, but not unacceptable. To further assess the exploration and exploitation constructs, a factor analysis was performed using the six item measures that made up the two scales (three each). The results from this factor analysis are shown below:

\section{Table 5.45 - Exploration and Exploitation Pattern Matrix}

\begin{tabular}{|l|r|r|}
\hline \multirow{2}{*}{} & \multicolumn{2}{|c|}{ Component } \\
\cline { 2 - 3 } & \multicolumn{1}{|c|}{1} & \multicolumn{1}{|c|}{2} \\
\hline Exploration Capability Q1 & $\mathbf{. 9 1 8}$ & -.087 \\
Exploration Capability Q2 & $\mathbf{. 9 0 1}$ & -.048 \\
Exploration Capability Q3 & $\mathbf{. 6 0 8}$ & .292 \\
Exploitation Capability Q1 & .220 & $\mathbf{. 5 8 3}$ \\
Exploitation Capability Q2 & -.200 & $\mathbf{. 9 2 8}$ \\
Exploitation Capability Q3 & .114 & $\mathbf{. 5 9 1}$ \\
\hline
\end{tabular}

Extraction Method: Principal Component Analysis.

Rotation Method: Promax with Kaiser Normalization.

Based on the results from the factor analysis both exploration and exploitation appear to be separate constructs. The three item measures for exploration load onto one factor (average loading $=.809$ ) and the three item measures for exploitation also load onto one factor (average loading $=.701)$, suggesting the convergent validity of each construct. Below these average loadings are shown along with the Average Variance Extracted, followed by the Component Correlation Matrix. 
Table 5.46 - Average Variance Extracted (Exploration and Exploitation)

\begin{tabular}{|l|l|l|}
\hline \multicolumn{1}{|c|}{ Dimension } & $\begin{array}{c}\text { Average } \\
\text { Factor } \\
\text { Loading }\end{array}$ & \multicolumn{1}{|c|}{ AVE } \\
\hline Exploration & .809 & .654 \\
\hline Exploitation & .701 & .491 \\
\hline
\end{tabular}

Table 5.47 - Exploration and Exploitation Component Correlation Matrix

\begin{tabular}{|l|r|r|}
\hline Component & \multicolumn{1}{|c|}{ 1 } \\
\hline 1 - Exploration & 1.000 & .459 \\
2 - Exploitation & .459 & 1.000 \\
\hline
\end{tabular}

Extraction Method: Principal Component Analysis.

Rotation Method: Promax with Kaiser Normalization.

In Table 5.46 above we can see that the exploration dimension easily meets the AVE criteria set by Hiar et al (2010) of convergent validity(.654>.5). Exploitation however does fall slightly short at .491 , but in our opinion, is close enough to still warrant consideration in the analysis. Finally, as a measure of discriminant validity Hiar et al. (2010) suggests that constructs share less than a .9 correlation between them, which is the case in this instance. Further, Fornell and Larcker (1981) suggest that is the AVE of each construct exceeds the square of the correlation term as found in the correlation matrix, then discriminant validity is supported. In this instance, the square of exploration and exploitation's correlation is $.459 * .459=.211$. Since the AVE of exploration (.654) and exploitation (.491) both exceed the square of their correlation, the discriminant validity of the constructs are supported.

As such, both the exploration and exploitation variables are considered appropriate to be included in the analysis. However, a decision was taken to modify the calculation of the ambidexterity variable. Previously, the ambidexterity calculation was 204 
proposed as the multiplication of the exploration and exploitation dimension (combined dimension $=$ exploration $*$ exploitation) multiplied by the similarity of exploration and exploitation (balance dimension $=7$-|exploration - exploitation|). Based on exploratory analysis of the data and discussions with participants however, we deemed a change in the calculation as appropriate. Specifically, to capture the effects of resource shortages in micro organizations we reformulated the balance dimension such that the new balance dimension $=1+$ exploration - exploitation $\mid$. We reasoned that given the demands faced by entrepreneurs in micro organizations, the maximization of both exploration and exploitation activities are unsustainable. To better understand the impact of the change Table 5.48 shows various sample exploration and exploitation scores and the resulting old and new ambidexterity scores.

Table 5.48 - Old versus New Ambidexterity Calculation Scores

\begin{tabular}{|r|r|r|l|l|r|}
\hline $\begin{array}{l}\text { Exploration } \\
\text { Score }\end{array}$ & $\begin{array}{l}\text { Exploitation } \\
\text { Score }\end{array}$ & $\begin{array}{l}\text { Old Balance } \\
\text { Dimension }\end{array}$ & $\begin{array}{l}\text { New } \\
\text { Balance } \\
\text { Dimension }\end{array}$ & $\begin{array}{l}\text { Old } \\
\text { Ambidexterity }\end{array}$ & $\begin{array}{l}\text { New } \\
\text { Ambidexterity }\end{array}$ \\
\hline 1 & 1 & 7 & 1 & 7 & 1 \\
\hline 2 & 2 & 7 & 1 & 28 & 4 \\
\hline 3 & 3 & 7 & 1 & 63 & 9 \\
\hline 4 & 4 & 7 & 1 & 112 & 16 \\
\hline 5 & 5 & 7 & 1 & 175 & 25 \\
\hline 6 & 6 & 7 & 1 & 252 & 36 \\
\hline 7 & 7 & 7 & 1 & 343 & 49 \\
\hline 1 & 7 & 1 & 7 & 7 & 49 \\
\hline 2 & 7 & 2 & 6 & 28 & 84 \\
\hline 3 & 7 & 3 & 5 & 63 & 105 \\
\hline 4 & 7 & 4 & 4 & 112 & 112 \\
\hline 5 & 7 & 5 & 3 & 175 & 105 \\
\hline 6 & 7 & 6 & 2 & 252 & 84 \\
\hline
\end{tabular}


From the table above, the difference in the two calculations is apparent. With regards to the old ambidexterity calculation, the higher the exploration and exploitation score (and closer together) the higher the ambidexterity. The new ambidexterity score also rewards higher exploration and exploitation scores, however, only does so to a point. In essence, the new ambidexterity tends towards rewarding a small disparity between exploration and exploitation. This new calculation suggests that to maximize the ambidexterity, it may be in the interest of micro entrepreneurs to maximize one dimension (either exploration or exploitation) while just being average at the other dimension as opposed to attempting to have exact scores on the two dimensions. Below in Figure 5.6 we see a scatter plot of the Old Ambidexterity (Ambidexterity) versus the New Ambidexterity (Finalambidexterity). Further a quadratic fit line was been inserted to better show the effects of the new calculation. Comparing the two (Ambidexterity $=$ old, Finalmbidexterity $=$ new) we can see that what would have been considered average scores on the old ambidexterity fall more into the top scores in the new calculation. 
Figure 5.6 - Visual Representation of Old versus New Ambidexterity

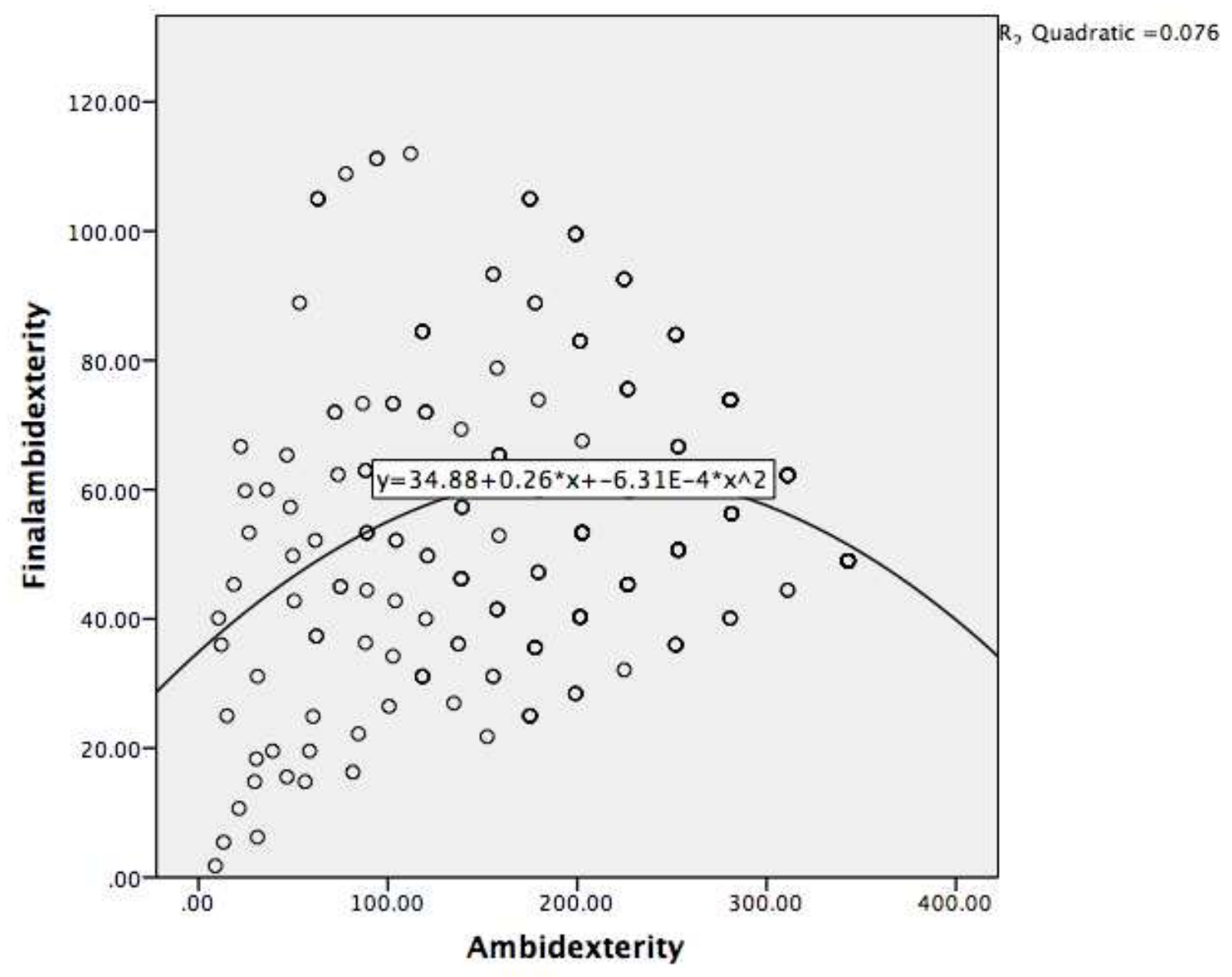

To test the effect of the new calculation, a series of regression analyses were performed using the control variables as independent variables, the three measures of performance as dependent variables and adding either the old or new ambidexterity calculation to the model to assess it relative chance to the applicability of the model. The results from these tests are summarized below: 
Table 5.49 - Test of Old versus New Ambidexterity - Dependent Variable $=$ Profits

\begin{tabular}{|l|c|c|c|}
\hline & $\begin{array}{c}\text { B- } \\
\text { unstandardized } \\
\text { coefficient }\end{array}$ & $\begin{array}{c}\text { Model R } \\
\text { squared }\end{array}$ & $\begin{array}{c}\text { F-Statistic } \\
\text { (significance } \\
\text { refers to change) }\end{array}$ \\
\hline Old Ambidexterity & $.003^{* *}$ & .189 & $8.396^{* *}$ \\
\hline New Ambidexterity & $.020^{* * *}$ & .255 & $12.295^{* * *}$ \\
\hline
\end{tabular}

$* * * \mathrm{p}<.001, * * \mathrm{p}<.05, * \mathrm{p}<.1$

Table 5.50 - Test of Old versus New Ambidexterity - Dependent Variable $=$ Growth

\begin{tabular}{|l|c|c|c|}
\hline & $\begin{array}{c}\text { B- } \\
\text { unstandardized } \\
\text { coefficient }\end{array}$ & $\begin{array}{c}\text { Model R } \\
\text { squared }\end{array}$ & $\begin{array}{c}\text { F-Statistic } \\
\text { (significance } \\
\text { refers to change) }\end{array}$ \\
\hline Old Ambidexterity & $.004^{* * *}$ & .218 & $10.032^{* * *}$ \\
\hline New Ambidexterity & $.015^{* * *}$ & .228 & $10.610^{* * *}$ \\
\hline
\end{tabular}

$* * * \mathrm{p}<.001, * * \mathrm{p}<.05, * \mathrm{p}<.1$

Table 5.51 - Test of Old versus New Ambidexterity - Dependent Variable = Sustainability

\begin{tabular}{|l|c|c|c|}
\hline & $\begin{array}{c}\text { B- } \\
\text { unstandardized } \\
\text { coefficient }\end{array}$ & $\begin{array}{c}\text { Model R } \\
\text { squared }\end{array}$ & $\begin{array}{c}\text { F-Statistic } \\
\text { (significance } \\
\text { refers to change) }\end{array}$ \\
\hline Old Ambidexterity & $.004^{* *}$ & .096 & $3.823^{* *}$ \\
\hline New Ambidexterity & $.014^{* *}$ & .096 & $3.825^{* *}$ \\
\hline
\end{tabular}

$* * * \mathrm{p}<.001, * * \mathrm{p}<.05, * \mathrm{p}<.1$

In the first instance above, when regressed onto profits, the new ambidexterity demonstrates that it is a much better fit to the data. The slope (.003 to .020) and significance of the unstandardized coefficient improves, and the model is able to account for $6.6 \%$ more of the variability in profits, which is considered a very large amount. The F-Statistic also improves greatly from old to new (8.396 to 12.295$)$ and also becomes 
more significant. The models that include growth and sustainability also improve on all measures with the new calculation, though admittedly not to the extent that the new calculation improves the fit with regards to profit. For both models (growth and sustainability) the new calculation of ambidexterity improves the R squared, the FStatistic and to a greater extent increases the positive effects of an increase of ambidexterity on the dependent variable (unstandardized coefficient). As a result of the findings from these tests the remainder of the analysis will include the new ambidexterity figure, while the old calculation is excluded.

\section{The Final Model Variables - Summary}

This chapter has considered the variables that are to used in the tests of the hypotheses that were proposed earlier. As a summary, each variable that is to be included in the final analysis is briefly outlined below.

Table 5.52 - Summary of variables for regression analysis

\begin{tabular}{|l|l|}
\hline Variable & Description \\
\hline $\begin{array}{l}\text { Number of years in } \\
\text { operation }\end{array}$ & $\begin{array}{l}\text { This variable is a measure of how long the business has } \\
\text { been in operation }\end{array}$ \\
\hline Full-time employees & $\begin{array}{l}\text { This variable measures how many staff members the } \\
\text { business employees on a full time basis }\end{array}$ \\
\hline Part-time employees & $\begin{array}{l}\text { This variables measures the number of individuals who } \\
\text { may assist with the business operations, but do not do so } \\
\text { on a full time basis }\end{array}$ \\
\hline Access to finance & $\begin{array}{l}\text { This variable is a measure of a businesses access to } \\
\text { financing should the need or opportunity arise }\end{array}$ \\
\hline Location & $\begin{array}{l}\text { There are four areas of Trinidad in which participants of } \\
\text { the survey operate. They have been dummy coded such } \\
\text { that West=1, Central=2, South=3 and East=4. }\end{array}$ \\
\hline $\begin{array}{l}\text { Type of Business } \\
\text { Activity }\end{array}$ & $\begin{array}{l}\text { Businesses have been categorized based on their type of } \\
\text { operations, with all participants either falling into one of } \\
\text { three categorizations such that 1=Distribution/Retail, }\end{array}$ \\
\hline
\end{tabular}




\begin{tabular}{|c|c|}
\hline & $2=$ Services, $3=$ Manufacturing/Production \\
\hline $\begin{array}{l}\text { Small Business } \\
\text { Orientation (Question } \\
\text { 1) }\end{array}$ & $\begin{array}{l}\text { This variable is a measure of the growth intentions of an } \\
\text { entrepreneur with its current size use as the base }\end{array}$ \\
\hline Innovativeness & $\begin{array}{l}\text { This variable is a composite of the responses from the } \\
\text { three item measures of the innovativeness of the business } \\
\text { (e.g. new products, changes to products) }\end{array}$ \\
\hline Risk-Taking & $\begin{array}{l}\text { This variable is a composite of the responses from the } \\
\text { three item measures of the willingness of the business to } \\
\text { take risk (e.g. high risk high reward versus low risk low } \\
\text { reward projects) }\end{array}$ \\
\hline Proactiveness & $\begin{array}{l}\text { This variable is a composite of the responses from the } \\
\text { three item measures based on the proactivity of the } \\
\text { business (e.g. first to market) }\end{array}$ \\
\hline $\begin{array}{l}\text { Entrepreneurial } \\
\text { Orientation }\end{array}$ & $\begin{array}{l}\text { The EO variable is the average of the composite scores of } \\
\text { the innovativeness, risk-taking and proactiveness variables }\end{array}$ \\
\hline Exploration & $\begin{array}{l}\text { This variable is the ability and willingness of a business to } \\
\text { explore new ideas, based on three item measures (e.g. } \\
\text { time spend on search for new products) }\end{array}$ \\
\hline Exploitation & $\begin{array}{l}\text { This variable measures the preoccupation with the } \\
\text { efficiency and profitability of the current operations (e.g. } \\
\text { customer appreciation of product line up, focus on } \\
\text { profitability) }\end{array}$ \\
\hline Ambidexterity & $\begin{array}{l}\text { This variable measures the combined effect of the firms } \\
\text { exploration and exploitation activity and is calculated by } \\
\text { the formula (exploration*exploitation) } *(1+\text { exploration- } \\
\text { exploitation|) }\end{array}$ \\
\hline
\end{tabular}

\section{Hypothesis Testing}

Having assessed the variables to be included in the model through several statistical tests we can confidently move on to the portion of the analysis that tests the hypotheses that have been put forward earlier. These tests will be carried out in the same order as they have been presented previously.

Hla: Both a reflective, unidimensional EO scale and a formative, multidimensional EO scale are positively and significantly related to performance 
$H 1 b$ : A formative, multidimensional EO scale explains significantly more variance in performance than a reflective, unidimensional EO scale

In order to test these hypotheses both models will be regressed unto the three dimensions of performance to determine the significance of each model. Model 1 contains only the control variables, while Model 2 shows the individual dimensions of EO (multi-dimensional) and Model 3 shows the summated EO (unidimensional)

Table 5.53 - Testing Hypothesis 1 - Profitability

\begin{tabular}{|c|c|c|c|}
\hline \multicolumn{2}{|c|}{ Dependent Variable: Profitability } & \multirow[b]{2}{*}{ Model 2} & \multirow[b]{2}{*}{ Model 3} \\
\hline & Model 1 & & \\
\hline (Constant) & $4.149 * * *$ & $2.691 * * *$ & $2.713 * * *$ \\
\hline Number of Years in Operation & -0.007 & -0.004 & -0.003 \\
\hline Full Time Employees & 0.005 & 0.002 & -0.002 \\
\hline Part Time Employees & $0.101 * *$ & $0.086 * *$ & $0.09 * *$ \\
\hline Access to Finance & $0.171 * * *$ & $0.141 * * *$ & $0.142 * * *$ \\
\hline Location & 0.077 & $0.11 *$ & $0.114^{*}$ \\
\hline Type of Business Activity & -0.069 & 0.002 & -0.008 \\
\hline Small Business Orientation Q1 & $-0.118 * * *$ & $-0.088 * *$ & $-0.08 * *$ \\
\hline Innovativeness & & $0.127 * *$ & \\
\hline Risk-taking & & 0.01 & \\
\hline Proactiveness & & $0.168 * *$ & \\
\hline $\mathrm{EO}$ & & & $0.301 * * *$ \\
\hline $\mathrm{F}$ & $7.607 * * *$ & $8.962 * * *$ & $10.836^{* * *}$ \\
\hline Change in $\mathrm{F}$ (beyond controls) & & $1.355^{* * *}$ & $3.229 * * *$ \\
\hline R squared & 0.156 & 0.239 & 0.231 \\
\hline Change in $\mathrm{R}$ squared & & 0.083 & 0.075 \\
\hline
\end{tabular}

$* * * \mathrm{p}<.001, * * \mathrm{p}<.05,{ }^{*} \mathrm{p}<.1$

Table 5.54 - Testing Hypothesis 1 - Growth

\begin{tabular}{|l|l|c|c|}
\hline \multicolumn{2}{|l|}{ Dependent Variable: Growth } & & \\
\hline (Constant) & Model 1 & Model 2 & \multicolumn{1}{c|}{ Model 3 } \\
\hline Number of Years in Operation & $-0.015^{* *}$ & $-0.011^{* *}$ & $-0.01 * *$ \\
\hline
\end{tabular}




\begin{tabular}{|l|l|r|r|}
\hline Full Time Employees & $0.107^{*}$ & $0.1^{*}$ & $0.099^{*}$ \\
\hline Part Time Employees & $0.104^{* *}$ & $0.086^{* *}$ & $0.091^{* *}$ \\
\hline Access to Finance & $0.152^{* * *}$ & $0.12^{* *}$ & $0.119^{* *}$ \\
\hline Location & -0.039 & 0.001 & 0.003 \\
\hline Type of Business Activity & -0.047 & 0.015 & 0.024 \\
\hline Small Business Orientation Q1 & $-0.146^{* * *}$ & $-0.108^{* *}$ & $-0.102^{* *}$ \\
\hline & & & \\
\hline Innovativeness & & 0.075 & \\
\hline Risk-taking & & 0.077 & \\
\hline Proactiveness & & $0.197^{* *}$ & \\
\hline & & & \\
\hline EO & & & $0.345^{* * *}$ \\
\hline & & & \\
\hline F & $8.819^{* * *}$ & $10.382^{* * *}$ & $12.743^{* * *}$ \\
\hline Change in F (beyond controls) & & $1.563^{* * *}$ & $3.924^{* * *}$ \\
\hline R squared & 0.176 & 0.266 & 0.261 \\
\hline Change in R squared & & 0.09 & 0.085 \\
\hline
\end{tabular}

$* * * \mathrm{p}<.001, * * \mathrm{p}<.05,{ }^{*} \mathrm{p}<.1$

Table 5.55 - Testing Hypothesis 1 - Sustainability

Dependent Variable: Sustainability

\begin{tabular}{|l|l|r|r|}
\hline & Model 1 & \multicolumn{1}{c|}{ Model 2 } & \multicolumn{1}{c|}{ Model 3 } \\
\hline (Constant) & 5.205 & $4.092^{* * *}$ & $4.106^{* * *}$ \\
\hline Number of Years in Operation & -0.011 & -0.009 & -0.008 \\
\hline Full Time Employees & 0.049 & 0.045 & 0.044 \\
\hline Part Time Employees & $0.119^{* *}$ & $0.102^{* *}$ & $0.11^{* *}$ \\
\hline Access to Finance & $0.12^{* *}$ & $0.1 * *$ & $0.098^{* *}$ \\
\hline Location & -0.039 & -0.014 & -0.011 \\
\hline Type of Business Activity & -0.014 & 0.02 & 0.033 \\
\hline Small Business Orientation Q1 & -0.016 & 0.005 & 0.013 \\
\hline & & & \\
\hline Innovativeness & & 0.016 & \\
\hline Risk-taking & & 0.028 & \\
\hline Proactiveness & & $0.192^{* *}$ & \\
\hline & & & \\
\hline EO & & & $0.231^{* *}$ \\
\hline & & & \\
\hline F & $2.703^{* *}$ & $3.135^{* *}$ & $3.612^{* * *}$ \\
\hline Change in F (beyond controls) & & $.432^{* *}$ & $.909 * *$ \\
\hline R squared & 0.061 & 0.099 & 0.091 \\
\hline
\end{tabular}




\begin{tabular}{|l|l|l|l|}
\hline Change in R squared & & 0.038 & 0.03 \\
\hline
\end{tabular}

$* * * \mathrm{p}<.001, * * \mathrm{p}<.05,{ }^{*} \mathrm{p}<.1$

Hypothesis 1a proposes that both the unidimensional EO model and the multidimensional model are significantly and positively related to performance. Based on the tables above, we see that the analysis does find support for this proposition. With regards to profitability, growth and sustainability the uni-dimensional EO variable is positively and significantly related to all three dimensions of performance with an unstandardized range of the $b$ coefficient of $.231-.345$, each with a significance at the $p<.05$ level. The individual variables (multidimensional scale) also show positive and significant relationships for profitability (innovativeness and proactiveness), growth (proactiveness) and sustainability (proactiveness), though admittedly the risk-taking dimensions fails to show significance on any of the tests. Further, the R squared and F-Statistic improved (all at the $p<.05$ level) for all tests of performance, when the variable for both the unidimensional and multi-dimensional EO construct were added to the model. These findings suggest support for H1a in that indeed both a unidimensional and multidimensional EO scale are significantly and positively related to performance.

Hypothesis $1 \mathrm{~b}$ suggests that the multi-dimensional EO construct would be able to explain a greater share of the variance in performance than the unidimensional construct as a result of the variance that could be extracted from the nuisances that can be explained due to the breakdown of the individual dimensions as opposed to it summation. When we consider the R squared for each model we can see that for each model the $\mathrm{R}$ squared statistic improved when the variables under consideration were added to the 
model. The table below shows a summary of the R squared for each measure of performance:

Table 5.56 - R squared for Control / Multidimensional / Unidimensional

\begin{tabular}{|l|l|l|l|}
\hline Model & $\begin{array}{l}\text { Profit R } \\
\text { squared }\end{array}$ & $\begin{array}{l}\text { Growth R } \\
\text { squared }\end{array}$ & $\begin{array}{l}\text { Sustainability } \\
\text { R squared }\end{array}$ \\
\hline Control Only & .156 & .176 & .061 \\
\hline Multi-dimensional EO & .239 & .266 & .099 \\
\hline Unidimensional EO & .231 & .261 & .091 \\
\hline
\end{tabular}

From the table above we note that for each dimension of performance, the $\mathrm{R}$ squared improved for both the unidimensional and multidimensional models suggesting that the full EO and the dimensions that make up EO are indeed related to performance. In terms of absolute amounts, the multi-dimensional model has a slightly higher R squared than the unidimensional model, lending some support for Hypothesis $1 b$.

However, the number of variables that have been input into the model affects the R squared calculation. As such, the multidimensional model with its three extra variables (beyond controls) as opposed to the unidimensional model, with only one extra variable (beyond controls) may be unduly positively affected simply by having more variables in the model. As such, a comparison utilizing the F-Statistic may be more appropriate as this test also considers the number of variables that have been used in the model. The table below shows the summary of F-statistic for each measure of performance:

Table 5.57 - F-Statistic for Control / Multidimensional / Unidimensional

\begin{tabular}{|l|l|l|l|}
\hline Model & $\begin{array}{l}\text { Profit F- } \\
\text { Statistic }\end{array}$ & $\begin{array}{l}\text { Growth F- } \\
\text { Statistic }\end{array}$ & $\begin{array}{l}\text { Sustainability } \\
\text { F-Statistic }\end{array}$ \\
\hline Control Only & 7.607 & 8.819 & 2.703 \\
\hline Multi-dimensional EO & 8.962 & 10.382 & 3.135 \\
\hline
\end{tabular}




\begin{tabular}{|l|l|l|l|}
\hline Unidimensional EO & 10.836 & 12.743 & 3.612 \\
\hline
\end{tabular}

The results from the above test suggest a different outcome from that of the $\mathrm{R}$ squared test. In all instances (various performance measures), the F-Statistic was the highest for the model with the unidimensional conceptualization of EO as opposed to the multidimensional. While for both multi and unidimensional the F-Statistic improved beyond that of the control measures alone, it did so to a greater extent for the unidimensional model. This finding suggests that while both conceptualizations of EO are valid and explain a greater amount of the variance in performance than the control variables alone, the additional parsimony that is offered by the unidimensional EO's scale is more beneficial than the inclusion of the three variables of the multidimensional scale. Thus, while there is some support for hypothesis $1 \mathrm{~b}$ (R squared testing), the F-Statistic testing suggests that the variance than can be explained by the inclusion of each of the three dimensions in the unidimensional EO construct is not warranted when compared with the additional variance than be explained through the inclusion of the summated EO alone.

H2: Firms that report high or low levels of innovativeness will perform better than firms that report moderate levels of innovativeness, reflecting a $U$ - shaped relationship

In order to test that hypothesis that firms with high or low levels of innovativeness perform better than those with moderate levels of innovativeness, we begin with our control variable and add the innovativeness variable, in addition to the squared term of this innovation variable. It should also be noted, that all variables of interest, in testing for non-linear relationships, have been mean centered to avoid issues of collinearity. 
Further, all VIF tests fell below 2, indicating that multicollinearity is not an issue in any model. The results from the regression analysis for innovativeness, with the three performance dependents are shown below:

Table 5.58 - Testing Hypothesis 2 - Innovativeness Non-Linear Relationship

\begin{tabular}{|l|l|l|l|}
\hline Dependent Variable: & Profit & Growth & Sustainability \\
\hline & Model 1 & Model 2 & Model 3 \\
\hline (Constant) & $3.848^{* * *}$ & $4.218^{* * *}$ & $4.962^{* * *}$ \\
\hline Number of Years in Operation & -0.004 & $-0.012^{*}$ & -0.009 \\
\hline Full Time Employees & 0.001 & $0.105^{*}$ & 0.044 \\
\hline Part Time Employees & $0.099 * * *$ & $0.102^{* *}$ & $0.118^{* *}$ \\
\hline Access to Finance & $0.154 * * *$ & $0.133^{* * *}$ & $0.116^{* *}$ \\
\hline Location & 0.1 & -0.016 & -0.027 \\
\hline Type of Business Activity & -0.009 & 0.019 & 0.005 \\
\hline Small Business Orientation Q1 & $-0.093^{* *}$ & $-0.12^{* * *}$ & -0.002 \\
\hline & & & \\
\hline MeanInnovativeness & $0.203 * * *$ & $0.205^{* * *}$ & $0.11 *$ \\
\hline MeanInnovativeness Square & $0.043^{*}$ & 0.03 & $0.058^{*}$ \\
\hline & & & \\
\hline F & $8.996 * * *$ & $9.393^{* * *}$ & $2.904 * *$ \\
\hline R squared & 0.22 & 0.228 & 0.083 \\
\hline
\end{tabular}

$* * * \mathrm{p}<.001, * * \mathrm{p}<.05, * \mathrm{p}<.1$

In order to prove a non-linear relationship, it is necessary for both the

'MeanInnovativeness' and 'MeanInnovativeness Square' to be significant in the model, with negative and positive signs respectively. For model 1, both terms do meet the criteria for significance, however the signs for both coefficients are positive. The significance and positivity of both signs indicate there is a non-linear relationship between innovativeness and profit performance, however it is not U-shaped as we had hypothesized. Rather the relationship is positive at low, moderate and high levels of innovativeness, with the strength of this relationship increasing at higher levels of innovativeness. Visually, the main effects of this relationship can be seen below: 
Figure 5.7 - Visualization of Non-Linear relationship between Innovativeness and Profit

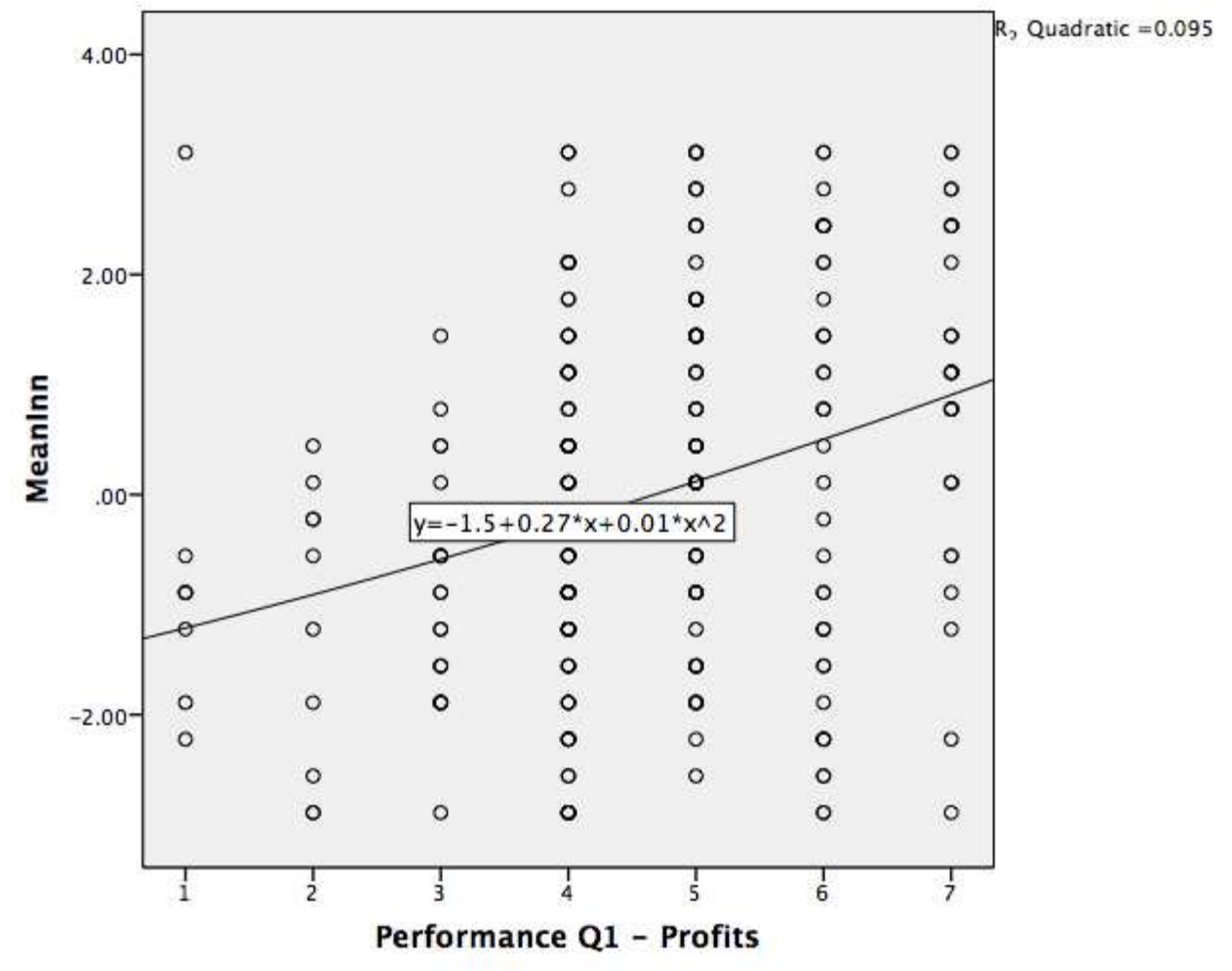

With regards to the sustainability dimension of performance, we find a similar result as that for the profit dimension in that both coefficients are significant and positive, suggesting a non-linear relationship that becomes stronger at higher levels of innovativeness. For growth, the squared term of innovativeness is not significant suggesting the absence of a non-linear relationship. In sum, Hypothesis 2 is only partially supported to the extent that a non-linear relationship exists between innovativeness and profit and innovativeness and sustainability, but does not exist for innovativeness and growth. Further, the non-linear relationships are not full U-shaped as all levels of innovativeness share a positive relationship with profit, but do so to a greater extent at higher rather than at lower levels of innovativeness. 
H3: Firms that report a moderate level of risk-taking will perform better than firms that report a high or low level of risk-taking, reflecting an inverted U-shaped relationship

As with the testing of $\mathrm{H} 2$ above, the mean centered terms of risk-taking and risktaking squared are added to a model with control variables. To support Hypothesis 3, both terms should show significance, with the risk-taking coefficient being positive, while the risk-taking squared term coefficient should be negative. The regression analysis results are shown below:

Table 5.59 - Testing Hypothesis 3 - Risk-taking Non-Linear Relationship

\begin{tabular}{|l|l|l|l|}
\hline Dependent Variable: & Profit & Growth & Sustainability \\
\hline & Model 1 & Model 2 & Model 3 \\
\hline (Constant) & $4.011^{* * *}$ & $4.272^{* * *}$ & $5.007^{* * *}$ \\
\hline Number of Years in Operation & -0.004 & -0.01 & -0.006 \\
\hline Full Time Employees & -0.007 & 0.081 & 0.016 \\
\hline Part Time Employees & $0.097^{* *}$ & $0.1 * *$ & $0.119^{* *}$ \\
\hline Access to Finance & $0.157^{* * *}$ & $0.137^{* * *}$ & $0.117^{* *}$ \\
\hline Location & 0.102 & -0.008 & -0.026 \\
\hline Type of Business Activity & -0.053 & -0.039 & -0.031 \\
\hline Small Business Orientation Q1 & $-0.088^{* *}$ & $-0.107^{* *}$ & 0.006 \\
\hline & & & \\
\hline MeanRiskTaking & $0.168^{* * *}$ & $0.207^{* * *}$ & $0.107^{*}$ \\
\hline MeanRisktaking Square & 0.004 & 0.033 & $0.069^{* *}$ \\
\hline & & & \\
\hline F & $7.511^{* * *}$ & $9.626^{* * *}$ & $3.146^{* *}$ \\
\hline R squared & 0.191 & 0.232 & 0.09 \\
\hline
\end{tabular}

$* * * \mathrm{p}<.001, * * \mathrm{p}<.05, * \mathrm{p}<.1$

Risk-taking was hypothesized to have a non-linear relationship with the dimensions of performance such that it reflected an inverted U-shaped relationship. To support this hypothesis, the coefficients of 'MeanRiskTaking' and 'MeanRiskTaking Square' should have both been significant, while having positive and negative signs respectively. For the performance dimensions of profit and growth, while the risk-taking 
term is significant, the squared term is not significant, suggesting that there is no nonlinear relationships between risk-taking and those dimensions of performance. The risktaking variables however are both significant when regressed with the sustainability dimension as the dependent. Again, the sign of the significant variables are not in the hypothesized direction with both being positive, suggesting that increased risk-taking leads to greater sustainability, but does so at a greater rate at higher levels of risk-taking. Thus, Hypothesis 3 is only partially supported in that a non-linear relationship exists between risk-taking and one dimension of performance (sustainability), though it does not match the type of non-linear relationship that was hypothesized. Figure 5.8 visually demonstrates the main effects of relationship:

Figure 5.8 - Visualization of Non-Linear relationship between Risk-taking and Sustainability

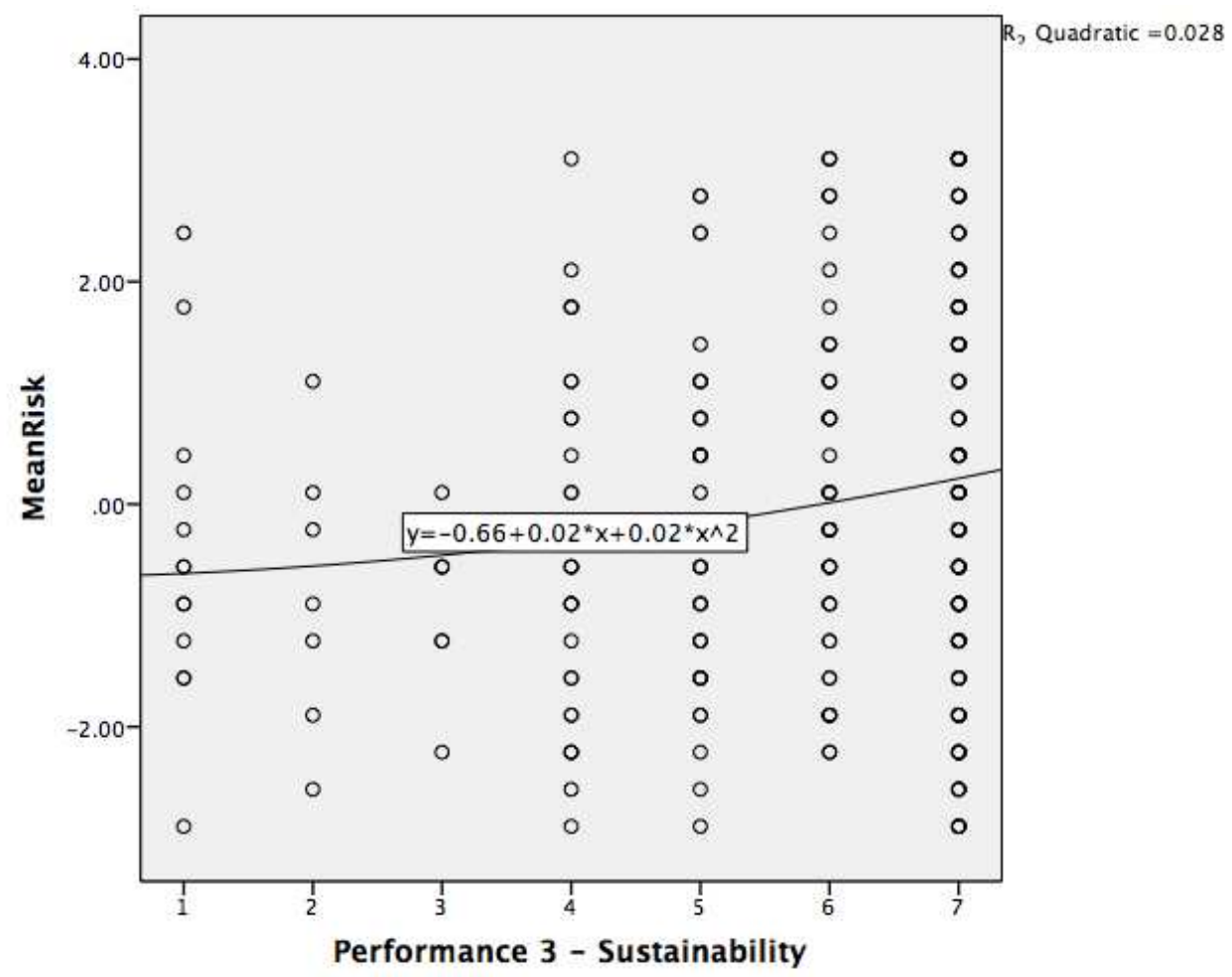


H4: Firms that report high or low levels of proactiveness will perform better than firms that report moderate levels of innovativeness, reflecting a $U$-shaped relationship

$\mathrm{H} 4$ was tested using the same technique that was used to test $\mathrm{H} 2$ and $\mathrm{H} 3$ above. H4 suggested that proactiveness shared a non-linear relationship with the dimensions of performance such that firms that showed high and low levels of proactiveness would out perform those firms that showed moderate levels of proactiveness. Support of the hypothesis could be found if the coefficients of 'MeanProactiveness' and 'MeanProactiveness Sqaure' were significant and their signs were negative and positive respectively. The results from the regression analysis is shown below:

Table 5.60 - Testing Hypothesis 4 - Proactiveness Non-Linear Relationship

\begin{tabular}{|l|l|l|l|}
\hline Dependent Variable: & Profit & Growth & Sustainability \\
\hline & Model 1 & Model 2 & Model 3 \\
\hline (Constant) & $4.074^{* * *}$ & $4.403^{* * *}$ & $5.093^{* * *}$ \\
\hline Number of Years in Operation & -0.006 & $-0.013^{*}$ & -0.009 \\
\hline Full Time Employees & 0.001 & $0.102^{*}$ & 0.045 \\
\hline Part Time Employees & $0.081^{* *}$ & $0.081^{*}$ & $0.098^{* *}$ \\
\hline Access to Finance & $0.15^{* * *}$ & $0.128^{* * *}$ & $0.1 * *$ \\
\hline Location & 0.101 & -0.011 & -0.019 \\
\hline Type of Business Activity & -0.039 & -0.012 & 0.013 \\
\hline Small Business Orientation Q1 & $-0.101^{* *}$ & $-0.126^{* * *}$ & -0.001 \\
\hline & & & \\
\hline MeanProactiveness & $0.242^{* * *}$ & $0.282^{* * *}$ & $0.229 * * *$ \\
\hline MeanProactiveness Square & 0.01 & 0.012 & 0.036 \\
\hline & & & \\
\hline F & $9.148^{* * *}$ & $10.885^{* * *}$ & $3.564 * * *$ \\
\hline R squared & 0.223 & 0.254 & 0.101 \\
\hline
\end{tabular}

$* * * \mathrm{p}<.001, * * \mathrm{p}<.05, * \mathrm{p}<.1$

Based on the results above it can be seen that while mean proactivness shows strong significance with the performance variables, its squared term fails to shown significance at any level on any dimension. As such, we do not find any support for $\mathrm{H} 4$ in that proactiveness does not share a non-linear relationship with performance. 
H5: Firms that report high or low levels of EO will perform better than firms that report moderate levels of EO, reflecting a U-shaped relationship

As with the testing of $\mathrm{H} 2, \mathrm{H} 3$ and $\mathrm{H} 4$, in order to test $\mathrm{H} 5$ was testing using the mean centered EO term, its square and the control variables. The hypothesis was tested against the three performance dimensions (profit, growth and sustainability). Support for the hypothesis would be found (a U-shaped relationship) if the coefficient term for EO is negative and significant, while the squared term's coefficient is positive and significant. The results from the analysis are shown below in Table 5.61:

Table 5.61 - Testing Hypothesis 5 - EO Non-Linear Relationship

\begin{tabular}{|l|l|l|l|}
\hline Dependent Variable: & Profit & Growth & Sustainability \\
\hline & Model 1 & Model 2 & Model 3 \\
\hline (Constant) & $3.92^{* * *}$ & $4.208^{* * *}$ & $4.975^{* * *}$ \\
\hline Number of Years in Operation & -0.003 & -0.01 & -0.007 \\
\hline Full Time Employees & -0.008 & 0.087 & 0.027 \\
\hline Part Time Employees & $0.09^{* *}$ & $0.092^{* *}$ & $0.112^{* *}$ \\
\hline Access to Finance & $0.146^{* * *}$ & $0.127^{* *}$ & $0.109 * *$ \\
\hline Location & $0.112^{*}$ & 0 & -0.015 \\
\hline Type of Business Activity & -0.018 & 0.004 & 0.004 \\
\hline Small Business Orientation Q1 & $-0.08^{* *}$ & $-0.102^{* *}$ & 0.014 \\
\hline & & & \\
\hline MeanEO & $0.296^{* * *}$ & $0.335^{* * *}$ & $0.216^{* *}$ \\
\hline MeanEO Square & 0.024 & 0.048 & 0.071 \\
\hline & & & \\
\hline F & $9.661^{* * *}$ & $11.51^{* * *}$ & $3.451^{* * *}$ \\
\hline R squared & 0.233 & 0.265 & 0.098 \\
\hline
\end{tabular}

$* * * \mathrm{p}<.001, * * \mathrm{p}<.05, * \mathrm{p}<.1$

The regression models above reveal that the relationship between EO and each of the three performance dimensions share a linear relationship with no sign of curvature. While the main effect of the EO variable is positive, and significant, its squared term fails 
to find any significance in any of the models. As such, no support has been found for H5 that suggested the existence of a U-shaped relationship between EO and performance.

H6: Firm ambidexterity (the interaction of exploration and exploitation capabilities) is positively and significantly related to firm performance

The sixth hypothesis introduces the interaction of exploration and exploitation, of which the joint effect is known as ambidexterity. Using a hierarchical regression analysis, Model 1 below contains the control variables for the model while Model 2 introduces the mean centered exploration and exploitation terms. Finally in Model 3 the mean centered ambidexterity term is introduced to the model. Further, a new set of models for each dimension of performance is included. Should the ambidexterity term be positive and significant for any dimension of performance, support would have been found for Hypothesis 6.

Table 5.62 - Testing Hypothesis 6 - Profitability

\begin{tabular}{|l|l|r|r|}
\hline \multicolumn{2}{|l|}{ Dependent Variable: Profitability } & \multicolumn{1}{l|}{} & \\
\hline & Model 1 & Model 2 & \multicolumn{1}{l|}{ Model 3 } \\
\hline (Constant) & $4.149^{* * *}$ & $4.244^{* * *}$ & $4.142^{* * *}$ \\
\hline Number of Years in Operation & -0.007 & -0.002 & -0.002 \\
\hline Full Time Employees & 0.005 & -0.062 & -0.05 \\
\hline Part Time Employees & $0.101^{* *}$ & $0.087^{* *}$ & $0.088^{* *}$ \\
\hline Access to Finance & $0.171^{* * *}$ & $0.164^{* * *}$ & $0.166^{* * *}$ \\
\hline Location & 0.077 & $0.104^{*}$ & $0.115^{*}$ \\
\hline Type of Business Activity & -0.069 & -0.129 & -0.115 \\
\hline Small Business Orientation Q1 & $-0.118^{* * *}$ & $-0.087^{* *}$ & $-0.08^{* *}$ \\
\hline & & & \\
\hline MeanExploration & & 0.06 & 0.083 \\
\hline MeanExploitation & & $0.404^{* * *}$ & $0.212^{* *}$ \\
\hline & & & \\
\hline MeanAmbidexterity & & & $0.013^{* * *}$ \\
\hline & & & \\
\hline F & $7.607^{* * *}$ & $11.002^{* * *}$ & $11.407^{* * *}$ \\
\hline
\end{tabular}




\begin{tabular}{|l|l|l|l|}
\hline R squared & 0.156 & 0.257 & 0.285 \\
\hline
\end{tabular}

${ }_{* * *} \mathrm{p}<.001,{ }^{* *} \mathrm{p}<.05,{ }^{*} \mathrm{p}<.1$

Table 5.63 - Testing Hypothesis 6 - Growth

\begin{tabular}{|l|l|l|l|}
\hline Dependent Variable: Growth & Model 1 & Model 2 & Model 3 \\
\hline & $4.49^{* * *}$ & $4.528^{* * *}$ & $4.458^{* *}$ \\
\hline (Constant) & $-0.015^{* *}$ & -0.008 & -0.008 \\
\hline Number of Years in Operation & $0.107^{*}$ & 0.04 & 0.048 \\
\hline Full Time Employees & $0.104^{* *}$ & $0.091^{* *}$ & $0.091^{* *}$ \\
\hline Part Time Employees & $0.152^{* * *}$ & $0.141^{* * *}$ & $0.143^{* * *}$ \\
\hline Access to Finance & -0.039 & -0.005 & 0.003 \\
\hline Location & -0.047 & -0.098 & -0.088 \\
\hline Type of Business Activity & $-0.146^{* * *}$ & $-0.108^{* *}$ & $-0.103^{* *}$ \\
\hline Small Business Orientation Q1 & & & \\
\hline & & $0.13^{* *}$ & $0.147^{* *}$ \\
\hline MeanExploration & & $0.306^{* * *}$ & 0.173 \\
\hline MeanExploitation & & & \\
\hline & & & $0.009^{* *}$ \\
\hline MeanAmbidexterity & & & \\
\hline & $8.819^{* * *}$ & $10.869^{* * *}$ & $10.360^{* * *}$ \\
\hline F & 0.176 & 0.254 & 0.266 \\
\hline R squared & & & \\
\hline
\end{tabular}

${ }^{* * *} \mathrm{p}<.001,{ }^{* *} \mathrm{p}<.05,{ }^{*} \mathrm{p}<.1$

Table 5.64 - Testing Hypothesis 6 - Sustainability

\begin{tabular}{|c|c|c|c|}
\hline \multicolumn{2}{|c|}{ Dependent Variable: Sustainability } & \multirow[b]{2}{*}{ Model 2} & \multirow[b]{2}{*}{ Model 3} \\
\hline & Model 1 & & \\
\hline (Constant) & $5.205^{* * * *}$ & $5.302^{* * *}$ & $5.274 * * *$ \\
\hline Number of Years in Operation & -0.011 & -0.004 & -0.004 \\
\hline Full Time Employees & 0.049 & -0.023 & -0.019 \\
\hline Part Time Employees & $0.119^{* *}$ & $0.104 * *$ & $0.104 * *$ \\
\hline Access to Finance & $0.12 * *$ & $0.112^{* *}$ & $0.113^{* *}$ \\
\hline Location & -0.039 & -0.009 & -0.006 \\
\hline Type of Business Activity & -0.014 & -0.077 & -0.073 \\
\hline Small Business Orientation Q1 & -0.016 & 0.018 & 0.02 \\
\hline MeanExploration & & 0.072 & 0.078 \\
\hline MeanExploitation & & $0.425^{* * *}$ & $0.373^{* *}$ \\
\hline MeanAmbidexterity & & & 0.004 \\
\hline
\end{tabular}




\begin{tabular}{|l|l|l|l|}
\hline & & & \\
\hline $\mathrm{F}$ & $2.703^{* * *}$ & $5.140^{* * *}$ & $4.665^{* * *}$ \\
\hline R squared & 0.061 & 0.139 & 0.140 \\
\hline$* * * \mathrm{p}<.001,{ }^{* *} \mathrm{p}<.05, * \mathrm{p}<.1$ & \multicolumn{3}{|l}{}
\end{tabular}

The results above provide some support for the suggestion that ambidexterity is positively and significantly related to the dimensions of performance. With regards to the profit dimension of performance, we can see that while exploitation capability shares a positive and significant relationship with profit performance, exploration does not. Adding ambidexterity to the model serves to improve the R squared and F-Statistics, while also having an unstandardized coefficient that is positive and significant, in line with the prediction. Similarly, on the growth dimension, ambidexterity is positively and significantly related to growth performance, however we see a switch in the significance between exploration and exploitation compared to the first test. That is, for growth (in the presence of the ambidexterity variable) exploitation loses its significance as a predictor of growth, but exploration is positive and significant; a reversal from the findings on the profit dimension. Support however is not found for the significance of ambidexterity with regards to the sustainability of the business. While positive, the ambidexterity term is not significant, neither is the exploration term. However, the exploitation term is indeed significant and positive in the final sustainability model.

H7: Firm ambidexterity positively moderates the relationship between innovativeness and performance at all levels of innovativeness

Having found support for the hypothesis that a firm's ambidexterity capabilities are positive and significant in the explanation of performance, we can test the hypothesis that firm ambidexterity positively moderates the relationship between innovativeness and 
performance. Again using hierarchal regression, three models will be used for each dimension of performance. The first will contain only the control variables, while the second will add the term for mean centered innovativeness and the term for mean centered ambidexterity. Finally the third model will add the interaction term (innovativeness*ambidexterity). If the coefficient of this new interaction term is significant and also positive, support would have been found for $\mathrm{H} 7$. The results are shown below.

Table 5.65 - Testing Hypothesis 7 - Ambidexterity as a Moderator of Innovativeness

\begin{tabular}{|l|l|l|l|}
\hline Dependent Variable: Profit & Model 1 & Model 2 & Model 3 \\
\hline & $4.149^{* * *}$ & $3.86^{* * *}$ & 3.859 \\
\hline (Constant) & -0.007 & -0.004 & -0.004 \\
\hline Number of Years in Operation & 0.005 & -0.01 & -0.01 \\
\hline Full Time Employees & $0.101^{* *}$ & $0.093^{* * *}$ & 0.093 \\
\hline Part Time Employees & $0.171^{* * *}$ & $0.147^{* * *}$ & 0.147 \\
\hline Access to Finance & 0.077 & $0.128^{* *}$ & 0.128 \\
\hline Location & -0.069 & 0.002 & 0.002 \\
\hline Type of Business Activity & $-0.118^{* * *}$ & $-0.068^{* *}$ & -0.068 \\
\hline Small Business Orientation Q1 & & & \\
\hline & & $0.235^{* * *}$ & $0.236^{* * *}$ \\
\hline MeanInnovation (MI) & & $0.021^{* * *}$ & $0.021^{* * *}$ \\
\hline MeanAmbidexterity (MA) & & & \\
\hline & & & 0.0 \\
\hline Interaction (MI * MA) & & & \\
\hline & $7.607^{* * *}$ & $15.209^{* * *}$ & $13.647^{* * *}$ \\
\hline F & 0.156 & 0.323 & 0.323 \\
\hline R squared & & & \\
\hline
\end{tabular}

$* * * \mathrm{p}<.001,{ }^{* *} \mathrm{p}<.05,{ }^{*} \mathrm{p}<.1$

Table 5.66 - Testing Hypothesis 7 - Ambidexterity as a Moderator of Innovativeness

\begin{tabular}{|l|l|l|l|}
\hline \multicolumn{2}{|l|}{ Dependent Variable: Growth } & & \\
\hline & Model 1 & Model 2 & Model 3 \\
\hline (Constant) & $4.49^{* * *}$ & $4.219^{* * *}$ & $4.21^{* * *}$ \\
\hline Number of Years in Operation & $-0.015^{* *}$ & $-0.012^{*}$ & -0.01 \\
\hline
\end{tabular}




\begin{tabular}{|l|l|l|l|}
\hline Full Time Employees & $0.107^{*}$ & $0.096^{*}$ & $0.096^{*}$ \\
\hline Part Time Employees & $0.104^{* *}$ & $0.097^{* *}$ & $0.097^{* *}$ \\
\hline Access to Finance & $0.152^{* * *}$ & $0.128^{* * *}$ & $0.127^{* * *}$ \\
\hline Location & -0.039 & 0.006 & 0.007 \\
\hline Type of Business Activity & -0.047 & 0.025 & 0.028 \\
\hline Small Business Orientation Q1 & $-0.146^{* * *}$ & $-0.101^{* *}$ & $-0.104^{* *}$ \\
\hline & & & \\
\hline MeanInnovation (MI) & & $0.229 * * *$ & $0.238^{* * *}$ \\
\hline MeanAmbidexterity (MA) & & $0.016^{* * *}$ & $0.016^{* * *}$ \\
\hline & & & \\
\hline Interaction (MI $* \mathrm{MA})$ & & & -0.003 \\
\hline & & & \\
\hline F & $8.819^{* * *}$ & $12.615^{* * *}$ & $11.548^{* * *}$ \\
\hline R squared & 0.176 & 0.283 & 0.288 \\
\hline
\end{tabular}

$* * * \mathrm{p}<.001, * * \mathrm{p}<.05, * \mathrm{p}<.1$

Table 5.67 - Testing Hypothesis 7 - Ambidexterity as a Moderator of Innovativeness

\begin{tabular}{|l|l|l|l|}
\hline Dependent Variable: Sustainability & & \\
\hline & Model 1 & Model 2 & Model 3 \\
\hline (Constant) & $5.205^{* * *}$ & $5.027 * * *$ & $5.026^{* * *}$ \\
\hline Number of Years in Operation & -0.011 & -0.009 & -0.008 \\
\hline Full Time Employees & 0.049 & 0.039 & 0.039 \\
\hline Part Time Employees & $0.119 * *$ & $0.113^{* *}$ & $0.113^{* *}$ \\
\hline Access to Finance & $0.12 * *$ & $0.107 * *$ & $0.106^{* *}$ \\
\hline Location & -0.039 & -0.006 & -0.006 \\
\hline Type of Business Activity & -0.014 & 0.026 & 0.026 \\
\hline Small Business Orientation Q1 & -0.016 & 0.017 & 0.016 \\
\hline & & & \\
\hline MeanInnovation (MI) & & $0.139 * *$ & $0.14 * *$ \\
\hline MeanAmbidexterity (MA) & & $0.015^{* * *}$ & $0.015^{* * *}$ \\
\hline & & & \\
\hline Interaction (MI * MA) & & & 0.0 \\
\hline & & & \\
\hline F & $2.703 * * *$ & $4.026^{* * *}$ & $3.613 * * *$ \\
\hline R squared & 0.061 & 0.112 & 0.112 \\
\hline
\end{tabular}

$* * * \mathrm{p}<.001, * * \mathrm{p}<.05, * \mathrm{p}<.1$ 
A look at the data above fails to show any support for the prediction of $\mathrm{H} 7$.

Specifically, although in all models innovativeness and ambidexterity are both

significantly and positively related to performance, their interaction does not demonstrate any significance and thus there is no moderation effect of ambidexterity with regard to the relationship between innovativeness and performance.

H8: Firm ambidexterity positively moderates the relationship between risk-taking and performance at all levels of risk-taking

As with the hypothesis above, in order to test the hypothesis that ambidexterity moderates the relationship between risk-taking and performance three hierarchical multiple regression analyses were conducted. Using the three measures of performance as the dependent variable in each analysis and checking for the sign and significance of the interaction term between risk-taking and ambidexterity (mean centered terms were used), H8 was tested as shown below:

Table 5.68 - Testing Hypothesis 8 - Ambidexterity as a Moderator of Risk-taking

\begin{tabular}{|c|c|c|c|}
\hline \multicolumn{2}{|l|}{ Dependent Variable: Profit } & \multirow[b]{2}{*}{ Model 2} & \multirow[b]{2}{*}{ Model 3} \\
\hline & Model 1 & & \\
\hline (Constant) & $4.149 * * *$ & $3.971 * * *$ & $3.972 * * *$ \\
\hline Number of Years in Operation & -0.007 & -0.004 & -0.004 \\
\hline Full Time Employees & 0.005 & -0.02 & -0.02 \\
\hline Part Time Employees & $0.101 * *$ & $0.091 * *$ & $0.092 * *$ \\
\hline Access to Finance & $0.171 * * *$ & $0.16 * * *$ & $0.16 * * *$ \\
\hline Location & 0.077 & $0.124 * *$ & $0.124 * *$ \\
\hline Type of Business Activity & -0.069 & -0.069 & -0.069 \\
\hline Small Business Orientation Q1 & $-0.118 * * *$ & $-0.07 * *$ & $-0.069 * *$ \\
\hline MeanRiskTaking (MR) & & $0.159 * * *$ & $0.158 * * *$ \\
\hline MeanAmbidexterity (MA) & & $0.019 * * *$ & $0.02 * * *$ \\
\hline Interaction $(\mathrm{MR} * \mathrm{MA})$ & & & 0.001 \\
\hline & & & \\
\hline
\end{tabular}




\begin{tabular}{|l|l|l|l|}
\hline F & $7.607^{* * *}$ & $12.743^{* * *}$ & $11.441^{* * *}$ \\
\hline R squared & 0.156 & 0.286 & 0.286 \\
\hline
\end{tabular}

*** $\mathrm{p}<.001,{ }^{* *} \mathrm{p}<.05,{ }^{*} \mathrm{p}<.1$

Table 5.69 - Testing Hypothesis 7 - Ambidexterity as a Moderator of Risk-taking

\begin{tabular}{|c|c|c|c|}
\hline \multicolumn{2}{|l|}{ Dependent Variable: Growth } & \multirow[b]{2}{*}{ Model 2} & \multirow[b]{2}{*}{ Model 3} \\
\hline & Model 1 & & \\
\hline (Constant) & $4.49 * * *$ & -0.011 & 4.279 \\
\hline Number of Years in Operation & $-0.015 * *$ & 0.083 & -0.01 \\
\hline Full Time Employees & $0.107^{*}$ & 0.094 & 0.083 \\
\hline Part Time Employees & $0.104 * *$ & $0.135 * *$ & $0.094 * *$ \\
\hline Access to Finance & $0.152 * * *$ & $0.011 * * *$ & $0.135 * * *$ \\
\hline Location & -0.039 & -0.037 & 0.012 \\
\hline Type of Business Activity & -0.047 & -0.092 & -0.037 \\
\hline Small Business Orientation Q1 & $-0.146^{* * *}$ & $-0.011 * *$ & $-0.094 * *$ \\
\hline MeanRiskTaking (MR) & & $0.215 * * *$ & $0.218 * * *$ \\
\hline MeanAmbidexterity (MA) & & $0.015 * * *$ & $0.014 * * *$ \\
\hline Interaction (MR * MA) & & & -0.002 \\
\hline $\mathrm{F}$ & $8.819 * * *$ & $12.263 * * *$ & $11.023 * * *$ \\
\hline R squared & 0.176 & 0.276 & 0.278 \\
\hline
\end{tabular}

$* * * \mathrm{p}<.001, * * \mathrm{p}<.05, * \mathrm{p}<.1$

Table 5.70 - Testing Hypothesis 8 - Ambidexterity as a Moderator of Risk-taking

Dependent Variable: Sustainability

\begin{tabular}{|l|l|l|l|}
\hline & Model 1 & Model 2 & Model 3 \\
\hline (Constant) & $5.205^{* * *}$ & $5.065^{* * *}$ & $5.065^{* * *}$ \\
\hline Number of Years in Operation & -0.011 & -0.008 & -0.008 \\
\hline Full Time Employees & 0.049 & 0.031 & 0.031 \\
\hline Part Time Employees & $0.119^{* *}$ & $0.111^{* *}$ & $0.111^{* *}$ \\
\hline Access to Finance & $0.12^{* *}$ & $0.111^{* *}$ & $0.111^{* *}$ \\
\hline Location & -0.039 & -0.003 & -0.003 \\
\hline Type of Business Activity & -0.014 & -0.012 & -0.012 \\
\hline Small Business Orientation Q1 & -0.016 & 0.022 & 0.022 \\
\hline & & & \\
\hline MeanRiskTaking (MR) & & $0.132^{* *}$ & $0.131^{* *}$ \\
\hline MeanAmbidexterity (MA) & & $0.014 * * *$ & $0.014 * *$ \\
\hline \multicolumn{2}{|l}{} & \\
\hline
\end{tabular}




\begin{tabular}{|l|l|l|l|}
\hline Interaction (MR * MA) & & & 0.0 \\
\hline $\mathrm{F}$ & & & \\
\hline R squared & $2.703 * * *$ & $3.947 * * *$ & $3.540 * * *$ \\
\hline
\end{tabular}

$* * * \mathrm{p}<.001, * * \mathrm{p}<.05, * \mathrm{p}<.1$

As can be seen from the coefficient and significance of the interaction term (MR *MA) for each of the models above, there appears to be no moderation effect of ambidexterity onto risk-taking. In all the models, the main effect relationships of risktaking and ambidexterity are positive and significant, however the interaction term is not significant. As such we have failed to find any support for $\mathrm{H} 8$.

H9: Firm ambidexterity positively moderates the relationship between proactiveness and performance at all levels of proactiveness

As with the other dimensions of EO, ambidexterity was hypothesized to have a moderation effect on proactiveness such that at all levels of proactiveness, a relatively higher ambidexterity would lead to better performance. Hierarchical regression analysis was performed for each of the performance measures with the results shown below:

Table 5.71 - Testing Hypothesis 9 - Ambidexterity as a Moderator of Proactiveness

\begin{tabular}{|c|c|c|c|}
\hline \multicolumn{2}{|l|}{ Dependent Variable: Profit } & \multirow[b]{2}{*}{ Model 2} & \multirow[b]{2}{*}{ Model 3} \\
\hline & Model 1 & & \\
\hline (Constant) & $4.149 * * *$ & $4.041 * * *$ & $4.043 * * *$ \\
\hline Number of Years in Operation & -0.007 & -0.006 & -0.006 \\
\hline Full Time Employees & 0.005 & -0.014 & -0.015 \\
\hline Part Time Employees & $0.101 * *$ & $0.077 * *$ & $0.077 * *$ \\
\hline Access to Finance & $0.171 * * *$ & $0.153 * * *$ & $0.154 * * *$ \\
\hline Location & 0.077 & $0.124 * *$ & $0.123 * *$ \\
\hline Type of Business Activity & -0.069 & -0.056 & -0.054 \\
\hline Small Business Orientation Q1 & $-0.118 * * *$ & $-0.081 * *$ & $-0.082 * *$ \\
\hline
\end{tabular}




\begin{tabular}{|l|l|l|l|}
\hline MeanProactiveness (MP) & & $0.233^{* * *}$ & $0.232^{* * *}$ \\
\hline MeanAmbidexterity (MA) & & $0.019^{* * *}$ & $0.019^{* * *}$ \\
\hline & & & \\
\hline Interaction (MP * MA) & & & -0.001 \\
\hline & & & \\
\hline F & $7.607 * * *$ & $14.899^{* * *}$ & $13.379^{* * *}$ \\
\hline R squared & 0.156 & 0.318 & 0.319 \\
\hline
\end{tabular}

$* * * \mathrm{p}<.001,{ }^{* *} \mathrm{p}<.05,{ }^{*} \mathrm{p}<.1$

Table 5.72 - Testing Hypothesis 9 - Ambidexterity as a Moderator of Proactiveness

Dependent Variable: Growth

\begin{tabular}{|l|l|l|l|}
\hline & Model 1 & Model 2 & Model 3 \\
\hline (Constant) & $4.49^{* * *}$ & $4.385^{* * *}$ & $4.379^{* * *}$ \\
\hline Number of Years in Operation & $-0.015^{* *}$ & $-0.013^{* *}$ & $-0.013^{* *}$ \\
\hline Full Time Employees & $0.107^{*}$ & 0.091 & $0.093^{*}$ \\
\hline Part Time Employees & $0.104^{* *}$ & $0.078^{* *}$ & $0.076^{* *}$ \\
\hline Access to Finance & $0.152^{* * *}$ & $0.131^{* * *}$ & $0.13^{* * *}$ \\
\hline Location & -0.039 & 0.007 & 0.007 \\
\hline Type of Business Activity & -0.047 & -0.025 & -0.03 \\
\hline Small Business Orientation Q1 & $-0.146^{* * *}$ & $-0.111^{* * *}$ & $-0.108^{* * *}$ \\
\hline & & & \\
\hline MeanProactiveness (MP) & & $0.273^{* * *}$ & $0.275^{* * *}$ \\
\hline MeanAmbidexterity (MA) & & $0.015^{* * *}$ & $0.016^{* * *}$ \\
\hline & & & \\
\hline Interaction (MP * MA) & & & 0.002 \\
\hline & & & \\
\hline F & $8.819^{* * *}$ & $13.877^{* * *}$ & $12.546^{* * *}$ \\
\hline R squared & 0.176 & 0.303 & 0.305 \\
\hline
\end{tabular}

*** $\mathrm{p}<.001,{ }^{* *} \mathrm{p}<.05,{ }^{*} \mathrm{p}<.1$

Table 5.73 - Testing Hypothesis 9 - Ambidexterity as a Moderator of Proactiveness

\begin{tabular}{|l|l|l|l|}
\hline Dependent Variable: Sustainability & & \\
\hline & Model 1 & Model 2 & Model 3 \\
\hline (Constant) & $5.205^{* * *}$ & $5.117^{* * *}$ & $5.132^{* * *}$ \\
\hline Number of Years in Operation & -0.011 & -0.009 & -0.009 \\
\hline Full Time Employees & 0.049 & 0.035 & 0.029 \\
\hline Part Time Employees & $0.119^{* *}$ & $0.098^{* *}$ & $0.102^{* *}$ \\
\hline Access to Finance & $0.12^{* *}$ & $0.104^{* *}$ & $0.105^{* *}$ \\
\hline Location & -0.039 & -0.001 & -0.002 \\
\hline Type of Business Activity & -0.014 & 0.001 & 0.015 \\
\hline
\end{tabular}




\begin{tabular}{|l|l|l|l|}
\hline Small Business Orientation Q1 & -0.016 & 0.014 & 0.007 \\
\hline & & & \\
\hline MeanProactiveness (MP) & & $0.211^{* * *}$ & $0.205^{* * *}$ \\
\hline MeanAmbidexterity (MA) & & $0.014^{* * *}$ & $0.013^{* *}$ \\
\hline & & & \\
\hline Interaction (MP * MA) & & & $-0.005^{*}$ \\
\hline & & & \\
\hline F & $2.703^{* * *}$ & $4.816^{* * *}$ & $4.682^{* * *}$ \\
\hline R squared & 0.061 & 0.131 & 0.141 \\
\hline
\end{tabular}

$* * * \mathrm{p}<.001, * * \mathrm{p}<.05, * \mathrm{p}<.1$

Above we can see the results of the testing of $\mathrm{H} 9$ which suggested that

ambidexterity had a moderating effect on proactiveness relationship with performance.

For the performance variables profit and growth, we again fail to find any significant moderation between ambidexterity and proactivness. We do find some significance that there is a moderation effect of ambidexterity on proactiveness with sustainability as the dependent variable. However, this effect is in the opposite direction than predicted (negative rather than positive). This means that rather than proactivness having a greater effect on sustainability at high levels of ambidexterity, we find that ambidexterity has a moderation effect on proactiveness at lower levels of ambidexterity. This effect is such that at low levels of ambidexterity, an increase in proactievness will have a greater positive effect on sustainability than a similar change in proactiveness at higher levels of ambidexterity. This result is shown graphically below: 
Figure 5.9 - Moderation effect of Ambidexterity on Proactivness, with Sustainability as dependent variable

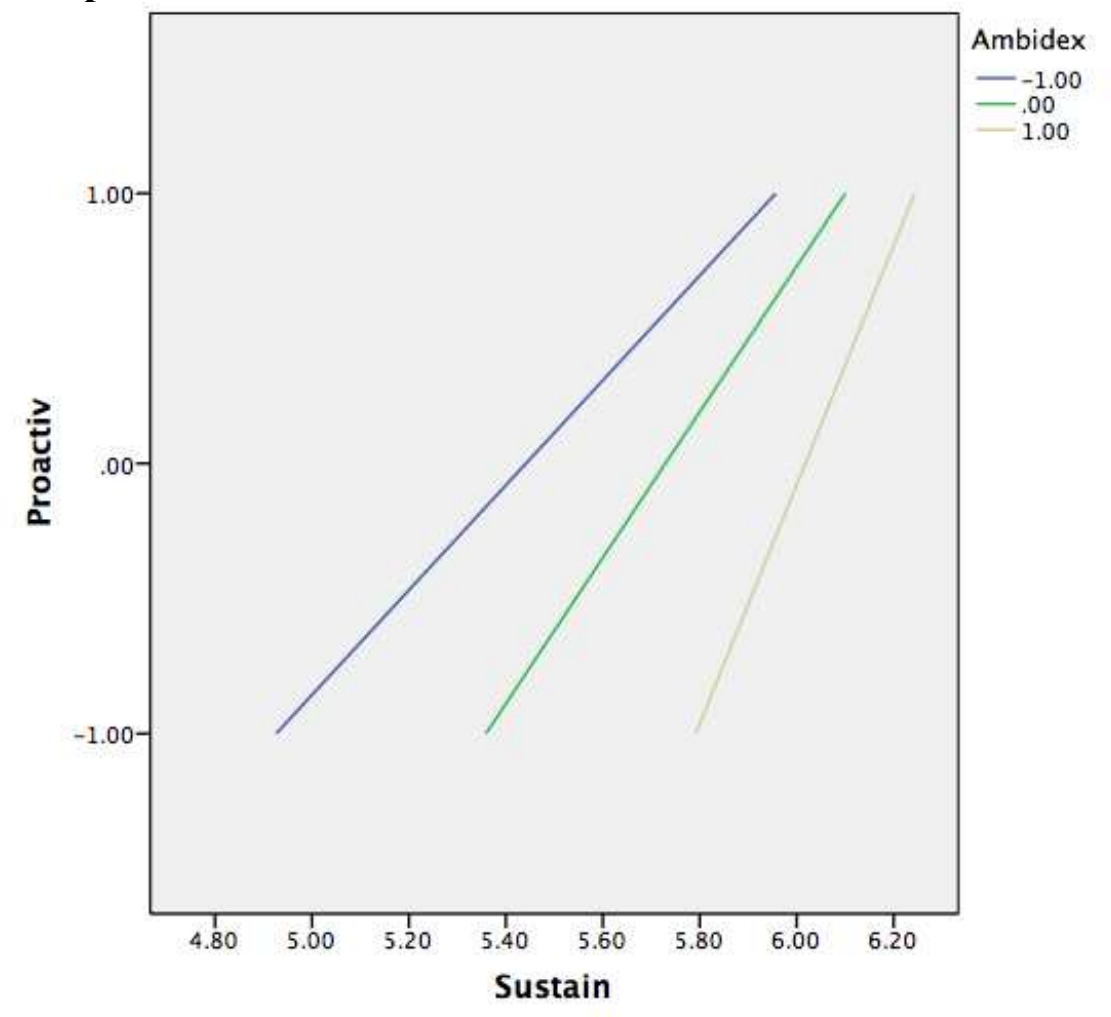

In the graph above we see three lines. The blue line (Ambidex $=-1$ ) shows the effect of a change in proactiveness at low levels of ambidexterity, while the green line shows the effect at moderate levels of ambidexterity $($ Ambidex $=0)$ and the yellow line at high levels of ambidexterity (Ambidex $=1)$. A more vertical line suggests that a change in the $\mathrm{X}$ variable (proactiveness) has a minimal effect of the $\mathrm{Y}$ variable (sustainability). A more horizontal line suggests that a change in the $\mathrm{X}$ variable (proactiveness) has a greater effect of the Y variable (sustainability) than a more vertical line. Based on the diagram, we can see that at high levels of ambidexterity the line is more vertical, where as at low levels of ambidexterity, the line is more horizontal, implying that at low levels of ambidexterity the effect of a change in proactiveness has a relatively greater effect on 
sustainability than at higher levels of ambidexterity. Thus, from the above we note that the performance measures of profit and growth fail to show any significance with regards to the moderation effect of ambidexterity on proactiveness. Although the sustainability measure does demonstrate some moderation between the predictor variables and the dependent variable it is in the opposite direction than was predicted. As a result we have failed to find support for H9.

H10: Firm ambidexterity positively moderates the relationship between EO and performance at all levels of EO

The final hypothesis suggests that the full EO dimension is moderated by the level of ambidexterity. As with H7-H9, this hypothesis was tested using hierarchical regressions, first adding the mean centered main effect terms and then the final interaction term to the regression. The results are shown below:

Table 5.74 - Testing Hypothesis 9 - Ambidexterity as a Moderator of EO Dependent Variable: Profit

\begin{tabular}{|l|l|l|l|}
\hline & Model 1 & Model 2 & Model 3 \\
\hline (Constant) & $4.149^{* * *}$ & 3.891 & 3.896 \\
\hline Number of Years in Operation & -0.007 & -0.003 & -0.003 \\
\hline Full Time Employees & 0.005 & -0.018 & -0.019 \\
\hline Part Time Employees & $0.101^{* *}$ & $0.084^{* *}$ & $0.084^{* *}$ \\
\hline Access to Finance & $0.171^{* * *}$ & 0.145 & 0.145 \\
\hline Location & 0.077 & $0.137^{* *}$ & $0.137^{* *}$ \\
\hline Type of Business Activity & -0.069 & -0.025 & -0.023 \\
\hline Small Business Orientation Q1 & $-0.118^{* * *}$ & -0.06 & $-0.062^{*}$ \\
\hline & & & \\
\hline MeanEO (MEO) & & $0.304^{* * *}$ & $0.305^{* * *}$ \\
\hline MeanAmbidexterity (MA) & & $0.02 * * *$ & $0.019 * * *$ \\
\hline & & & \\
\hline Interaction (MEO * MA) & & & -0.002 \\
\hline & & & \\
\hline F & $7.607^{* * *}$ & $15.808^{* * *}$ & $14.242^{* * *}$ \\
\hline R squared & 0.156 & 0.331 & 0.332 \\
\hline
\end{tabular}


$* * * \mathrm{p}<.001, * * \mathrm{p}<.05, * \mathrm{p}<.1$

Table 5.75 - Testing Hypothesis 9 - Ambidexterity as a Moderator of EO

\begin{tabular}{|c|c|c|c|}
\hline \multicolumn{2}{|l|}{ Dependent Variable: Growth } & \multirow[b]{2}{*}{ Model 2} & \multirow[b]{2}{*}{ Model 3} \\
\hline & Model 1 & & \\
\hline (Constant) & $4.49 * * *$ & $4.216^{* * *}$ & $4.218 * * *$ \\
\hline Number of Years in Operation & $-0.015 * *$ & -0.01 & -0.01 \\
\hline Full Time Employees & $0.107^{*}$ & 0.087 & 0.087 \\
\hline Part Time Employees & $0.104 * *$ & $0.087 * *$ & $0.087 * *$ \\
\hline Access to Finance & $0.152 * * *$ & $0.121 * *$ & $0.121 * *$ \\
\hline Location & -0.039 & 0.022 & 0.022 \\
\hline Type of Business Activity & -0.047 & 0.01 & 0.011 \\
\hline Small Business Orientation Q1 & $-0.146 * * *$ & $-0.087 * *$ & $-0.088 * *$ \\
\hline MeanEO (MEO) & & $0.347 * * *$ & $0.347 * * *$ \\
\hline MeanAmbidexterity (MA) & & $0.015 * * *$ & $0.015 * * *$ \\
\hline Interaction (MEO * MA) & & & -0.001 \\
\hline $\mathrm{F}$ & $8.819 * * *$ & $14.588 * * *$ & $13.092 * * *$ \\
\hline R squared & 0.176 & 0.314 & 0.314 \\
\hline
\end{tabular}

$* * * \mathrm{p}<.001, * * \mathrm{p}<.05, * \mathrm{p}<.1$

Table 5.76 - Testing Hypothesis 9 - Ambidexterity as a Moderator of EO

Dependent Variable: Sustainability

\begin{tabular}{|l|l|l|l|}
\hline & Model 1 & Model 2 & Model 3 \\
\hline (Constant) & $5.205^{* * *}$ & 5.011 & 5.027 \\
\hline Number of Years in Operation & -0.011 & -0.007 & -0.006 \\
\hline Full Time Employees & 0.049 & 0.033 & 0.029 \\
\hline Part Time Employees & $0.119^{* *}$ & $0.106^{* *}$ & $0.107 * *$ \\
\hline Access to Finance & $0.12^{* *}$ & $0.1 * *$ & $0.1 * *$ \\
\hline Location & -0.039 & 0.006 & 0.005 \\
\hline Type of Business Activity & -0.014 & 0.021 & 0.027 \\
\hline Small Business Orientation Q1 & -0.016 & 0.028 & 0.02 \\
\hline & & & \\
\hline MeanEO (MEO) & & $0.232^{* *}$ & $0.238^{* * *}$ \\
\hline MeanAmbidexterity (MA) & & $0.014 * * *$ & $0.013^{* *}$ \\
\hline & & & \\
\hline Interaction (MEO * MA) & & & $-0.006^{*}$ \\
\hline & & & \\
\hline
\end{tabular}




\begin{tabular}{|l|l|l|l|}
\hline $\mathrm{F}$ & $2.703 * * *$ & $4.605 * * *$ & $4.443 * * *$ \\
\hline $\mathrm{R}$ squared & 0.061 & 0.126 & 0.134 \\
\hline
\end{tabular}

$* * * \mathrm{p}<.001, * * \mathrm{p}<.05, * \mathrm{p}<.1$

From the above, we see that the interaction term fails to show any significance when the performance dependent is profit or growth, lending support to the rejection of H10. However, as with proactiveness, the full EO does show the effects of moderation at different levels of ambidexterity to the sustainability of the business. This is shown below in Figure 5.10:

Figure 5.10 - Moderation effect of Ambidexterity on EO, with Sustainability as dependent variable

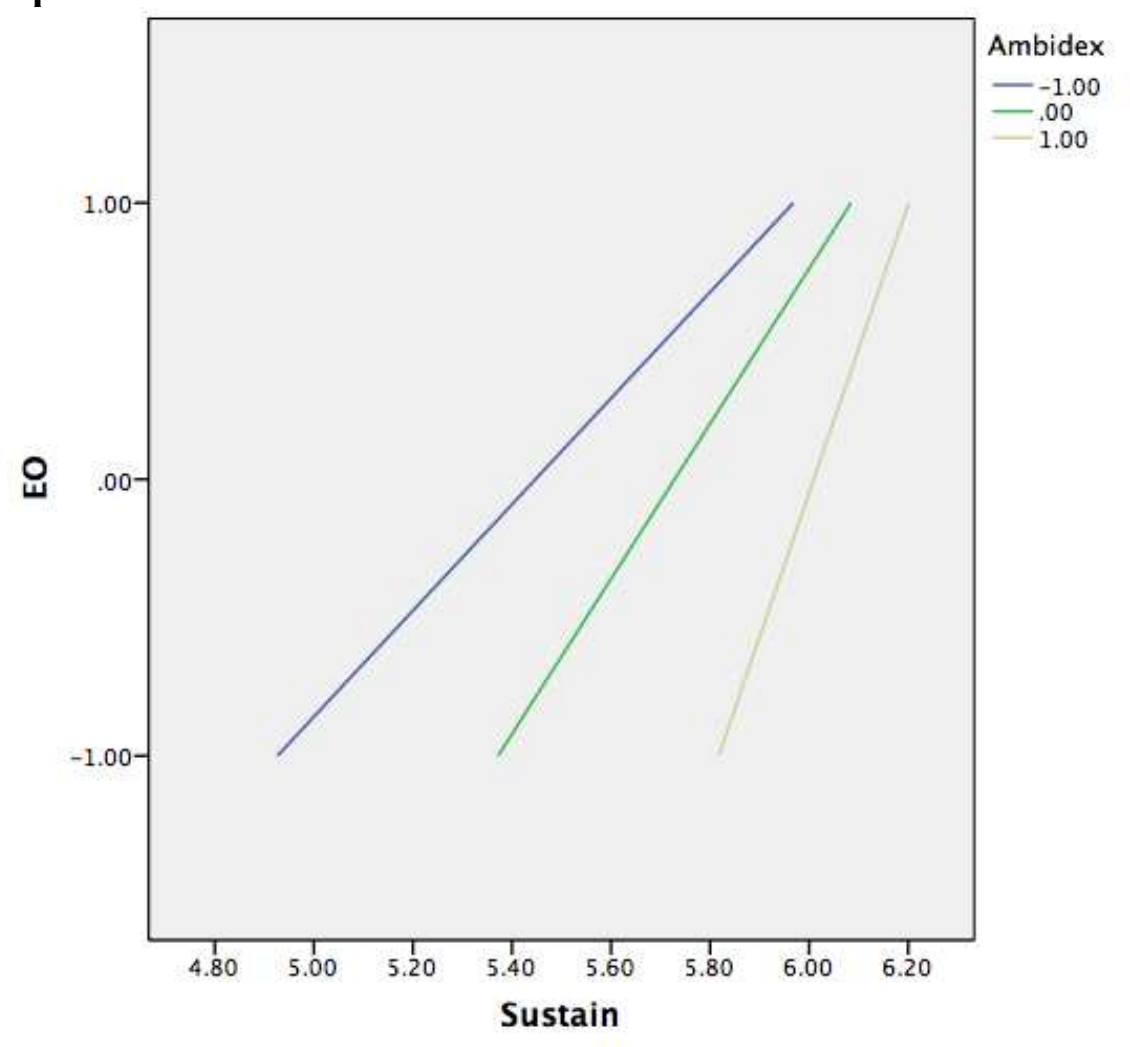

In the figure above we can see the effects of the moderation of ambidexterity on EO. The blue line to the furthest left shows the relationship between EO and 
sustainability at low levels of ambidexterity (Ambidex $=-1$ ). This line is the most horizontal line indicating that a small change in the $\mathrm{X}$ variable (EO) would have a proportionately larger impact on the Y variable (sustainability) than at the other levels. Given the increasing slopes of the moderate $($ Ambidex $=0)$ and high $($ Ambidex $=1)$ the data suggests that the effect of increasing EO on improving sustainability falls as ambidexterity increases. Thus, the effect of the moderation of ambidexterity on EO with relation to sustainability outcomes decreases with progressively higher levels of ambidexterity. Given the non-significance of the interaction term in the profit and growth models, and the fact that the moderation is in the opposite direction as predicted by the hypothesis, we must reject $\mathrm{H} 10$.

\section{Summary}

This chapter has presented the results from the quantitative data analysis. First we discussed pre-testing that was carried out, as well as the rationale for adding the additional competitive aggressiveness and small business orientation scales to the final questionnaire. We laid out the actual process of data collection, inclusive of the necessary deviations from the initial data collection plan. Using a direct approach of physically visiting the workplaces of entrepreneurs, the response rate was $38.4 \%$, however this figure jumps to $69.7 \%$ if we only consider those entrepreneurs that were present at the time of the visit.

A total of 304 completed responses were collected, and after data screening tests was this number was reduced to 297 . The responses that were eliminated all shared obvious issues with their data in terms of skewedness and inconsistency. Of the full 
sample ( $\mathrm{n}=304) 49.3 \%$ of the respondents were classified as retail/distribution, $32.6 \%$ as service providers and $18.1 \%$ as manufactures or those who produce their own products for sale. The age of the businesses ranged from 1 month to 70 years with full time employees ranging from $1-5$ and part time employees from $0-20$.

Tests of internal consistency, convergent and discriminant validity were carried out on all the constructs that were measured via the questionnaire. Due to its failure to add to the model fit, competitive aggressiveness was dropped from the analysis, as were three of the four small business orientation questions. The scales measuring innovativeness, risk-taking, proactiveness, exploration and exploitation as well as the full EO showed acceptable levels of internal consistency and demonstrated convergent validity and met normality assumptions.

The calculation of ambidexterity that was initially proposed in the methodology was found to be inferior to a new calculation that differently weighted a gap in the balance between the two dimensions. By changing the ambidexterity calculation so that firms that showed a very high level on one dimension (exploration or exploitation) and a moderate level on the other were given a higher ambidexterity score than a firm that reported very high levels on both, the ambidexterity calculation became more significant in its relationship on all dimensions of performance. Once the final variables were decided upon, tests of the hypothesis were carried out with a summary of the results below: 
Table 5.77 - Summary of Hypothesis Tests

\begin{tabular}{|l|c|}
\hline Hypothesis & Supported \\
\hline $\begin{array}{l}\text { H1a: Both a reflective, unidimensional EO scale and a formative, multi- } \\
\text { dimensional EO scale are positively and significantly related to performance }\end{array}$ & Yes \\
\hline $\begin{array}{l}\text { H1b: A formative, multidimensional EO scale explains significantly more } \\
\text { variance in performance than a reflective, unidimensional EO scale }\end{array}$ & No \\
\hline $\begin{array}{l}\text { H2: Firms that report high or low levels of innovativeness will perform better } \\
\text { than firms that report moderate levels of innovativeness, reflecting a U- shaped } \\
\text { relationship }\end{array}$ & No \\
\hline $\begin{array}{l}\text { H3: Firms that report a moderate level of risk-taking will perform better than } \\
\text { firms that report a high or low level of risk-taking, reflecting an inverted U- } \\
\text { shaped relationship }\end{array}$ & No \\
\hline $\begin{array}{l}\text { H4: Firms that report high or low levels of proactiveness will perform better } \\
\text { than firms that report moderate levels of innovativeness, reflecting a U- shaped } \\
\text { relationship }\end{array}$ & No \\
\hline $\begin{array}{l}\text { H5: Firms that report high or low levels of EO will perform better than firms } \\
\text { that report moderate levels of EO, reflecting a U-shaped relationship }\end{array}$ & No \\
\hline $\begin{array}{l}\text { H6: Firm ambidexterity (the interaction of exploration and exploitation } \\
\text { capabilities) is positively and significantly related to firm performance }\end{array}$ & Yes \\
\hline $\begin{array}{l}\text { H7: Firm ambidexterity positively moderates the relationship between } \\
\text { innovativeness and performance at all levels of innovativeness }\end{array}$ & No \\
\hline $\begin{array}{l}\text { H8: Firm ambidexterity positively moderates the relationship between risk- } \\
\text { taking and performance at all levels of risk-taking }\end{array}$ & $\begin{array}{l}\text { No } \\
\text { proactiveness and performance at all levels of proactiveness }\end{array}$ \\
\hline $\begin{array}{l}\text { H10: Firm ambidexterity positively moderates the relationship between EO and } \\
\text { performance at all levels of EO }\end{array}$ & No \\
\hline
\end{tabular}




\section{Chapter 6}

\section{Qualitative Data Collection and Analysis}

In an attempt to add depth to the findings from the previous chapter (quantitative results), we asked a selection of businesses that favorably responded to the quantitative survey to participate in a structured interview. Beyond the willingness to participate, we selected potential interview candidates to ensure that the demographic composition of the questionnaires respondents was similar to those that participated in the interview. We conducted a total of 12 interviews, all face to face, over the period August 6 - August 24, 2015. The interviews ranged between 45 minutes to 90 minutes in length and with the permission of the interviewee, all interviews were recorded and transcribed to aid in the analysis of the data. All interviews were conducted with the entrepreneur/owner of the business. Table 6.1 below shows a descriptive analysis of the participants in the interviews (participant number in brackets):

Table 6.1 - Interview Participant Descriptive Statistics

\begin{tabular}{|l|l|r|r|r|}
\hline Business Activity & Location & $\begin{array}{l}\text { Age of } \\
\text { business }\end{array}$ & $\begin{array}{l}\text { Full time } \\
\text { Employees }\end{array}$ & $\begin{array}{l}\text { Part time } \\
\text { Employees }\end{array}$ \\
\hline Craft supplies and flowers (1) & Chaguanas & 8 years & 1 & 1 \\
\hline Snacks and drinks (2) & San Fernando & 25 years & 1 & 1 \\
\hline Computer game sales (3) & Arima & 9 years & 3 & 1 \\
\hline Wig Manufacturing (4) & Princes Town & 6 years & 1 & 2 \\
\hline Religious Bookstore (5) & San Fernando & 12 years & 3 & 1 \\
\hline Pharmacy (6) & San Juan & 24 years & 2 & 3 \\
\hline Cake Maker (7) & San Fernando & 1 year & 2 & 0 \\
\hline Make up Artist (8) & San Juan & 7 years & 1 & 0 \\
\hline Tailor (9) & Curepe & 25 years & 1 & 0 \\
\hline Shoe Repair (10) & Maraval & 8 years & 2 & 0 \\
\hline Clothing (11) & Port of Spain & 6 years & 3 & 0 \\
\hline Party Supply Rentals (12) & San Juan & 3 months & 1 & 1 \\
\hline
\end{tabular}


Table 6.1 above shows the type of primary business activity that interviewees engage in. Using the criteria from the previous chapter, 6 of the business are primarily retail stores, 3 engage in some form of manufacturing and the final 3 primarily engage in the provision of services. Further, the location of the businesses represent the four areas as categorized in the questionnaire such that the number of participants from the West, Central, South and East were 6, 1, 4 and 1 respectively. The businesses that participated in the interview ranged in age from only 3 months in existence, to 25 years, with an average age of 10.94 years.

We conducted the interviews utilizing a semi-structured format. While there was a script of questions, deviations were allowed and sometimes encouraged. These deviations from the interview script allowed for the interviewee to expand on his/her responses and for the interviewer to ascertain a better contextual understanding. During the interviews we explored the individual dimensions of the EO construct, as well as the exploration and exploitation activity of the business. Further, the interview allowed for the development of some contextual background including why the participants started their business, the competitive landscape, their perceived level of performance and satisfaction with this performance.

\section{Reasons for Becoming an Entrepreneur}

Interview participants expressed a variety of reasons for having entered entrepreneurship. Some participants were first introduced to entrepreneurship by their family members, in particular their parents: 
"I never really worked for anybody.... my mother and father worked and from there they started a business...we used to sell on the street and the quickest thing to make money was to sell clothes, you could have gone to Curacao and come back and my mother used to travel to New York so she used to bring stuff, that's how we came to be involved in clothing" (11-Clothing sales)

"I wanted to do something so I decided to do this-and then I grew up in business and all that. My father had a tire shop then he had a mini mart-you know you grow up in it and you just...I said before I turn 25 I have to have something of my own, because I was fed up of home too. I had a baby-I had all these things and I was home like a housewife and I couldn't take it - that's not for me. That housewife role is not my roleso I was like before I turn 25 I have to have something so I tried all kinds of ways for a year and something - maybe two years trying and trying all over how to get the funds to do this and then I decided to go into our own funds to empty everything and do this" (12 - Party supply rentals)

Other participants implied that they started the business due to necessity:

"When I was small my mother and father sent me to learn trade. There was nothing like why did I want-I had no choice. It was their decision at that time-that the family in those days would make the decision for their children because if you were poor you would have no money to go to high school so the next best thing was to learn a trade" (9 - Tailor)

"I worked for a multinational company for 8 years and then they decided to lay off some workers, I was one of the persons that they laid off and the criteria was the last in first out... after that I got fed up and I said you know something? I will open my own pharmacy" (6 - Pharmacy)

Some participants expressed that the decision to start their own business was driven from a love or passion for the businesses' activity:

"I was really into the beauty. . thing. It was a good business area. It was lacking in Princess Town so. . . I did a little research and it needed it, so here I am and I'm good at it." (4 - Wig manufacturing)

"Because, at the end of the day I always liked cake decorating-to get the supplies was hard, especially in South and even though I am a qualified accountant and I have a first degree and whatever else, that wasn't working it out-it just seemed like it wasn't working and I started to save up and I said this is what I want to do-and that's pretty much why." (7 - Cakes) 
"Well it was a passion-we decided to start the business because it was a passion not only mine but a group of us and we liked the entertainment industry-so it was a passion that made us start." (3 - Computer games)

"Well this business started because of church firstly, and then-just thought about the idea of selling Christian books-reaching the wider world so that's really the start." (5-Religious bookstore)

Interviewees also expressed that starting their own business was a matter of lifestyle and opportunistic thinking. These participants noted that their desire was to work for themselves:

"I was home, I was a housewife, my children had all grown up and I saw this ad in the papers and I decided to go for it. I went-made an appointment and I bought (an outlet) in the franchise" (2 - Snacks)

"I wanted to be my own boss" (10-Shoe repair)

\section{Goals for Business}

With varied reasons for starting a business it follows that the goals and expectations for the business also vary and change over time. As such, we asked interviewees to share their current goals for their business. It is worth noting that separating the goals for the business from the personal goals of the entrepreneur was a challenge. Some participants suggested that they wished to increase the profitability performance of their business:

"Well, right now I'm trying to get this up and running perfectly" (8-Make up artist)

"The main thing that I just wanted to be for the business itself, I want it to be able to stand on its own feet which it has been able to do meaning it's been able to pay its own bills so far, so thank God. It has not been able to pay a salary yet" (7 - Cakes)

"Well goals change over years. At first it was just to make a name for yourself and that's the - profitable. It wasn't actually - it wasn't about profit it was about staying- 
getting it together and then afterward you want to now-then there is expansion and then there is profitability and then there is the business running itself with the [owner] not being there" (3-Computer games)

Others are more focused on growth opportunities that may exist:

"I want to go into making sandals and things too. So-- What I did now was put down a foundation for me to relax when I start to make sandals. And [since] I already put down the foundation, so I can focus now on something else." (10 - Shoe repair)

"Well I always have plans because the more you invest is the more you will seeinvest more, so you always have-the goal is just to get money and see about these things" (2 - Snacks)

"Brand name, exporting. I recently went to a clinic -it's an intellectual property clinic so they help you to patent your name and stuff like that-So, I'm looking in that area. I'm kind of trying to get out of the store-hiring someone soon." (4 - Wig manufacturing)

Some business owners were less concerned with maximizing the financial performance of the business. Instead, they care most about its societal or personal impact. This finding helps to justify the inclusion of the control variable referencing the desire for growth in the previous quantitative chapter:

"The main goals for this business really-it's a small store, we may expand as demand gets bigger but it's just - reaching the world you know? Reaching the people in the world with-trying to-you know? The word of God-trying to get it out" (5 Religious bookstore)

"Well, the main goal is the make a living so that I could give my wife and children the best education and the best life possible and to save a little bit of money just in case something goes wrong I have something there" (6 - Pharmacy)

"This business here, is to keep me occupied. I lost my wife almost two years now, after 46 years of marriage and this-I don't make money here, but it keeps me occupied. Sometimes I don't even make my rent and light bills, but I'm an old age pensioner so I use that money, but this business is really to keep me occupied for a few hours every day because if I stay home I don't know what will become of me, I would just dwindle into. . . anything. The thing is that, I'm here and every once in a while a nice person like you comes along so I can stay and chat with ... but I have no plans to expand this business. As a matter of fact probably by the end of the year I might finish because it's just so 
much, I really can't go on much more because I am sick all the time-sickly now-just came out of two months of pneumonia and all kinds of things—really sickly" (9 Tailor)

\section{The Competitive Environment}

Over the course of the interviews several participants noted the competitive environment as being more intense currently than it was previously. Trinidad is a small island that imports the vast majority of its finished products for consumption. As such, many small businesses involved in the retail trade are increasingly facing competition from international online stores. Many of the small businesses are not able to buy in bulk and consequently cannot exploit opportunities of scale. Online shopping is often cheaper than visiting a physical local store that adds on their own mark up to the price.

"I don't think right now it is at a high period right now we are in a transition and change. Systems change, things change so right now we're in a position-retail side of a lot of businesses, internet is affecting a lot of businesses-everybody is buying stuff online and feel that they can get it cheaper so on the retail side that's a problem. On the entertainment side there is competition so that would split people-all the people that would come would be split. That's what I tell you people try different things, they might come here one day, they may go somewhere else another day-that kind of thing. Services side-services are strong, repairs are strong to a point, but there are other things that we can do that's why I say 50\% there is room for improvement and expansion - so to me this is just 50\%" (3-Computer games)

We can discern that while the emergence of online shopping has negatively affected the retail side of the business, service opportunities have seemingly begun to emerge to repair the products that have been purchased through online shopping. That is, though proportionally there is a high availability of finished goods that are manufactured abroad, many of the manufacturers of these products do not have a physical sales or service center locally. When these products inevitably need repair, local repair service 
providers are increasingly stepping in in to fill the gap. However, one can also make the case that that not all service providers are benefitting in this way.

"You can't compete with the Chinese people, they are producing everything and like-I charge \$200 to make a tailor made pants right? That's without material. Basically, if a man wants something good, it might cost him \$500-you can get 5 pants for that in the store so why is he going to come here for one pants when he can get five pants in the store? These kind of businesses are coming to an end, nobody goes by the tailor it's only a few old time people who make clothes but the younger people like you don't go by the tailor to make anything. You want something you go online and order it or you go in the store and buy it and I'm sure you don't go by anybody to make anything" (9 - Tailor)

While some products, for instance phones, televisions and other relatively expensive goods are worth repairing, cheaper products and those that are increasingly mass manufactured, such as clothing, are in many instances no longer worth repairing. Indeed, the cost of repairing a garment in the current competitive environment is often more expensive than the purchase of a new garment.

Although businesses have recognized the new threat that online shopping has created, some are still coming to terms with the implications and reasoning for the new competitive landscape:

"too much competition now and then a lot of people are shopping online so that's why business (is slow)... people prefer to go online and shop and pay more for their stuff than purchasing in Trinidad... to me, people - like Trinidadians, they want to tell people they shopped online for this or they shopped online for an item-that is their way of life." (1-Crafts and flowers)

In fact, even entrepreneurs that sell non-physical or service type products, the emergence of the online environment has created new forms of localized competition as well: 
"Let me just put it this way, YouTube caused an avalanche of competitionbecause everybody who owns a makeup palette - a 120 palette and a brush set is a makeup artist these days" (8 - Make up artist)

Certainly the emergence of online shopping is having an impact on Trinidadian small businesses, but international competition is not the only competition faced by the entrepreneurs. Businesses that exceed normal levels of profitability tend to attract competitors to the industry:

"So at your high point a lot of people come, they patronize you, at that point in around [the previous] 5 years you had less players in the field-competition in the field and then you start to get competition, not only in your area but you started to get competition like closer to the malls so a lot of people who would come to you would go to other people and check their prices and things... The decline happened because of a lotmany-competition online and offline" (3-Computer games)

Beyond the difficulties that have been suggested by entrepreneurs relating to the emergence of the online environment, some entrepreneurs appear to be considering or already utilizing the online environment in a productive manner:

"We actually considered opening a website where people could order their stuff online and maybe they could just come and collect it or something like that. We didn't really have all the details worked out as yet but we were thinking about it and maybe, if people want stuff - a particular item in a large quantity, we would try to facilitate them in that way as well" (5 - Religious bookstore)

"...[I learned] also from online, because you have to try to keep abreast. Sometimes there is a product that is big and it's out in the US but people don't necessarily know about it here, so you advise people about it. Once you have confidence in that particular product and you know there is a market for it-once I know there is a market for it I will bring it and I know for a fact that people will buy it." (4 - Wig manufacturer)

"We do promotions on Facebook, social media and basically that's it, that's how we get most of our customers" (7 - Cakes)

Overall, the entrepreneurs we interviewed suggested that the competitive environment has become more intense in recent years. Certainly the Internet and the 
online environment has given consumers more choice in purchasing physical goods, and further, has afforded many individuals the opportunity to learn specialized skills creating competition on the service side as well. Micro entrepreneurs who are becoming increasingly affected by the emergence of online competition are beginning to think of the technology as a possible resource rather than a threat. However, the change locally appears to be effectuated slower than it has internationally, putting the entrepreneurs at a disadvantage in the short run.

\section{Innovativeness}

The impact of entrepreneurial orientation on the performance of a business has been a major theme in this research. In this section, we investigate the innovativeness dimension of the EO and the innovative tendencies of the entrepreneurs. Some entrepreneurs reported having low levels of innovation, in part due to the market or personal conditions:

"there really is no kind of scope [for innovation] in this kind of tailoring business there are only so many ways you can assemble a pants or a suit-there are no 10 and 20 different ways you can make a pants for someone. There was really never any scope to go into design or anything. Men's clothing is basically one way all the time, it [only] changes every 20 years" (9 - Tailor)

"[with regards to the lack of innovative products] I downsized my business to suit me and [with my] health I only do pre-packaged stuff, anything in packets by companies like snacks and sweets and anything" (2 - Snacks)

"[with regards to product mix changes] Minor changes, like anything else you'll get-you would get some changes but nothing drastic to cause any adverse effect" (6 Pharmacy)

Comparing the above responses to the questionnaire responses from the previous chapter, we can attempt another measure of scale validation. The three businesses above 
reported an average innovativeness score (in their questionnaire) of 2.7/7 as opposed to the mean innovativeness for the entire sample of 3.9/7. The impact on performance for the entrepreneurs with low innovativeness in the interviews is also notable as the average profitability and growth score was $3 / 7$ and 3/7 respectively for the above three firms, compared to a entire sample mean of 4.63 and 4.75 respectively.

Those with low innovativeness tendencies all spoke of their inability to innovate, but interestingly did so from primarily a product type perspective. That is, when the above entrepreneurs were asked about being innovative they all cited their primary product for sale. They seemingly failed to recognize that innovation is not only applicable to the product alone, but for instance can be useful in the methods of production or marketing as well. Some interview participants did report having innovative methods of production and marketing.

"Ok let me show you a little example. We-you know brown lifts? I don't know-you don't fix shoes so often? You know shoes come with brown lifts. There are some high heels. Look at this, look at what I'm telling you about, [shows interviewer a shoe] a shoe will come with that. I can't order that, it's hardly likely you get brown and tan lifts on the market ... right? And if you bring in this kind of shoe [to repair] you don't want any black lifts on this, you wouldn't want any black lifts. But this now, is a black lift, if you look at the bottom. What I did was use nail polish and polished it." (10 - Shoe repair)

"My goal for this time or visiting this time [trip to the USA for a Cake Event] is to see and go and take pictures and be seen with these people so that the customers now can identify you as being seen with these people, being seen with people like Cake Boss who you see on TV is going to be there-so if it means if I have to wait a whole hour and line up to get a picture I will do it and I'll put it up in my store too, you know? " (7 Cakes)

Other entrepreneurs reported innovative techniques in the changes that were made to the product offering, or the differences between the business and its competitors resulting in higher profit margins or greater growth of the business: 
“When I started I didn't know anything about making wigs - I didn't even know what was weave! You know, I'd never even heard about these things [laughs]. I always thought that was just people's hair. When I first started I didn't know a thing about making wigs. One day we were going through some stressful times and I just took up a wig-I looked at it and-let me see how to make this thing and from there I started making that and I started trying new things and now I offer a wide range of things that I make so.... it's not something that I invented, but it's something that I began here. I don't know of anyone in Trinidad that makes those. If anybody has it they bring it in, but I produce those, so I produce a higher profit margin because I make all myself. (4 -Wig manufacturer)

When I'm selecting new products, I like stuff that nobody else has. I like unique stuff I like stuff that people will say - you can try so and so for your party but I know one place that has this-[Store name given] - that's the kind of thing-not because I have it, this person has it - that person has it and they are just comparing their prices-you know who has it cheaper and that's why-the only reason they'd come by me is because they know mine is cheaper-No! Come by me because I'm the only person that has-I like new stuff, I like weird stuff (12 - Part supply rentals)

As with the businesses that reported low levels of innovativeness showing less than average performance, the businesses above who reported higher levels of innovativeness had higher levels of performance. On average from the questionnaire in the previous chapter, the five businesses above reported an average innovativeness score of $4.2 / 7$ as opposed to the mean innovativeness for the entire sample of $3.9 / 7$. The impact on performance for entrepreneurs with higher innovation was mixed as the average profitability and growth score was $4.2 / 7$ and 5.2/7 respectively. This score falls below (profit) and above (growth) compared to the entire sample mean of 4.63 and 4.75 respectively. 


\section{Risk-Taking}

Starting a business inherently involves risk. Entrepreneurs often not only pour a large share of their financial resources into the business, but often sacrifice large amounts of their time. These sentiments were echoed in the interviews:

"Yes we would see it as a huge risk at that time because we were basically putting all our money into it, we were putting what available funds we had into it, we never borrowed any money in the bank ever...Actually when we started we had no products you know, we started with $\$ 20,000^{1}$ and that's $\$ 20,000$ that we just came together andbecause I had some stuff and my partner had some stuff and we put it together we talked to our mentor-he gave us a chance." (3 - Computer games)

"Yes! Yes I believe this is a risk because of what I told you, I emptied everything [bank account] and-this was a risk I didn't know if it would really [payoff] . . you know?" (12 - Party supply rentals)

"Yeah it does because basically my entire savings is tied up here and I always say people see what is face value which is-but they won't see the hard work that you put into it and the hours that you really put into it and the risk is that you can lose your savings, the risk is that you lose your-all your hard earned money you would have worked for before and that kind of thing. The risk-to me that's the biggest risk." (7 - Cakes)

"Risking my time. Time you can't get back, so that's the biggest risk. I mean I've put everything else on hold - family, education-Time you cannot get back-time-you have to make the best of it. Money is something you can always get-you risk money, but you can get that back." (4 - Wig Manufacturer)

Although some individuals we interviewed did suggest that they faced a great deal of financial and personal risk, an equal amount of the entrepreneurs felt that starting the business did not involve much risk. This is primarily due to the personal circumstances that prompted their decision to enter into their own business, as a facet of their

personality itself or due to a weaker competitive environment:

\footnotetext{
${ }^{1}$ Figures in TTD\$. 1 CAD\$ = 5 TTD\$.
} 
"You see I come from the street, I started on the street with nothing I just bought and sold with the little money I had. I didn't have anything when I was on the street but now I have my things-sometimes business is always ups and downs." (11-Clothing Sales)

[Does your business involve risk] "No I wouldn't say that because it's something you enjoy doing so it wouldn't be-ok I see what you mean, risk in what way? Like if the business fails or something like that?" [Interviewer: Yes] "No. I never gave a second thought to that...I don't think we ever took any risks... No, I never thought about it being risky I just-you know the truth is I never really gave it a thought." (1 - Crafts and Flowers)

[Did starting the business involve risk?] "Not at that time. There weren't all these other businesses around and I was the only person with that product." (2 - Snacks)

"Financially, I wouldn't say it's a risky industry because it's not like a big capital-like a huge capital you have to have to start this. I basically took like $\$ 5000$ and started my business with it, so it's not like a big . . risk factor." [8-Make up artist]

Some interviewees offered suggestions on minimizing the risks faced by micro businesses including research and taking relatively small risks:

"I did not have a clue about weave. People were coming in and would be like" She doesn't know what she's doing"-of course I didn't know what I was selling but-I had the risk of just shutting down, because I didn't know about the stuff until I did research." (4 - Wig manufacturer)

"Small risks are like-for instance we bring a small quantity of something -it didn't really sell well or it wasn't successful so it's not-it wasn't huge, it wasn't a big way. . . so it wasn't a big risk to try it because it's not a big investment. We didn't start with a big investment to bring certain things . . . so for instance if we are bringing jewelry stuff we bring it in a small quantity, not a big investment, so then we see how it goes and then we would increase as the demand gets bigger so-small risks." (5 Religious bookstore)

"Anything involves risk but you can minimize the risks, you can minimize the risks by doing a study like what you're doing of a particular business that you want to get into and I think business owners need to do that." (3 - Computer games)

While ideally budding entrepreneurs can preform or attempt to perform an industry analysis, it may be the case that doing so is difficult in the Trinidadian 
environment. Specifically, as was previously experienced in attempting to gather entrepreneur contact information in the course of this research, the government is often slow to act, may never act or in some cases may act inappropriately or fail to provide the necessary infrastructure to securely operate a business adding to the risks faced by entrepreneurs:

"In Trinidad there is not a lot of statistical data that you can pull from or draw from to see how businesses do and if you do read the data that is available the majority of businesses that start up fail within the first year." (7-Cakes)

"There is a product called 'Petidin' it is a painkiller, its a highly narcotic painkiller it is under control you must have a prescription for it and there is a risk with people who really want it because of the addiction they will break into your place to get it so I don't really stock that - that's the distance at which they will go to obtain the product and I don't want to have to face that." (6-Pharmacy)

"I went to them [NEDCO] with the party idea and I wanted to do the rentals and stuff so they told me-they interviewed me and were like there are so much of those things around and asked if I thought I could really make [money] with that. I said that I knew what I was seeing, I know what I am seeing and I could do this. They told me to go back home and think again and when I got another idea I could go back to them and all of that." (12 - Party supply rentals)

As a further method to validate the scales from the previous chapter and to investigate the risk-taking dimension of EO, we asked all interview participants to choose between alternative investment options as a gauge to their level of risk-taking. We gave each participant two separate options, each with two choices. The first was a choice to be made was between a $50 \%$ chance at $\$ 10$ or a $10 \%$ chance of $\$ 50$. Over the long run, the expected value of the decisions are equal, however, we assumed that those who choose the $10 \%$ chance at $\$ 50$ were greater risk takers than those who chose the $50 \%$ chance at $\$ 10$. This is due to the fact that although the expected values of the payouts are the same, the probability of the payout is not. 
Having made their choice in the first question, a second question was posed. If an individual chose the 'riskier' $10 \%$ chance at $\$ 50$ option above, he/she was asked to then choose between a $5 \%$ chance at $\$ 50$ or the $50 \%$ chance at $\$ 10$. Here, unlike the first question, the expected values are not the same, with the 50\% chance at $\$ 10$ having an expected payout of $\$ 5$, compared to the other option with an expected value of $\$ 2.50$. If an individual chose the $5 \%$ chance at $\$ 50$ this person is considered the biggest risk taker.

On the other end of the spectrum, when asked the first question, if the participant chose the less risky option $(50 \%$ chance at $\$ 10)$, the second question given was the choice between a $25 \%$ chance at $\$ 10$ or a $10 \%$ chance at $\$ 50$. Here, the expected value of the 'riskier' option is higher $(5>2.50)$ than the less risky option. The assumption being that only the most risk adverse participants would choose the $25 \%$ chance at $\$ 10$. Thus, we were able to generate 4 different risk-taking scores (very high risk taker, above average risk taker, below average risk taker, very low risk taker). A comparison of the results from the interview with the responses given in the questionnaire are shown below in table 6.2:

Table 6.2 - Comparison of Questionnaire versus Interview Risk-taking Score

\begin{tabular}{|l|l|l|l|l|}
\hline $\begin{array}{l}\text { Participant } \\
\text { Number }\end{array}$ & $\begin{array}{l}\text { Questionnaire } \\
\text { Risk-taking } \\
\text { Score (1-7) }\end{array}$ & $\begin{array}{l}\text { Interview } \\
\text { Risk-taking } \\
\text { (Q1) }\end{array}$ & $\begin{array}{l}\text { Interview } \\
\text { Risk-taking } \\
\text { (Q2) }\end{array}$ & $\begin{array}{l}\text { Interview } \\
\text { Risk-taking } \\
\text { Total }\end{array}$ \\
\hline 1 & 3 & Low & High & Below Average \\
\hline 2 & 1 & Low & Low & Very Low \\
\hline 3 & 4 & Low & Low & Very Low \\
\hline 4 & 4.33 & High & Low & Above Average \\
\hline 5 & 3.33 & Low & Low & Very Low \\
\hline 6 & 3.67 & Low & High & Below Average \\
\hline 7 & 4.33 & High & Low & Above Average \\
\hline 8 & 5.33 & High & Low & Above Average \\
\hline 9 & 2.33 & Low & Low & Very Low \\
\hline 10 & 3.33 & Low & Low & Very Low \\
\hline
\end{tabular}




\begin{tabular}{|l|l|l|l|l|}
\hline 11 & 3 & Low & High & Below Average \\
\hline 12 & 4.33 & High & High & Very High \\
\hline
\end{tabular}

Based on the results above, a two tailed Pearson correlation table was

calculated that shows the relationship between the measure of risk-taking in the questionnaire and the measure in the interview:

Table 6.3 - Correlation between risk-taking responses in Questionnaire and Interview

\begin{tabular}{|ll|r|r|}
\hline & & Questionnaire & \multicolumn{1}{|c|}{ Survey } \\
\hline Questionnaire & Pearson & 1 & $.671^{*}$ \\
& Correlation & & .017 \\
& Sig. (2-tailed) & & 12 \\
\hline $\mathrm{N}$ & 12 & 1 \\
\hline Survey & Pearson & $.671^{*}$ & \\
& Correlation & .017 & \\
& Sig. (2-tailed) & 12 & 12 \\
\hline
\end{tabular}

*. Correlation is significant at the 0.05 level (2-tailed).

Based on the above, we can infer that the measures of risk-taking for both the questionnaire and the interview are significantly and positively correlated. In terms of the risk-taking measures through the survey and its relationship to performance, Table 6.4 below shows the relative performance as measured through the questionnaire and compares it to the risk-taking level as measured in the interview and is directly followed by a summary table of the results: 
Table 6.4 - Questionnaire Performance and Interview Risk-taking

\begin{tabular}{|l|l|l|l|l|}
\hline Participant Number & $\begin{array}{l}\text { Risk-taking } \\
\text { Interview }\end{array}$ & $\begin{array}{l}\text { Profi } \\
\mathbf{t}\end{array}$ & $\begin{array}{l}\text { Growt } \\
\text { h }\end{array}$ & $\begin{array}{l}\text { Sustainabilit } \\
\text { y }\end{array}$ \\
\hline 1 - Crafts and flowers & Below Average & 4 & 4 & 7 \\
\hline 2 - Snacks & Very Low & 4 & 4 & 7 \\
\hline $3-$ Computer games & Very Low & 5 & 4 & 6 \\
\hline $4-$ Wig manufacturer & Above Average & 4 & 6 & 7 \\
\hline $5-$ Religious bookstore & Very Low & 5 & 6 & 6 \\
\hline $6-$ Pharmacy & Below Average & 4 & 4 & 5 \\
\hline $7-$ Cake maker & Above Average & 4 & 4 & 7 \\
\hline $8-$ Make up artist & Above Average & 5 & 5 & 7 \\
\hline $9-$ Tailor & Very Low & 1 & 1 & 1 \\
\hline $10-$ Shoe Repair & Very Low & 4 & 5 & 5 \\
\hline $11-$ Clothing Sales & Below Average & 1 & 4 & 4 \\
\hline $12-$ Party Supply Rentals & Very High & 4 & 7 & 7 \\
\hline
\end{tabular}

Table 6.5 - Summary Performance and Risk-taking by risk-taking level

\begin{tabular}{|l|l|l|l|}
\hline Risk Level & $\begin{array}{l}\text { Average } \\
\text { Profit }\end{array}$ & $\begin{array}{l}\text { Average } \\
\text { Growth }\end{array}$ & $\begin{array}{l}\text { Average } \\
\text { Sustainability }\end{array}$ \\
\hline Very Low (5) & 3.8 & 4 & 5 \\
\hline Below Average (3) & 3 & 4 & 5.33 \\
\hline Above Average (3) & 4.33 & 5 & 7 \\
\hline Very High (1) & 4 & 7 & 7 \\
\hline
\end{tabular}

Although the sample size is relatively small $(n=12)$, the summary table does show some trends toward increasing risk-taking and growth and sustainability. That is, as an entrepreneur's level of risk-taking increases the average growth of the entrepreneur's business also increases, though this change is primarily at higher levels of risk-taking. The sustainability of the business also gets better with additional risk. This relationship between risk and sustainability is somewhat counter intuitive as excessive risk is often seen as a shortcut to business failure (Baron 2007). However, possibly the size and scope of risk of these small business entrepreneurs are small enough that a large risk, is still 255 
relatively small enough to avoid complete business failure. Profitability also shows an overall increase with rising levels of risk-taking, however, it first falls with increased risk (from very low to below average), before rising.

\section{Proactiveness}

The third dimension of the EO construct is that of proactiveness. Quantitatively, in the previous chapter we identified that proactivness had a significant effect on performance. Throughout the interviews, we discussed proactiveness in more detail. In one facet of proactiveness, businesses can benefit from being one of the first to offer a new product or service in the marketplace:

"I think it's beneficial because you are the only person that's in that and then whenever they think about having-getting this thing-your name comes first and they come to you -I think its beneficial in a way" (12 - Party supply rentals)

[Do you think being first to market is beneficial?] "Well normally my customers come-every time I travel and come back it's different stuff. Yes it's beneficial." [Why?] "Because when customers see this here they would go and tell other customers and they will always come as long as you have it first" (11-Clothing)

"I would say we have been the first to introduce a few products in the area, firstly. Example, multi stations-certain systems and some repairs we were the first to do it in the area I would say. We have been trendsetters but I would honestly say that now we have gotten comfortable and I think we fell behind a bit and right now that's where I'm trying to turn around things to be a trendsetter again." (3 - Computer games)

Despite the advantages that may exist from being the first to market, there can also be drawbacks:

[Is being first to market always beneficial?] "Not all the time because somebody can come and-there will be a loophole and somebody could be better than you, they will see something that you are not doing for example Facebook was not the first in the market, there was MySpace and Tag and Mr. Zuckerberg realized that he could do it 
better than them and that's sometimes okay - sometimes you need to keep certain secrets to your chest and you need to release it at the right time." (3 - Computer Games)

"The only drawback is-of course you are putting your energy and money out there and-you have to give it time to catch on-people are kind of slow in Trinidad so . . . your money is out there jumping up and you're waiting-- relaxing and waiting for it to start selling." (4 - Wig Manufacturing)

Some micro businesses are yet to recognize the advantages of being proactive and admit as much:

“Well. . let's see what new products? No not really.” (2 - Snacks)

"I don't believe so. No I don't believe it's the first." (5 - Religious bookstore)

[Have you ever been the first to introduce a product on the market?] "No" (6Pharmacy)

Interestingly, those who revealed that they had never been first to market with a good or service also revealed that their lack of responsiveness to market research was a possible limiting factor:

"Well as we always say just go with the flow if someone asks for something-but then again we really don't --if somebody asks for an item you really don't go into it because sometimes one or two persons will come and ask and after that no one else, you have to be very careful what you are purchasing for business today so we just go with the things that will sell fast—-the everyday items —we stick to that" (2 - Snacks)

"Not really-we never really carried out any big process like market research and stuff we just experimented with stuff-have ideas and things like that--that would be beneficial - that might sell and so that's how we just... ") (5-Religious bookstore)

"I wouldn't do any kind of market research physically, but I'd do it mentally....For example they brought out a soap recently called 'Ascepcia' for acne when they introduced the soap, on two occasions I didn't buy it. When people started asking for it then I purchased and sold it" (6-Pharmacy)

Being first to market may not always be possible, but the process is certainly aided by conducting market research. Micro businesses need to be constantly surveying 
the market place in search of new ideas and being mindful of trends that may be developing.

"I am actually following a lot of blogs and I follow a lot of cake decorators and it means therefore when I leave here, besides the cakes, for hours and hours and hours on end I am doing research. What some people might say is looking at Facebook, reading blogs whatever it might be, your idling - but no I'm doing research because that is the one way you would see what is up and coming you know? And what I have planned and what we'll be doing in September, we're actually going to a-there are three major cake shows in the US-held every year and one of them is held in Orlando so we have already booked our stuff to go and meet with the distributors and main persons who make things like Wilton and Artico and the CK's and FMMs-all those people we are going to meet directly with them and see what they have new to offer." (7-Cakes)

"I don't do like an official survey but I go to other stores I am very .. . I go to other stores, by now I guess one or two people know who I am. I go to other stores, I pretend to be a customer, I ask questions, I watch their layout, I go online to get a global view of the way things are, I read a lot of tech stuff, I read a lot of stuff, I read business stuff, I read the markets how-trending, so I do a lot of nightly research and my business partner also does a lot of research into repairs and so on. If you don't research and you don't do anything you can't get anywhere really... I do a lot of research in it first and or-you talk to somebody who is very knowledgeable about the business that you want to get into, don't go into a business that you don't know anything about, don't go into business without some kind of money and don't go into business without your suppliers or who you know you're going to get your stuff from. Bad, totally bad." (3 - Computer games)

"In this industry you always have to be in the know about what new products come out, what customers want - all the time. It's an industry that's constantly changing, so you always need to be in the know." (8-Makeup artist)

[On researching new ideas] "I would tell them [customers] about it or I would listen to them, I would listen to them when they say "you know, I really wanted this" I would listen to those little things and then I would think about something that I could do so that - could help in a way and then I would come up with an idea' (12 - Party supply rentals)

In sum, proactiveness revolves around two distinct but interrelated components.

In the first instance, firms must be alert to the opportunities that exist in the market.

Through varied methods, micro businesses can conduct market research to identify the 
needs of the market or two investigate new ideas and innovations that they believe has potential to generate sales at a local level. Once the research has been carried out, entrepreneurs must combine and consolidate their findings into a coherent plan of action. Not all new ideas are certain to work in the market and as such, a level of selectivity must prevail. Often, micro organizations have limited working capital and a large investment into a failed product can severely hamper the prospects of the business. However, by actively seeking and carefully considering the information available, entrepreneurs need to filter the available options and can then select the best product mix for their business.

\section{Ambidexterity}

As has been discussed previously, ambidexterity has been defined to be the interaction between the exploration and exploitation capabilities of a business. The relationship is similar to that of growth and profitability whereby though unique, they can often be maximized through their interaction:

"Without growth you'll just be one way, you'll be left behind and then your profit will dwindle, so you need to grow, always grow, even if it's in your own business you don't have to be like a big expansion always - I believe you can always revamp stuff. I think every 5 years you should revamp stuff - every year you look at something, but every 5 years you do a total revamp of something and not everybody does that" (3 - Computer games)

Well if you grow you will be investing more and growth means more customer flow and of course the profitability will come after (6 - Pharmacy)

But achieving an ambidextrous organization can be difficult. Often it involves tradeoffs between exploration and exploitation or growth and profitability:

"For instance I would love to have a Linx machine (debit card) here or a credit card machine, I would love to, but when that is eating into your profits, every single thing 
is eating into your profits yes - it means really that the prices have to be higher in order to cover that cost and that cost is high (7-Cakes)

"In the past time I've been here the business has always shown a profit but what happened, I had workers and I wasn't here and I left them to do my job and-the business always made a profit but they did what they had to do and whatsoever... It wasn't profitable-it was profitable, but the money wasn't showing.... If I was here it would have been .... if I came in the evening and they sold \$1000 they would tell me they sold $\$ 500$, so you should know what's going on" (11-Clothing)

"I might have to sacrifice the profit sometimes-yes! Because sometimes I have to do certain things and I know I'm going to make a big loss but because I want to reach somewhere or a want a certain thing in the store-something to grow a little more I would be okay with that because I know that after things will start to go smoothly again and then profits will start to come in after that." (12 - Party supply rentals)

Exploration involves the identification of new opportunities and the learning of new skills, although not every entrepreneur believes in the value in exploration activities:

"Balloon decorating and then some people actually want you to come for themcome and set up and all of that stuff - I don't do that - those things are needed for this type of business and I don't do these things-I just-what I tell them-I'd be like the most I'll do is provide the stuff you come and you buy and that's it then after you hire somebody to come and do your party - I don't do that - they want balloons and they come for a balloon arrangement and then I don't know how to do a balloon arrangement and then they are like "you're in the wrong business" you know? Customers are really rude, they'd be like" but then you are in the wrong business" I just don't take them on, I'm like ok whatever" (12 - Party supply rentals)

"This - this business - you really - it is a business where you don't have to have much education much talent, but you must have a little-you must have education because everything is measurements, you must have a little mathematics, like measurements. Basically, you don't need a lot of skills you know, you really don't need any once you go by a competent person they'll teach you tailoring and you are above average you could be a tailor" (9 - Tailor)

Well I think the current skills are enough maybe something a little minor might be helpful but basically I'm there (6-Pharmacy)

"I mean the current skills for this business I think are enough. . . but could always improve-be a better salesman. . . but I think the current skills are enough-required for this business" (5-Religious bookstore) 
I'm sufficient for now and I'm satisfied with that, I don't need any-because I am settled (2 - Snacks)

Others, swear by the need for exploration capability and are frank about the need for the development and acquisition of new skills:

"You always have to learn new skills. Always." (10-Shoe Repair)

"Well, as I say, this industry is always changing-so yea-all the time you need to be upgrading yourself" (8-Make up artist)

"Definitely. Where hair is concerned, hair trends are always evolving-you have to keep up" (4 - Wig Manufacturing)

"There is always room for improvement, there are always new skills" (1-Craft and flowers)

Micro businesses can indeed attempt to grow their business through the acquisition of new skills, new goods and new services, however the execution of the introduction is just as important. That is, just doing something new isn't enough to capitalize on the potential growth and profits. Rather, firms must also master their current operations in an attempt to maximize on the economic rents that may be available:

"Well . . a lot of it had to do with giving the customer whatever it is-whatever product they brought in on time. When something is not ready and a customer comes in-it's not ready - they have their money in their hand to pay you. If it's not ready that money is gone. You wouldn't see that money until the next month. So . . just having a product ready on time is money. Because, if three customer come in and you tell the three of them " hear what, it's not ready" -check it out-you lose in a high way for the day." ( 10 - Shoe repair)

"I do have one that is coming up which is-we have actually decided to go with a different shipment company because the last shipping company-they weren't providing us with proper documentation and their fees kept going up for no-and they could not explain it. The more shipping cost goes up the more these items will go up too so it cuts back on not only our profitability - it also increases the cost for the customer too so because of that we have actually done a lot of research and decided that going to the cake show part of our trip, to finalize the arrangements that we have with a shipping 
company abroad in order to have our things consolidated and shipped to us at about 1/10 (one tenth) of the cost it would have cost before" (7 - Cakes)

"By giving more and more consultations and in business, even though I've never been to business school but I have learnt in business to always recommend your higher profit item. For example if you have two creams one is for $\$ 10$ and one is for $\$ 60$ and they serve the same purpose, when you are recommending you recommend the higher priced one-the profit margin is higher than the $\$ 10$ where the profit is small. That's a business procedure!" (6 - Pharmacy)

\section{Performance}

The quantitative survey gathered information as to the performance of the sample population. We also asked interview participants to share their views on their own performance compared to that of their competitors. The results suggest that there may be some bias at play in the performance self reporting by participants:

"The performance of my business? Customer service again-I mean-everything is much better, comfort-people can come in-we have a personal relationship. Most places you go to people take your money and they just want your money-they don't want to see you, you know, get something that you're comfortable with-when you're walking down the road and people are going to say " where did you get that" or "who made that wig for you" and those kinds of things. They (other businesses) don't think about the long run-that's what I think about, the long run." (4 - Wig manufacturing)

"I'm the best [Yes?] Yes I am! I cannot say somebody is better than me hello!" ( 8 - Make up artist)

"I am top of the line, once I am-my knowledge and my experience and the way I promote myself - they are not equal to me-no way - I could boast about that." (6Pharmacy)

The bias of inflated self-performance becomes more apparent if compared with the profitability results of such all alleged high levels of performance. Participant 6 (Pharmacy) claims to be top of the line, but the actual success does not seem to reflect this claim: 
[Is your business more successful than the competition?] "I wouldn't say so because of how the public perceives the place. There are some people who love cheap medicine, I don't practice that I buy good quality medicine you find very little products here made in India and rejected products, I don't operate with that, but there are people who believe in that because they want to spend 10 cents and get 10 dollars worth-all well and good for them, I don't operate that way. We retain basically the intelligent customers who understand the quality of our product."

Others had difficultly in assessing the performance of their competitors to their own:

"I'm not exactly sure to tell you the truth but, I believe the store is performing pretty well in spite of the little competition. I believe the performance is good for this store. . I'm not too sure about the other stores, but I believe the performance is good for this store" (5-Religious bookstore)

"Well my performance is ---I'm satisfied with what I have, I don't look at other people business - I don't know and I don't ask questions, what I have I'm satisfied with." (11-Clothing)

All of the micro entrepreneurs interviewed were guarded with reference to their actual level of profitability. They were however willing to share growth statistics which were mixed:

"Have to run a report to see how last month went, I didn't really see last month's report yet but yea-it increased - I got and increase so it's good-it gets better even if it's by a $\$ 1000$ alone every month, it gets better and that's good-but I plan to be seeing a lot of zeros I want to see a lot of profit-I want to see profit and that's why I want to bring in new stuff and do different things to actually bring in profit whatever is going to pay in rent here-because I'm not paying the rent" (12 - Party supply rentals)

"Yea, actually it is growing-current level of sales growing-it grows every year, you might see a little increase profits. Yea, I believe it is growing." (5-Religious bookstore)

"Yea, it's always growing." (11-Clothing)

Slowly but steadily I suppose yes." (7 - Cakes) 
[Are sales growing?] "Not really, I wouldn't say so because of the same thing. More and more people come out on the streets with everything; anything and they are not paying any rent." (2 - Snacks)

I think business before was more-people used to come out and shop before but now they don't shop as they did before - buy what is important and as we say there are more shops all over, there are people selling the same things all over and then the online shopping that we go back to again (1-Crafts and flowers)

\section{Summary}

This chapter has considered the findings from the qualitative component of the research. Specifically, through 12 interviews that were conducted with a selection of entrepreneurs (who also completed the survey), we considered the dimensions of the EO construct in greater detail as it related to the contextual situations faced by the research participants. The entrepreneurs who participated in the survey shared their reasons for entering entrepreneurship including, the influence of family members, economic necessity, a passion for the businesses' primary good or service or simply as a result of opportunistic thinking at a particular moment crossed with an actual opportunity.

Entrepreneurs also shared their varied goals for their business. While in larger organizations, especially those governed by shareholders, the utmost goal of the business is the generation of shareholder value in a financial sense, in micro organizations, the goals may be different. Certainly some entrepreneurs in micro organizations are keen to return increasing levels of profit and sales growth, while others are seemingly content to have the business return enough to meet the expenses of the business.

Based on the interviews, a change in the competitive landscape also came to the fore. The explosion of online shopping, greater availability of credit cards locally and the 
boom of 'freight forwarders' have resulted in the average Trinidadian consumer having access to a greater variety than ever before. Local micro entrepreneurs are increasingly feeling the effects of the increased competition on an international scale. Devoid of the ability to capitalize on bulk economies of scale, consumers are becoming increasingly aware that by buying online and shipping to their home address is often more convenient and cheaper than sourcing the items from small businesses locally. While the intensifying competitive environment has had negative impacts on most entrepreneurs, others have begun to look to the technology as a new means of generating growth and profits.

We explored the dimensions of EO and revealed the diversity in approaches and outcomes of low and high scores on the EO scale. In terms of innovativeness, surprisingly several entrepreneurs admitted that either their own, or their belief as to the scope of innovativeness that was possible in their business was low. Interestingly, those who made this claim all did so with regards to the nature of the end product itself. Others, despite also selling products that leave little scope for innovation, have creatively utilized facets of the businesses operation such as its marketing in an attempt to capture the benefits of firm innovativeness.

Interview participants also shared views as to the nature, benefits and drawbacks of risk-taking. The propensity to take risks was fairly evenly split between risk taker and risk adverse. In several instances entrepreneurs shared that their level of investment financially and with regards to their time was all consuming. It was also apparent that despite some participants declaring that they did not view starting their own business as 
risky, these individuals may share a extremely high level of risk tolerance. One participant even admitted to have never even considered the potential risks involved.

Proactiveness, operationalized as the level of market research and the speed to market was also mixed. Some participants shared that they conducted little to no market research. In a form of scale validation, these same individuals also had never been first to market with any good or service. Despite the lack of formal resources other entrepreneurs demonstrated strong market research skills. Either through constant discussion with their clients or after hours research as to the new innovations in the market space some entrepreneurs insisted that the only avenue to increased growth and profitability was through the a proactive business posture.

Participants were asked about the facets of ambidexterity, exploration and exploitation. Some agreed that exploration and exploitation went 'hand in hand' while others were keen to point out the potential tradeoffs involved. A few entrepreneurs suggested that exploration and the development of new skills was difficult given the circumstances of their businesses' resources, though these same individuals also admitted to lower than desired levels of profit and growth.

Those entrepreneurs who were able to spend some time focused on the exploration capabilities as well as the exploitation capabilities of the business were rewarded with increasing levels of growth and profitability. Despite the limited human resources that exist in these micro businesses, those entrepreneurs who can find a way to investigate new ideas and acquire new skills while keeping a keen eye on the day-to-day 
operations of the business, in particular its profits, tend to have more success than those who are unable to do both.

Finally, in terms of growth performance there seemed to be a mix of results. Several entrepreneurs reported growth, while others failed to do so. Entrepreneurs also seem to have a performance bias such that they believed their personal performance was well above the normal standard, even if this does not translate into profitability and growth. While it is difficult to disprove their claims, one participant suggested a reason for the possible belief of many of the entrepreneurs who rate their own performance well above normal:

"I would say I am one of the best from what I've seen, but I haven't seen much." (9-Tailor) 


\section{Chapter 7}

\section{Discussion}

The following discussion considers the data that has been collected and analyzed in an attempt to explore and understand the major findings. In this chapter we explore the relative effects of the use of a unidimensional or multidimensional EO scale, followed by an investigation of unique effect of risk taking as a dimension of EO. Next the findings with regards to the non-linearity of $\mathrm{EO}$ and its dimensions to performance is assessed and then we consider the competitive aggressiveness dimension and its applicability to the EO scale. Insights from the relationships between the control variables and measures of performance are then discussed, while the chapter concludes with a discussion surrounding the discovery of a new ambidexterity calculation and its impact on EO and performance.

\section{Unidimensional Versus Multidimensional EO Conceptualizations}

The summated construct of Entrepreneurial Orientation and the individual dimensions that combine to form the construct are positively and significantly related to multiple dimensions of performance (profit, growth and sustainability) in micro organizations. The majority of the relationships between EO, and its dimensions of innovativeness, risk-taking and proactiveness to that of the dimensions of performance, are linear such that an increase in EO or its dimensions tends to result in an increase in the expected performance of the business.

The relationships shared between the various EO constructs and various dimensions performance varied in their size and strength. Based on the findings, it 
appears that EO and its dimensions are most closely related to the growth performance of micro organizations, followed by profitability and then sustainability. The results were consistent whether we used the unidimensional or multidimensional construct in the analysis. These findings demonstrate the importance of the choice of the specific performance variables used in research and also suggests that EO may be most applicable as a tool for explaining the variance in growth between organizations, followed by its profit performance and finally sustainability.

The finding that EO is more significantly related to growth than profitability is a slight departure from the findings of the field, where profit has been shown to have a slightly stronger effect. One possible explanation for the finding is increased efficacy of EO as a growth tool in micro organizations over that of larger organizations. Rauch, Wiklund, Lumpkin and Frese (2009) note an increasingly significant relationship between EO and performance as company size decreases, reporting an aggregated correlation between EO and performance of .345 for firms of $1-49$ employees. Our findings, for the respective relationship shows correlations of .362 for profit and .401 for growth. In both instances, we note the finding that the correlated measures for our sample of business of 1 -5 employees shows and increase over firms sized $1-49$ employees, and by even greater amounts for larger firms (.198 for firms $50-499$ and .240 for firms over 500 employees). Thus, there seems to be a relative advantage of a higher EO as the size of the firm decreases. Further, given the small size of the organizations under study, the greater the room for proportional expansion and growth relative to larger organizations.

With regards to the strength of the relationships shared between the individual 
dimensions of EO and performance, there exists a gap between the perceptions of the participants of the research versus that of the national experts referenced in the GEM report for Trinidad and Tobago. These experts hold views that regarded local entrepreneurs as not being innovative or proactive and being risk adverse. While an assessment of the accuracy of their beliefs are beyond the scope of this paper, the correlation table in Exhibit 3 demonstrates that relative to the strength of the relationships between the EO dimensions and performance for previous studies in the field (Rauch, Wiklund, Lumpkin and Frese, 2009). Within the context of the Trinidadian sample, the EO dimensions are more strongly related to successful performance. Rauch, Wiklund, Lumpkin and Frese (2009) report correlations of .195, .139 and .178 between innovativeness, risk taking and proactiveness based on a meta analysis of the field. Our findings show comparative relationships of $.307, .276$ and .330 (profit) and $.303, .345$ and .361 (growth). Though we are unable to provide an absolute answer as to the relatively levels of EO dimensions across contexts, as can be seen, the positive relationships between the dimensions and performance within the Trinidadian context appear to be very strong.

One core component of the research we conducted was an evaluation of efficacy of the EO construct as both reflective and unidimensional (innovativeness, risk-taking and proactiveness are summated) versus that of a formative and multidimensional scale (the dimensions are not summated and left to individually vary). The summated EO construct was indeed a significant predictor of performance on all of its measured dimensions and explained an additional $7.5 \%$ of profit, $8.5 \%$ of growth and $3 \%$ of 
sustainability in the variance that has been accounted for by the model beyond that of control variables (increase in R squared).

Comparatively, the multidimensional construct managed to explain an additional $8.3 \%$ of profit, $9 \%$ of growth and $3.8 \%$ of sustainability beyond that of the control variables. Thus it appears that based on the increase in the R squared, that the multidimensional EO construct is able to account for more variance in the model than the unidimensional model. However, it must be noted that due to the deconstruction of the dimensions of the EO construct, the multidimensional model had more predictors than the unidimensional model. Adding even unrelated, random variables to any model may result in an increase in the R squared of the model as such, the F statistic of both models were compared.

Unlike the R squared, the F statistic accounts for the number of variables that have been included in any model and therefore is considered a more appropriate measure of two models that may have a differing number of variables. When comparing the $\mathrm{F}$ statistics of the models, the summated EO shows a significant higher F statistic in each analysis. With regards to profit, the summated EO model's F statistic is higher than the multidimensional model $(10.836>8.962)$, as well for growth $(12.743>10.382)$ and sustainability $(3.612>3.135)$. Thus, if we were considering a measure of significance that includes model parsimony, it seems that the summated EO construct is more appropriate.

While the summated EO construct may be favored due to its robustness and parsimony, the differing effects of the individual dimensions on performance are worthy of some discussion. Plouffe, Hulland and Vanderbosch (2001) consider the effects of 
model parsimony versus explanatory power. They argue, that an understanding of the full range of model dimensions, which may otherwise be combined or eliminated in a more parsimonious model, is important given variance in contextual factors. Because of the likelihood of individuals responding differently in varying contexts, there may be value in sacrificing parsimony to investigate additional variables.

With specific reference to our models, consider the dependent variable of profit. The summated EO construct shows a positive linear relationship with profit that shows significance at the $\mathrm{p}<.001$ level. Comparatively, the individual dimension of innovativeness also shows a positive linear relationship with performance, but at the lesser $\mathrm{p}<.05$ level. This is also true for the proactiveness dimension (which has the greatest significance of the dimensions); however, the risk-taking dimension fails to show any significant impact when profit is the dependent variable. In this example, using the parsimonious and robust unidimensional EO scale we sacrifice an understanding of the variables that may uniquely contribute to this relationship. Without the benefit of a deconstruction of the individual dimensions, one may be led to assume that innovativeness, proactiveness and risk taking all positively contribute towards improved profit performance. Through deconstruction however, we can identify that while innovativeness and proactiveness do seem to positively contribute, the same does not seem to be true of the effect of risk taking.

As has been noted earlier, the number of EO research articles has been trending upwards with the majority of growth being driven by use of the multidimensional scale (Wales, Gupta and Mousa, 2013). Based on our findings this is a positive indicator for the 
development of the EO literature as more nuanced relationships will be uncovered leading to an increased understanding of the effects of the EO dimensions in isolation. Additionally, researchers may find benefit from the joint analysis of the EO dimensions as a unidimensional and multi dimensional scale. The data collection for both scales are identical, the analysis techniques only requiring slight modifications between them as well as both offering opportunities for unique and independent discoveries from the results.

With growth as the dependent variable, risk remains insignificant, and innovativeness also loses its significance. Interestingly, proactiveness remains significant suggesting the paramount importance of conducting effective market research and being first to market, which are primary characteristics of a proactive business. The findings are duplicated when using sustainability as the dependent variable leading to two beliefs. First, proactiveness seems to be the most important dimension in the EO scale, contrary to the findings of previous research in the field (Rauch, Wiklund, Lumpkin and Frese, 2009) in which innovativeness was shown to have the greater impact.

One reason for the difference could be the size of the businesses that formed this study's population. Possibly, micro businesses rely to a greater extent on sound market research due to the high consequences of failure to have correctly assessed the market. In fact, in their interviews, several entrepreneurs suggested that purchasing stock that failed to sell not only had severe implications for their cash flows, but also negatively affected their willingness to entertain future unproven opportunities. Further, given their small size, micro organizations are able to instantaneously respond to the changing needs and 
wants of the market. As such, the speed at which these businesses can respond to changing market conditions appears to be a major strength of micro organizations.

Second, based on the failure to find significance between risk-taking and any dimension of performance, we are left questioning the applicability of the risk-taking dimension. One possible explanation for the finding could be the self-classification of an entrepreneur's risk-taking propensity. Specifically, through an analysis of the survey and interviews it was apparent that although all entrepreneurs could be generally considered risk takers, they do not all identify as such.

\section{The Unique Effect of Risk-taking}

It follows then, that entrepreneurs as a group, may have a higher risk tolerance than non-entrepreneurs. That is, to a non-entrepreneur opening a business is perceived as high risk, but to an actual entrepreneur opening a business in 'just another day at the office'. Consider the response given by interview participant 2 . When asked about the level of risk involved in starting the business, the entrepreneur answered that there was no risk at the time and suggested that this was because competition was low at the time of start up. While non-entrepreneurs may consider the establishment of a any new business to always be a risky endeavor, entrepreneurs seem to be able to better gauge the risk involved not isolation, but rather as a function of the scale of the opportunity (performance potential). In fact, when entered into each model as one of the EO predictor variables, including the innovativeness and proactiveness dimensions and differing performance dependent variables, the risk-taking dimension failed to show statistical significance in any test. However, in post-hoc tests, removing the innovativeness and 
proactiveness dimensions from the models resulted in risk-taking showing strong statistical significance $(p<.001)$ to profit and growth and moderate significance to sustainability $(\mathrm{p}<.05)$. This finding suggests that some form of relationship between the dimensions of EO exist that is influenced by the innovativeness and proactiveness dimensions.

To explore the possible mediation effects of the individual dimensions of the EO, we conducted further post hoc tests that revealed that risk-taking mediates the relationship between innovativeness and proactiveness and the performance variables of profit and growth. The results of the post hoc tests of risk-taking as a mediator of innovativeness and proactiveness are illustrated below in Figure 7.1:

Figure 7.1 - Risk-taking as a Mediator of Innovativeness and Proactiveness

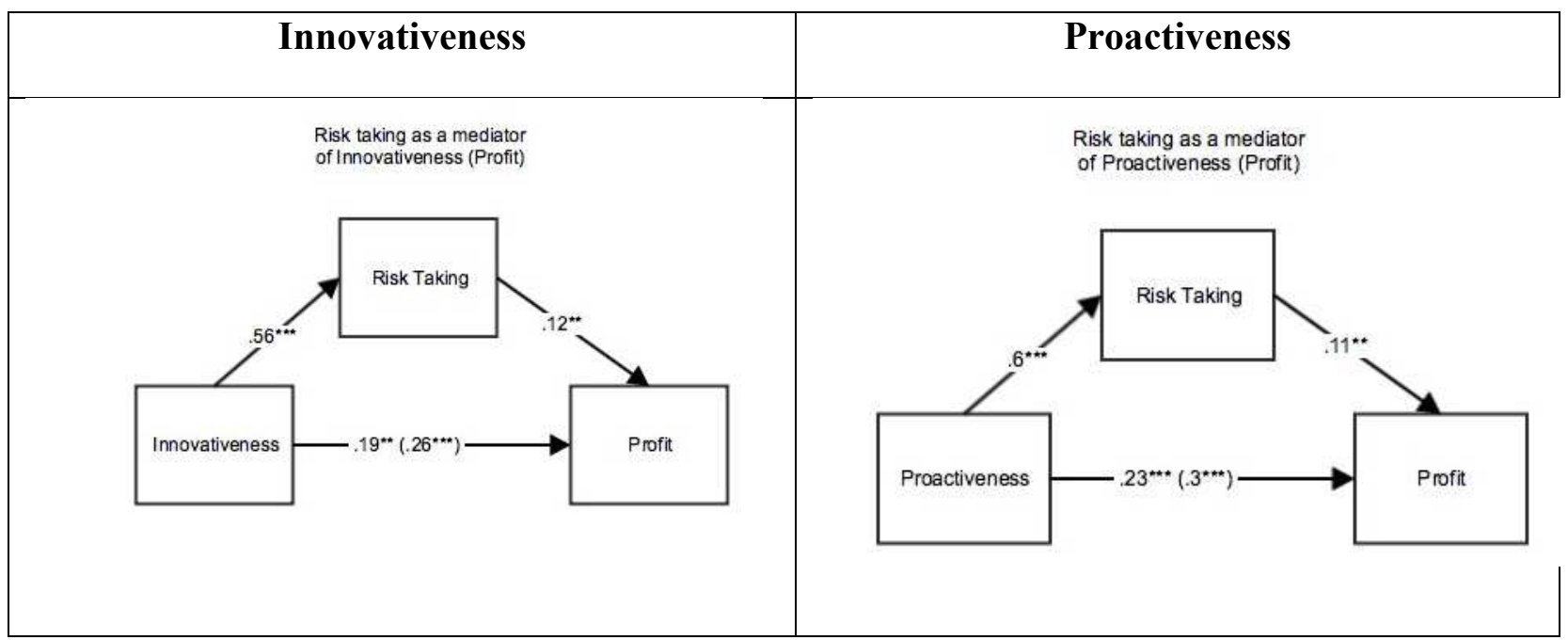




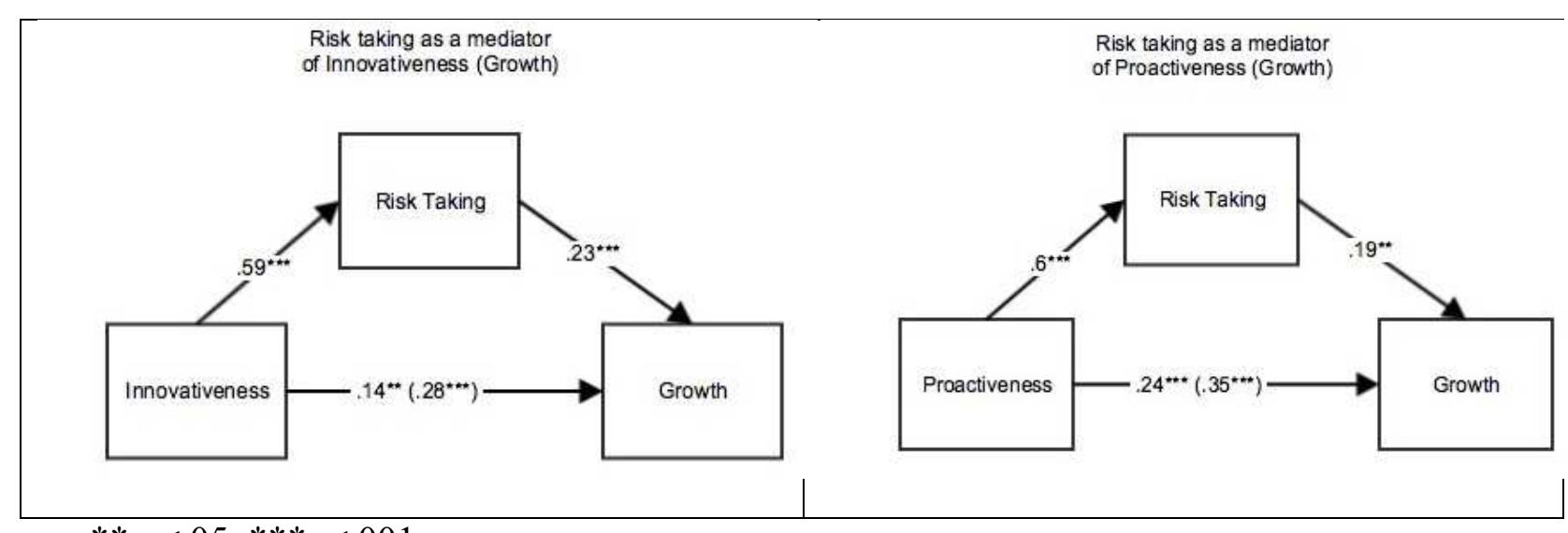

$* * \mathrm{p}<.05, * * * \mathrm{p}<.001$

As illustrated above, risk-taking shows high statistical significance as a mediator of the relationship between innovativeness and proactiveness to profit and growth. Notably, the mediation effects for growth are more pronounced than for profits and even with the mediation effect, the direct effect of innovativeness/proactivity and performance remains significant, suggesting partial mediation.

The mediation effect in Figure 7.1 above suggests that while the direct effects of innovativeness and proactiveness are significant in the explanation of profit and growth, they are also significant in the explanation of risk-taking, which in turn is significant in the explanation of profit and growth. Risk-taking therefore plays an important role in understanding the relationship that is shared between the other dimensions of EO and performance. In short, innovation appears to entail the firm's capacity to generate new ideas, while proactiveness dictates the ability of the firm to effectively execute those ideas. Conversely, risk-taking seems to act as the gatekeeper between innovativeness and proactiveness each unto performance. For instance, a micro organization may learn new skills and generate new ideas for products and services (innovativeness). This may be as a result of informed market research, and facilitate the ability to be the first to the market 
with the new products and services (proactiveness). However, the likelihood of the innovativeness and proactiveness of the firm having a productive impact is mediated by the level of the firm's risk-taking. Those firms with high levels of risk-taking are more likely to have the efforts from its innovative and proactive behavior come to fruition, while those with lower levels of risk-taking, (despite possibly having well researched new ideas) may never have the idea see the light of day. As such, beyond being the first to develop new ideas, firms must be willing to commit resources to the successful implementation of an execution strategy with regards to the launch of those new ideas.

The results from the post hoc mediation analysis show that the significant indirect effect of innovativeness and proactiveness on profit through risk-taking accounts for $27.9 \%$ and $22.7 \%$ of the total effect of innovativeness and proactiveness on profit respectively. In other words, in the absence of risk-taking, the effect of innovativeness and proactiveness on profit performance is weakened by $27.9 \%$ and $22.7 \%$ respectively. With regards to growth, the effect of risk-taking as a mediator is even more significant accounting for $49.1 \%$ and $32.3 \%$ of the total effect in the relationship between innovativeness and proactiveness towards growth respectively. Thus, although risk-taking does not seem to show significance in the models, it is important based on its effects on the variables that are significant in the models. Consider the example of the shoe repair entrepreneur that was interviewed. While this entrepreneur showed elevated levels of innovativeness in the repair techniques that he utilized, he scored very low on the risktaking measures. As such, it seems the innovativeness of the entrepreneur may be tempered by the low levels of risk-taking, limiting the ability of the entrepreneur to grow 
or achieve higher levels of profits.

\section{Non-linear Relationships between EO, its Dimensions and Performance}

While the summated EO demonstrated more salience as a parsimonious model than models with the deconstructed dimensions, we found some evidence of non-linear relationships between the dimensions and performance suggesting that individual attention to the dimensions is important. In one instance, we found support for a nonlinear relationship existing between the EO dimension of innovativeness and its relationship to profit. Specifically, we found the strength of the relationship between innovativeness and profit exponentially increased at higher levels of innovativeness. That is, a firm that reports low levels of innovativeness and moves toward moderate levels of innovativeness is expected to improve its profit levels, but do so to a proportionally smaller extent than a firm that moves from moderate to high levels of innovativeness. It should be noted, in support of the multidimensional EO conceptualization, that the summated EO subsumes this relationship and hides the nonlinear relationship between one of its dimensions and profit. Further, the finding suggests that the true benefits of innovative behavior in micro organizations occur at the highest levels of innovativeness. This finding contradicts Tang, Tang, Marino, Zhang and Li (2008) who find that the impact of EO diminished at higher levels of EO.

We discovered another nonlinear relationship between the EO dimension of risktaking and the sustainability dimension of performance, suggesting that increased risktaking leads to greater sustainability, but does so at a greater rate at higher levels of risk- 
taking. This finding supports the proposition of several local micro entrepreneurs who live by the notion, "you can't be lucky and coward" or in other words as it relates to the study, a micro business has a harder time staying alive if the entrepreneur fails to take risks. As with above, the summated EO dimension fails to demonstrate the nonlinear relationship that exists between one of its dimensions and the dependent variable, further supporting the use of the multidimensional over the unidimensional scale to better understand the nuances of the impact of the individual dimensions on various aspects of performance.

Despite the finding of the above two non-linear relationships, we explored a further 10 relationships that did not yield any non-linearity. This suggests that for the most part, an increase in EO, or any of its dimensions tends to have a similar effect on performance, regardless of the initial level of EO, innovativeness, risk-taking or proactiveness. This finding is contrary to the findings of Dai, Maksimov, Gilbert and Fernhaber (2014) who found that innovativeness and proactiveness shared a U shaped relationship with performance, while risk-taking shared an inverted U shaped relationship with performance. One possible reason for the differences in findings is the performance variables used in their analysis were based on international scope, rather than profit or growth. Similarly, Chen and Hsu (2013) suggested an inverted U shaped relationship between innovativeness, risk-taking and proactiveness, however they utilized non-profit companies in their sample, a possible reason for the discrepancy.

Wales, Patel, Parida and Kreiser (2013), found evidence of inverted U shaped relationships between EO and performance and suggest that the level of resource 
abundance may be playing a role in the relationship. Specifically, in resource poor environments, high levels of EO can be unproductive. It seems then that the Trinidadian micro business context is either resource rich or simply behaves differently to the sample populations in previous studies. Zahra and Covin (1995) suggest that the hostility of the competitive environment strengthens the relationship between EO and its dimensions and performance. Given that the majority of findings suggest that increasing EO (or its dimensions) improves performance, it follows that despite the possible abundance of resources, the competitive landscape is still hostile. This makes sense given that the majority of interview participants cited international competition as the biggest threat to the current business operations. While these international competitors are unlikely to compete for many of the micro businesses resources (resource abundance), they do compete aggressively for the businesses market share (hostile competitive environment).

\section{Competitive Aggressiveness and the EO scale}

Beyond its use as a unidimensional or multidimensional scale, the EO construct has often been linked with the dimensions of competitive aggressiveness and autonomy (Lumpkin and Dess, 2006). With regards to autonomy, we made a decision to exclude it from the analysis due to the fact that the sample population, specifically micro business entrepreneurs, is assumed to have very high levels of autonomy. On the other hand we measured competitive aggressiveness and analyzed it with reference to its impact beyond the common EO measures of innovativeness, risk-taking and proactiveness. Competitive aggressiveness measured the probable firm actions in dealing with its competitors and we 
found it only had a marginal impact on the dimensions of performance. With regards to profit performance, adding the competitive aggressiveness score of the entrepreneur to a model that already included the other dimensions of EO resulted in no significant change in the F statistic suggesting that the variable may not warrant a place in the analysis. For growth, the addition of the competitive aggressiveness score did result in weak significance such that $\mathrm{p}<.1$, but failed to meet the conventional $\mathrm{p}<.05$ cut off. Finally, for sustainability the improvement in model fit was zero. Thus, there seems to be only weak support for the inclusion of competitive aggressiveness in EO models that use growth as the dependent variable. As such, there may be a possibility that higher levels of competitive aggressive behavior can result in higher levels of growth. However, we found no support for the use of competitive aggressiveness in models that use profit and sustainability indicators of performance.

One potential reason for the lack of significance found within the competitive aggressiveness dimension in relation to performance is the small size of the businesses. Large organizations, often governed by a board of directors and its shareholders are primarily driven by the financial potential of the organization, such that sustained profitability is often the primary, secondary and tertiary goal of the organization. Micro organizations such as those who made up the sample are instead primarily driven by the desires of the organizations entrepreneur, which do not always align with financial performance. For instance interview participant 5 (Religious Bookstore) has a focus on spreading the word of God, for which competitive aggressiveness is not necessary. Similarly participants number 6 (Pharmacy) and 9 (Tailor) shared that the primarily goal 
of their business was to keep occupied, for which competitive aggressiveness is not a requirement to achieve.

The lack of support that was found for the competitive aggressiveness dimension carries with it implications for the common item measures that are used in the EO construct. Specifically, this research attempted to isolate the competitive aggressiveness dimension from the traditional item measures. For instance, based on the original Covin and Selvin (1989) EO scale, one item measure for proactiveness, was the extent to which the firm attempts to avoid competitive clashes or maintains an aggressive competitive posture. In this research however, we removed this item from the proactiveness scale and reassigned it to the competitive aggressiveness scale. This change may have been significant for two reasons. First, as discussed, the competitive aggressiveness dimension does not appear to explain a significant amount of variability in firm performance and as such does not appear to warrant inclusion in the EO scale. Second, in this research, contrary to findings in the field (Rauch, Wiklund, Lumpkin and Frese, 2009) proactiveness rather than innovativeness was the most significant predictor of performance for profit, growth and sustainability. Possibly, the effect of the competitive aggressiveness leaning items in the conventional proactiveness measures weakens the true effect of proactiveness. Researchers will benefit if they make attempts to ensure that EO item measures of innovativeness, proactiveness and risk taking that appear to lean towards assessing the competitive aggressiveness of a firm are deconstructed to remove the elements of competitive aggression and instead focus on the individual dimension (innovativeness, risk-taking or proactiveness) itself. 


\section{The impact of the control variables}

The inclusion of the control variables in the various models that were analyzed also led to some insights into their impact upon the performance of micro organizations. With regards to profitability growth and sustainability, we found that the level of part time employees was positively and significantly related. Small businesses often rely on their relatively smaller size to quickly respond to market conditions, having an advantage by doing so faster than larger organizations that may be burdened by greater levels of bureaucracy. It seems that by having higher levels of available part time staff members, small organizations are able to respond efficiently to the changing market conditions without the burden of full time staffing costs. Thus, in slower periods when there is no need for employees, the micro organization with part time employees is not obligated to pay the workers. In busier periods however, these part time employees can be called out to work to assist the business in period when their assistance is absolutely needed, and thus their value exceeds their cost.

In comparison, full time employees showed a positive significant relationship with the growth performance indicator, but did not show significance in the explanation of the variability in profits and sustainability. In one instance, the effect of full time employees in micro organization towards profit and sustainability can add value to the organization, but in others, the cost of the employee seems to exceed the benefits. However, with regards to growth it appears that the existence of full time employees significantly facilitates the growth of the organization. Through the presence of full time 
employees micro organizations are able to have some level of slack resources. These slack resources become vital in times of growth as they have the capacity to perform additional tasks and carry out more responsibilities. Growth it seems (specifically in small organizations) is tied to the availability of spare human resources.

Similar to the need for slack human resources to facilitate growth, financial resources also share a significant and positive relationship to performance. In fact, in all models, a firm's access to financial resources was significant at the $\mathrm{p}<.05$ level. With regards to profitability, it is difficult to ascertain if firms make more profit if there are slack financial resources, or if the existence of profit leads to the ability to secure additional financing. Growth performance on the other hand, is more likely to follow the access to financial resources. That is, without the access to finance, a firm would find it difficult or impossible to grow, affirming the importance of access to sources of finance for micro organizations. Sustainability is also positively influenced by the access to financial resources. It logically follows that a business that can call on additional financing to cover its liabilities can survive for a longer period than a business for which this is not possible.

The growth intentions of a micro business entrepreneur also weighs heavily on the performance of the business. Theoretically, the growth performance of a micro business should be influenced by its growth intentions and this was confirmed by the analysis. In short, if an entrepreneur had little or no plans for growth, the business did not grow. If however, the entrepreneur was pursuing growth, the business tended to follow. Interestingly, the relationship also held for the profitability dimension of performance. 
That is, entrepreneurs who had little intention of growing the business were less likely to experience higher than average levels of profitability than those who were actively seeking to grow. Businesses that fail to continuously seek new ways to grow their business, or at the very least, those that consciously limit the growth of the business, pay a price beyond flat growth.

The lack of significance found between growth intentions and sustainability however suggests that while limiting growth has adverse effects on profits as well as growth, its negative effects do not stretch to the extent that it puts the businesses sustainability in jeopardy of closing in the short term. In the longer run however, the lack of growth intentions could have even more adverse effects. Several businesses noted the changing competitive landscape, for instance the increasing competitive threat from the international online marketplace. Micro businesses that are growth adverse will encounter increasing levels of competition that may erode their current levels of revenue. If there is a failure to adjust, specifically, the inability to implement strategies to recapture these lost sales, these firm's performance will tend toward negative.

\section{A New Ambidexterity Calculation}

While the EO and its dimensions made up a large part of the analysis we also investigated the exploration and exploitation capabilities of micro organizations and their interaction termed ambidexterity. We found ambidexterity to be positively and significantly related to the performance dimensions of profit and growth, beyond the effects of exploration and exploitation. In the model with just control variables, the 
exploration and exploitation dimensions (and profit as the dependent variable) demonstrated an R squared of .257, of which the addition of the ambidexterity calculation improved the model's R squared to .285 . The F statistic also improved with the addition of the ambidexterity calculation from 11.002 to 11.407 . With growth as the dependent the $\mathrm{R}$ squared improved with the addition of ambidexterity from .254 to .266 .

After a critical assessment of the relationship shared between the initial conceptualization of ambidexterity and performance, a new ambidexterity calculation we devised and formed the basis of the analysis. The two calculations (old and new ambidexterity) are shown below in Table 7.1:

Table 7.1 - Old versus New Ambidexterity Calculation

\begin{tabular}{|l|l|}
\hline \multicolumn{1}{|c|}{ Old Ambidexterity } & \multicolumn{1}{|c|}{ New Ambidexterity } \\
\hline $\begin{array}{l}\text { (Exploration * Exploitation }) *(7- \\
\text { exploration - exploitation } \mid)\end{array}$ & $\begin{array}{l}\text { (Exploration * Exploitation }) *(1+ \\
\text { |exploration }- \text { exploitation } \mid)\end{array}$ \\
\hline
\end{tabular}

The initial ambidexterity calculation was based upon an interaction of the combined dimension of ambidexterity (exploration * exploitation) and the ambidexterity balance of dimension (7-|exploration - exploitation|) (Cao, Gedajlovic and Zhang, 2009). Based upon this conceptualization of ambidexterity, it mathematically follows that a firm that has very high levels of both exploration and exploitation will have higher levels of ambidexterity than a firm with lower exploration and exploitation capabilities. However, based on the results from the analysis, it was apparent that the fit of this calculation of ambidexterity and performance was not as strong we initially theorized. This weak fit 
with the old ambidexterity led to thinking about additional calculations of ambidexterity that did a better job of explaining the differences in performance. We reasoned that given the size of the firms under investigation and the resource shortages they face, the effective maximization of both exploration and exploitation is very difficult, and as such, we conceived a new calculation of ambidexterity. Unlike the old calculation, the new calculation weighs the impact of the balance dimension differently. In the old calculation, a high balance dimension was achieved through the exact exploration and exploitation score. That is, a firm that reported a $1 / 7 \quad(7-|1-1|=7)$ for exploration and exploitation had the same balance dimension score as a firm that scored $7 / 7(7-|7-7|=7)$ on both dimensions because their exploration and exploitation scores were the same.

While in larger organizations ambidexterity can be achieved through specialist departments that focus on one aspect of the task (exploration or exploitation), in smaller organizations, there tends to be a resource shortage. Often, micro entrepreneurs as described by interview participants 6 (Pharmacy) and 9 (Tailor) became entrepreneurs out of necessity and start their business with extremely limited resources. This lack of resources translates into an inability to effectively execute a maximized dual exploration and exploitation strategy. In fact, even once established and operating micro organizations are faced with challenges that result in the need for sacrifice.

Interview participant 7 (cake maker) describes her challenges with affording the terminal charge and commission fees associated with the machines. A Linx machine terminal can carry fixed rental costs of between TTD $\$ 300-\$ 450$ per month, as well as commissions on credit card sales that can run as high as $5 \%$ for smaller business. In 
addition to being able to absorb the fixed rental charges on these Linx machines more easily than their smaller counterparts due to their volumes, larger business, deemed more 'secure' by the local banking sector, are offered commission rates as low as $1.5 \%$ on credit card transactions. As such, beyond the resource shortages that exist internally, micro businesses are faced with systemic challenges that force tradeoffs between exploration/growth (getting the new Linx machine) and exploitation/profitability (Rental charges, commission fees). Similar, is the plight of interview participant 11 (Clothing retailer) who related the story of her suspicions of employee theft. At their current level of sales employing private security to stem theft is unaffordable. In order to ensure that all sales are accounted for, the entrepreneur is forced to sacrifice exploration activity (buying new trendy clothing, additional locations) that would require her to leave the physical store.

Based on the results, it seems that micro organizations that attempt to maximize their exploration and exploitation activities have difficulty transforming both their exploration and exploitation capabilities into above average performance. In other words, these organizations run the risk of 'spreading themselves too thin' if it attempts to maximize both dimensions of performance. A business that has only one or a couple employees will find it incredibly difficult to maximize their exploration activities while also maintaining very high levels of exploitation. As a result of this discovery, the new ambidexterity calculation tends towards scoring the highest level of ambidexterity when there exists a relatively small gap between the two dimensions.

Micro firms seem to benefit most from attempting to maximize one dimension of 
ambidexterity, while attempting to be at least relatively average in the other dimension. For instance, a firm that has a very high exploration score is likely devoting a lot of time to the search for new opportunities and acquiring new skills. In order to score high on the ambidexterity dimension, this firm must also devote a moderate amount of time towards refining the businesses' current procedures and improving the efficiency of operations. Failure to at least be relatively average on one dimension creates an imbalance that appears to negatively influence the performance of the organization. Continuing the example above, maximizing exploration at the complete expense of exploitation is likely to be unsustainable given the costs of exploration. Maximizing both exploration and exploitation also appears unsustainable given the resource shortage that micro organizations face. Thus, some degree of trade off must be made between exploration and exploitation in micro organizations in order to appropriately execute the specific capability.

\section{The Impact of Ambidexterity}

A component of the research was the search for the moderation effects of ambidexterity. With regards to innovativeness, we were unable to find any evidence of a moderating effect of ambidexterity between innovativeness and performance on any dimension. These findings were consistent with regards to the moderation effect of ambidexterity on the relationship between risk-taking and performance. For proactiveness, the results were similar in that there was no moderation effect of ambidexterity found between proactiveness and profit or growth, however there was a 
weak moderation effect of ambidexterity that was found between proactiveness and sustainability. The findings support the notion that a firm with lower levels of ambidexterity benefits to a greater degree in terms of sustainability based on a corresponding rise in proactiveness than do firms with average or high ambidexterity. Tests for the moderation effect of ambidexterity on the full EO model revealed similar insignificance of the moderation effect of ambidexterity between EO and profit or growth, but did show weak significance between EO and sustainability. As with the proactiveness dimensions, it seems that firms with low ambidexterity benefit to a greater extent (in terms of sustainability) from a rise in EO than those firms with average or high ambidexterity.

Some weak moderation effects were found between EO and its proactiveness dimension and performance based on the level of ambidexterity, however the findings are in general not supportive of the interaction effects of EO and ambidexterity and the calls from Wales, Gupta and Moussa (2011) to identify moderators in the EO/Performance relationship remain unanswered. While we initially theorized this relationship as significant, the findings seem to suggest otherwise. Instead of being a moderator variable, ambidexterity appears to be significant as a predictor of performance on its own accord. In the model that contained only the control variables the R squared of the model was .156 for profit, .176 for growth and .061 for sustainability. Adding the EO variable to the model improves the R squared of the model to .231 for profit, .261 for growth and .091 for sustainability, and represents a significant positive change in the F statistic for all models. Adding ambidexterity to the models that contains the controls and EO again 
increases the R squared of the model for profit to .331 (increase over control and EO of .1 ), for growth to .314 (increase of .053) and for sustainability to .126 (increase of 0.35 ). Further, all addition of ambidexterity to all these models significantly improves the $\mathrm{F}$ statistic suggesting that the ambidexterity variable is a worthwhile predictor in the model. Ambidexterity then, like EO appears to be an essential building block of micro organization's performance. When combined with the controls that have been included in the models, EO and ambidexterity are able to explain over $30 \%$ of the variance in profits and growth between organizations, a significant amount by any measure.

\section{The Final Model}

A primary purpose of this study has been the investigation of the various implications and consequences from the choice of a unidimensional or multidimensional EO scale. In Chapter 3, Figure 3.1 showed a multidimensional model of EO that deconstructed all the dimensions of EO into unique variables. Further, the initial multidimensional model showed ambidexterity as a potential moderator, influencing the size and strength of the relationships between the EO variables and performance. On the other hand, the unidimensional model in Figure 3.2 showed the unidimensional model, which combined the three dimensions into the summated EO. This aggregate figure of EO was shown to have a relationship with performance that was also expected to be moderated by the levels of firm ambidexterity.

Having considered the implications and results from the use of both models we offer the Final Model in Figure 7.2 below: 
Figure 7.2 - The Final Model

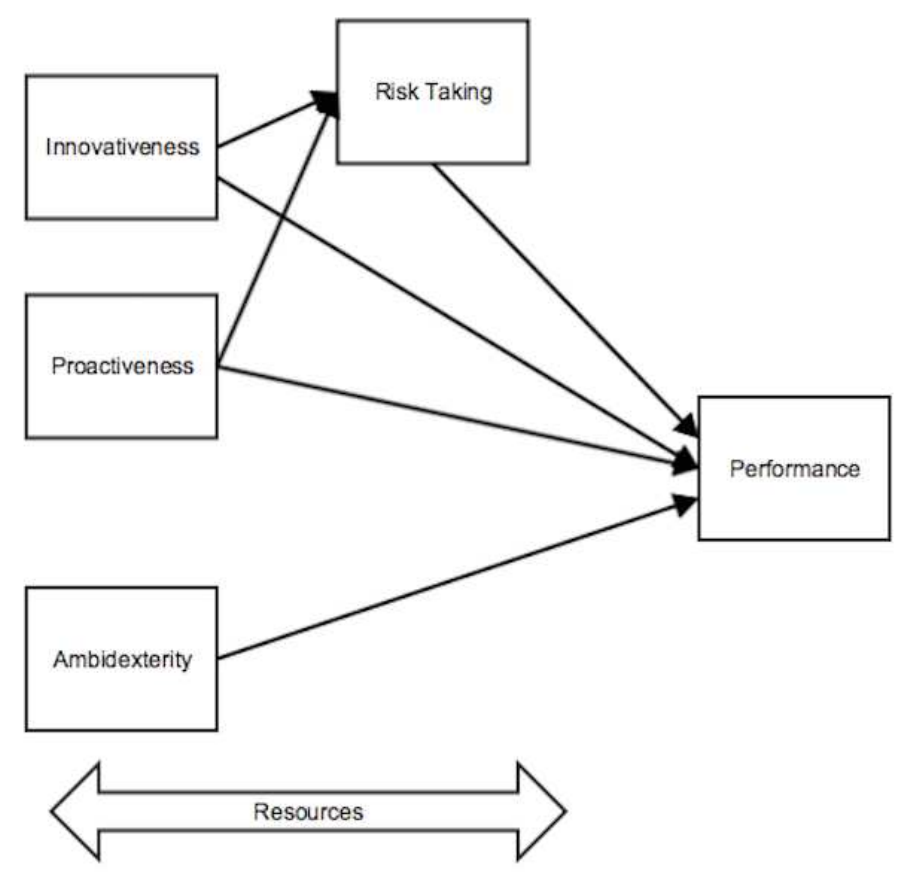

In comparison to the initial unidimensional and multidimensional models that were proposed earlier in the paper, the final model is unique in that is incorporates elements of both types of models. In one instance, the ambidexterity variable is given its due as a variable in its own merit. Whereas previously ambidexterity was only considered for its possible moderation effects, our findings reveal that ambidexterity does not act as a moderator in the relationship between EO and performance. Instead, ambidexterity shares a strong positive linear relationship with various facets of performance such that it warrants its inclusion in the model as a direct predictor of performance.

In addition, the final model treats the EO dimensions in a novel, hybrid manner. Through our study, we have seen multiple instances of the dimensions all being lumped 
together, or all being separate. However, our model proposes that risk taking functions as a mediator variable between innovativeness and performance and proactiveness and performance. This proposition builds on Miller (2011) who suggests that in some research contexts, analysis based on both the full and individual EO components may be the most beneficial. New research by Anderson, Kreiser, Kurato, Hornsby ad Esima (2015) dissect the EO construct into an "exhibition of entrepreneurial behaviors and of managerial attitude towards risk as jointly necessary dimensions that collectively forms the higher-order EO construct." (p. 1579).

In line with their analysis, our research has also suggested that while innovativeness and proactiveness seem to vary together, risk taking does not seems to behave in a similar manner. Taken together, this research and new findings from the field suggest that the EO construct may finally entering a stage of metamorphosis. After years of debate and analysis as to the superior incarnation of the EO scale (uni vs. multi), a compromise of sorts may indeed be the most agreeable outcome. By deconstructing the dimensions such that risk is unencumbered by the other dimensions, we maintain elements of a formative construct. On the other hand, innovativeness and proactiveness may have greater significance as a single combined variable, a carry over from the unidimensional construct. Of course, the complete assimilation of the field to a single construct is difficult in the short term. However continued findings that support the risk dimension as fundamentally different from that of innovativeness and proactiveness can eventually lead to greater consensus in the field as to the primarily choice of model operationalization. 


\section{Summary}

In this chapter we considered the results of the quantitative and qualitative data collection and analysis. The results show that both a multidimensional and a unidimensional conceptualization of EO are significant and beneficial. With the goal of parsimony, the unidimensional EO construct is able to explain a significant amount of variance between measures of performance with the additional of a single variable. The multidimensional construct is less parsimonious (it adds three variables) but does manage to explain a bit more variance in performance than its unidimensional counterpart.

Further, the multidimensional models allows for greater understanding of the individual impact of each dimension of EO. This research has shown proactiveness to be the most significant of the three EO dimensions and risk-taking the least significant. Further, some evidence of non-linear relationships between the sustainability dimension of performance and proactiveness was found, which would not have been possible unless the EO had been deconstructed. Further, by analyzing the multidimensional scale, the mediating impact of risk-taking on the innovativeness and proactiveness dimensions was discovered. Although ambidexterity did not support the initial theorization as a moderator of the EO construct, we found it to have great significance on its own as a predictor of performance. In combination with the control variables and EO, ambidexterity was able to explain over $30 \%$ of the variability in profit and growth performance for micro organizations. 


\section{Chapter 8}

\section{Conclusion}

\section{Revisiting the Research Questions}

The research and analysis contained within was motivated by three guiding research questions. The first, asked about the efficacy of the unidimensional EO scale versus its multidimensional counterpart. Based on the findings, we propose that both conceptualizations can add value and understanding to the study of micro organizations. With regards to the unidimensional (summated) construct, we found it to be positive and significant in the explanation of profit performance, growth and the sustainability. The multidimensional scale, which deconstructed the dimensions of EO, also showed positive and significant relationships between the various dimensions and the indicators of performance. In fact, the multidimensional model demonstrated a higher $\mathrm{R}$ squared than the unidimensional model. However, despite the higher R squared, based solely the results of the f test, the unidimensional model was a better model. In short, the formative multidimensional model does explain a greater amount of variance than the unidimensional model, however does so less effectively (based on the impact of each included variable) than the multidimensional model.

The second guiding research question considered the impact of the individual dimensions of the EO construct and their relationship to the indicators of performance. In this regard, we sought evidence of non-linear relationships between the dimensions and indicators of performance, but yielded limited returns. We did not find evidence of nonlinear relationships between proactiveness or the full EO summation on any dimension of 
performance. Innovativeness did show some weak significance suggesting a non-linear relationship with profit performance such that at higher levels of innovativeness changes in innovativeness resulted in a greater than proportionate change in performance than at lower levels of innovativeness. Similarly, risk-taking showed some evidence of a nonlinear relationship with sustainability such that at high levels of risk-taking, a change in risk-taking has a proportionately greater effect (positive effect) on sustainability performance than at lower levels. While these findings are interesting, of greater significance is the implication of unique variability between the dimensions of EO. Thus, while in the first research question we found support of the efficacy of both conceptualizations, the fact that the dimensions of EO behave differently from each other supports the use of a multidimensional rather than a unidimensional EO scale. For instance, the discovery of non-linear relationships between innovativeness and profit, and risk-taking and sustainability, is not possible with the summated EO measure. In fact, the summated EO measure did not show any signs of non-linearity with any dimension of performance, suggesting that the summated scale subsumes the unique relationships that may exist between its dimensions and performance.

The final guiding research question considered the impact of exploration and exploitation capabilities and their interaction, termed ambidexterity. We found evidence that supported the efficacy of the ambidexterity concept beyond that of the main effects of exploration and exploitation capability. Initially, we reasoned that increasing amounts of exploration and exploitation led to a greater ambidexterity score and in turn greater performance, however, the data revealed a more nuanced relationship. That is, while it 
does appear that very high levels of either exploration or exploitation are positively and significantly related to profit and growth performance, the ambidexterity relationship is more strongly related to performance when the other dimension is not maximized, but rather, average. Following from this finding, we suggest that there is a tradeoff that must be made between exploration and exploitation in order to yield maximum benefits from their interaction. The scarcity of resources faced by micro organizations suggests that attempting to maximize both exploration and exploitation leads to a scenario in which neither in actuality can be maximized.

However, by choosing to focus on either exploration or exploitation micro businesses can more effectively attempt to maximize the performance returns that may result from the specialization. This is not to say micro organizations should ignore the secondary dimension. We found that while focusing on maximization of one dimension, profit and growth performance is strongest when the second dimension is within a relatively average range relative to other firms in the sample. For instance, firms that choose to focus on exploration and the search for new ideas cannot ignore the elements of exploitation; the search for new ideas cannot finance itself. Past exploration must be monetized and exploited so that the funds are available to continue exploration. Similarly, the firm that only focuses on exploitation will eventually encounter a scenario where competitive forces have eroded any advantage that may have existed. In the absence of new ideas generated from exploration activity, productive exploitation will cease. Therefore, it is likely that the tradeoff between maximization of exploration or exploitation is temporal such that at different stages of the business life cycle a focus on 
one aspect of exploration or exploitation can yield differing impacts unto performance. For instance, new firms may find it worthwhile to commence operations with a focus towards exploration. Once productive benefits are yielded from the exploration process (e.g. new ideas) a switch in focus to exploitation may be beneficial to maximize possible returns.

We theorized that ambidexterity would have a moderation effect on the relationship between EO and performance. However on the EO dimensions of innovativeness and risk-taking, we could not find any evidence of moderation. Of the tests of moderation between proactiveness and the three dimension of performance, only proactiveness and sustainability showed any moderation in the relationship. Similar moderation results were found in the relationship between EO and sustainability, however, these two findings were the exception and not the norm. Rather than a moderator to the $\mathrm{EO} /$ performance relationship, ambidexterity on its own seems to be a powerful indicator of the expected level of performance. In the previous chapter EO and ambidexterity were referred to as building blocks of micro firm performance. Regression models that included only the controls and EO reported an R squared of .231 and .261 for profit and growth respectively. Adding the ambidexterity calculation that has been conceived in this research, the R squared jump to .331 and .314 , representing an increase of .1 and .053 respectively. This increase also represents a significant increase based on $\mathrm{f}$ tests and affirms both EO and ambidexterity as key components in successful performance by micro organizations. 


\section{Contributions}

Our research has attempted to investigate and uncover relationships that exist between the dimensions of EO, ambidexterity and their effect on performance. Through testing, we were able to contribute to the debate that exists with regards to the operationalization of the EO construct. Specifically, we were able to find that there exists a tradeoff between the use of the unidimensional and multidimensional scale. The unidimensional scale offers a parsimonious option that allows for easy comparisons with other research using a single figure as a representation of EO. However, it's efficacy as a predictor of variance is lesser than the multidimensional scale. The multidimensional scale allows researchers to reveal more nuanced relationships between the dimensions of EO and measures of performance.

Only the multidimensional scale can adequately assess the mediating role of risk taking in the relationship between proactiveness and performance and innovativeness and performance. The finding that risk taking may not co-vary with the other dimensions of EO is significant as differences between the EO dimensions are hidden when using a unidimensional scale. Thus, given our finding that the dimensions of EO do not always co-vary we have contributed to the EO debate as to whether the multidimensional or unidimensional is a more appropriate construct. Assuming that risk behaves differently in other contexts as well, there is a strong impetus to utilize the multidimensional scale.

On the other hand, as discussed above, there have been suggestions from the field that innovativeness and proactiveness do co-vary. In fact, our findings also suggest that innovativeness and proactiveness behave in a similar manner. While this research is far 
from absolutely conclusive, our failure to find differences between innovativeness and proactivenss to the extent that was found between these dimensions and risk taking is enough to suggest that a unidimensional scale may be appropriate for these two variables. Thus, based on the findings presented, this research has contributed to the debate surrounding the multidimensional versus unidimensional conceptualization of EO and pushes the debate forward with the development of a new hybrid model that incorporates elements of both multi and unidimensional theorists.

This research has also contributed to the debate surrounding which dimensions should be included in the EO construct. In the first instance, the efficacy of autonomy must be questioned. While appearing in several EO studies, autonomy does not appear universal. While a measure of autonomy is possibly of use in larger organizations, in small organizations it quickly loses its substance. As the number of employees falls, so does the implications of autonomy. In larger organizations, with multiple levels of bureaucracy, a measure of autonomy may be helpful to identify the ability of employees to function in an 'entrepreneurial' manner. However, in smaller organizations this measure is less applicable and leads to questions as to why it is included in measures of EO. We suggest that the universality of the EO construct is of paramount significance in its continued acceptance as a measure of entrepreneurship and as such suggest that the use of autonomy as a measure in EO research either be modified to be applicable to all business types, or be eliminated from future EO studies.

In addition, this research has contributed to the debate surrounding the competitive aggressiveness dimension of the EO scale. Our results show that competitive 
aggressiveness does show some initial significance in it relationship with the growth performance of an organization. However, once the firm's intentions to grow are included as a variable in the model, competitiveness aggressiveness loses its already weak significance it shared with performance. Our analysis of the competitive aggressiveness dimension suggested that its efficacy as a predictor of performance beyond the dimensions of proactiveness, innovativeness and risk taking was insignificant for our sample, leading to questions about its viability as an EO construct dimension. Given this finding we suggest that the use of competitiveness aggressiveness as a dimension of EO be stopped, and in its place researchers assess the growth intentions of the firm. In short, it seems that firms that are very aggressive with regards to the competition also have strong growth intentions. However, these firms do not seem to enjoy better performance than other firms who are not very competitively aggressive, but maintain their growth intentions.

Another contribution of this research is the finding that related to the non-linear relationships between the EO, its dimensions and performance. Increasingly, EO researchers are attempting to push the boundaries of their study to uncover greater detail about its workings. As such, the non-linearity of these relationships have been under increasing scrutiny. However, despite some suggestions from the field, in the vast majority of instances, this research was unable to uncover any non-linear relationships of great significance. In all models with growth performance as the dependent variable, we were unable to find any non-linear relationship of significance using each EO dimensions as well as the full construct. Admittedly, non-linear relationships were discovered 
between innovativeness and sustainability and profit performance as well as risk taking and sustainability, meanings that of the 12 relationships investigated for non-linearity, only three showed minimal significance. One possibly reason for the contrary results is the type and size of organization under investigation. Chen and Hsu (2013) find many non-linear relationships of significance in their study of EO and performance, however, they utilize non-profit organizations as the bases of their sample. It is therefore possible that the linearity of the EO dimensions with regards to the their relationship to profit is contingent on the goals, type and size of the organization being studied. As such, this paper has contributed to the extent that the linearity of the relationship between EO dimensions and performance is positive and significant in micro organizations, but does not show significant non-linearity in the relationship.

This research has also contributed to the resource-based view through our attempts to integrate RBV thinking with more entrepreneurship centric study. Through critical analysis we first proposed a calculation for ambidexterity that married the 'balance dimension' and the 'combined dimension', positing ambidexterity as an organizational capability that can potentially and significantly positively impact performance. Although our initial calculation did show significance, further investigation revealed a new ambidexterity calculation that proved a superior predictor or performance. This new calculation suggested that ambidexterity as a capability is likely to have the greatest impact on performance when the two dimensions that make up ambidexterity are maximized and average respectively, such that for improved performance a firm can 
make either exploration or exploitation its primary focus, with the other dimension remaining average.

Beyond the major findings of the analysis, this paper has also contributed in other areas. One such area is the implication of staffing decisions in micro organizations. Our findings show that there are direct and significant implications for the choice of part time versus full time staff and the levels of each in an organization. With respect to part time staff, we suggest that micro organizations develop a system of utilizing part time to aid in their operations. Quantitatively, the results show that firms that have higher levels of part time staff enjoy a positive and significant effect profit and sustainability performance. In times where there is little or no business, the entrepreneur is not obligated to pay these staff and can send them home, avoiding the costs of the staff. Conversely, in busier periods the staff can be called out to work when the entrepreneur is certain that the cost of the staff's service will be outweighed by the additional sales revenue that they can help to generate.

Full time staff on the other hand share a different relationship with performance variables. While seemingly not sharing the strength of relationship with profit or sustainability as with part time staff, the full time staff of an organization seems to positively impact the growth performance of the organization. For instance, Interview participant 4 (Wig Manufacturer) indicated a desire to hire part time staff so that she could enjoy a level of freedom from the physical store as to pursue related opportunities such as patent protection of her unique designs and looking for additional retail space in new areas. Despite the fact that full time employees are more prone to periods of paid 
downtime, this space capacity is integral for the growth of the organization. Consider interview participant 7 (Cake Maker) who planned to make international trips on behalf of her business. In the absence of full time staff, the business would be required to shutter its doors having a negative impact on growth in the short run. With full time staff however, the cake maker can meet with international suppliers and marketers while maintaining her current levels of sales. Upon her return with new products and ideas, growth is more feasible as she has been able to add to her stockpile of resources, without the need for much sacrifice to acquire them.

Finally, a contribution of this work has been the novelty of the research population. As has been mentioned previously, this EO research is the first to be conducted within the Caribbean region. In the first instance, use of the EO construct in this novel location contributes to its acceptance as a global construct. Our findings propagate the use of the scale as significant in the study of entrepreneurship, but also contribute to the belief that the scale's use is applicable and beneficial in a variety of contexts. Further, by targeting micro organizations, within an already underexplored geographic region this research has gone to great lengths to investigate a context that is unique and difficult to access. In this regards the findings act in a revelatory manner for EO scholars, however also contributed by doing the same for participants. Several participants noted that they had never formed part of a research population and were intrigued by the process of research and the possibility of findings of significance. Unsolicited, many participants shared that the experience of being included in the research had helped to think about their own actions and behaviors. By considering the 
dimensions of EO, ambidexterity and performance, participants were better able to categorize their own performance. Completing the survey had the unexpected implication of positively contributing towards participants who were forced to consider their own decision-making and for the first time also considered the consequences of such action and the possible alternatives.

\section{Implications}

The implications from the research presented can be broadly broken down into three areas: academic, professional and government (policy). In the first instance, academics may find value in the debate and findings related to the multidimensional versus unidemensional scale. Specifically, future decisions about the operationalization of the scale can be better informed through consideration of the results contained within. This is especially important given the finding that not all dimensions co-vary in all instances. Further, the unique impact of risk-taking that was discovered can serve as a basis for the continued study of the dimension such that its role as a mediator of innovativeness and proactivenss can be further investigated and more implication discovered.

Professionals can also hope to perform better if they draw from the findings contained within. In one instance, results from our analysis point to the fact that the dimensions of EO share unique relationship (in terms of size and strength) to various dimensions of performance. Based on the findings, a professional keen on business growth should invest time and energy into proactivity, including market research and 
attempts to be first to market. For above normal profits, in addition to a need for proactiveness, there seems to be the need for relatively high levels of innovativeness as well. Further, levels of exploration and exploitation capabilities of a firm can have major implications for performance. Through the maximization of one dimension of ambidexterity and the relative average level of the second dimension, micro organizations can best utilize their scarce resources. Micro firms are encouraged to select either exploration or exploitation capability as a primary organizational focus, in search of developing a core competitive advantage over its rivals. To ensure the sustainability of the advantage micro firms are also encouraged devote a relatively lesser, but still moderate portion of its resources to the non-core capability. The strategy allows for a micro firm's scare resources to avoid being overburdened, while also delivering value in relation to the firm's profit and growth performance.

Finally local policymakers can utilize the findings contained within to inform their decision-making. As noted earlier, the local entrepreneurship experts were critical of the local levels of innovativeness, risk-taking and proactiveness. However, the findings of this report contradict the belief that Trinidad is lacking in these dimensions. Rather than devote state resources to the search for entrepreneurs who are perceived to have high EO, more should be done to develop the current entrepreneurial infrastructure that is already in place. For instance, entrepreneurial development programs and financing should be extended beyond those who wish to establish a new business and also consider the advancement of entrepreneurs who are already in business. While the establishment of new business is still important, renewed efforts to accommodate growth in the size of 
entrepreneurial ventures can have positive effects on productivity, employment and local exports. The growth and success of these entrepreneurial ventures can then serve as the stimuli for the development of new businesses.

\section{Study Limitations}

It is prudent to also acknowledge the limitations of the research that we conducted. One such limitation was the selection of the research sample population. Ideally, in this research we would have utilized listings of micro enterprises sourced from Governmental agencies. As has been noted previously, it was estimated that approximately $80 \%$ of micro organizations are registered with the local authorities, while the remainder operate outside this framework. However, the failure of the local Government authorities to deliver any listings of registered businesses meant that we needed to execute contingency plans. Instead, we selected participants in the research primarily based on availability, being only confined by the size of their workforce and attempts to ensure that there was geographic disparagement. The absence of the listings of registered businesses meant that the breakdown of registered versus unregistered is unknown. As such, it may be possible that the assumed 80/20 split between registered and unregistered businesses as exists in the population may not have been equally represented in the final sample.

Further, participants were solicited during regular business hours and in the majority of instances, were asked to participate in the survey immediately. On several occasions the volume of customer traffic at some of the business prevented the successful completion of the survey by the business owner, whereas in businesses that were not as 
busy, the rate of survey completion was higher. This circumstance created another limitation of the research in that, it is possible that the data collected does not adequately represent those entrepreneurs who were experiencing very high levels of customer traffic. This limitation means that the data that has been collected may be biased against entrepreneurs who are experiencing very high levels of success and were unable to participate in the research, as doing so would have meant lost sales and possibly unhappy customers.

Another limitation of the research are the lack of comparable studies that been conducted within the Trinidadian context. For instance, the performance of the micro businesses was the major dependent variable that was used in the study. Within the academic literature, performance is primarily assumed to be related to concepts of profit and growth. However, when asked to evaluate their performance in the interviews, the majority of participants assessed their performance independently of the business itself, for example, the Pharmacist who rated his performance highly based on the extended free consultation times he afforded his customers. Though possibly beneficial towards the profit and growth of the business, the performance evaluations may not be adequately indicative of the actual performance that is being measured.

Added to this limitation is the method of reporting performance. Because of the sensitivity of accessing micro business financial data, participants in the study were asked to self evaluate their profit, growth and sustainability performance. This self-evaluation can lead to a scenario whereby the relative scales used by participants do not assess their performance equally. Where as actual financial data can be compared between businesses 
objectively, perceived performance can introduce bias through the evaluation of the entrepreneur. This is particularly true for micro entrepreneurs who often enter business with goals beyond having a sizable market share or super normal profits. Consider Entrepreneur A, who despite making less profit than Entrepreneur B, may report high profit performance as the level of profits may be closer to his/her goal than Entrepreneur B.

\section{Future Research}

However, despite these limitations, the findings from this study reveal that within the Trinidadian context, a significant amount of variance in profits, growth and sustainability performance can be explained through measures of EO and ambidexterity. These encouraging findings support the notion that the concepts of EO and ambidexterity should continue to be a subject of academic study and investigation. As has been suggested, EO and ambidexterity appear to be building blocks of entrepreneurial success and can be considered in additional contexts. Similar studies in any Caribbean country would be useful to compare and contrast the results of the various Caribbean states. By generating a pool of data, specific to the Caribbean region, the regional impact of EO and ambidexterity can be assessed and compared to that of regions that have had the benefit of multiple studies (North America, Europe and Asia). Further, starting with EO and ambidexterity, additional building blocks of micro organization success can be developed and measured for their efficacy. While this research has been able to explain a respectable 
$30 \%$ of the variability in the measures of profit and growth, the search for the remaining $70 \%$ should continue.

Specific to the EO construct, we found that risk-taking plays a unique role amongst the other dimensions of the EO construct. Post-hoc analysis revealed that risktaking acts as a gatekeeper of the efficacy of the innovativeness and proactiveness dimensions. These findings were strongly statistically significant and as such, we propose that further investigation be carried out regarding the effects of risk-taking as a mediator between innovativeness and proactiveness and performance. For instance, does the industry type affect the significance of the risk-taking mediation? Does risk-taking also act as a mediator in larger businesses? Further, the lack of statistical significance shared between risk-taking and the dimensions of performance (in the presence of the other EO dimensions) creates questions about the desirability and efficacy of risk-taking as part of the unidimensional EO measure. Future scholars may want to further consider the unique implications of risk-taking forming a part of the EO scale. Additionally, we did not find strong significance of the competitive aggressiveness measure as a predictor of performance. This is contrary to positions held by some researchers in the field who continue to advocate competitive aggressiveness as a dimension of the EO scale. Possibly, future researchers can continue to assess the relevance and significance of competitive aggressiveness in different contextual situations.

Ambidexterity is another exciting potential area of future research. Based on the findings from the regression models, the ambidexterity calculation that was developed through the course of this research appears to be a better predictor of profit and growth 
performance than EO. Given the extensive body of research that has been built around EO in the Entrepreneurship literature, it stands to reason that the strong statistical significance shown by ambidexterity should be a catalyst for a similar volume of work in its individual relationship with the various dimensions of performance. Further, the nuances of the ambidexterity calculation can be a breeding ground for new research. This study has found that a small gap between the levels of exploration and exploitation is beneficial to a firm's performance, but questions remain as to which dimension should be maximized. That is, this research has gone far enough to suggest that a gap should exist, but fell short of assessing which individual dimension should be greater or smaller, or if there is even a difference at all. 


\section{Exhibit 1 - Questionnaire}

- Inform participant that questionnaire has 23 questions

- There are no wrong answers

- Unless otherwise indicated all answers are on a scale of 1 to 7

- I will read two statements that indicating the response extremes of 1 and 7, from which you can pick, 1, 2, 3, 4, 5,6 or 7 to best match your answer

- At any time you can withdraw your participation

- Shall we begin?

\section{Innovativeness}

1: In general, my business favors:

$\begin{array}{lllllllll}\text { A strong emphasis on the } & 1 & 2 & 3 & 4 & 5 & 6 & 7 & \text { A strong emphasis on the }\end{array}$ marketing of tried and true marketing of new and products and services innovative products and services

2. How many new types of products or services has your business marketed during the past three years?

$\begin{array}{lllllllll}\text { No new types of products or } & 1 & 2 & 3 & 4 & 5 & 6 & 7 & \text { Very many new types of }\end{array}$ services products or services

3. Changes to the types of products or services my business provides has:

$\begin{array}{lllllllll}\text { Been mostly of a minor } & 1 & 2 & 3 & 4 & 5 & 6 & 7 & \text { Usually been quite dramatic }\end{array}$ nature

\section{Risk-taking}

4. In general, my business has:

$\begin{array}{llllllllll}\text { A strong tendency for low- } & 1 & 2 & 3 & 4 & 5 & 6 & 7 & \text { A strong tendency for high- }\end{array}$ risk projects (with normal risk projects (with chances and certain rates of return) of very high return)

5. In general, my business believes that:

Because of the nature of the $\quad \begin{array}{lllllll}1 & 2 & 3 & 4 & 5 & 6 & 7\end{array}$ Because of the nature of the business environment, it is business environment, taking best not to take any risks risks is essential 
6. When confronted with decision-making situations involving uncertainty, my business:

Typically adopts a cautious, $\quad \begin{array}{llllllll}1 & 2 & 3 & 4 & 5 & 6 & 7 & \text { Typically adopts a bold, }\end{array}$ 'wait-and-see' approach in $\quad \begin{array}{llllll}1 & 2 & 3 & 4 & 5 & 6\end{array}$ order to minimize the chances of making costly to maximize the chances of decisions exploiting potential opportunities

\section{Proactiveness}

7. In dealing with my competitors, my business:

$\begin{array}{lllllllll}\text { Is very seldom the first } & 1 & 2 & 3 & 4 & 5 & 6 & 7 & \text { Is very often the first }\end{array}$ business to introduce new business to introduce new products, services and ways of doing business products, services and ways of doing business

8: In general, my business has a tendency to:

$\begin{array}{llllllllll}\begin{array}{l}\text {..to 'follow the leader' in } \\ \text { the introduction of new } \\ \text { products and ideas }\end{array} & 1 & 2 & 3 & 4 & 5 & 6 & 7 & \begin{array}{l}\text {..be ahead of competitors in } \\ \text { the introduction of new } \\ \text { products and ideas }\end{array} \\ \end{array}$

9: In dealing with my competitors, my business:

\begin{tabular}{lllllllll}
$\begin{array}{l}\text {..typically responds to } \\
\text { actions which competitors } \\
\text { initiate }\end{array}$ & 1 & 2 & 3 & 4 & 5 & 6 & 7 & $\begin{array}{l}\text {..typically initiates actions } \\
\text { which competitors then } \\
\text { respond to }\end{array}$ \\
\hline
\end{tabular}

\section{Competitive Aggressiveness}

10: In dealing with my competitors, my business:

$\begin{array}{llllllll}\text {...makes no special effort to } & 1 & 2 & 3 & 4 & 5 & 6 & 7\end{array}$ take market share from the competition

11. In dealing with my competitors, my business:

$\begin{array}{llllllllll}\text { Typically seeks to avoid } & 1 & 2 & 3 & 4 & 5 & 6 & 7 & \text { Typically adopts a very }\end{array}$ competitive clashes, competitive, 'undo-the preferring a 'live-and-letcompetitors' approach

...is very aggressive and intensely competitive

live' approach 


\section{Exploration}

12: My business spends a great deal of time searching for new business opportunities:

$\begin{array}{llllllllll}\text { To a very small extent } & 1 & 2 & 3 & 4 & 5 & 6 & 7 & \text { To a very large extent }\end{array}$

13: My business spends a great deal of time considering the options with respect to new way to make profits:

$\begin{array}{llllllllll}\text { To a very small extent } & 1 & 2 & 3 & 4 & 5 & 6 & 7 & \text { To a very large extent }\end{array}$

14: Learning new skills and being adaptable is important to my business:

$\begin{array}{llllllllll}\text { To a very small extent } & 1 & 2 & 3 & 4 & 5 & 6 & 7 & \text { To a very large extent }\end{array}$

\section{Exploitation}

15. My business always emphasizes the same products and services because our customers enjoy the current offering:

$\begin{array}{llllllllll}\text { To a very small extent } & 1 & 2 & 3 & 4 & 5 & 6 & 7 & \text { To a very large extent }\end{array}$

16. Operating my business involves the using the knowledge I already have:

$\begin{array}{llllllllll}\text { To a very small extent } & 1 & 2 & 3 & 4 & 5 & 6 & 7 & \text { To a very large extent }\end{array}$

17: Reducing expenses and improving efficiency are important preoccupations to my business:

$\begin{array}{llllllllll}\text { To a very small extent } & 1 & 2 & 3 & 4 & 5 & 6 & 7 & \text { To a very large extent }\end{array}$

\section{Performance}

18: Over the past three years, in comparison to my competitors my business profits are:

$\begin{array}{lllllllll}\text { Well below normal } & 1 & 2 & 3 & 4 & 5 & 6 & 7 & \text { Well above normal }\end{array}$

19: Over the past three years, the business' growth in sales has been: 


\begin{tabular}{llllllllll}
\hline Very weak & 1 & 2 & 3 & 4 & 5 & 6 & 7 & Very strong
\end{tabular}

20: At its present level of operations my business is sustainable for at least 3 more years:

$\begin{array}{llllllllll}\text { Not true at all } & 1 & 2 & 3 & 4 & 5 & 6 & 7 & \text { Very true }\end{array}$

\section{Small Business Orientation}

21: I have no plans to significantly expand the size of my business:

$\begin{array}{llllllllll}\text { Not true at all } & 1 & 2 & 3 & 4 & 5 & 6 & 7 & \text { Very true }\end{array}$

22: I established my business because it better fit my personal life than working for someone else:

$\begin{array}{lllllllll}\text { Not true at all } & 1 & 2 & 3 & 4 & 5 & 6 & 7 & \text { Very true }\end{array}$

23: I consider my business to be an extension of my personality:

$\begin{array}{llllllllll}\text { Not true at all } & 1 & 2 & 3 & 4 & 5 & 6 & 7 & \text { Very true }\end{array}$

24: I am emotionally attached to my business:

$\begin{array}{llllllllll}\text { Not true at all } & 1 & 2 & 3 & 4 & 5 & 6 & 7 & \text { Very true }\end{array}$

\section{Controls}

25. How many years has your business been in continuous operation?

26. How many full time employees does your business have?

27. How many part time employees does your business have?

28. With 1 representing not true at all and 5 representing very true, how true is the following statement: "If there was a need for business financing, my business would be able to secure any amount it needed":

$\begin{array}{lllllllll}\text { Not true at all } & 1 & 2 & 3 & 4 & 5 & 6 & 7 & \text { Very true }\end{array}$

29. Firm location? 
30. Primary product/service/industry?

- Thank participant for their time.

- Remind participant that withdrawal is possible any time before $1^{\text {st }}$ march 2015 and that all responses are confidential.

- Ensure participant has contact information as given previously.

- Ask participant if there are any questions they may have.

$\circ$ Questions (types):

- Ask participant if they would be open to the possibility of a 30 minute interview at a later date to discuss some of their feedback in more detail

$\bigcirc$ Interview Possibility (yes/no):

- Thank participant and end communication 


\section{Exhibit 2 - Semi-structured Interview Questions}

\section{Interview Protocol:}

- Reintroduction of researcher

- Explanation of research objectives and an indication as to the types of questions that will be asked

- A request to audio record the conversation

- A reminder that participation is voluntary and may be withdrawn at any time without any consequences

\section{Background Questions:}

1. Why did you decide to start a business?

2. What are your main goals for the business?

3. What is your current role/relationship with the business?

4. How satisfied are you with your business?

5. What are the primary products/services your business offers?

\section{Innovativeness}

6. How did you decide on your current product/service offering?

a. Is there a process involved in selecting new product/services?

b. Have you discontinued any products/services

c. Can you tell me about some of your more successful products/services?

i. Probe as to how long these products/services were or have been successful?

ii. Are sales of the same product/service responsible for the majority of your sales?

d. Has your product service/offering changed much in the past few years?

i. How many new products or services have been introduced in the past three years?

ii. Can you give some examples of new products or services your business has introduced?

iii. What was your most innovative product or service?

iv. Why do you think it was so innovative?

\section{Proactiveness}

7. Has your business been the first introduce a product/service into the market?

i. If yes, probe as to examples

ii. Was it beneficial to be the first to market?

iii. Are their drawbacks to being the first to market? 
iv. Did your business conduct market research prior to the introduction of successful products?

8. Do you think there are advantages to waiting for other firms to try new products and ideas before jumping in yourself?

i. Can you give an example of a time when this was a good idea?

ii. Can you give an example of a time when you wished you would have acted sooner on a product/service introduction?

\section{Risk-taking}

9. Would you say that starting the business involved risk?

a. What risks would you say you have faced through the starting and operation of the business?

b. What would you say is the biggest risk you have taken?

c. Why do you think this is such a large risk?

10. Have there been opportunities for your business that you have passed up because it was too risky?

i. If yes, can you describe the opportunity?

ii. What made it so risky?

iii. If no, have all the risks taken by the business paid off?

11 . Which is more appealing, 1) a $50 \%$ chance at $\$ 10$ or 2) a $10 \%$ chance at $\$ 50$ ?

a. Probe as to why?

b. Would you always make the same choice?

i. If choose 1) $50 \%$ chance at $\$ 10 \ldots$. then ask......what if was a $25 \%$ chance at 10 and a $10 \%$ chance at $\$ 50$, would you still make the same decision?

ii. If choose 2) $10 \%$ chance at $\$ 50 \ldots$...then ask.... what if it was a $5 \%$ chance at 50 and a $50 \%$ chance at 10 , would you still make the same decision?

\section{Exploration}

12. What opportunities do you think exist for the business to grow?

i. How to your identify opportunities?

ii. Are all the opportunities related to your current operations?

iii. How do you evaluate a potential opportunity to grow?

13. What are the most important skills needed in your business?

i. Why?

ii. Is learning new skills important to your business or are your current skills enough? 


\section{Exploitation}

14. Is growth or profitability more important to your business?

i. Why?

ii. Can you give an example of how profitability has been improved in the past?

iii. Are their things that you believe can be done to improve profitability further?

iv. Is there a tradeoff between trying to be profitable and growing the business?

\section{Competitive Aggressiveness}

15. Who are your top three competitors?

a. Why do you think of them as competitors?

b. Is competition intense?

c. Have there been any aggressive competitive actions taken by you or your competitors?

\section{Performance}

16. How you would you say the performance of your business compares to that of your competitors?
a. Why?
b. Has it been variable over the past three years?

17. Are your current levels of sales growing?
a. How much growth have you experienced since inception?
b. How much growth in the past three years?
c. Do you wish to continue growing the business?

18. What are your plans for the future of the business?

\section{Thank participant for their time.}




\section{Exhibit 3 - Correlation Matrix}

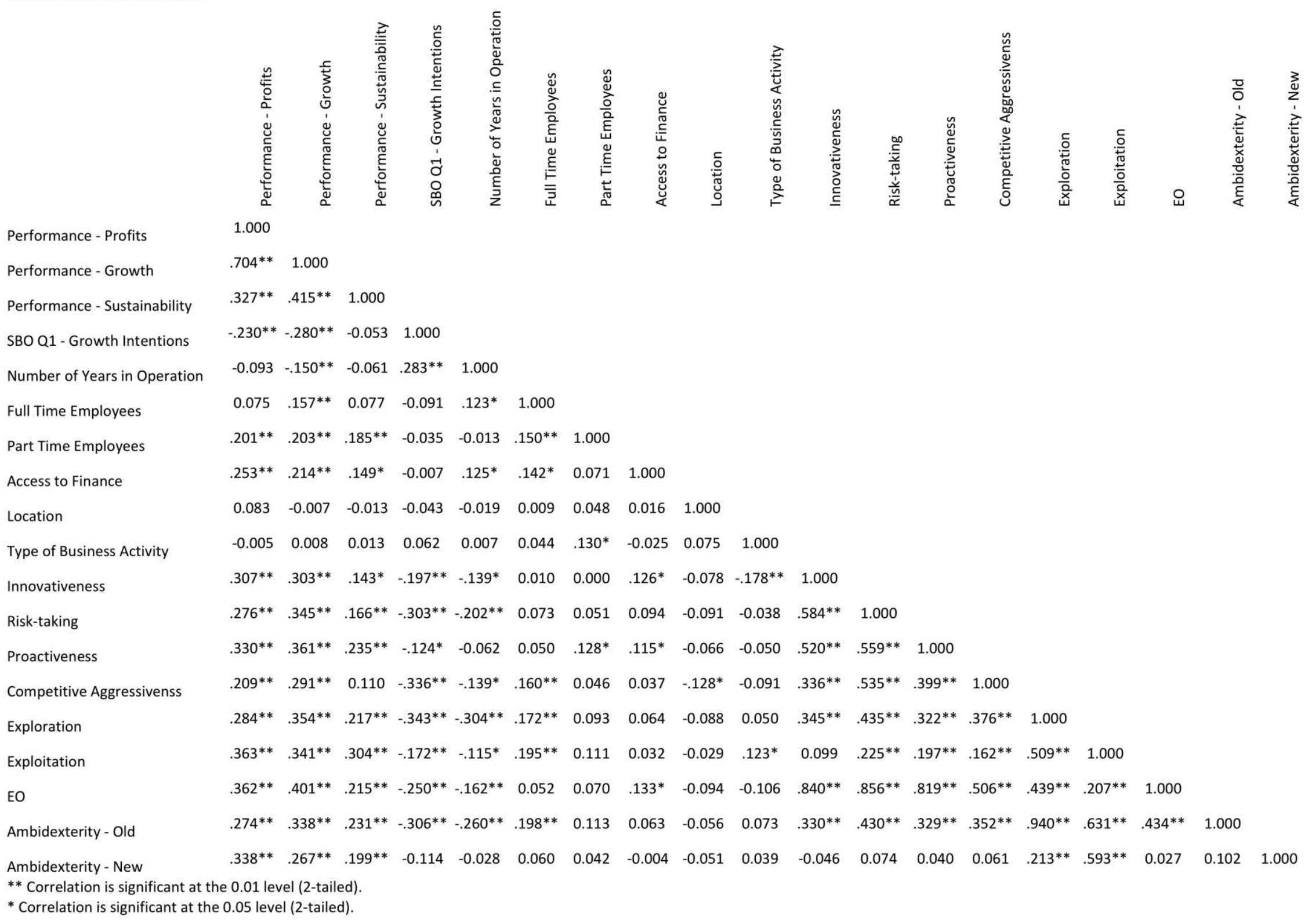




\section{References}

Abebe, M. A., and Angriawan, A. (2014). Organizational and competitive influences of exploration and exploitation activities in small firms. Journal of Business Research, 67, 339-345.

Ahuja, G., and Lampert, C. (2001). Entrepreneurship in the large corporation: A longitudinal study of how established firms create breakthrough inventions. Strategic Management Journal, 22, 521-543.

Aiken, L. S., and West, S. G. (1991). Multiple regression: Testing and interpreting interactions. Newbury Park: Sage.

Allen, M. J., and Yen, W. M. (1979). Introduction to Measurement Theory. Brooks/Cole, Monterey, CA.

Amit, R., and Schoemaker, P. (1993). Strategic Assets and Organization Rent. Strategic Management Journal, 14, 33-46.

Ancona, D. G., Goodman, P. S., Lawrence, B. S., and Tushman, M. L. (2001). Time: A new research lens. Academy of Management Review, 26: 645-663.

Anderson, B. S., and Eshima, Y. (2013). The influence of firm age and intangible resources on the relationship between entrepreneurial orientation and firm growth among Japanese SMEs. Journal of Business Venturing, 28, 413-429.

Anderson, B. S., Kreiser, P. M. Kuratko, D. F., Hornsby, J. S., and Eshima, Y. (2015). Reconceptualizing Entrepreneurial Orientation. Strategic Management Journal, 36, 1579-1596.

Andrews, K . R . (1971). The Concept of Corporate Strategy, Dow Jones-Irwin, New York.

Andrews, K. R. (1980). The concept of corporate strategy (2nd ed.). Homewood, IL: Richard D. Irwin.

Arbaugh, J.B., Cox, L. W., and Camp, S. M. (2009). Is Entrepreneurial Orientation a Global Construct? A Multi-Country Study of Entrepreneurial Orientation, Growth Strategy and Performance. The Journal of Business Inquiry, 8(1), 12-25.

Armstrong, C. E., and Shimizu, K. (2007). A review of approaches to empirical research on the resource-based view of the firm. Journal of Management, 33, 959-986.

Bailey, H., Pacheco, M., Harewood, W., and Carrillo, J. M. (2011). Global Entrepreneurship Monitor Caribbean 2011: Trinidad and Tobago National Report, Arthur Lok Jack GSB, Trinidad, WI.

Bailey, H., Pacheco, M., Carrillo, J. M., and David, T. (2012). Global Entrepreneurship Monitor Caribbean: Trinidad and Tobago 2012 Report, Arthur Lok Jack GSB, Trinidad. WI.

Baird, I. S., and Thomas, H. (1985). Toward a contingency model of strategic risk-taking. Academy of Management Review, 10, 230-243.

Barney, J. (1986). Organizational Culture: Can It Be a Source of Sustained Competitive Advantage? Academy of Management Review, 11(3), 656-665.

Barney, J. (1991). Firm Resources and Sustained Competitive Advantage. Journal of Management, 17(1), 99-120.

Barney J. (1997). Gaining and Sustaining Competitive Advantage. Addison-Wesley: 
Reading, MA.

Baron, R. A. (2007). Behavioral and cognitive factors in entrepreneurship. Strategic Entrepreneurship Journal, 1, 167-182.

Bartholomew, S., and Smith, A. D. (2006). Improving Survey Response Rates from Chief Executive Officers in Small Firms: The Importance of Social Networks. Entrepreneurship Theory and Practice, January, 83-96.

Baruch, Y. (1999). Response rates in academic studies: A comparative analysis. Human Relations, 52(4), 421-438.

Bates, T. (1995). Self-employment across industry groups. Journal of Business Venturing, 10(2), 143-156.

Becherer, R. C., and Maurer, J. G. (1999). The proactive personality disposition and entrepreneurial behaviour among small company presidents. Journal of Small Business Management, 37(1), 28-36.

Begley, T. M., and Boyd, D. P. (1987). Psychological characteristics associated with performance in entrepreneurial firms and smaller businesses. Journal of Business Venturing, 2, 79-93.

Berman, S. L., Down, J., and Hill, C. W. L. (2002). Tacit Knowledge as a Source of Competitive Advantage in the National Basketball Association. Academy of Management Journal, 45(1), 13-31.

Bonesso, S., Gerli, F., and Scapolan, A. (2014). The individual side of ambidexterity: Do individuals' perceptions match actual behaviours in reconciling the exploration and exploitation trade-off? European Management Journal, 32, 392-405.

Brockhaus, R. H. (1980). Risk-taking propensity of entrepreneurs. Academy of Management Journal, 23, 509-520.

Brockhaus, R. H. (1982). The psychology of the entrepreneur. In C.A. Kent, D.L. Sexton, and K.H. Vesper (Eds.) Encyclopedia of Entrepreneurship. Englewood Cliffs, N.J.: Prentice-Hall, 39-56.

Bruderl, J., Preisendorfer, P., and Ziegler, R. (1992) Survival Chances of Newly Founded Business Organizations. American Sociological Review, 57(2), 227-242.

Bryman, A. (2004). Social Research Methods. Oxford: Oxford UP.

Burgelman, R. A. (1994). Fading memories: A process theory of strategic business exit in dynamic environments. Administrative Science Quarterly, 39, 24-56.

Busenitz, L. (1999). Entrepreneurial risk and strategic decision making. Journal of Applied Behavioral Science, 35(3), 325-340.

Campos, H. M., de la Parra, J. P. N., and Parellada, F. S. (2012). The Entrepreneurial Orientation-Dominant Logic-Performance Relationship in New Ventures: an Exploratory Quantitative Study, Brazilian Administrative Review, Special Issue 9, 60-77.

Cantillon, R. (1734). Essai sur la nature du commerce en general [Essay on the nature of general commerce]. (Henry Higgs, Trans.). London: Macmillan.

Cao, Q., Gedajlovic, E., and Zhang, H. (2009). Unpacking organizational ambidexterity: dimensions, contingencies, and synergistic effects. Organization Science, 20(4), 781-796.

Carland, J. W., Hoy, F., Boulton, W. R., and Carland, J. C. (1984). Differentiating Entrepreneurs from Small Business Owners: A Conceptualization. Academy of 
Management Review 9(2), 354-359.

Cerny, C. A., and Kaiser, H.F. (1977). A study of a measure of sampling adequacy for factor-analytic correlation matrices. Multivariate Behavioral Research, 12(1), 4347.

Chandler, A. D. (1962). Strategy and Structure, MIT Press, Cambridge, MA.

Chen, C., Greene, P., and Crick, A. (1998). Does entrepreneurial self-efficacy distinguish entrepreneurs from managers? Journal of Business Venturing, 13, 295-318.

Chen, H. L., and Hsu, C. H. (2013). Entrepreneurial orientation and firm performance in non-profit service organizations: contingent effect of market orientation. The Service Industries Journal, 33(5) 445-466.

Chen, Y. C., Li, P. C., and Evans, K. R. (2012). Effects of interaction and entrepreneurial orientation on organizational performance: Insights into market driven and market driving, Industrial Marketing Management, 41, 1019-1034.

Chin, W. W. (1998). Issues and opinion on structural equation modeling. MIS Q , 70.

Christensen, C. (1997). Innovator's Dilemma. Cambridge, MA: Harvard University Press.

Christmann P . (2000). Effects of 'best practices' of environmental management on cost advantage: the role of complementary assets. Academy of Management Journal 43, 663-680.

Cho, H. J., and Pucik, V. (2005). Relationship between innovativeness, quality, growth, profitability, and market value. Strategic Management Journal, 26, 555-575.

Choi, Y. R., Lévesque, M., and Shepherd, D. A. (2008). When should entrepreneurs expedite or delay opportunity exploitation? Journal of Business Venturing, 23, 333-355.

Cohen, J. (1977). Statistical power analysis for the behavioral science. New York: Academic Press.

Coltman, T., Devinney, T., Midgley, D., and Venaik, S., (2008). Formative versus reflective measurement models: two applications of formative measurement. Journal of Business Research, 61(12), 1201-1302.

Cooper, A. C. (1993). "Challenges in Predicting New Firm Performance," Journal of Business Venturing 8, 241-253.

Cooper, A. C., and Dunkelberg, W. C. (1986). Entrepreneurship and paths to business ownership. Strategic Management Journal, 7, 53-68.

Conner, K. R., and Prahalad, C. K. (1996). A resource-based theory of the firm: Knowledge versus opportunism. Organization Science, 7, 477-501.

Covin, J. G., Green, K. M., and Slevin, D. (2006). Strategic process effects on the entrepreneurial orientation-Sales growth rate relationships. Entrepreneurship Theory and Practice, 30(1), 57-81.

Covin, J. G., and Miles, M. P. (1999). Corporate entrepreneurship and the pursuit of competitive advantage. Entrepreneurship Theory and Practice, 23(3), 47-63.

Covin, J. G., and Slevin, D. P. (1989). Strategic management of small firms in hostile and benign environments. Strategic Management Journal, 10, 75-87.

Covin, J. G., and Slevin, D. P. (1991). A conceptual model of entrepreneurship as firm behaviour. Entrepreneurship Theory \& Practice, 161, 7-25.

Covin, J. G., Slevin, D., and Covin, T. J. (1990). Content and performance of growth 
seeking strategies. Journal of Business Venturing, 5, 391-412.

Crant, M. J. (1996). The proactive personality scale as a predictor of entrepreneurial intentions. Journal of Small Business Management, 34(3), 42-50.

Crant, M. J. (2000). Proactive behaviour in organizations. Journal of Management, 26(3), 435-462.

Creswell, J. W., and Clark, V. L. (2011). Designing and Conducting Mixed Methods Research. Los Angeles: SAGE Publications.

CSO Pocket Digest (2010). Pocket Digest, Ministry of Planning and Sustainable Development, Central Statistical Office, Trinidad.

Dai, L., Maksimov, V., Gilbert, B. A., and Fernhabler, S. A. (2014). Entrepreneurial orientation and international scope: The differential roles of innovativeness, proactiveness, and risk-taking. Journal of Business Venturing, 29, 511-524.

Daily, C. M. and Dalton, D. R. (1992). The relationship between governance structure and corporate performance in entrepreneurial firms. Journal of Business Venturing, 7(5), 375-386.

Dickson, P. H., Solomon, G. T., and Weaver, K. M. (2008). Entrepreneurial Selection and Success: Does Education Matter? Journal of Small Business and Enterprise Development 15(2), 239-58.

Dierickx, I., and Cool, K. (1989). Asset Stock Accumulation and Sustainability of Competitive Advantage. Management Science, 35(12), 1504-1511.

Dollinger, M. J. (1999). Entrepreneurship: Strategies and Resources. Prentice-Hall, Upper Saddle River, NJ.

Duncan, R. (1976). The ambidextrous organization: Designing dual structures for innovation. In R. H. Killman, L. R. Pondy, \& D. Sleven (Eds.), The management of organization, 1: 167-188. New York: North Holland.

Dziuban, C. D., \& Shirkey, E. C. (1974). When is a correlation matrix appropriate for factor analysis? Psychological Bulletin, 81, 358-361.

Edwards, J. R. (2001). Multidimensional constructs in organizational behaviour research: An integrative analytical framework. Organizational Research Methods, 4, 144 192.

Eisenhardt, K. M., and Martin, J. A. (2000). Dynamic capabilities: What are they? Strategic Management Journal, 21(10/11), 1105-1121.

Engelen, A., Kube, H., Schmidt, S., Flatten T. C. (2014). Entrepreneurial orientation in turbulent environments: The moderating role of absorptive capacity. Research Policy, 43, 1353-1369.

Farmer, S. M., Yao, X., and Kung-Mcintyre, K. (2010). The Behavioral Impact of Entrepreneur Identity Aspiration and Prior Entrepreneurial Experience. Entrepreneurship Theory and Practice, 35(2), 245-73.

Firebaugh, G. (2008). Seven Rules for Social Research, Princeton University Press, New Jersey.

Garcia, R., Calantone, R., and Levine, R. (2003). The role of knowledge in resource allocation to exploration versus exploitation in technologically oriented organizations. Decision Sciences, 34(2), 323-349.

Gasse, Y. (1982). Elaborations on the psychology of the entrepreneur. In C. A. Kent, D. L. Sexton, and K. H. Vesper (Eds.), Encyclopedia of entrepreneurship. 
Englewood Cliffs, NJ: Prentice Hall, 209-223.

George, B. A. (2006). Entrepreneurial orientation: A theoretical and empirical examination of the consequences of differing construct representations. Paper presented at the 2006 Babson College Entrepreneurship Research Conference. Bloomington, Indiana, June 8-10.

George, D., and Mallery, P. (2003). SPSS for Windows step by step: A simple guide and reference. 11.0 update (4th ed.). Boston: Allyn \& Bacon.

George, G. A., and Marino, L. (2011) The Epistemology of Entrepreneurial Orientation: Conceptual Formation, Modeling, and Operationalization. Entrepreneurship Theory and Practice, September, 989-1024.

Gilbert, C. G. (2006). Change in the presence of residual fit: Can competing frames coexist? Organization Science, 17, 150-167.

Gorsuch, R. L. (1983). Factor analysis (2nd ed.). Hillsdale, NJ: Lawrence Erlbaum.

Granovetter, M. (1973). The strength of weak ties. American Journal of Sociology, 78(6), 1360-1380.

Grant, R. M. (1991). The resource-based theory of competitive advantage: Implications for strategy formulation. California Management Review, 33, 114-135.

Greene, P. G., and Brown, T. E. (1997), Resource needs and the dynamic capitalism typology, Journal of Business Venturing, 12(3), 161-73.

Groves, R., Fowler, F. J., Couper, M. P., Lepkowski, J. M., Singer, E. Tourangeau, R. (2009). Survey Methodology, $2^{\text {nd }}$ Edition, Wiley.

Gupta, A. K., Smith, K. G., and Shalley, C. E. (2006). The interplay between exploration and exploitation. Academy of Management Journal, 4, 693-706.

Hansen, J. D., Deitz, G.D., Tokman, M., Marino, L.D., and Weaver, K.M. (2010). Crossnational invariance of the entrepreneurial orientation scale. Journal of Business Venturing 26, 61-78.

Hansen, G. S., and Wernerfelt, B. (1989). Determinants of firm performance: The relative importance of economic and organizational factors. Strategic Management Journal. 10, 399-411.

Harper, D. (1998). Institutional conditions for entrepreneurship. Advances in Austrian Economics, 5, 241-275.

He, Z., and Wong, P. (2004). Exploration vs. exploitation: An empirical test of the ambidexterity hypothesis. Organization Science, 15, 481-494.

Helfat, C. E. (1997). Know-how and asset complementarity and dynamic capability accumulation: the case of R\&D. Strategic Management Journal, 18(5), 239-60.

Helfat, C. E. (2000). Guest editor's introduction to the special issue: the evolution of firm capabilities. Strategic Management Journal, Special Issue 21(10/11), 955 - 959.

Helfat, C. E., and Peteraf, M. A. (2003). The dynamic resource-based view: Capabilities lifecycles. Strategic Management Journal, 24, 997-1010.

Hendrickson, M. (2009). SME Competitiveness in the Caribbean: Challenges and Opportunities, Presented at United Nation ECLAC, Port of Spain.

Hills, G., Lumpkin, G. T., and Singh, R. P. (1997). Opportunity recognition: perceptions and behaviours of entrepreneurs. Frontiers of Entrepreneurship Research. Babson College, Wellesley, MA, 203-218.

Hitt, M. A., Dacin, M. T., Levitas, E., Arregle, J. L., and Borza, A. (2000). Partner 
selection in emerging and development market contexts: resource-based and organizational learning perspectives. Academy of Management Journal, 43, 449467.

Hoopes, D. G., Madsen, T. L., and Walker, G. (2003). Guest editors' introduction to the special issue: Why is there a resource-based view? Toward a theory of competitive heterogeneity. Strategic Management Journal, 24, 889-902.

Hughes, M., and Morgan, R. E. (2007). Deconstructing the relationship between entrepreneurial orientation and business performance at the embryonic stage of firm growth. Industrial Marketing Management, 36, 651-661.

Hult, G. T. M., Hurley, R. F., and Knight, G. A. (2004). Innovativeness: Its antecedents and impact on business performance. Industrial Marketing Management, 33, 429438.

Hunter, J. E., and Schmidt, F. L. (1990). Methods for meta-analysis: Correcting error and bias in research findings. Newbury Park, CA: Sage.

Introduction to SAS. UCLA: Statistical Consulting Group. From http://www.ats.ucla.edu/stat/sas/notes2/ (accessed November 24, 2007).

Ireland, R. D. and Hitt, M. A. (1999). Achieving and maintaining strategic competitiveness in the twenty-first century: The role of strategic leadership. Academy of Management Executive, 13(1), 43-57.

Ireland, R. D., Hitt, M. A., and Sirmon, D. G. (2003). A model of strategic entrepreneurship: The construct and its dimensions. Journal of Management, 29(6), 963-989.

Jenkins, M., and Johnson, G. (1997). Entrepreneurial Intentions and Outcomes: A Comparative Causal Mapping Study. Journal of Management Studies, 34(6), 895920.

Jansen, J. J. P., Van Den Bosch, F. A., and Volberda, H. W. (2006). Exploratory innovation, exploitative innovation, and performance: Effects of organizational antecedents and environmental moderators. Management Science, 52(11), 16611674.

Jennings, D. and Young, D. (1990). An empirical comparison between objective and subjective measures of the product innovation domain of corporate entrepreneurship. Entrepreneurship Theory and Practice, 15, 53-66.

Ioana, I. M. (2007). Physical Resources Needed to Start a Business. N.p., n.d. Web. 01 June 2014. <http://steconomiceuoradea.ro/anale/volume/2007/v1-managementand-marketing/61.pdf $>1$.

Julienti, L., Baker, A., and Ahmad, H. (2010). Assessing the relationship between firm resources and product innovation performance, Business Process Management Journal, 16(3), 420-435.

Karides, M. (2005). Whose Solution is It? Development Ideology and the Work of Micro- Entrepreneurs in Caribbean Context, International Journal of Sociology and Social Policy, 25(1/2), 30-62.

Katila, R., and Ahuja, G. (2002). Something old, something new: A longitudinal study of search behaviour and new product introduction. Academy of Management

Journal, 45(6), 1183-1194. 
Kelliher, F., and Reinl, L. (2009). A resource-based view of micro-firm management practice, Journal of Small Business and Enterprise Development, 16(3), 521-532.

Khandwalla, P. (1976). Some top management styles, their context and performance. Organization and Administrative Sciences, 7(4), 21-51.

Khandwalla, P. (1977). The design of organizations. New York: Harcourt, Brace.

Kogut, B., and Zander, U. (1992). Knowledge of the firm, combinative capabilities, and the replication of technology. Organization Science, 3(3), 383-397.

Kraaijenbrink, J., Spender, J. C., and Groen, A. J. (2010). The resource-based view: A review and assessment of its critiques. Journal of Management, 36, 349-372.

Kreiser, P. M., and Davis, J. (2010). EO and firm performance: the unique impact of innovativeness, proactiveness, and risk-taking. Journal of Small Business \& Entrepreneurship, 23(1), 39-51.

Kreiser, P. M., Marino, L. D., Kuratko, D. F., and Weaver, K. M. (2013). Disaggregating entrepreneurial orientation: the non-linear impact of innovativeness, proactiveness and risk-taking on SME performance. Small Business Economics, 40, 273-291.

Kreiser, P. M., Marino, L. D., and Weaver, K. M. (2002). Assessing the psychometric properties of the entrepreneurial orientation scale: A multi-country analysis. Entrepreneurship Theory and Practice, 26(4), 71-94.

Lee, C., Lee, K., and Pennings, J. M. (2001). Internal capabilities, external networks, and performance: A study on technology-based ventures, Strategic Management Journal, 22, 615-640.

Lee, J. H., and Y. U. Ryu. (2002). Exploration, exploitation, and adaptive rationality: The Neo-Schumpeterian perspective, Simulation Model. Practice Theory, 10, 297320.

Levinthal, D., and March, J. G. (1993). The myopia of learning. Strategic Management Journal, Winter Special Issue 14, 95-112.

Lippman, S. and Rumelt, R. (1982). Uncertain Imitability: An Analysis of Interfirm Differences in Efficiency under Competition, Bell Journal of Economics, Autumn, 418-438.

Lin, Y., and Wu, L. (2014). Exploring the role of dynamic capabilities in firm performance under the resource-based view framework, Journal of Business Research, 67, 407-413.

Liu, Q., Manolova, T. S., and Edelman, L. F. (2009). Entrepreneurial orientation and firm performance in China: The role of resource endowments. Frontiers of Entrepreneurship Research, 29(13), Article 3.

Low, M. R., and MacMillian, I. C. (1988). Entrepreneurship: Past Research and Future Challenges, Journal of Management, 14(2), 139-161.

Lubatkin, M. H., Simsek, Z., Ling, Y., and Veiga, J. F. (2006). Ambidexterity and performance in small- to medium-sized firms: The pivotal role of TMT behavioral integration. Journal of Management, 32, 1-17.

Ludwig, G., and Pemberton, J. (2011). A managerial perspective of dynamic capabilities in emerging markets: The case of the Russian steel industry. Journal of East European Management Studies, 16(3), 215-236.

Lumpkin, G. T., and Dess, G. (1996). Clarifying the entrepreneurial orientation construct and linking it to performance. Academy of Management Review, 21(1), 135-173. 
Lumpkin, G. T. and Dess, G. (2001). Linking two dimensions of entrepreneurial orientation to firm performance: The moderating role of environment and industry life cycle. Journal of Business Venturing, 16(5), 429-451.

Luo, Y. (2002). Capability Exploitation and Building in a Foreign Market: Implication for Multinational Enterprises. Organizational Science, 2002, 13(1), 48-63.

Ma, R., Huang, Y. C., and Shenkar, O. (2011). Social networks and opportunity recognition: A cultural comparison between Taiwan and the United States. Strategic Management Journal, 32(11), 1183-1205.

Makadok, R. (1999). Interfirm differences in scale economies and the evolution of market shares. Strategic Management Journal, 20, 935-952.

Makadok, R. (2001). Towards a synthesis of resource-based and dynamic capability views of rent creation. Strategic Management Journal, 22, 387-402.

March, J. G. (1991). Exploration and exploitation in organizational learning. Organization Science, 2, 71-87.

McClelland, D. C. (1967). The Achieving Society. Princeton, NJ: Van Nostrand, Reinhold.

McGill, M. E., Slocum, J. W., and Lei, D. (1992). Management practices in learning organizations. Organization Dynamics, 21(1), 5-17.

McGrath, R. G., MacMillian, I. C., and Scheinberg, S. (1992), Elitists, risk-takers, and rugged individualists? An exploratory analysis of cultural differences between entrepreneurs and non-entrepreneurs, Journal of Business Venturing, 7(2), 115 35.

Merz, G. R., and Sauber, M. H. (1995). Profiles of managerial activities in small firms. Strategic Management Journal, 16(7), 551-564.

Miles, M. P., Covin, J. G., and Heeley, M. B. (2000). The Relationship between Environmental Dynamism and Small Firm Structure, Strategy, and Performance. Journal of Marketing Theory and Practice 8(2), 63-74.

Miller, D. (1983). The correlates of entrepreneurship in three types of firms. Management Science, 29(7), 770-792.

Miller, D. (1988). Relating Porter's business strategies to environment and structure: Analysis and performance implications. Academy of Management Journal, 31, 280-308.

Miller D. (2003). An asymmetry-based view of advantage: towards an attainable sustainability. Strategic Management Journal, October Special Issue 24, 961-976.

Miller, D. (2011). Miller (1983) Revisited: A Reflection on EO Research and Some Suggestions for the Future. Entrepreneurship Theory and Practice, September, 873-894.

Miller, A., and Camp, B. (1985). Exploring determinants of success in corporate ventures. Journal of Business Venturing, 1, 87-105.

Miller, D., and Friesen, P. H. (1986). Generic strategies and performance: An empirical examination with American data Part I: Testing Porter. Organization Studies, $7(1), 37-55$.

Miller, D., and Shamsie, J. (1996). The resource-based view of the firm in two environments: The Hollywood film studios from 1936 to 1965. Academy of Management Journal, 39, 519-543. 
Mintzberg, H. (1973). Strategy-making in three modes. California Management Review, $16(2), 44-53$.

Mom, T. J. M., van den Bosch, F. A. J., and Volberda, H. W. (2007). Investigating managers' exploration and exploitation activities: The influence of top-down, bottom-up, and horizontal knowledge inflows. Journal of Management Studies, 44(6), 910-931.

Murdock, K. A., Mc Donald, C., Joseph, J., Dardaine-Edwards, A., and Carrillo, J. M. (2010). Global Entrepreneurship Monitor: Trinidad and Tobago 2010 Report, Arthur Lok Jack GSB, Trinidad, WI.

Murphy, G. B., Trailer, J. W., \& Hill, R. C. (1996). Measuring performance in entrepreneurship research. Journal of Business Research, 36(1), 15-24.

NationMaster: Country Profiles. (n.d.). Retrieved October 7, 2015.

Neter, J., Wasserman, W., and Kutner, M. H. (1990). Applied linear statistical models (3rd ed.). Homewood: Richard D. Irwin.

Newbert, S. L. (2007). Empirical research on the resource-based view of the firm: An assessment and suggestions for future research. Strategic Management Journal, 28, 121-146.

Newsday. (2014). Entrepreneurship is not a label, it's a lifestyle, Trinidad and Tobago's Newsday : Newsday.co.tt, 08 May 2014. Web. 28 May 2014. $<$ http://www.newsday.co.tt/businessday/0\%2C194471.html $>$.

Nisbett, R., and Wilson, T. (1977). Telling more than we can know: Verbal reports on mental processes. Psychological Review, 84, 231-259.

Palich, L. E., and Bagby, D. R. (1995). Using cognitive theory to explain entrepreneurial risk-taking: Challenging conventional wisdom. Journal of Business Venturing, $10(6), 425-438$.

Pedhazur, E. J., and Schmelkin, L. P. (1991). Measurement, design and analysis: An integrated approach. Hilsdale, NJ: Erlbaum.

Pelham, A. M. (2000). "Market Orientation and Other Potential Influences on Performance in Small and Medium Sized Manufacturing Firms," Journal of Small Business Management 38(1), 48-67.

Penrose, E. (1959). The Theory of the Growth of the Firm. New York: John Wiley and Sons.

Peng, M. W. (2014). Global Strategy. Mason, OH: South-Western,

Plouffe, C. R., Hulland, J. S., and Vandenbosch, M. (2001) Research Report: Richeness Versus Parsimony in Modeling Technology Adoption Decisions - Understanding Merchant Adoption of a Smart Card-Based Payment System. Information Systems Research, 12(2), 208-222.

Podsakoff, P., MacKenzie, C., Lee, J., and Podsakoff, N., (2003). Common method biases in behavioral research: a critical review of the literature and recommended remedies. Journal of Applied Psychology 88 (5), 879-903.

Porter, M. E. (1980) Competitive Strategy, Free Press, New York,

Premkumar, G. and Roberts, M. (1999). Adoption of New Information Technologies in Rural Small Businesses. Omega: The International Journal of Management Science, 27(4), 467-484.

Price, D., Stoica, M., and Weaven, S. (2013). A Resource-Based View of Entrepreneurial 
Orientaion: Its Impact on SME Performance, Academy of Entrepreneurship Proceedings, 19(1), 37-44.

Proactive. (2014). In CollinsDictionary.com. Retrieved May 15, 2014, from http://www.collinsdictionary.com/dictionary/english/proactive

Raisch, S., and Birkinshaw, J. (2008). Organizational Ambidexterity: Antecedents, Outcomes, and Moderators. Journal of Management, 34(3), 375-409.

Ramkissoon-Babwah, N. (2012). Entrepreneurship Education Model for Trinidad and Tobago, Journal of Emerging Trends in Educational Research and Policy Studies, $3,(3), 307-311$.

Rauch, A., Wiklund, J., Frese, M., and Lumpkin, G. T. (2004). Entrepreneurial orientation and business performance: cumulative empirical evidence. In Brush, C. G., Davidsson, P., Fiet, J., Greene, P. G., Harrison, R. T., Lerner, M., Mason, C., Meyer, G. D., Sohl, J., Zacharakis, A. and Zahra, S. A. (Eds), Frontiers of Entrepreneurship Research. Wellesley, MA: Babson College, 164-77.

Rosenbusch, N., Brinkmann, J., and Bausch, A. (2011). Is innovation always beneficial? A meta-analysis of the relationship between innovation and performance in SMEs. Journal of Business Venturing, 26, 441-457.

Rothaermel, F. T., and Deeds, D. L. (2004). Exploration and exploitation alliances in biotechnology: a system of new product development. Strategic Management Journal, 25(3), 201-21.

Rumelt, R. P. (1984). Towards a Strategic Theory of the Firm. In Robert Lamb (ed.) Competitive Strategic Management. Englewood Cliffs, N.J.: Prentice-Hall, 55670.

Runyan, R., Droge, C., and Swinney, J. (2008). Entrepreneurial Orientation versus Small Business Orientation: What Are Their Relationships to Firm Performance? Journal of Small Business Management, 46(4), 567-588.

Sanchez, R., Heene, A., and Thomas, H. (1996) Towards the Theory and Practice of Competence-Based Compeition, in Dynamics of Competence-Based Competition. R. Sanchez, A. Heene and H. Thomas editors, Elsevier, London.

Schumpeter, J. (1934). The Theory of Economic Development. Harvard University Press, Cambridge, MA.

Schumpeter, J. (1950). Capitalism, socialism, and democracy (3rd ed.). New York: Harper and Row.

Shane, S. (2000). Prior knowledge and the discovery of entrepreneurial opportunities. Organization Science, 11(4), 448-469

Sherr, I. (2013). Sony Says PlayStation 4 Launches Nov. 15. Wall Street Journal, 20 Aug. 2013. Web. 1 June 2014. <http://blogs.wsj.com/digits/2013/08/20/sonysays-playstation-4-launches-nov-15/>.

Singh, R., Hills, G., Hybels, R., and Lumpkin, G. (1999). Opportunity recognition through social network characteristics of entrepreneurs. In P. D. Reynolds, W. D. Bygrave, N. M. Carter, S. Manigart, C. M. Mason, D. Meyer, et al. (Eds.), Frontiers of entrepreneurship research: Babson Park, MA: Babson College Press, 228-241.

Singleton, R. A. Jr., and Straits, B. C. (2010). Approaches to social research (5th ed.). New York: Oxford University Press. 
Sitkin, S. B. (1992). Learning through failure: the strategy of small losses. In: Staw, B.M., Cummings, L.L. (Eds.), Research in Organizational Behavior, 14. JAI Press, Greenwich, CT, 231-266.

Sitkin, S. B., and Pablo, A. L. (1992). Reconceptualizing the determinants of risk behaviour. Academy of Management Review, 17(1), 9-38.

Smith, W. K., and Tushman, M. L. (2005). Managing strategic contradictions: A top management model for managing innovation streams. Organizational Science, 16, 522-536.

Stam, W., and Elfring, T. (2008). Entrepreneurial orientation and new venture performance: The moderating role of intra- and extraindustry social capital. Academy of Management Journal, 51(1), 97-111.

Stefana, G. D., Peteraf, M., and Verona, G. (2014). The Organizational Drivetrain: A Road to Integration of Dynamic Capabilities Research. Academy of Management Perspectives, 28(4), 307-327.

Stetz, P. E., Howell, R., Stewart, A., Blair, J. D., and Fottler, M.D. (2000). Multidimensionality of entrepreneurial firm-level processes: Do the dimensions covary? In R.D. Reynolds, E. Autio, C.G. Brush, W.D. Bygrave, S. Manigart, H.J. Sapienza and D.L. Sexton (Eds.), Frontiers of entrepreneurship research, Wellesley, MA: Babson College, 459-469.

Stevens, J. (1996). Applied Multivariate Statistics for the Social Sciences. Hillsdale, NJ, Lawrence Erlbaum Associates.

Stevens, J. P. (2001). Applied multivariate statistics for the social sciences (4th ed.). Mahwah, NJ: Lawrence Erlbaum.

Stevenson, H. H., and Jarillo, J. C. (1990). A paradigm of entrepreneurship: Entrepreneurial management. Strategic Management Journal, 11, 17-27.

Stewart, W. H., Watson, W. E., Carland, J. C., and Carland, J. W. (1998). A proclivity of entrepreneurship: a comparison of entrepreneurs, small business owners, and corporate managers. Journal of Business Venturing, 14, 189-214.

Tan, J., and Tan, D. (2005). Environment-strategy coevolution and coalignment: A staged-model of Chinese SOEs under transition. Strategic Management Journal, 26(2), 141-157.

Tang, J., Tang, Z., Marino, L. D., Zhang, Y., \& Li, Q. (2008). Exploring an inverted ushape relationship between entrepreneurial orientation and performance in Chinese ventures. Entrepreneurship Theory and Practice, 32, 219-239.

Tang, Z., Kreiser, P. M., Marino, L., Dickson, P., and Weaver, M. (2009). A hierarchical perspective of the dimensions of entrepreneurial orientation. International Entrepreneurship Management Journal, 5, 181-201.

Teece, D. (2014). The foundations of enterprise performance: Dynamic and ordinary capabilities in an (economic) theory of firms. Academy of Management Perspectives, 28(4) 328-352.

Teece, D. J., Pisano, G., and Shuen, A. (1997). Dynamic capabilities and strategic management. Strategic Management Journal, 18, 509-533.

Thornhill, S., and Amit, R. (2003). Learning about failure: bankruptcy, firm age, and the resource-based view. Organization Science, 14, 497-509.

TTCrime.com (n.d.). Trinidad \& Tobago Crime Rate. Retrieved October 7, 2015. 
Tushman, M. L., and O’Reilly, C. (1996). Ambidextrous organization: Managing evolutionary and revolutionary change. California Management Review, 38, 8-30.

Ucbasaran, D., Westhead, P., and Wright, M. (2008). Opportunity Identification and Pursuit: Does an Entrepreneur's Human Capital Matter? Small Business Economics, 30 (2), 153-173.

Venkatraman, N. (1989). Strategic orientation of business enterprises: The construct, dimensionality and measurement. Management Science, 35(8), 942-962.

Venkataraman, S. (1997). The distinctive domain of entrepreneurship research: An editor's perspective. In: J. Katz and R. Brockhaus (Eds.), Advances in entrepreneurship, firm emergence, and growth. Greenwich, CT: JAI Press.

Volberda, H., and Lewin, A. (2003). Co-evolutionary dynamics within and between firms: From evolution to coevolution. Journal of Management Studies, 40, 2111 2136.

Vuletin, G. (2008). Measuring the informal Economy in Latin America and the Caribbean, International Monetary Fund Working Paper, 08(102), 1-29.

Wales, W. J., Gupta, V. K., and Mousa, F.T. (2011). Empirical research on entrepreneurial orientation: An assessment and suggestions for future research. International Small Business Journal, 31(4), 357-383.

Walkes, W. J., Patel, P. C., Parida, V., and Kreiser, P. M. (2013). Nonlinear effects of entrepreneurial orientation on small firm performance: The moderating role of resource orchestration capabilities. Strategic Entrepreneurship Journal, 7, 93-121.

Walsh, G., and Beatty, S. E. (2007). Customer-based corporate reputation of a service firm: scale development and validation. Journal of the Academy of Marketing Science, 35, 127-143.

Wernerfelt, B. (1984). A resource-based view of the firm. Strategic Management Journal 5(2), 171-181.

Wetter, E., and Wennberg, K. (2007). Education Background and entrepreneurship: A review of graduate entrepreneurship in Sweden 1990-2002, Civil Economics: Sweden.

Wiggins, R. R., and Ruefli, T. W. (2002). Sustained competitive advantage: Temporal dynamics and the incidence and persistence of superior economic performance. Organization Science, 13, 82-105.

Wiggins, R. R., and Ruefli, T. W. (2005). Schumpeter's ghost: Is hypercompetition making the best of time shorter? Strategic Management Journal, 26, 887-911.

Wiklund J. (1999). The sustainability of the entrepreneurial orientation-performance relationship. Entrepreneurship Theory and Practice, 24(1), 37-49.

Wiklund, J., and Shepherd, D. (2003). Knowledge-based resources, entrepreneurial orientation, and the performance of small and medium-sized businesses. Strategic Management Journal, 24(13), 1307-1314.

Wiklund, J. and Shepherd, D. (2005), Entrepreneurial orientation and small business performance: a configurational approach. Journal of Business Venturing, 20(1), 71-91.

Williamson, O. E. (1979). Transaction-Cost Economics: The Governance of Contractual Relations. Journal of Law and Economics, 22(2), 233-261.

Winborg, J. and Landstrom, H. (2001). Financial bootstrapping in small businesses: 
examining small business managers' resource acquisition behaviours. Journal of Business Venturing, 16(3), 235-54.

Yalcinkaya, G., Calantone, R. J., and Griffith, D. A. (2007). An examination of exploration and exploitation capabilities: Implications for product innovation and market performance. Journal of International Marketing, 15(4), 63-93.

Zahra, S. (1991). Predictors and financial outcomes of corporate entrepreneurship: an explorative study. Journal of Business Venturing, 6, 259-285.

Zahra, S. A. (1993). Environment, corporate entrepreneurship, and financial performance: A taxonomic approach. Journal of Business Venturing, 8, 319-340.

Zahra, S. A. (1996). Technology strategy and financial performance: examining the moderating role of the firm's competitive environment. Journal of Business Venturing, 11, 189-219.

Zahra, S. A., and Covin, J. G. (1995). Contextual influences on the corporate entrepreneurship-performance relationship: A longitudinal analysis. Journal of Business Venturing, 10(1), 43-58.

Zahra, S. A., and Garvis, D. M. (2000). International corporate entrepreneurship and firm performance: the moderating effect of international environmental hostility. Journal of Business Venturing 15(5), 469-492.

Zahra, S. A., and George, G. (2002). Absorptive capacity: A review, reconceptualization, and extension. Academy of Management Review, 27, 185-203.

Zahra, S. A., and Neubaum, D. O. (1998). Environmental adversity and the entrepreneurial activities of new ventures. Journal of Developmental Entrepreneurship, 3(2), 123-140.

Zahra, S. A., Sapienza, H. J., and Davidsson, P. (2006). Entrepreneurship and Dynamic Capabilties: A Review, Model and Research Agenda. Journal of Management Studies, 43(4), 917-955.

Zaltman, G., Duncan, R., and Holbek, J. (1973). Innovations and Organizations. Wiley, New York. 